\title{
CÁLCULO DE ESFORÇOS E DESLOCAMENTOS EM ESTRUTURAS DE PISOS DE EDIFÍCIOS, CONSIDERANDO-SE A INFLUÊECIA DAS TENSÕES CISALHANTES
}

Engo Rodrigo de Azevêdo Neves

Dissertação apresentada ao Departamento de Engenharia de Estruturas da EESC-USP, como parte dos requisitos necessários à obtenção do título de Mestre em Engenharia de Estruturas

Orientador:

Prof.Tit. Wilson Sérgio Venturini 
Ficha catalográfica preparada pela Seção de Tratamento da Informação do Serviço de Biblioteca - EESC-USP

Neves, Rodrigo de Azevêdo

N519c Cálculo de esforços e deslocamentos em estruturas de pisos de edifícios, considerando-se a influência das tensões cisalhantes / Rodrigo de Azevêdo Neves. -- São Carlos, 2000.

Dissertação (Mestrado) -- Escola de Engenharia de São Carlos-Universidade de São Paulo, 2000.

Área: Engenharia de Estruturas.

Orientador: Prof. Dr. Wilson Sérgio Venturini.

1. Mecânica do dano. 2. Elementos finitos.

3. Análise não-linear. 4. Viga de Timoshenko.

I. Título. 


\section{FOLIYA DE APROVACÃO}

\section{Candidato: Engenheiro RODRIGO DE AZEVÊDO NEVES}

Dissertação defendida e aprovada em 19-04-2000 pela Comissão Julgadora:

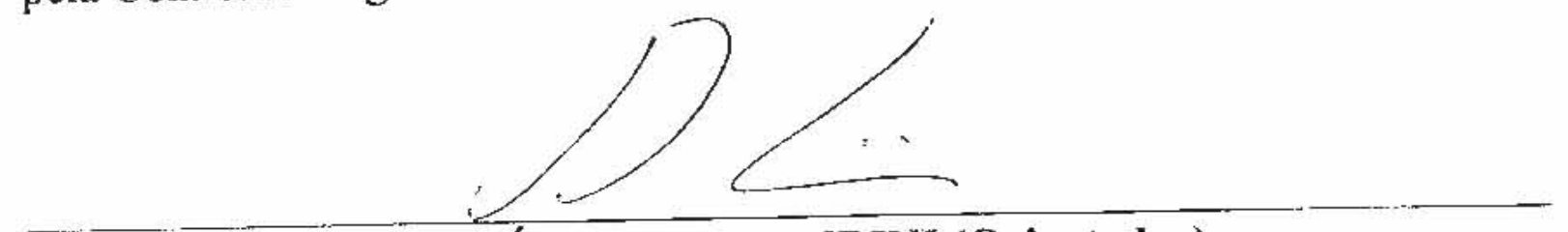

Prof. Titular WILSON SÉRGIO VENTURINI (Orientador)

(Escola de Engenharia de São Carlos - Universidade de São Paulo)

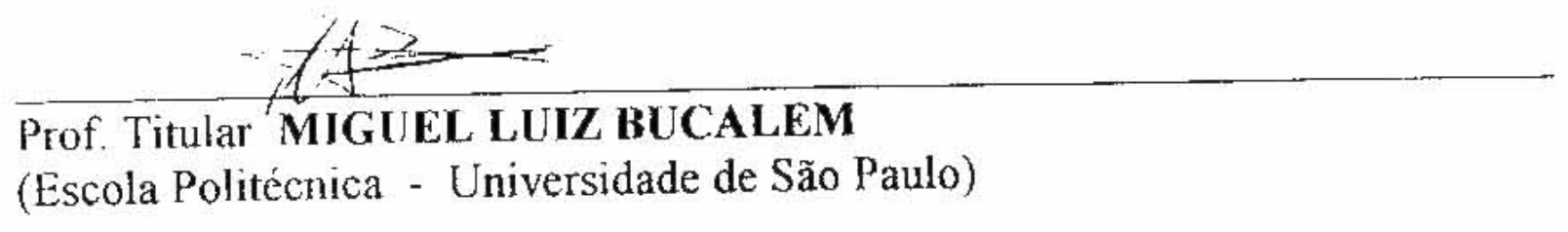

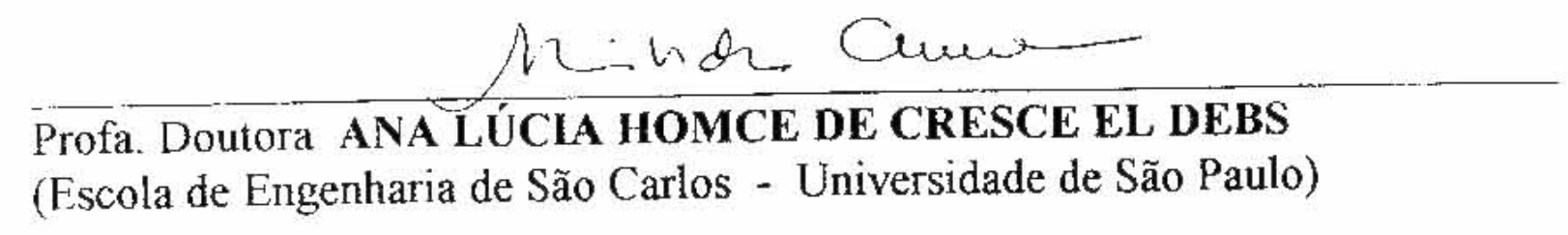
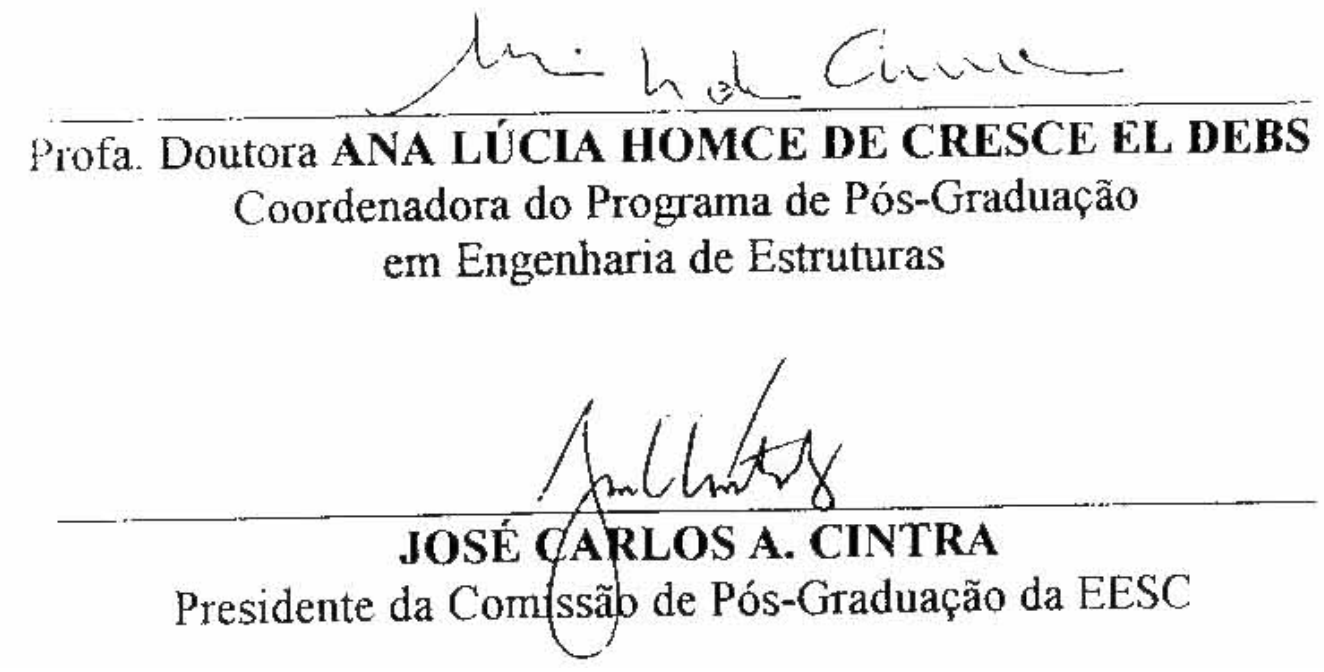
Dedico este trabalho aos meus pais 


\section{AGRADECIMENTOS}

A Deus.

Ao Prof. Wilson Sérgio Venturini pela dedicação, interesse, e amizade.

A minha família, sempre presente em todos os momentos de minha vida.

A Rä̈ssa Pereira Alves, pela compreensão nas minhas ausências e pelo constante companheirismo e amizade.

Aos colegas do departamento de estruturas, pela amizade.

Aos funcionários do departamento pela atenção e ajuda.

À CAPES, pelo apoio financeiro. 


\section{SUMÁRIO}

LISTA DE FIGURAS

LISTA DE TABELAS

LISTA DE SÍMBOLOS

RESUMO

\section{Abstract}

1 INTRODUÇÃo

1.1 GENERALIDADES 1

1.2 OBJETIVOS ... 2

1.3 JUSTIFICATIVA 3

1.4 METODOLOGIA 4

1.5 SÍNTESE DO CONTEÚDO DA DISSERTAÇÃO 5 
2 MODELOS PARA O CONCRETO ARMADO 6

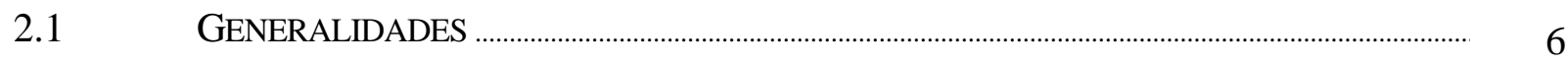

2.2 RECOMENDAÇÕES .................................................................................................................... 7

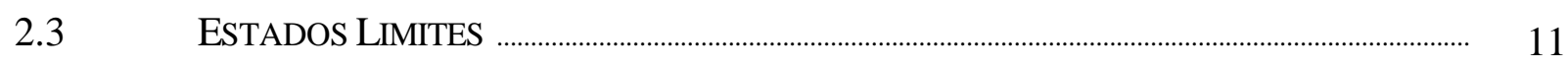

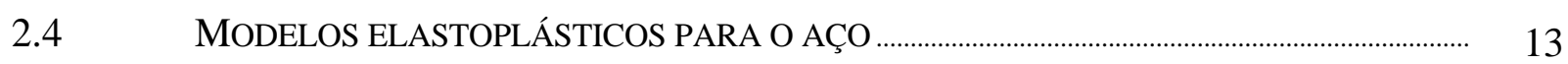

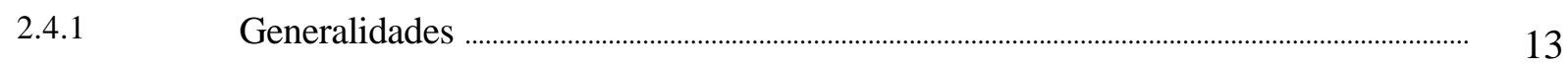

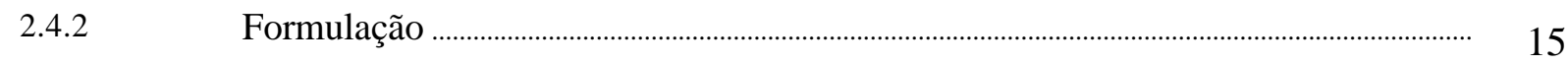

2.4.3 Critério de plastificação ................................................................................................... 16

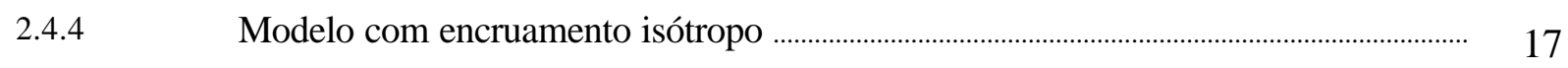

3 Vigas de Timoshenko 19

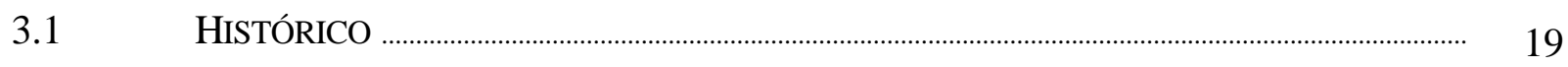

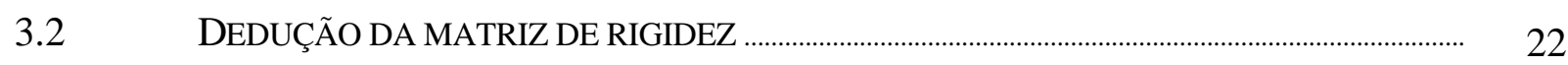

3.3 MATRIZ DE RIGIDEZ DO ELEMENTO DE GRELHA ……………………................................. 32

4 MODELO CONSTITUTIVO DE DANO 33

4.1 GENERALIDADES ..................................................................................................................... 33

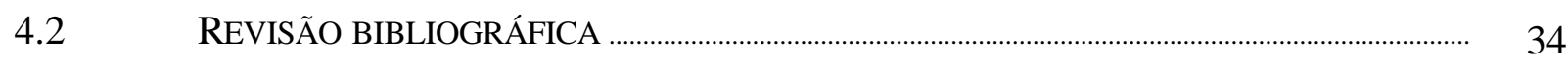

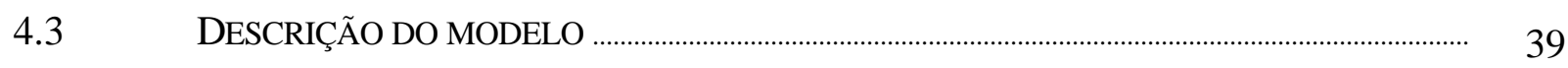

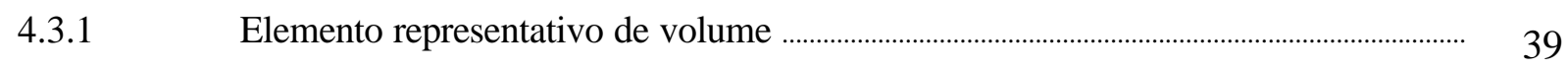

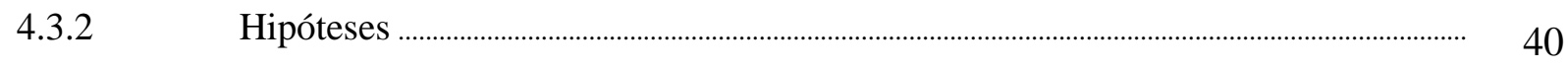

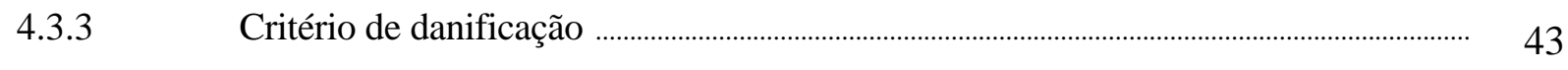

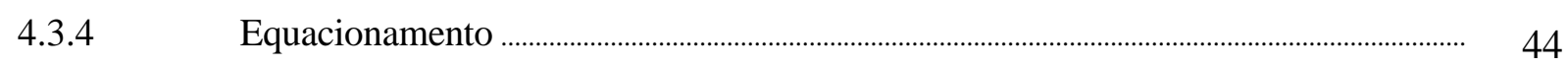




\section{ANÁLISE NÃO-LINEAR DE GRELHAS}

5.1 MÉTODO DA ENERGIA 50

5.2 SOLUÇÃO DO SISTEMA DE EQUAÇÕES 52

5.4 RELAÇÕES CONSTITUTIVAS MOMENTO x CURVATURA

5.5 CÁLCULO DO VETOR DE ESFORÇOS RESIDUAIS ………………………............................... 62

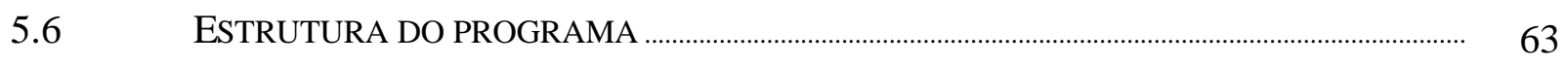

6 MECANISMOS RESISTENTES AO CISALHAMENTO 65

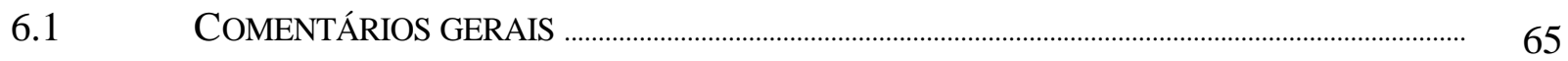

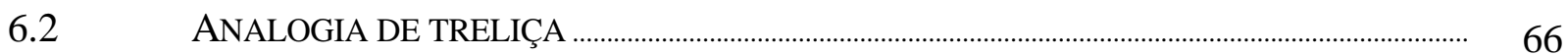

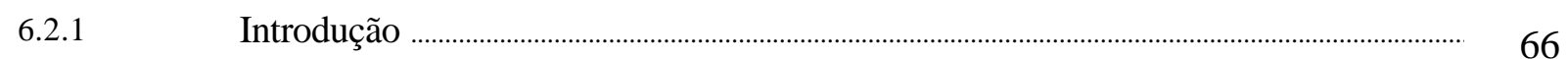

6.2.2 Determinação dos esforços na treliça ................................................................................... 67

6.2.3 Cálculo das tensões no aço e no concreto ………….......................................................... 69

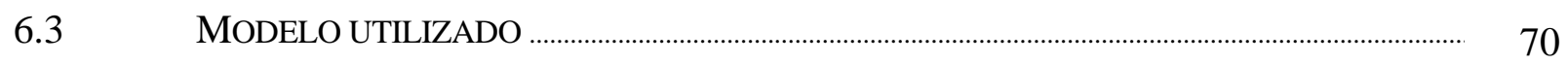

7 EXEMPLOS $\quad 73$

7.1 COMENTÁRIOS GERAIS ....................................................................................................... 73

7.2 VIGA BIAPOIADA COM CARGAS CONCENTRADAS ………………….................................. 74

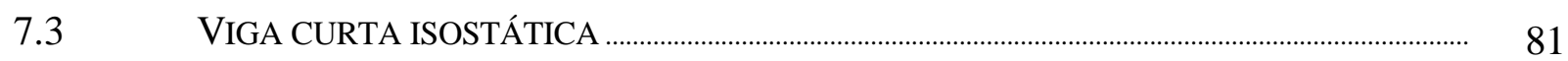

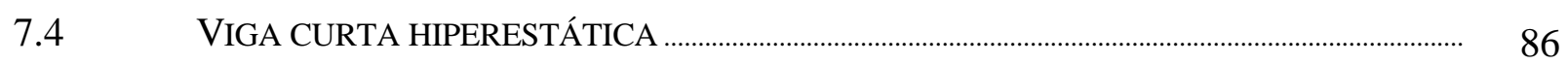

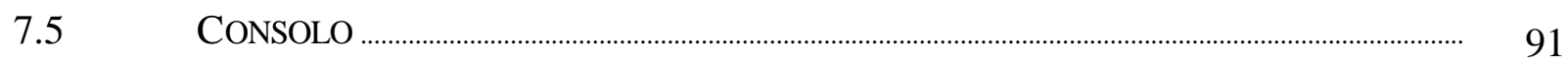

7.6 GRELHA SEM INFLUÊNCIA DA TORÇÃO …………………………………….............................. 96

7.7 VERIFICAÇÃO DA PRECISÃO DO MODELO ……………………............................................ 101 
8 Conclusão

REFERÊNCIAS BIBLIOGRÁFICAS

BIBLIOGRAFIA COMPLEMENTAR 


\section{LISTA DE FIGURAS}

Figura 2.1 Distribuições de tensão em uma seção de concreto armado submetida à flexão

Figura 2.2 Tensões de tração no concreto e na armadura entre duas seções fissuradas

Figura 2.3 Diagrama momento x curvatura do CEB/158

Figura 2.4 Tensões na seção transversal segundo a NBR-6118

Figura 2.5 Diagrama tensão deformação experimental do aço

Figura 2.6 Lei constitutiva de um material com comportamento Elasto-Plástico Perfeito

Figura 2.7 Material com encruamento isótropo

Figura 3.1 Elemento Infinitesimal de Viga

Figura 3.2 Continuidade dos Parâmetros Nodais

Figura 3.3 Convenções de sinais da Resistência dos Materiais

Figura 3.4 Convenções de sinais da Formulação em elementos finitos

Figura 3.5 Elemento de grelha e graus de liberdade considerados

Figura 4.1 Mecânica do Dano e Mecânica da Fratura

Figura 4.2 Elemento representativo de volume danificado

Figura 4.3 Hipótese da deformação equivalente

Figura 4.4 Diagrama experimental do concreto à tração e diagrama adotado pelo modelo

Figura 4.5 Evolução dos parâmetros DT e DC com a deformação equivalente

Figura 5.1 Elemento de barra submetido a um carregamento genérico

Figura 5.2 Procedimento de solução através da rigidez secante 54

Figura 5.3 Iteração genérica 55

Figura 5.4 Distribuição das tensões na seção transversal 57 
Figura 5.5 Modelo genérico de dano escrito em relação constitutiva momento x curvatura ……….. 60

Figura 5.6 Caso genérico de determinação do vetor de esforços residuais .............................................. 62

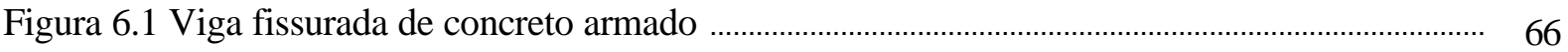

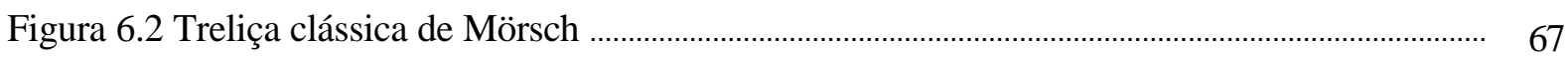

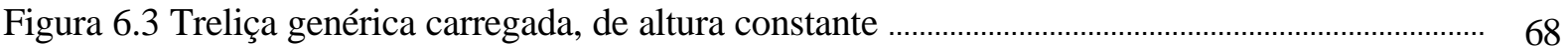

Figura 6.4 Diagrama de momentos da viga de substituição ………………………………………….. 68

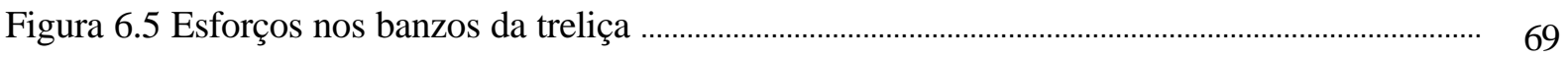

Figura 6.6 Diagrama teórico de carga x deformação nos estribos ................................................................ 71

Figura 6.7 Esquema teórico de absorção dos esforços cortantes em uma seção .................................... 71

Figura 6.8 Configuração do elemento distorcido ................................................................................. 72

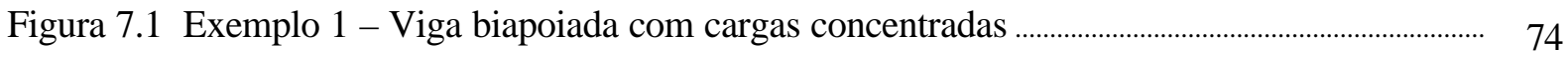

Figura 7.2 Exemplo 1 - Diagrama carga deslocamento do ponto central da viga ………………........... 76

Figura 7.3 Exemplo 1 - Rigidez de um elemento na região de momento máximo ................................... 77

Figura 7.4 Exemplo 1 - Diagrama momento x curvatura da seção central ………….............................. 78

Figura 7.5 Exemplo 1 - Variação da rigidez nas barras ............................................................................... 80

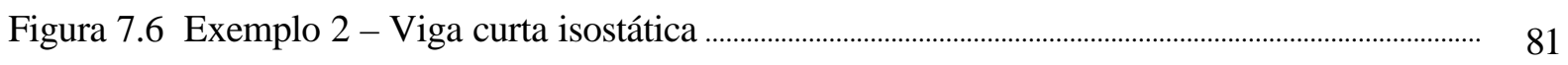

Figura 7.7 Exemplo 2 - Deslocamento da extremidade do balanço ................................................................ 82

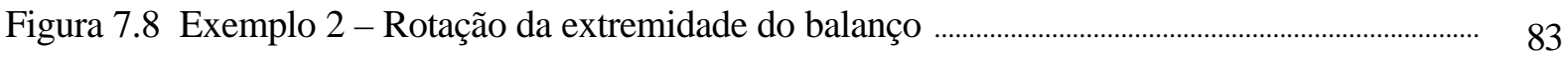

Figura 7.9 Exemplo 2 - Diagrama momento curvatura da seção do engaste .......................................... 84

Figura 7.10 Exemplo 2 - Rigidez do elemento solicitado pelo momento máximo ……………………... 84

Figura 7.11 Exemplo 2 - Variação da rigidez ao longo do comprimento ……………………………….... 85

Figura 7.12 Exemplo 3 - Viga curta hiperestática ............................................................................................ 86

Figura 7.13 Exemplo 3 - Deslocamento do ponto central da viga $(\mathrm{cm})$................................................... 87

Figura 7.14 Exemplo 3 - Diagrama momento curvatura de um dos engastes ........................................ 88

Figura 7.15 Exemplo 3 - Rigidez do elemento solicitado pelo momento máximo …………………….. 88

Figura 7.16 Exemplo 3 - Variação da rigidez ao longo do comprimento da barra ……………............ 89

Figura 7.17 Exemplo 3 - Diagramas de momentos fletores ........................................................................ 90 
Figura 7.18 Exemplo 4 - Consolo

Figura 7.19 Exemplo 4 - Deslocamento da extremidade do balanço $(\mathrm{cm})$

Figura 7.20 Exemplo 4 - Rotação da extremidade do balanço (cm)

Figura 7.21 Exemplo 4 - Diagrama momento curvatura da seção do engaste

Figura 7.22 Exemplo 4 - Rigidez do elemento solicitado pelo momento máximo

Figura 7.23 Exemplo 4 - Variação da rigidez ao longo do comprimento 95

Figura 7.24 Exemplo 5 - Grelha sem influência da torção 96

Figura 7.25 Exemplo 5 - Deslocamentos no ponto de cruzamento das vigas 97

Figura 7.26 Exemplo 5 - Rotações nos apoios 98

Figura 7.27 Exemplo 5 - Rigidez de um elemento na região de momento máximo 99

Figura 7.28 Exemplo 5 - Diagrama momento curvatura da seção no cruzamento das vigas 99

Figura 7.29 Exemplo 5 - Variação da rigidez ao longo do comprimento da viga 100

Figura 7.30 Exemplo 6 - Viga ensaiada 101

Figura 7.31 Exemplo 6 - Seção transversal da viga ensaiada 102

Figura 7.32 Exemplo 6 - Deslocamentos no meio do vão 103

Figura 7.33 Exemplo 6 - Deformações nos estribos 104 


\section{LISTA DE TABELAS}

Tabela 4.1 Casos de determinação da deformação equivalente

Tabela 4.2 Casos de determinação dos parâmetros $\alpha_{T}$ e $\alpha_{C}$

Tabela 5.1 Procedimento da rigidez secante - Adaptado de CORRÊA(1991)

Tabela 7.1 Exemplo 1 - Deslocamentos no centro da viga 75

Tabela 7.2 Exemplo 1 - Variação da rigidez nas barras 79

Tabela 7.3 Exemplo 2 - Deslocamento da extremidade do balanço $(\mathrm{cm})$ 82

Tabela 7.4 Exemplo 2 - Rotação da extremidade do balanço $(\mathrm{cm})$ 83

Tabela 7.5 Exemplo 2 - Variação da rigidez ao longo do comprimento 85

Tabela 7.6 Exemplo 3 - Deslocamento do ponto central da viga $(\mathrm{cm})$ 87

Tabela 7.7 Exemplo 3 - Variação da rigidez ao longo do comprimento da barra 89

Tabela 7.8 Exemplo 4 - Deslocamento da extremidade do balanço $(\mathrm{cm})$ 92

Tabela 7.9 Exemplo 4 - Rotação da extremidade do balanço $(\mathrm{cm})$ 93

Tabela 7.10 Exemplo 4 - Variação da rigidez ao longo do comprimento 95

Tabela 7.11 Exemplo 5 - Deslocamentos no ponto de cruzamento das vigas 97

Tabela 7.12 Exemplo 5 - Rotações nos apoios 98

Tabela 7.13 Exemplo 6 - Deslocamentos no meio do vão 102

Tabela 7.14 Exemplo 6 - Deformações nos estribos 104 


\section{LISTA DE SÍMBOLOS}

\section{GREGOS}

$\alpha \quad$ Variável interna do modelo elasto-plástico

$\dot{\alpha}$

Derivada de $\alpha$ em relação ao tempo

$\alpha_{\mathrm{C}}$

Coeficiente que multiplica o parâmetro de dano à compressão no modelo de Mazars

$\alpha_{\mathrm{T}}$

Coeficiente que multiplica o parâmetro de dano à tração no modelo

de Mazars

$\beta$

Rotação total de uma seção

$\delta$

Tolerância do erro da norma do vetor de resíduos

$\varepsilon$

Deformação uniaxial total do modelo elasto-plástico

$\dot{\varepsilon}$

Variação da deformação no tempo (velocidade de deformação)

$\tilde{\varepsilon}$

Deformação equivalente

$\varepsilon^{\mathrm{e}}$

Deformação uniaxial elástica do modelo elasto-plástico

$\varepsilon^{\mathrm{p}}$

Deformação uniaxial plástica do modelo elasto-plástico 
$\varepsilon_{\mathrm{d} 0} \quad$ Deformação correspondente ao pico de tensão de um ensaio de tração uniaxial no concreto

$\underline{\varepsilon} \quad$ Tensor das deformações

$\varepsilon_{\mathrm{i}} \quad$ Deformação principal

$\left\langle\varepsilon_{\mathrm{i}}\right\rangle_{+} \quad$ Parte positiva do tensor de deformações principais

$\underline{\varepsilon}_{\mathrm{C}} \quad$ Parte negativa do tensor de deformações

$\underline{\varepsilon}_{\mathrm{T}} \quad$ Parte positiva do tensor de deformações

$\gamma \quad$ Distorção de uma seção transversal

$\varphi \quad$ Rotação de uma seção devida à flexão

Vetor de resíduos da análise não-linear

$\|\varphi\| \quad$ Norma do vetor de resíduos na análise não-linear

$\dot{\lambda} \quad$ Valor absoluto da velocidade de deformação plástica do modelo elasto-plástico

$\checkmark \quad$ Coeficiente de poisson

$\pi$

Energia potencial total

$\theta$

Rotação de uma seção transversal devida à flexão

$\rho$

Taxa geométrica de armadura na seção

$\sigma$

Tensão uniaxial do modelo elasto-plástico

$\underline{\sigma}$

Tensor de tensões 
Tensão efetiva unidimensional

$\underline{\widetilde{\sigma}}$

Tensor de tensões efetivas

$\langle\underline{\sigma}\rangle_{+}$

Parte positiva do tensor de tensões efetivas

$\langle\underline{\sigma}\rangle$

Parte negativa do tensor de tensões efetivas

$\sigma_{\mathrm{BC}}$

Tensão na biela

$\sigma_{\mathrm{CT}}$

Tensão de tração no concreto

$\sigma_{\mathrm{ST}}$

Tensão de tração na armadura

$\sigma_{\mathrm{SC}}$

Tensão de compressão na armadura

$\sigma_{\mathrm{y}}$

Tensão limite de plastificação do aço

$\tau_{0}$

Tensão tangencial de referência

$\xi_{\mathrm{i}}$

Pontos do domínio normalizado de Gauss

\section{ROMANOS}

$\frac{1}{\mathrm{r}}$

Curvatura de uma seção

$\mathrm{A}_{\mathrm{C}}, \mathrm{B}_{\mathrm{C}} \quad$ Parâmetros de dano à compressão do modelo de Mazars

$\mathrm{A}_{\mathrm{T}}, \mathrm{B}_{\mathrm{T}} \quad$ Parâmetros de dano à tração do modelo de Mazars

$\mathrm{A}_{\mathrm{SM}} \quad$ Área dos montantes tracionados da treliça de Mörsch

Bw

Base da seção 
d

$\mathrm{D}$

$\dot{\mathrm{D}}$

$\mathrm{D}_{\mathrm{C}} \quad$ Variável escalar de dano à compressão do modelo de Mazars

$\mathrm{D}_{\mathrm{T}}$

$\underline{\mathrm{D}}_{0}$

$\mathrm{E}$

$\widetilde{\mathrm{E}}$

$\mathrm{f}$

$\dot{\mathrm{f}}$

$\mathrm{f}_{\mathrm{CT}}$

$\mathrm{f}_{\mathrm{CTM}}$

$\mathrm{F}_{\mathrm{C}}(\widetilde{\varepsilon})$

$\mathrm{F}_{\mathrm{T}}(\widetilde{\varepsilon})$

g

G

Altura útil da seção

Variável escalar de dano do modelo de Mazars

Variação do dano

Variável escalar de dano à tração do modelo de Mazars

Tensor elástico linear do material íntegro

Módulo de elasticidade longitudinal

Módulo de elasticidade do material com dano

Critério de plastificação ou critério de dano

Variação do critério de plastificação

Resistência à ruptura do concreto à tração

Resistência média do concreto à tração

Função contínua e positiva da deformação equivalente do modelo de

Mazars

Função contínua e positiva da deformação equivalente do modelo de

Mazars

Constante adimensional

Módulo de elasticidade transversal do concreto 
Módulo plástico do aço com encruamento isótropo

Fator de forma de uma seção transversal

$[\mathrm{K}]_{\mathrm{S}} \quad$ Matriz de rigidez secante

$[\mathrm{K}]_{\mathrm{L}} \quad$ Parcela linear da matriz secante

$[\mathrm{K}]_{\mathrm{N}} \quad$ Parcela não-linear da matriz secante

LN Posição da linha neutra da seção transversal

I $\quad$ Momento de inércia de uma seção homogeneizada no estádio I

M Momento fletor atuante em uma seção

$\mathrm{M}_{\mathrm{r}} \quad$ Momento de fissuração da seção

n Reta normal à uma superfície

$\mathrm{R}_{\mathrm{C} 45} \quad$ Esforço resultante nas diagonais a $45^{\circ}$

$\mathrm{R}_{\mathrm{CC}, \mathrm{X}+\Delta \mathrm{X}} \quad$ Esforço resultante no banzo comprimido da treliça clássica

$\mathrm{R}_{\mathrm{ST}} \quad$ Esforço resultante de tração na armadura

$\mathrm{R}_{\mathrm{ST}, \mathrm{X}} \quad$ Esforço resultante de tração na armadura da treliça clássica de

Mörsch

$\mathrm{R}_{\mathrm{TT}} \quad$ Esforço de tração nos tirantes da treliça de Mörsch

S Área total de uma superfície

$\mathrm{S}_{0} \quad$ Área danificada de uma superfície

$\widetilde{\mathrm{S}} \quad$ Área resistente efetiva de uma superfície

$\mathrm{Sr} \quad$ Espaçamento entre duas fissuras consecutivas 
Momento torçor em um elemento

$\mathrm{U}$

Energia de deformação de um elemento

V

Esforço cortante em uma seção

V

Deslocamento transversal de um ponto

VD

Esforço de tração nos tirantes da treliça de Mörsch

W

Energia potencial das cargas externas

$\mathrm{W}_{\mathrm{i}}$

Pesos dos pontos do domínio normalizado de Gauss

$\mathrm{Z}$

Altura da treliça de Mörsch 


\section{RESUMO}

Neste trabalho analisam-se grelhas de concreto armado, adaptando-se modelos não-lineares baseados na teoria mecânica do dano contínuo, com a incorporação da distorção da seção transversal ao estado de deformações. Discutem-se os modelos do CEB-158 (1985), da NBR-6118, para o concreto armado e modelos elastoplásticos para as barras da armadura longitudinal. Estuda-se a teoria de vigas de Timoshenko, onde são incorporadas as distorções da seção transversal à matriz de rigidez do elemento finito de viga. Discute-se o modelo de dano de MAZARS(1984), mostrando a sua formulação e parâmetros. Dedica-se especial atenção também à análise não-linear de grelhas de concreto armado, enfatizando-se as técnicas de solução dos sistemas de equações não-lineares. Por fim, faz-se uma revisão sobre o modelo da treliça clássica de Mörsch, tomando-a como base para a formulação de um modelo de resistência de esforços cortantes em uma seção transversal de concreto armado.

Palavras-chave: mecânica do dano, elementos finitos, análise não-linear, viga de Timoshenko 


\section{AbStract}

In this work, Reinforced concrete grids are analysed, assuming non-linear models based on the damage theory, and also incorporating into shear deformations. The proposed CEB-158 and the NBR-6118 models for reinforced concrete members are discussed, as well as the elastoplastic model assumed for the reinforcement. The Timoshenko's beam theory is studied and adopted to modify the beam stiffness matrix to take into account the shear deformation. The MAZARS' damage model is discussed, presenting the main aspects and parameters. Particular attention has been given to the reinforced concrete grid, pointing out the usual non-linear system solution techniques. Finally, the Mörsch truss model is revised and adopted to formulated an algorithm to deal with reinforced concrete beam elements, dividing the shear forces into two parts: the concrete and the reinforcement resultants.

Key words: damage mechanics, finite elements, non-linear analysis, Timoshenko's beam. 


\section{Introdução}

\section{1 - GENERALIDADES}

Os modelos de cálculo de esforços e deslocamentos para as estruturas de concreto armado visam encontrar uma forma matemática capaz de descrever o seu comportamento, produzindo respostas próximas das observadas em estruturas reais. Com a utilização da lei de Hooke, portanto considerando-se válido o comportamento elástico linear e ainda assumindo-se o comportamento linear geométrico, pode-se chegar a uma modelagem bastante simples, mas que conduz a aproximações satisfatórias apenas em situações de serviço para estruturas de concreto armado, devidas ao forte grau de não-linearidade apresentado pelos materiais que constituem o concreto.

Em análises mais rigorosas, baseadas em modelos de caráteres físico e geométrico não-linear, obtêm-se resultados mais precisos, mas que apresentam a desvantagem de necessitar do emprego de computador, além de exigir grande tempo de processamento computacional. Estas modelagens são extremamente viáveis quando se deseja fazer análises na ruína. Nesse caso, os modelos existentes permitem a obtenção de soluções próximas dos resultados experimentais. Com a introdução do método dos elementos finitos nos programas correntes de cálculo estrutural, os modelos não-lineares ganharam força e estão se incorporando lenta mas definitivamente aos procedimentos já existentes para a elaboração de projetos no meio técnico.

Paralelamente aos avanços no campo dos estudos sobre a modelagem do concreto armado, torna-se interessante adicionar novos modelos de simulação de seu comportamento àqueles já utilizados pelos "softwares" existentes hoje no mercado e no meio técnico. Isto só se tornou possível graças à grande evolução apresentada pelos microprocessadores nos últimos anos, o que reduziu significativamente o tempo dispensado no processamento numérico. 


\section{2 - OBJETIVOS}

No projeto estrutural de peças em concreto armado, o calculista deve garantir a segurança contra a ruína de todas as peças constituintes isoladamente ou considerando-se o conjunto estrutural como um todo. Além disso, deve assegurar que os deslocamentos na estrutura não ultrapassem determinados valores, cujos limites garantem a sua utilização de modo satisfatório durante a sua vida útil. Há algum tempo, este segundo fator limitante, não tinha tratamento especial por parte dos projetistas. $\mathrm{O}$ que se viu até os dias atuais foi uma rápida evolução dos modelos mecânicos e de materiais, que não foi devidamente acompanhada pelos procedimentos de cálculo e verificações utilizados para projetos. Aliado a esse fato, verifica-se hoje a utilização de concretos de melhor qualidade levando a uma conseqüente redução de seções transversais e utilização de vãos mais longos, e portanto, têm-se estruturas mais esbeltas.

Pretende-se, com este trabalho, desenvolver um software que incorpore modelos não-lineares para peças unidimensionais de concreto armado. No modelo proposto pretende-se levar em conta que a seção de concreto armado está sujeita a deformações produzidas pelo esforço cortante, efetuando-se assim, uma determinação mais rigorosa dos deslocamentos, esforços internos, deformações e tensões na estrutura, para qualquer nível de carregamento.

As verificações podem ser feitas alterando-se qualquer variável estrutural, como por exemplo as dimensões de uma seção transversal, ou a quantidade de armadura, objetivando-se uma melhor distribuição de esforços e conseqüentemente, um bom arranjo estrutural. O comportamento não-linear do concreto é representado, neste trabalho, por relações constitutivas do tipo tensão-deformação, dando-se enfoque particular ao modelo de Dano de MAZARS (1984), considerando-se um estado biaxial de deformações. Durante o desenvolvimento do algoritmo, encontra-se a representação equivalente do modelo em termos de relação momento $\mathrm{x}$ curvatura que, embora modifique a sua concepção original, conduz a bons resultados. Além disso, o diagrama momento x curvatura é necessário, pois neste trabalho, utiliza-se um modelo mecânico de barras. 
Os procedimentos e algoritmos aqui desenvolvidos podem ser com certa facilidade implementados em softwares disponíveis no mercado, bem como no dia-a-dia dos escritórios de cálculo especializados em projeto estruturais, já que possuem explicação fundamentada e simples, além de não exigirem tempo de processamento demasiadamente grande, considerando-se os processadores mais comuns utilizados hoje.

\section{3 - JUSTIFICATIVA}

Em função do exposto anteriormente, a automatização do cálculo de estruturas usuais de concreto armado mostra que poderá ser, em breve, uma realidade perfeitamente exeqüível para os calculistas de nosso país. Na EESC-USP a preocupação atual dos pesquisadores que estudam o comportamento não-linear do concreto armado inserido nas linhas de pesquisa de mecânica das estruturas e métodos numéricos, é criar procedimentos fundamentados em modelos que representem com eficácia o comportamento do material. Percebe-se que essa preocupação com o aprimoramento das técnicas está entre os objetivos principais das escolas Brasileiras de Engenharia. Além disto, este trabalho permite a continuação dos estudos de temas relativos ao cálculo e verificação de peças de concreto armado e análise de estruturas de edifício em geral, que atualmente são objeto de diversos estudos já realizados ou em andamento na própria EESC-USP.

Vale ressaltar aqui, que a forma mais simples e comum de se analisar uma estrutura de concreto armado é através de modelos lineares. Isto se dá por razões óbvias, como por exemplo: a mais fácil compreensão e utilização, a possibilidade de superposição de efeitos, e ainda dificuldades que os engenheiros apresentam para absorver alterações dos procedimentos usuais. No entanto, com os avanços dos modelos de cálculo é importante que no ensino de Engenharia e em projetos usuais estes modelos sejam levados em consideração, trazendo como conseqüência análises estruturais mais fiéis, em particular no estudo de grelhas representativas de pisos de edifícios. 


\section{4 - Metodologia}

Durante o decorrer deste trabalho, a estrutura a ser tratada será a referente a pavimentos de edifícios, para a qual o subsistema estrutural grelha será empregado como modelo. A determinação dos carregamentos nos elementos da grelha deve ser efetuada anteriormente, através do cálculo de reações de apoio das lajes sobre as vigas e de outros carregamentos atuantes diretamente sobre os elementos, utilizando-se técnicas já conhecidas para esta finalidade.

A análise é do tipo não-linear, considerando-se apenas a não-linearidade física, enquanto que o sistema global de equações será construído a partir do método dos elementos finitos.

A não-linearidade física foi considerada através do modelo fundamentado na mecânica do dano contínuo, proposto por MAZARS (1984). Os parâmetros necessários ao cálculo são advindos de dados experimentais obtidos por ÁLVARES (1993). O modelo, originalmente escrito em tensão x deformação, é escrito em termos de momento x curvatura.

Para a determinação das tensões resultantes no concreto nas seções transversais será utilizada a integração numérica do tipo Gausseana.

O sistema de equações não-lineares que resulta do procedimento de cálculo é resolvido numericamente através de algoritmos fundamentados nos métodos tipo Newton-Raphson, empregando-se aqui a matriz secante, procedendo-se ao que se chama de linearização do equilíbrio, recorrendo-se ao procedimento incrementaliterativo.

Para a determinação dos esforços resultantes na armadura, admite-se a compatibilidade de deformações entre as barras e o concreto ao longo de toda a sua extensão, isto é, admite-se aderência perfeita. A relação constitutiva a ser considerada para a armadura é elasto-plástica com encruamento linear.

Os códigos computacionais foram escritos em linguagem de programação Fortran, empregando-se o compilador Power Station da Microsoft. A ferramenta utilizada para a sua montagem, bem como o processamento dos exemplos necessários para os testes, foi um microcomputador PC que dispõe de um processador Pentium de 200 MHz e 32Mb de memória RAM. 


\section{5 - SÍNTESE DO CONTEÚDO DA DISSERTAÇÃO}

O segundo capítulo deste texto aborda alguns aspectos sobre o comportamento em serviço do concreto armado, enfocando-se os modelos usualmente empregados.

No terceiro capítulo faz-se uma breve revisão bibliográfica que trata do tema vigas de Timoshenko. Em seguida, é dado um enfoque sob a ótica do método da energia, com o propósito de deduzir a matriz de rigidez de um elemento de grelha, que incorpore o termo referente às deformações por esforço cortante.

No quarto capítulo, descreve-se o modelo de dano de MAZARS, para o concreto armado, incorporando-se a distorção da seção transversal ao estado de deformações do concreto. Complementa-se a revisão bibliográfica, enfocando-se os tópicos de interesse.

No quinto capítulo, são vistas as noções elementares sobre a análise estrutural com a consideração da não-linearidade física. Descreve-se o procedimento para o cálculo da linha neutra da seção transversal, que antecede a determinação dos esforços internos na seção, através do processo de integração numérica de Gauss, também explicitado. São comentadas as perdas de rigidez, através do modelo de dano. É apresentada ainda a estrutura do programa computacional desenvolvido.

No sexto capítulo apresenta-se uma breve explicação sobre o modelo clássico de absorção de esforços cortantes em uma seção transversal de uma peça de concreto armado. É apresentado o modelo simplificado proposto para a transferência de esforços, análogo ao da treliça de Mörsch.

No sétimo capítulo, apresentam-se exemplos de aplicação dos estudos realizados, e os resultados correspondentes.

E por fim, no oitavo capítulo apresentam-se as conclusões obtidas pelo trabalho. São dadas aqui sugestões para novas pesquisas. 


\section{MODELOS PARA O CONCRETO ARMADO}

\section{1 - GENERALIDADES}

Criar um modelo que represente bem o concreto armado não é uma tarefa fácil. Por tudo o que já se conhece sobre a variabilidade das propriedades dos materiais constituintes do concreto, somando-se ao evidente comportamento elasto-plástico da armadura, cria-se um problema de dimensões tão grandes, que embora já se tenha muitos anos de estudo e pesquisa, ainda não foi possível para o meio técnico a definição de uma solução fechada. Como exemplo, pode-se citar a análise não-linear da flexão simples de uma peça de concreto armado.

Vários pesquisadores, já efetuaram modelagens relativamente complexas do material, como CARVALHO(1994), que faz um interessante estudo utilizando-se da técnica da analogia de grelha, para representar pisos de edifícios. Ele realizou simulações de perdas de rigidez utilizando o modelo do CEB baseado em relações do tipo momento x curvatura, seguindo um procedimento incremental para a análise nãolinear.

No trabalho de CILONI(1993), são descritas algumas interessantes modelagens para peças lineares de concreto armado considerando-se a não-linearidade física e relações momento x curvatura médias propostas pelo CEB e pelo ACI. No trabalho ainda constam análises feitas com não-linearidade geométrica de pórticos planos deslocáveis.

MACHADO(1989), em um trabalho bastante extenso, analisa os efeitos da fluência no comportamento de peças lineares de concreto armado. Simula estruturas protendidas, utilizando modelos próprios para computar os efeitos da fissuração com atuação constante dos esforços ao longo do tempo. Também apresenta um estudo aprofundado dos modelos do CEB-90, Ghali-Favre(1986) e Debernardi(1989). 
OLIVEIRA(1997), integra modelos não-lineares de concreto armado para elementos de barra e placa em um sistema de análise não-linear de pavimentos, utilizando um diagrama momento $\mathrm{x}$ curvatura trilinear.

SANCHES Jr.(1998), também faz análises não-lineares do concreto armado, com os modelo de DEBERNARDI(1989) e GHALI \& FAVRE(1996), escritos também em termos de momento x curvatura, embutindo em sua análise os efeitos de deformações causadas pela fluência do concreto, exibindo como principal resultado a redistribuição dos esforços devida à presença da armadura. Os modelos desenvolvidos são utilizados em um sistema de grelhas adotado para representar estruturas de pavimentos de edifícios.

Justifica-se então, neste capítulo, a utilização de um modelo de dano para simular o diagrama tensão x deformação do concreto, aliado a um modelo elastoplástico com encruamento isótropo para a armadura, utilizando-se um elemento de barra que leva em conta a deformabilidade por esforço cortante.

\section{2 - RECOMENDAÇÕES}

Vários são os estudos e pesquisas que colaboram no sentido de tentar realizar uma modelagem simples e ao mesmo tempo precisa para o concreto armado. À medida que as ferramentas de análise se aprimoram, esse processo tende a abandonar as simplificações, descartando aproximações e refinando hipóteses, para tentar avaliar melhor as perdas de rigidez envolvidas no processo.

Esta tendência acontece devida à resposta sempre complexa do concreto. As peças apresentam baixíssima resistência à tração, apresentando até um quadro de microfissuração mesmo antes de serem carregadas. Segundo NEVILLE(1996), isto se deve a processos físicos existentes na interface entre a matriz de pasta de cimento e os agregados presentes no concreto, podendo-se concluir portanto que a heterogeneidade é inerente ao material.

Submetida a baixas solicitações, uma peça de concreto armado ainda resiste às tensões de tração, não estando fissurado o concreto tracionado abaixo da linha neutra. Esta situação caracteriza o estádio I de comportamento do concreto armado. 
Aumentando-se a intensidade do carregamento, a resistência à tração do concreto é superada, iniciando-se o processo de fissuração na região tracionada. Quando o concreto não resiste mais à tração, caracteriza-se o estádio II de comportamento do concreto armado. Neste estádio, o concreto solicitado à compressão, apresenta resposta que ainda pode ser considerada linear.

Aumentando-se ainda mais a intensidade do carregamento aplicado atinge-se um ponto limite convencional, caracterizado pelo valor máximo do momento resistente. Esta situação caracterizada pelo limite da resistência do material é definida como estádio III.

A importância de se definirem esses limites aparece quando se efetuam as verificações da estrutura em serviço, ou o seu dimensionamento. Os diagramas de tensões na seção transversal característicos de cada estádio de comportamento do concreto armado podem ser vistos na Figura 2.1.
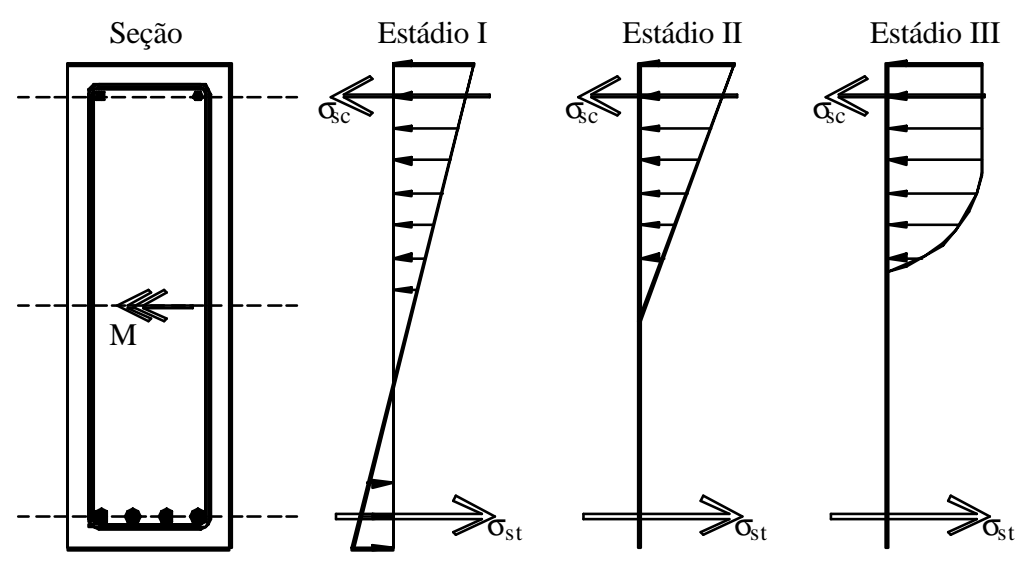

Figura 2.1 Distribuições de tensão em uma seção de concreto armado submetida à flexão.

Analisando-se o quadro da fissuração em uma peça de concreto, percebese que ela ocorre nas seções onde estão presentes as maiores tensões de tração. Observase então, que as seções da peça não apresentam um estádio de comportamento único, variando de uma para outra. O que acontece é que algumas seções entre as fissuras permanecem não fissuradas, gerando um mecanismo particular de absorção de esforços.

Isto ocorre devido ao fato de ser nula a tensão de tração no concreto na seção fissurada, enquanto nas demais seções entre duas fissuras as tensões têm valores 
diferentes de zero e crescentes à medida que a seção se afasta da fissura. Para que o equilíbrio seja verificado, a armadura recebe o esforço que deveria ser resistido pelo concreto, havendo nela um aumento de esforço de tração. Isto faz com que os diagramas de tensões no concreto e na armadura apresentem características peculiares quando se analisa o intervalo entre duas fissuras consecutivas.

Mesmo para elementos de seções constantes, as propriedades físicas estarão alteradas ao longo do comprimento da peça, como conseqüência da fissuração. Como por exemplo pode-se citar o momento de inércia à flexão que entre fissuras deverá ter a contribuição da região de tensões de tração.

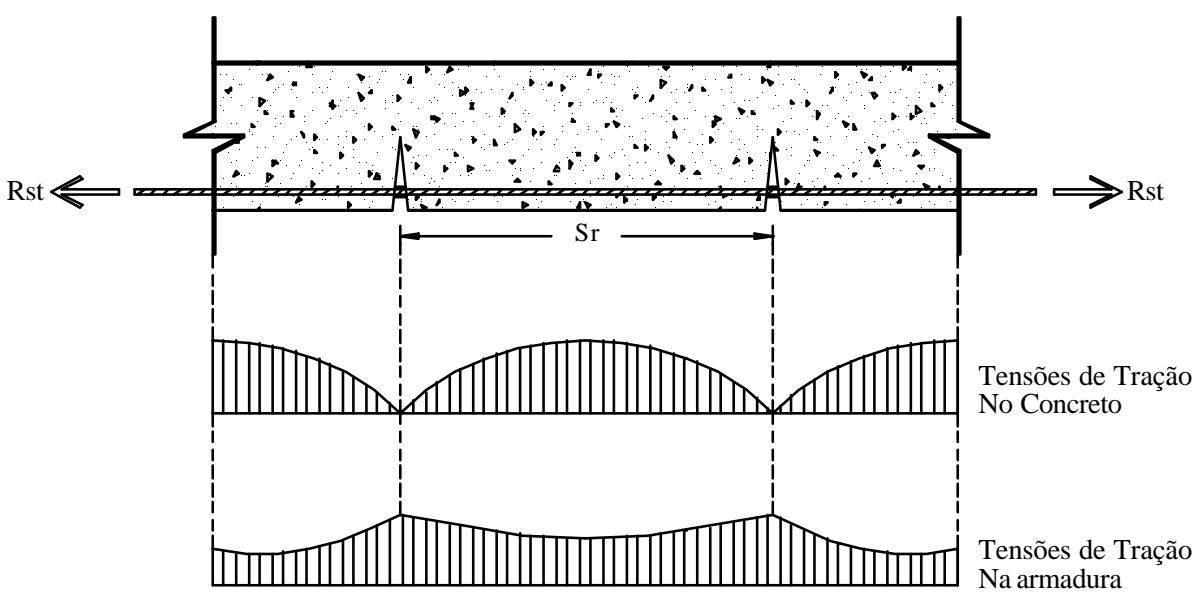

Figura 2.2 Distribuição de tensões de tração no concreto e na armadura entre duas seções fissuradas.

Fica claro então porque o mecanismo resistente do material é diferente para cada seção da peça, e porque cada uma se encontra submetida a uma distribuição diferente de tensões normais. No geral, a situação real de uma seção compreendida entre duas fissuras está situada entre os limites dos estádios I e II.

No CEB-158 (1985) é proposto um diagrama teórico de momentocurvatura para uma seção de concreto armado, conforme pode ser observado na Figura 2.3. O ramo não-linear do diagrama, segundo esta recomendação, inicia-se no ponto em que é atingido o momento de fissuração da peça, dado pela expressão:

$M_{r}=\frac{f_{c t m} I_{1}}{\left(h-x_{1}\right)}$ 
onde $\mathrm{f}_{\mathrm{ctm}}$ é a resistência média do concreto à tração, $\mathrm{I}_{1}$ é o momento de inércia da seção homogeneizada, h é a altura da seção, e $\mathrm{x}_{1}$ é a posição da linha neutra no estádio I.

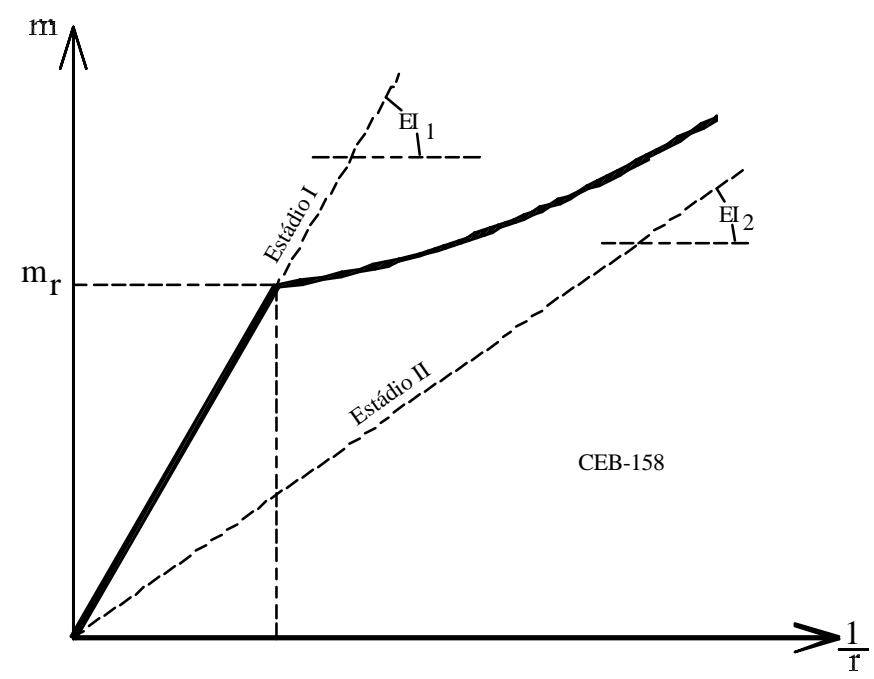

Figura 2.3 - Diagrama momento x curvatura do CEB-158.

A norma Brasileira que trata do assunto, a NBR-6118, preconiza que as verificações em serviço para as peças de concreto armado sejam feitas no estádio II. Observando-se o diagrama momento x curvatura proposto pelo CEB-158, fica claro a verificação da Norma Brasileira encontra-se em níveis altos de segurança, levando a uma superavaliação dos deslocamentos.

Relações momento x curvatura, ou distribuições de tensões em função de deformações, ambos descritos anteriormente, são modelos mecânicos utilizados nas verificações em serviço ou para dimensionamento, que consideram que a seção transversal seja homogênea. Qualquer um dos dois pode conduzir a bons resultados se formulados corretamente. Não se justifica a afirmação de que um seja melhor que o outro. O que se faz comumente é desconsiderar defeitos localizados, como fissuração, ou modificação no módulo de elasticidade além de se considerar o material contínuo. No entanto, procura-se representar com fidelidade a somatória dos defeitos de quaisquer natureza presentes na peça. Um modelo de dano, conforme será visto mais adiante neste trabalho, também pode ser utilizado para representar este fenômeno, adotando-se uma aproximação média para todo o volume do corpo em estudo. 


\section{3 - ESTADOS LIMITES}

Estado limite é a situação a partir da qual a estrutura não desempenha mais a função para a qual foi projetada. Na NBR-6118 são definidos dois Estados Limites que devem ser considerados em projetos de peças de concreto armado.

- Estados limites últimos

- Estados limites de utilização

Os Estados limites últimos são aqueles relacionados ao colapso da estrutura ou parte dela, ou à qualquer outra forma de ruína estrutural, que determine a paralisação do uso da estrutura. São três os estados limites últimos considerados pela NBR-6118:

- Ruptura por esmagamento do concreto

- Alongamento plástico excessivo da armadura

- Instabilidade

Um estado limite de utilização é atingido quando a estrutura ou parte dela apresenta deslocamentos inaceitáveis ou aberturas de fissuras grandes o suficiente para comprometerem a finalidade principal da estrutura. Computam-se aqui também os requisitos referentes à durabilidade. Os códigos vigentes em cada país fixam seus próprios limites de deformações, bem como as leis de variações de tensões nas seções transversais, conforme a resistência do concreto.

$\mathrm{Na}$ verificação da segurança estrutural deve-se manter afastada a possibilidade de uma seção qualquer da estrutura atingir um estado limite, fixando-se deformações máximas para o encurtamento do concreto e para o alongamento da armadura. Para o dimensionamento no regime de ruptura das seções de concreto armado, são desprezadas as tensões de tração no concreto presente nas seções fissuradas. Fixando-se então as deformações nos elementos estruturais, é possível dimensioná-los para qualquer tipo de solicitação. Nas verificações em serviço devem ser computadas as ações de serviço, que são majoradas por coeficientes adequados.

É permitido pela NBR-6118 que seja utilizado o diagrama parábolaretângulo de tensões para o concreto submetido aos esforços de compressão, conforme ilustra a Figura 2.4 e um diagrama elasto-plástico perfeito para as barras da armadura. 


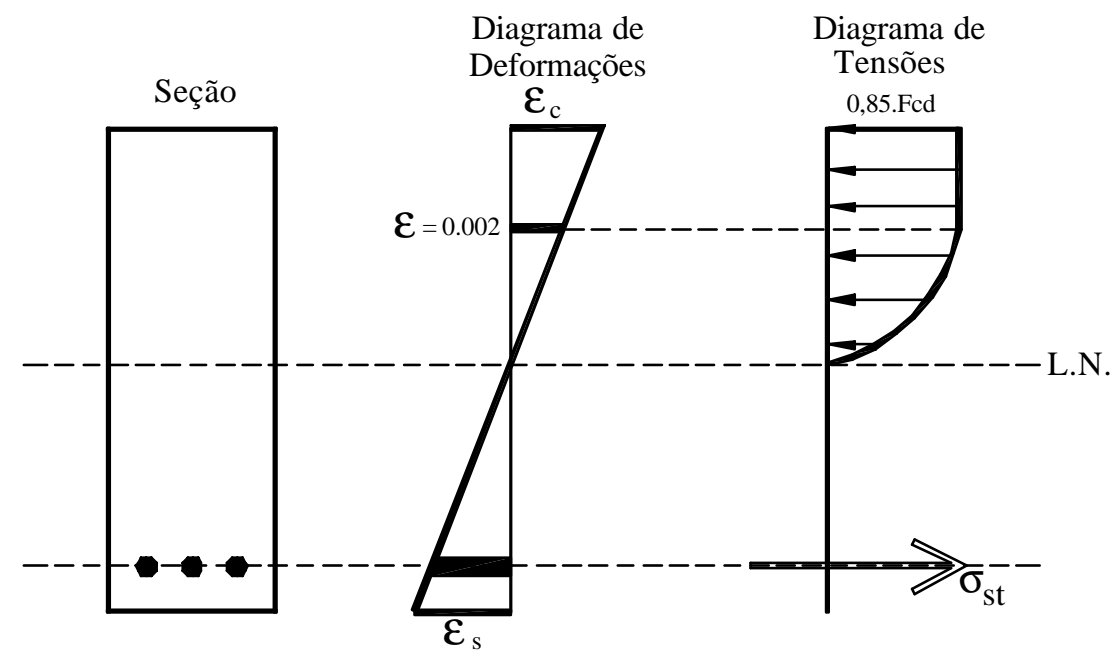

Figura 2.4 - Tensões na seção transversal segundo a NBR-6118

Na verificação em serviço recomendada pelo CEB-158(1985), permite-se considerar o "tension stiffening", que é a colaboração do concreto intacto entre duas fissuras consecutivas que leva a um pequeno aumento da rigidez em relação ao estádio II.

Estes modelos aqui mostrados não foram utilizados na análise realizada neste trabalho. Fez-se, no entanto, uso de um modelo de dano para uma avaliação dos esforços nas peças de concreto armado. Na obtenção dos esforços internos ou resistentes, fez-se uso de artifício de integração numérica para o cálculo das resultantes

Os modelos não-lineares para o concreto armado estão abrindo espaço e calcando-se em teorias complexas como a mecânica do dano, a mecânica da fratura e a teoria da plasticidade. Passam, assim, a levar em conta na determinação das resultantes dos esforços internos, efeitos nunca antes modelados simultaneamente como a consideração de efeitos viscosos, fluência, retração, variação da rigidez, dentre outros.

Pretende-se ao final deste trabalho de dissertação, mostrar os resultados de análises de grelhas representativas de pisos de edifícios que foram tratadas com modelo de dano para o concreto, barras deformáveis ao esforço cortante e modelo elasto-plástico para as barras da armadura. 


\section{4 - MODElos ELASTOPLÁSTICOS PARA O AÇO}

\subsection{1 - Generalidades}

$\mathrm{Na}$ modelagem do comportamento elastoplástico uniaxial, pode-se considerar como principais modelos, aqueles que consideram o encruamento nulo (elastoplástico perfeito) e os com encruamento linear. A plastificação e ductilidade ficam evidentes em qualquer ensaio de tração unixial envolvendo os metais. A plastificação é caracterizada pelo aparecimento de deformações residuais permanentes. Estes modelos nada mais são do que aproximações matemáticas teóricas, que buscam representar o diagrama tensão x deformação dos aços obtidos em laboratórios, conforme é visto na Figura 2.5 .

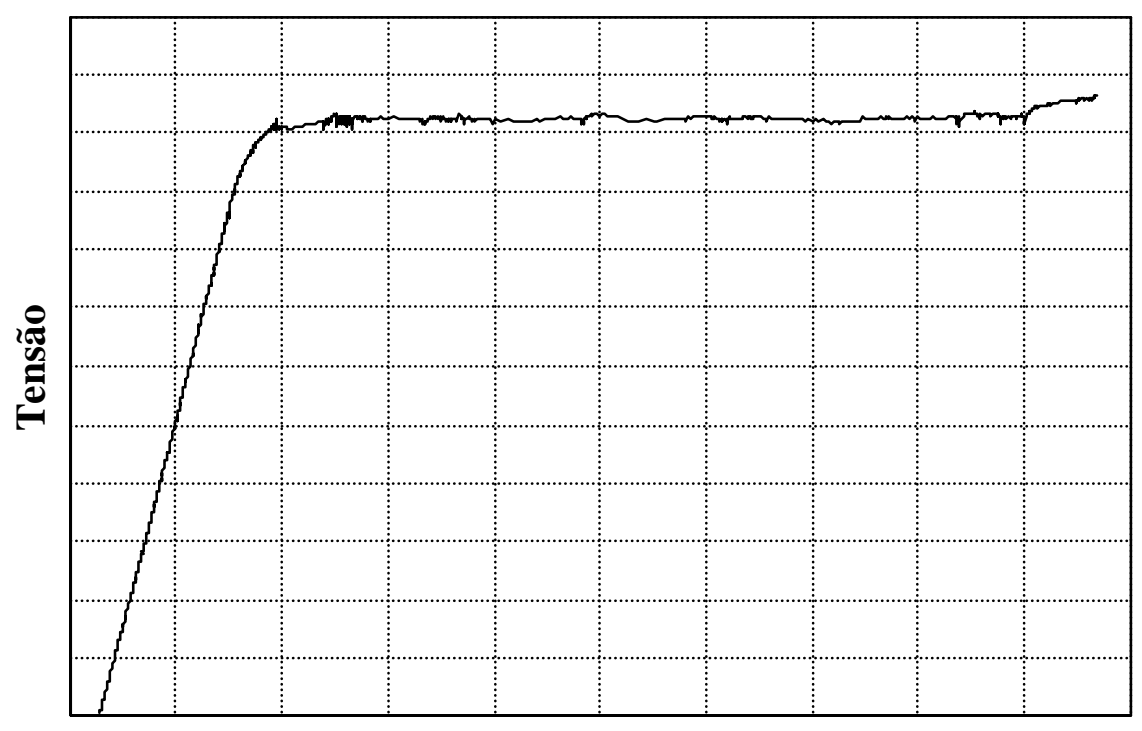

\section{Deformação}

Figura 2.5 - Diagrama tensão deformação experimental do aço

Os modelos mostrados a seguir são ditos em taxas porque apresentam suas grandezas definidas em função da sua variação em relação ao tempo. Os modelos aplicados computacionalmente não são escritos em taxas, mas sim em passo finito, o que quer dizer que a deformação deve ser aplicada em incrementos discretos. O motivo é óbvio: em programação, todo incremento deve ter um valor real, mesmo sendo muito 
pequeno. A sua utilização aqui apenas serve para determinar a tensão no aço, dada a deformação na fibra de concreto correspondente à armadura. Considera-se a armadura pelo seu eixo, em uma única camada, e que é válida a hipótese da perfeita aderência entre o aço e o concreto.

Vale lembrar que as relações aqui tratadas são válidas em teorias baseadas em hipóteses de pequenos deslocamentos e portanto também em pequenas deformações.

Muitos autores estudaram modelos elasto-plásticos, já que são fartamente utilizados nas aplicações correntes de engenharia. No trabalho de HINTON \& OWEN (1980) aborda-se o assunto de maneira ampla, no contexto do método dos elementos finitos. Para maiores detalhes recomenda-se essa referência.

Esses modelos fornecem resultados razoáveis aplicados ao concreto armado, muito embora seja de domínio do meio técnico, que a ruptura apresentada pelo concreto é frágil. Já nas análises com materiais metálicos, onde observa-se grande ductilidade devida à própria estrutura interna dos mesmos, estes modelos são extremamente viáveis

Sob um aspecto mais genérico, os modelos são na sua maioria representados por um trecho linear, e um ou dois outros trechos onde as tensões e deformações têm outras razões de proporcionalidade, que não o módulo de elasticidade. 


\subsection{2 - Formulação}

Após a plastificação, quem passa a registrar a evolução da deformação no tempo é a deformação plástica acumulada $\grave{a}^{p}$. O modelo elasto-plástico perfeito está indicado na Figura 2.5 será considerado. :

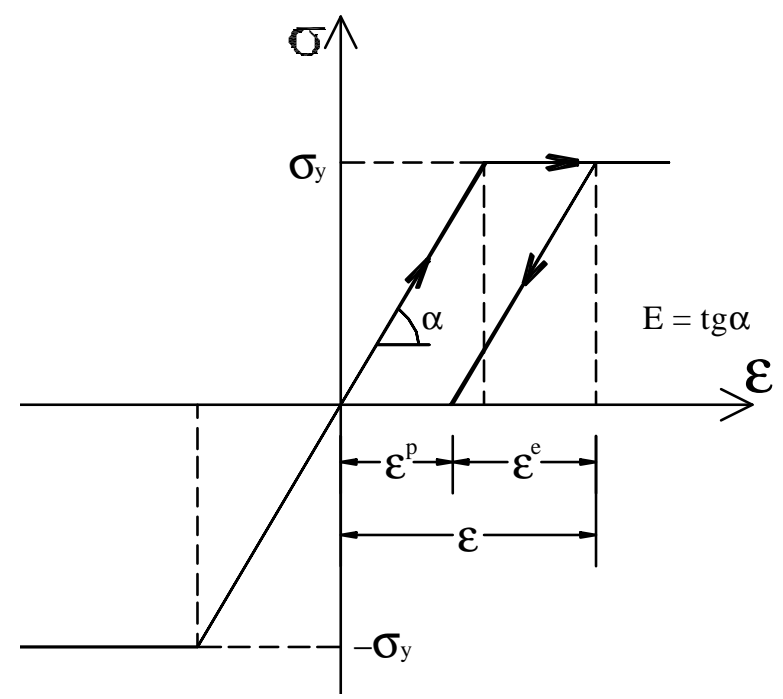

Figura 2.6 - Lei constitutiva do aço com comportamento Elasto-Plástico Perfeito.

Observando-se a figura 2.5, escrevem-se as seguintes equações:

$$
\begin{aligned}
& \mathcal{E}^{\mathrm{e}}=\boldsymbol{\varepsilon}-\varepsilon^{\mathrm{p}} \\
& \sigma=\mathrm{E} \boldsymbol{\varepsilon}^{\mathrm{e}}=\mathrm{E}\left(\boldsymbol{\varepsilon}-\boldsymbol{\varepsilon}^{\mathrm{p}}\right)
\end{aligned}
$$

Como as grandezas $\varepsilon, \sigma$, e $\mathcal{E}^{\mathrm{p}}$, podem ser funções do tempo, pode-se defini-las em termos de taxas. Então:

$$
\dot{\varepsilon}^{\mathrm{P}}=\frac{\mathrm{d} \varepsilon^{\mathrm{p}}}{\mathrm{dt}}
$$

Diz-se então que as deformações plásticas irreversíveis aparecem quando esta taxa é diferente de zero. Pode-se, portanto, determinar a deformação plástica em um certo intervalo de tempo $\left[\mathrm{t}_{1}, \mathrm{t}_{2}\right]$, como sendo:

$$
\varepsilon^{\mathrm{p}}=\int_{\mathrm{t}_{1}}^{\mathrm{t}_{2}} \dot{\varepsilon}^{\mathrm{P}} \mathrm{dt}
$$


A relação $\sigma \times \varepsilon$ também pode ser expressa em função de taxas:

$$
\dot{\sigma}=\mathrm{E} \cdot \dot{\varepsilon}^{\mathrm{e}}=\mathrm{E} \cdot(\dot{\varepsilon}-\dot{\varepsilon} \mathrm{p})
$$

\subsection{3 - Critério de plastificação}

Para definir os estados de tensão admissíveis, que podem ser desenvolvidos no material, define-se o critério de plastificação, com a seguinte representação:

$\mathrm{f}(\sigma)=|\sigma|-\sigma_{\mathrm{y}} \leq 0 \quad(\mathrm{f}: \mathrm{R} \rightarrow \mathrm{R})$

onde se lê: f é função de R em R.

Portanto, o conjunto de estados de tensão admissíveis engloba todos aqueles em que se verifica a relação $\mathrm{f}(\sigma) \leq 0$. As deformações plásticas só irão aparecer caso o valor da tensão atuante seja igual ou maior que o da tensão de escoamento $\sigma_{\mathrm{y}}$.

Analisando-se o critério de plastificação, surgem as seguintes situações:

- Se $\mathrm{f}(\sigma)<0$, então $|\sigma|<\sigma_{\mathrm{y}}$, logo o material se encontra na fase elástica.

- Se $\mathrm{f}(\sigma)=0$, então $|\sigma|=\sigma_{\mathrm{y}}$; o material está na fase plástica.

- Se $\mathrm{f}(\sigma)>0$, então estamos diante de um estado de tensões inadmissível.

Pode-se ainda definir a grandeza auxiliar $\dot{\lambda}$ como o módulo da velocidade de deformação plástica, onde:

$\dot{\varepsilon}=\dot{\lambda} \operatorname{Sgn}(\sigma)$

A grandeza $\operatorname{Sgn}(\sigma)$ é o sinal da tensão solicitante, valendo:

$\operatorname{Sgn}(\sigma)=\left\{\begin{array}{llll}+1 & \text { Se } & \sigma>0 & \quad \text { (tração) } \\ -1 & \text { Se } & \sigma<0 & \text { (Compressão) }\end{array}\right.$

A fórmula (2.08) vale somente para $\mathrm{f}=0$, já que se esta condição não for verificada, é fácil observar-se que não existe variação na deformação plástica e portanto:

$\dot{\varepsilon}=0$ 
Observando-se agora, a unilateralidade das grandezas f e $\lambda$, podemos definir algumas relações de interesse. Define-se assim a chamada condição de complementaridade de Kuhn-Tucker:

$\dot{\lambda} . \mathrm{f}=0$

Além disso, definem-se as seguintes situações:

Quando $\dot{\mathrm{f}}<0$, configura-se um descarregamento e portanto $\dot{\lambda}=0$;

Quando $\dot{\mathrm{f}}=0$, tem-se $\dot{\lambda}>0$;

A situação $\dot{\mathrm{f}}>0$ é inadmissível.

Define-se então a relação que é chamada de condição de consistência :

$\dot{\lambda} \cdot \dot{f}=0 \quad$ para $\dot{\mathrm{f}} \leq 0$

\subsection{4 - Modelo com encruamento isótropo}

Estuda-se agora, o modelo elastoplástico com encruamento isótropo, que é de interesse aqui. Nesse caso, o diagrama tensão x deformação característico é:
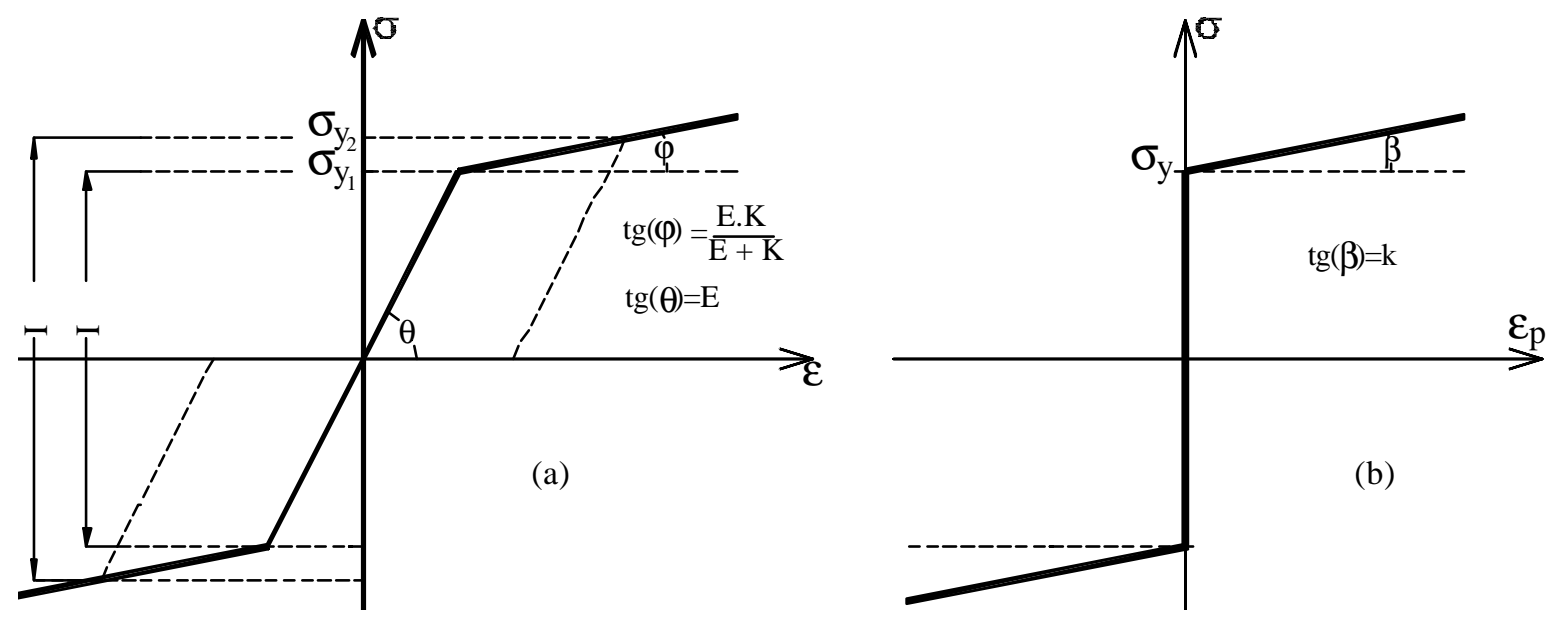

Figura 2.7 - Material com encruamento isótropo

Neste modelo, ocorre, como pode-se ver, a expansão do intervalo elástico, do intervalo "1" para o intervalo "2", de maneira simétrica em relação ao seu centro, na origem do diagrama das tensões. No espaço das tensões, isto caracteriza-se por «m aumento da superfície de plastificação, sem translação da mesma. 
As equações que regem esse modelo constitutivo são determinadas de maneira análoga ao modelo perfeito:

$$
\begin{aligned}
& \dot{\varepsilon}=\dot{\varepsilon}+\dot{\varepsilon} \\
& \dot{\sigma}=\mathrm{E} .\left(\dot{\varepsilon}^{\mathrm{e}}+\stackrel{\mathrm{p}}{\varepsilon}\right)
\end{aligned}
$$

O critério de plastificação agora é:

$$
\mathrm{f}(\sigma, \alpha)=|\sigma|-\left(\sigma_{\mathrm{y}}+\mathrm{K} . \alpha\right) \leq 0 \quad(\mathrm{f}: \mathrm{R} \rightarrow \mathrm{R})
$$

onde f é função de $\mathrm{R}$ em $\mathrm{R}, \mathrm{K}$ é chamado de módulo plástico, dado pela tangente da reta no diagrama $\sigma \times \varepsilon^{\mathrm{p}}$, como na Figura 2.6b, e $\alpha$ é uma variável que evolui proporcionalmente à deformação plástica, controlando a expansão do intervalo elástico com a plastificação.

\section{Portanto:}

$\mathrm{K}=\frac{\mathrm{d} \sigma}{\mathrm{d} \varepsilon^{\mathrm{p}}}$

A função $\mathrm{f}$ depende de $\sigma$ e $\alpha$, limitando um conjunto de tensões admissíveis que varia de amplitude à medida que $\alpha$ varia. Define-se, então, a grandeza $\dot{\alpha}=\left|\dot{\varepsilon}^{\mathrm{p}}\right|$, de tal maneira que ao terminar-se um ciclo, de tensão, mesmo sem existirem deformações plásticas, a tensão limite $\sigma_{\mathrm{y}}$ cresce de um valor $\mathrm{K} . \alpha$, conforme visto anteriormente na Figura 2.6a, onde $\sigma_{\mathrm{Y} 2}=\sigma_{\mathrm{Y} 1}+\mathrm{K} . \alpha$.

Valem também as relações de complementaridade e de consistência, também apenas para $\dot{\mathrm{f}} \leq 0$. Dessas equações, pode-se determinar:

$$
\begin{aligned}
& \dot{\lambda}=\frac{\operatorname{Sign}(\sigma) \cdot \mathrm{E} \cdot \dot{\varepsilon}}{\mathrm{E}+\mathrm{K}} \\
& \dot{\varepsilon^{\mathrm{p}}}=\dot{\lambda} \operatorname{Sign}(\sigma)=\frac{\mathrm{E} \cdot \dot{\varepsilon}}{\mathrm{E}+\mathrm{K}} \\
& \dot{\sigma}=\dot{\varepsilon}-\frac{\mathrm{E} \cdot \dot{\varepsilon}}{\mathrm{E}+\mathrm{K}}=\frac{\mathrm{E} \cdot \mathrm{K}}{\mathrm{E}+\mathrm{K}} \dot{\varepsilon} \quad \text { se } \dot{\lambda}>0
\end{aligned}
$$




\section{VigAS DE TIMOSHENKO}

\section{1 - HiSTóRICO}

A teoria de vigas de Timoshenko é uma extensão da teoria de EulerBernoulli para considerar o efeito da deformação transversal por esforço cortante, considerando-se que as seções planas permanecem planas, porém não mais necessariamente perpendiculares ao eixo deformado. Admite-se, então uma deformação adicional à curvatura de flexão, sendo portanto a distorção diferente de zero, conforme está indicado na Figura 3.1.

$\mathrm{Na}$ hipótese de Euler-Bernoulli admite-se que todas as deformações causadas por tensões de cisalhamento (distorções) nas seções transversais são nulas. Entretanto, o efeito da distorção na solução da flexão não pode ser negligenciado quando se trata, por exemplo, de vigas curtas ou com baixo módulo de elasticidade transversal, pois nesses casos o efeito se torna relativamente significante.

Considera-se então, que a rigidez da peça esteja diminuída de um pequeno fator, que será mostrado mais adiante neste trabalho, fazendo com que os deslocamentos nodais aumentem.

O efeito das distorções também deve ser considerado quando se necessitar de uma melhor precisão na determinação da elástica de um elemento de barra. Esta é a finalidade da implementação desse efeito no elemento finito tratado neste trabalho. 


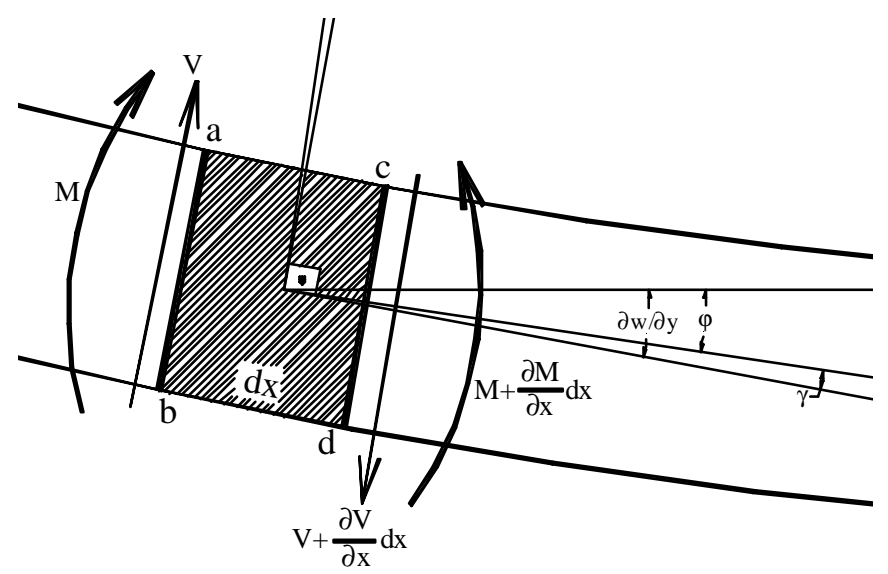

Figura 3.1 Elemento infinitesimal de viga.

Vários foram os autores que propuseram elementos finitos para a viga de Timoshenko, podendo-se citar NICKEL \& SECOR(1972), TESSLER \& DONG (1981), PRATHAP \& BHASHYAM(1982), HEYLIGER \& REDDY(1988), NAVARRA(1995) e uma série de outros. Eles diferem entre si apenas na escolha da função de interpolação utilizada para aproximar os deslocamentos transversais e rotações. As formulações existentes são baseadas no método dos deslocamentos ou em métodos mistos, conforme consta na literatura consultada.

O modelo mais simples para a formulação em elementos finitos, conforme visto em BATHE (1996), NÓBREGA(1997) e RIGITANO (1999), é aquele que considera interpolações lineares tanto para os deslocamentos transversais, quanto para as rotações. No entanto, este modelo se mostra muito rígido para as vigas pouco deformáveis ao esforço cortante. Este comportamento acarreta o bloqueio da solução ou travamento, conhecido como o efeito "shear locking".

O travamento acontece devido à inconsistência da ordem das funções de deslocamentos transversais e rotações. Alguns artifícios matemáticos foram propostos para superá-lo, podendo-se utilizar uma função de interpolação de ordem igual tanto para os deslocamentos quanto para as rotações, mas utilizando um polinômio de menor ordem para a distorção. É também freqüentemente utilizada a integração seletiva, na qual a integração em ordem reduzida é empregada para calcular os coeficientes de rigidez associados à distorção, enquanto os demais coeficientes da matriz de rigidez são calculados com uma integração precisa. 
A integração reduzida é feita usando-se quadratura de Gauss com apenas um ponto; uma vez que o polinômio aproximador tem grau $\mathrm{P}=2 \mathrm{~N}-1$, a aproximação é constante.

Através dessas técnicas, chega-se a uma nova matriz de rigidez, como mostrada em NÓBREGA(1997), onde a parcela de esforço cortante tem a sua participação diminuída, o que leva ao alívio do travamento da solução. Este procedimento deve ser utilizado com cautela, segundo RIGITANO(1999).

Uma solução bastante elegante e precisa do problema foi proposta por REDDY(1997), que emprega um elemento que se adequa a um campo de deslocamentos com polinômios cúbicos para representar as distorções na seção transversal, admitindo que as seções não permaneçam planas. Este tipo de solução é complexa, levando a dificuldades matemáticas, e seu estudo não será tratado aqui.

Outro fator importante neste estudo é a necessidade de continuidade das funções aproximadoras. A escolha dos graus de liberdade deve levá-la em consideração, já que em um procedimento baseado em elementos finitos, as funções aproximadoras escritas em função dos parâmetros nodais devem representar grandezas contínuas.

NARAYANASWAMI \& ADELMAN(1974) concluíram que em qualquer formulação do método dos elementos finitos, em que as deformações causadas por esforço cortante serão consideradas, é essencial que a rotação da reta normal (e não a derivada da elástica no ponto) seja tomada como grau de liberdade.

Este problema nasce do fato de ser necessária, em um mesmo nó, a continuidade à esquerda e à direita de quaisquer grandezas que se tome como grau de liberdade, conforme consta da Figura 3.2. Se isto não acontecer, a formulação em elementos finitos torna-se inviável.

Já que os diagramas de esforço cortante apresentam descontinuidades frente a cargas concentradas e a distorção da seção é proporcional a este esforço, ela não é contínua e não pode ser utilizada como parâmetro nodal. Neste estudo, determinou-se a equação da distorção em função dos outros parâmetros nodais encontrados. 


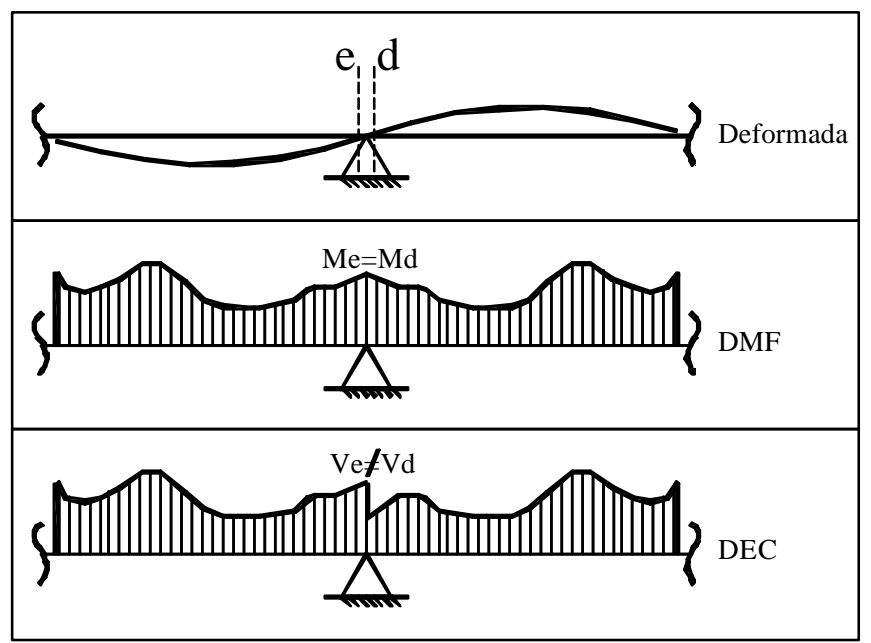

Figura 3.2 Continuidade dos Parâmetros Nodais

Conclui-se também que a rotação total da seção, que é a soma da rotação devida à flexão com aquela produzida pelo esforço cortante, não é contínua. Logo, ela também não serve para ser utilizada como parâmetro nodal. A implementação feita neste trabalho contempla a flecha total correspondente aos esforços de flexão e cisalhamento e a rotação devida apenas à flexão, que são graus de liberdade contínuos em todo o intervalo do problema. A matriz de rigidez do elemento de barra, cuja dedução será mostrada agora, é a apresentada em GERE \& WEAVER (1981); aqui é apenas dado um enfoque mais genérico, chegando-se a ela através da definição, utilizando-se o método da energia.

\section{2 - DEDUÇão DA MATRIZ DE RIGIDEZ}

Existe nesta dedução uma certa incompatibilidade, pelo fato de existirem diferenças entre as convenções adotadas nas equações clássicas da resistência dos materiais e as convenções ideais para a formulação de um determinado problema através do método dos elementos finitos. Para sanar este problema, deve-se entender as convenções utilizadas para esforços e para deslocamentos de acordo com o seu enfoque. Os parâmetros nodais mostrados, são definidos conforme comentado anteriormente, por questões de continuidade dos polinômios aproximadores. 
São os seguintes os parâmetros nodais utilizados:

$\mathrm{v}_{1} \mathrm{e} \mathrm{v}_{2}$ - Flechas devidas a momento fletor e força cortante

$\theta_{1}$ e $\theta_{2}$ - Rotações devidas apenas a momento fletor

Voltando à definição das convenções: Nas equações da resistência dos materiais, tem-se:

Deslocamentos
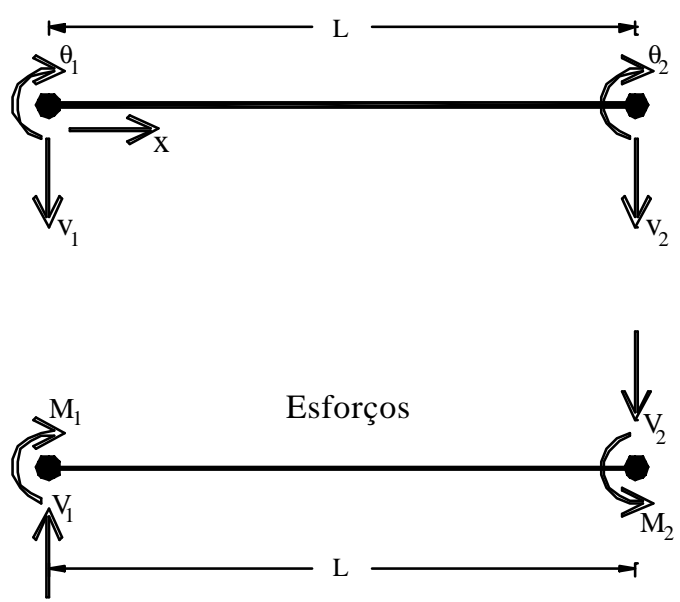

Figura 3.3 Convenções de sinais da Resistência dos Materiais 
Já na formulação em elementos finitos, tem-se as convenções:
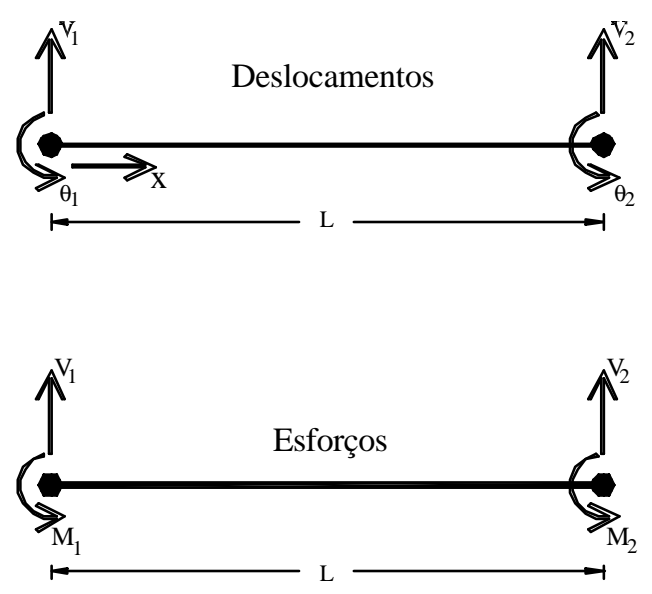

Figura 3.4 Convenções de sinais para a formulação em elementos finitos

A partir da Figura 3.1, escrevem-se as seguintes relações geométricas:

$v_{t}=v_{f}+v_{c} \rightarrow \frac{d v_{t}}{d x}=\frac{d v_{f}}{d x}+\frac{d v_{c}}{d x}$

onde:

$\mathrm{v}_{\mathrm{t}}$ - Deslocamento transversal devido ao momento fletor + esforço cortante

$\mathrm{v}_{\mathrm{f}}$ - Deslocamento transversal devido ao momento fletor

$\mathrm{v}_{\mathrm{c}}$ - Deslocamento transversal devido ao esforço cortante

\section{Portanto:}

$\beta=\varphi+\gamma$

Isolando-se o elemento infinitesimal mostrado na Figura 3.1, na ausência de momentos distribuídos, escrevem-se as já conhecidas relações de equilíbrio:

$\frac{\mathrm{dV}}{\mathrm{dx}}=-\mathrm{q}$

$\frac{\mathrm{dM}}{\mathrm{dx}}=\mathrm{V}$

onde:

V - Força cortante

q - Carga distribuída ao longo do elemento

M - Momento fletor 
Escrevem-se ainda, segundo a resistência dos materiais, as seguintes relações constitutivas:

$$
\begin{aligned}
& M=-E I \frac{d \varphi}{d x} ; \quad V=-E I \frac{d^{2} \varphi}{d^{2}} \\
& V=K G A \cdot \gamma=\operatorname{KGA}\left(\frac{d v}{d x}-\varphi\right)
\end{aligned}
$$

Onde "K" é o fator de forma da seção transversal:

- $\frac{1}{1,2}$ para Seção retangular

- $\frac{1}{0,9}$ para Seção circular

É conveniente que a troca de sinais devida à diferença de convenções seja feita somente no final dos cálculos. Portanto, a partir de agora, trabalha-se com a formulação em elementos finitos, adotando os sinais de sua convenção, fazendo-se a compatibilização mais adiante. Adianta-se, aqui, que esta troca será feita na imposição das condições de contorno do elemento.

Já que na formulação em elementos finitos constrói-se o vetor de cargas nodais equivalentes, sem perda de precisão da solução, admite-se que não haja cargas distribuídas ao longo do comprimento do elemento. Portanto, escreve-se:

$$
\frac{\mathrm{dV}}{\mathrm{dx}}=0
$$

Substituindo-se (3.05) em (3.06), vem:

$$
\begin{aligned}
& \frac{\mathrm{d}}{\mathrm{dx}} \operatorname{KGA}\left(\frac{\mathrm{dv}}{\mathrm{dx}}-\varphi\right)=0 \Rightarrow \\
& \frac{\mathrm{d}}{\mathrm{dx}}\left(\frac{\mathrm{dv}}{\mathrm{dx}}-\varphi\right)=0
\end{aligned}
$$


Substituindo-se (3.04) e (3.05) em (3.03), tem-se:

$$
\begin{aligned}
& \frac{d}{d x}\left(-E I \frac{d \varphi}{d x}\right)-\operatorname{KGA}\left(\frac{d v}{d x}-\varphi\right)=0 \Rightarrow \\
& E I \frac{d^{2} \varphi}{d x^{2}}+\operatorname{KGA}\left(\frac{d v}{d x}-\varphi\right)=0
\end{aligned}
$$

Sabendo-se que a terceira derivada da rotação deve ser nula, escreve-se:

$\varphi=\mathrm{A}+\mathrm{B} \cdot \mathrm{X}+\mathrm{C} \cdot \mathrm{X}^{2}$

De (3.01), sabe-se que:

$\frac{\mathrm{dv}}{\mathrm{dx}}-\varphi=\gamma$

Substituindo-se (3.09) e (3.10) em (3.08), tem-se:

$\mathrm{EI}(2 \mathrm{C})+\mathrm{KGA}(\gamma)=0 \Rightarrow$

$\gamma=-\frac{2 \mathrm{C} \cdot \mathrm{EI}}{\mathrm{KGA}}$

Substituindo-se (3.11) e (3.09) em (3.10), vem:

$\frac{\mathrm{dv}}{\mathrm{dx}}=\mathrm{A}+\mathrm{B} \cdot \mathrm{X}+\mathrm{C} \cdot \mathrm{X}^{2}-\frac{2 \mathrm{C} \cdot \mathrm{EI}}{\mathrm{KGA}}$

Integrando-se (3.12), vem:

$$
\begin{aligned}
& \mathrm{v}=\mathrm{D}+\mathrm{A} \cdot \mathrm{X}+\frac{\mathrm{B} \cdot \mathrm{X}^{2}}{2}+\frac{\mathrm{C} \cdot \mathrm{X}^{3}}{3}-\frac{2 \mathrm{C} \cdot \mathrm{EI}}{\mathrm{KGA}} \cdot \mathrm{X} \Rightarrow \\
& \mathrm{v}=\mathrm{D}+\mathrm{A} \cdot \mathrm{X}+\frac{\mathrm{B} \cdot \mathrm{X}^{2}}{2}+\mathrm{C}\left(\frac{1}{3} \cdot \mathrm{X}^{3}-\frac{2 \cdot \mathrm{EI}}{\mathrm{KGA}} \cdot \mathrm{X}\right)
\end{aligned}
$$


Admitindo-se a constante:

$g=\frac{6 \cdot E I}{\text { KGA.L }}$

Escreve-se a equação (3.13) da seguinte forma:

$\mathrm{v}=\mathrm{D}+\mathrm{A} \cdot \mathrm{X}+\frac{\mathrm{B} \cdot \mathrm{X}^{2}}{2}+\frac{\mathrm{C}}{3}\left(\mathrm{X}^{3}-\mathrm{g} \cdot \mathrm{L}^{2} \mathrm{X}\right)$

Definido o polinômio aproximador dos deslocamentos, parte-se agora para escrevê-lo em função dos parâmetros nodais.

Estabelecendo-se as condições de contorno, atentando aqui para as diferentes convenções entre as formulações da teoria técnica de flexão e do método dos elementos finitos, tem-se:

$\begin{array}{ll}\text { Em } X=0 & v=-v_{1} \\ \text { Em } X=0 & \varphi=-\theta_{1} \\ \text { Em X=L } & v=-v_{2} \\ \text { Em X }=L & \varphi=-\theta_{2}\end{array}$

Em forma matricial:

$\left[\begin{array}{cccc}0 & 0 & 0 & 1 \\ 1 & 0 & 0 & 0 \\ \mathrm{~L} & \frac{\mathrm{L}^{2}}{2} & \frac{\mathrm{L}^{3}}{3}(1-\mathrm{g}) & 1 \\ 1 & \mathrm{~L} & \mathrm{~L}^{2} & 0\end{array}\right] \times\left[\begin{array}{l}\mathrm{A} \\ \mathrm{B} \\ \mathrm{C} \\ \mathrm{D}\end{array}\right]=\left[\begin{array}{l}-\mathrm{v}_{1} \\ -\theta_{1} \\ -\mathrm{v}_{2} \\ -\theta_{2}\end{array}\right]$ 
Solucionando-se o sistema (3.16), vem:

$$
\left[\begin{array}{l}
\mathrm{A} \\
\mathrm{B} \\
\mathrm{C} \\
\mathrm{D}
\end{array}\right]=\left[\begin{array}{c}
-\theta_{1} \\
-\frac{2}{\mathrm{~L}^{2}} \frac{\left(-\mathrm{L} \cdot \theta_{2}-2 \cdot \mathrm{L} \cdot \theta_{1}+\mathrm{L} \cdot \theta_{2} \cdot \mathrm{g}-\mathrm{L} \cdot \theta_{1} \cdot \mathrm{g}+3 \cdot \mathrm{v}_{2}-3 \cdot \mathrm{v}_{1}\right)}{(1+2 \cdot \mathrm{g})} \\
-\frac{3}{\mathrm{~L}^{3}} \frac{\left(\mathrm{L} \cdot \theta_{2}+\mathrm{L} \cdot \theta_{1}-2 \cdot \mathrm{v}_{2}+2 \cdot \mathrm{v}_{1}\right)}{(1+2 \cdot \mathrm{g})} \\
-\mathrm{v}_{1}
\end{array}\right]
$$

A derivada da rotação de flexão é:

$\varphi^{\mathrm{I}}=\mathrm{B}+2 \cdot \mathrm{X} \cdot \mathrm{C}$

Substituindo-se os valores encontrados (3.17) em (3.18), tem-se:

$$
\begin{aligned}
\varphi^{I}= & {\left[-\frac{2}{\mathrm{~L}^{2}} \frac{\left(-\mathrm{L} \cdot \theta_{2}-2 \cdot \mathrm{L} \cdot \theta_{1}+\mathrm{L} \cdot \theta_{2} \cdot \mathrm{g}-\mathrm{L} \cdot \theta_{1} \cdot \mathrm{g}+3 \cdot \mathrm{v}_{2}-3 \cdot \mathrm{v}_{1}\right)}{(1+2 \cdot \mathrm{g})}\right] } \\
& +2 . \mathrm{X} \cdot\left[-\frac{3}{\mathrm{~L}^{3}} \frac{\left(\mathrm{L} \cdot \theta_{2}+\mathrm{L} \cdot \theta_{1}-2 \cdot \mathrm{v}_{2}+2 \cdot \mathrm{v}_{1}\right)}{(1+2 . \mathrm{g})}\right]
\end{aligned}
$$

A distorção será obtida substituindo-se os valores de (3.17) em (3.11) :

$$
\begin{aligned}
& \gamma=\left[\frac{3}{\mathrm{~L}^{3}} \frac{\left(\mathrm{L} \cdot \theta_{2}+\mathrm{L} \cdot \theta_{1}-2 \cdot \mathrm{v}_{2}+2 \cdot \mathrm{v}_{1}\right)}{(1+2 . \mathrm{g})}\right] \times \frac{\mathrm{gL}}{3} \Rightarrow \\
& \gamma=\frac{\mathrm{g}}{\mathrm{L} \times(1+2 . \mathrm{g})} \times\left[\mathrm{L}\left(\theta_{1}+\theta_{2}\right)+2\left(\mathrm{v}_{1}-\mathrm{v}_{2}\right)\right]
\end{aligned}
$$

A energia de deformação é:

$$
\mathrm{U}=\frac{\mathrm{EI}}{2} \times \int_{0}^{\mathrm{L}}\left(\varphi^{\mathrm{I}}\right)^{2} \mathrm{dX}+\frac{\mathrm{KGA}}{2} \times \int_{0}^{\mathrm{L}}(\gamma)^{2} \mathrm{dX}
$$


Substituindo-se (3.19) e (3.20) em (3.21), tem-se:

$$
\begin{aligned}
& \mathrm{U}=\frac{\mathrm{EI}}{2}\left\{\int_{0}^{\mathrm{L}}\left[\begin{array}{l}
\left.\left[-\frac{2}{\mathrm{~L}^{2}} \frac{\left(-\mathrm{L} \cdot \theta_{2}-2 \cdot \mathrm{L} \cdot \theta_{1}+\mathrm{L} \cdot \theta_{2} \cdot \mathrm{g}-\mathrm{L} \cdot \theta_{1} \cdot \mathrm{g}+3 \cdot \mathrm{v}_{2}-3 \cdot \mathrm{v}_{1}\right)}{(1+2 \cdot \mathrm{g})}\right]+\right]^{2} \\
2 \cdot \mathrm{X} \cdot\left[-\frac{3}{\mathrm{~L}^{3}} \frac{\left(\mathrm{L} \cdot \theta_{2}+\mathrm{L} \cdot \theta_{1}-2 \cdot \mathrm{v}_{2}+2 \cdot \mathrm{v}_{1}\right)}{(1+2 \cdot \mathrm{g})}\right]
\end{array}\right]^{2}\right]^{+3 \cdot \frac{\mathrm{EI}}{\mathrm{gL}^{2}}\left\{\int_{0}^{\mathrm{L}}\left[\left[\frac{3}{\mathrm{~L}^{3}} \frac{\left(\mathrm{L} \cdot \theta_{2}+\mathrm{L} \cdot \theta_{1}-2 \cdot \mathrm{v}_{2}+2 \cdot \mathrm{v}_{1}\right)}{(1+2 \cdot \mathrm{g})}\right] \times \frac{\mathrm{gL}^{2}}{3}\right]^{2} \mathrm{dX}\right\}}
\end{aligned}
$$

Efetuando-se os cálculos, chega-se à expressão da energia de deformação:

$$
\begin{aligned}
\mathrm{U}= & \frac{\mathrm{EI}}{(1+2 \cdot \mathrm{g}) \cdot \mathrm{L}^{3}}\left(2 \cdot \mathrm{L}^{2} \cdot \theta_{2}{ }^{2}+\mathrm{L}^{2} \cdot \theta_{2}{ }^{2} \cdot \mathrm{g}+2 \cdot \mathrm{L}^{2} \cdot \theta_{1} \cdot \theta_{2}-2 \cdot \theta_{1} \cdot \theta_{2} \cdot \mathrm{L}^{2} \cdot \mathrm{g}-6 \cdot \mathrm{v}_{2} \cdot \theta_{2} \cdot \mathrm{L}\right. \\
& +6 \cdot \mathrm{v}_{1} \cdot \theta_{2} \cdot \mathrm{L}+\theta_{1}{ }^{2} \cdot \mathrm{L}^{2} \cdot \mathrm{g}+2 \cdot \theta_{1}{ }^{2} \cdot \mathrm{L}^{2}-6 \cdot \mathrm{v}_{2} \cdot \theta_{1} \cdot \mathrm{L}+6 \cdot \mathrm{v}_{1} \cdot \theta_{1} \cdot \mathrm{L}-12 \cdot \mathrm{v}_{1} \cdot \mathrm{v}_{2} \\
& \left.+6 \cdot \mathrm{v}_{1}{ }^{2}+6 \cdot \mathrm{v}_{2}{ }^{2}\right)
\end{aligned}
$$

Derivando-se (3.23) em relação aos parâmetros nodais, segundo o princípio da mínima energia potencial total, tem-se:

$$
\begin{aligned}
& \frac{\mathrm{dU}}{\mathrm{dv}_{1}}=\frac{6 \cdot \mathrm{EI}}{(1+2 \cdot \mathrm{g}) \cdot \mathrm{L}^{3}}\left(2 \cdot \mathrm{v}_{1}+\mathrm{L} \cdot \theta_{1}-2 \cdot \mathrm{v}_{2}+\mathrm{L} \cdot \theta_{2}\right) \\
& \frac{\mathrm{dU}}{\mathrm{d} \theta_{1}}=\frac{-2 \cdot \mathrm{EI}}{(1+2 \cdot \mathrm{g}) \cdot \mathrm{L}^{2}}\left(-3 \cdot \mathrm{v}_{1}-2 \cdot \mathrm{L} \cdot \theta_{1}-\theta_{1} \cdot \mathrm{L} \cdot \mathrm{g}+3 \cdot \mathrm{v}_{2}-\mathrm{L} \cdot \theta_{2}+\theta_{2} \cdot \mathrm{L} \cdot \mathrm{g}\right) \\
& \frac{\mathrm{dU}}{\mathrm{d} \mathrm{v}_{2}}=\frac{-6 \cdot \mathrm{EI}}{(1+2 \cdot \mathrm{g}) \cdot \mathrm{L}^{3}}\left(2 \cdot \mathrm{v}_{1}+\mathrm{L} \cdot \theta_{1}-2 \cdot \mathrm{v}_{2}+\mathrm{L} \cdot \theta_{2}\right) \\
& \frac{\mathrm{dU}}{\mathrm{d} \theta_{2}}=\frac{2 \cdot \mathrm{EI}}{(1+2 \cdot \mathrm{g}) \cdot \mathrm{L}^{2}}\left(3 \cdot \mathrm{v}_{1}+\mathrm{L} \cdot \theta_{1}-\theta_{1} \cdot \mathrm{L} \cdot \mathrm{g}-3 \cdot \mathrm{v}_{2}+2 \cdot \mathrm{L} \cdot \theta_{2}+\theta_{2} \cdot \mathrm{L} \cdot \mathrm{g}\right)
\end{aligned}
$$


Organizando-se as equações, tem-se a matriz de rigidez e a equação característica:

$$
\{\mathrm{f}\}=[\mathrm{K}] \times\{\mathrm{u}\}
$$

onde $[\mathrm{K}]$ é a matriz de rigidez do elemento :

$$
\frac{\mathrm{EI}}{1+2 \mathrm{~g}} \times\left[\begin{array}{cccc}
\frac{12}{\mathrm{~L}^{3}} & \frac{6}{\mathrm{~L}^{2}} & -\frac{12}{\mathrm{~L}^{3}} & \frac{6}{\mathrm{~L}^{2}} \\
\frac{6}{\mathrm{~L}^{2}} & \frac{2}{\mathrm{~L}}(2+\mathrm{g}) & -\frac{6}{\mathrm{~L}^{2}} & \frac{2}{\mathrm{~L}}(1-\mathrm{g}) \\
-\frac{12}{\mathrm{~L}^{3}} & -\frac{6}{\mathrm{~L}^{2}} & \frac{12}{\mathrm{~L}^{3}} & -\frac{6}{\mathrm{~L}^{2}} \\
\frac{6}{\mathrm{~L}^{2}} & \frac{2}{\mathrm{~L}}(1-\mathrm{g}) & -\frac{6}{\mathrm{~L}^{2}} & \frac{2}{\mathrm{~L}}(2+\mathrm{g})
\end{array}\right] \times\left\{\begin{array}{c}
\mathrm{v}_{1} \\
\theta_{1} \\
\mathrm{v}_{2} \\
\theta_{2}
\end{array}\right\}=\left\{\begin{array}{l}
\mathrm{V}_{1} \\
\mathrm{~V}_{2} \\
\mathrm{~V}_{2}
\end{array}\right\}
$$

Vale salientar aqui, que para a implementação do grau de liberdade correspondente às deformações devidas ao esforço cortante no algoritmo para análise não-linear de grelhas, faz-se necessário deduzir também as expressões das curvaturas no início e no fim de cada elemento de barra. Isto ocorre porque a determinação dos esforços internos ou resistentes, será efetuada através das relações constitutivas dentro de um procedimento incremental-iterativo.

Passa-se agora, à determinação das expressões das curvaturas, em função dos deslocamentos nodais, incluindo-se as distorções dos elementos:

A equação da curvatura ao longo do comprimento de um elemento, de acordo com (3.19) é :

$$
\begin{aligned}
\varphi^{\mathrm{I}}= & {\left[-\frac{2}{\mathrm{~L}^{2}} \frac{\left(-\mathrm{L} \cdot \theta_{2}-2 \cdot \mathrm{L} \cdot \theta_{1}+\mathrm{L} \cdot \theta_{2} \cdot \mathrm{g}-\mathrm{L} \cdot \theta_{1} \cdot \mathrm{g}+3 \cdot \mathrm{v}_{2}-3 \cdot \mathrm{v}_{1}\right)}{(1+2 \cdot \mathrm{g})}\right] } \\
& +2 . \mathrm{X} \cdot\left[-\frac{3}{\mathrm{~L}^{3}} \frac{\left(\mathrm{L} \cdot \theta_{2}+\mathrm{L} \cdot \theta_{1}-2 \cdot \mathrm{v}_{2}+2 \cdot \mathrm{v}_{1}\right)}{(1+2 \cdot \mathrm{g})}\right]
\end{aligned}
$$


Substituindo-se os pontos $\mathrm{X}=0$ e posteriormente, $\mathrm{X}=\mathrm{L}$, obtém-se:

$$
\begin{aligned}
& \varphi_{\mathrm{x}=0}^{\mathrm{I}}=\left[\frac{6}{\mathrm{~L}^{2} \cdot(1+2 \cdot \mathrm{g})}\right] \cdot \mathrm{v}_{1}+\left[\frac{4 \cdot\left(1+\frac{\mathrm{g}}{2}\right)}{\mathrm{L} \cdot(1+2 \cdot \mathrm{g})}\right] \cdot \theta_{1}-\left[\frac{6}{\mathrm{~L}^{2} \cdot(1+2 \cdot \mathrm{g})}\right] \cdot \mathrm{v}_{2}+\left[\frac{2 \cdot(1-\mathrm{g})}{\mathrm{L} \cdot(1+2 \cdot \mathrm{g})}\right] \cdot \theta_{2} \\
& \varphi_{\mathrm{x}=\mathrm{L}}^{\mathrm{I}}=\left[\frac{6}{\mathrm{~L}^{2} \cdot(1+2 \cdot \mathrm{g})}\right] \cdot \mathrm{v}_{1}-\left[\frac{2 \cdot(1-\mathrm{g})}{\mathrm{L} \cdot(1+2 \cdot \mathrm{g})}\right] \cdot \theta_{1}+\left[\frac{6}{\mathrm{~L}^{2} \cdot(1+2 \cdot \mathrm{g})}\right] \cdot \mathrm{v}_{2}-\left[\frac{4 \cdot\left(1+\frac{\mathrm{g}}{2}\right)}{\mathrm{L} \cdot(1+2 \cdot \mathrm{g})}\right] \cdot \theta_{2}
\end{aligned}
$$

Reunindo-se as curvaturas em um vetor, tem-se:

$$
\left\{\begin{array}{c}
\frac{1}{\mathrm{r}_{\mathrm{X}=0}} \\
\frac{1}{\mathrm{r}_{\mathrm{X}=\mathrm{L}}}
\end{array}\right\}=\frac{1}{1+2 \mathrm{~g}}\left[\begin{array}{cccc}
\frac{6}{\mathrm{~L}^{2}} & \frac{4}{\mathrm{~L}}\left(1+\frac{\mathrm{g}}{2}\right) & -\frac{6}{\mathrm{~L}^{2}} & \frac{2}{\mathrm{~L}}(1-\mathrm{g}) \\
-\frac{6}{\mathrm{~L}^{2}} & -\frac{2}{\mathrm{~L}}(1-\mathrm{g}) & \frac{6}{\mathrm{~L}^{2}} & -\frac{4}{\mathrm{~L}}\left(1+\frac{\mathrm{g}}{2}\right)
\end{array}\right] \times\left\{\begin{array}{l}
\mathrm{v}_{1} \\
\theta_{1} \\
\mathrm{v}_{2} \\
\theta_{2}
\end{array}\right\}
$$




\section{3 -MATRIZ DE RIGIDEZ DO ELEMENTO DE GRELHA}

Considere-se um elemento de grelha com seus graus de liberdade característicos, como indicado na Figura (3.5). Vale salientar aqui, que os deslocamentos $\mathrm{Vi}, \mathrm{Vj}, \theta \mathrm{y}_{\mathrm{i}}$ e $\theta \mathrm{y}_{\mathrm{j}}$ são os graus de liberdade definidos anteriormente.

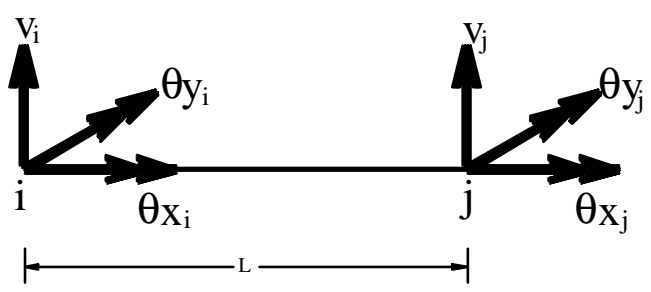

Figura 3.5 Elemento de grelha e graus de liberdade considerados.

Para essa parte da análise, somente é necessária considerar a parcela da energia referente à torção, pois as outras estão embutidas na matriz de rigidez (3.28). Deseja-se agora calcular o valor desta parcela:

$$
\mathrm{U}=\frac{1}{2} \int_{\mathrm{L}}\left(\frac{\mathrm{T}^{2}}{\mathrm{GJ}_{\mathrm{t}}}\right) \mathrm{dx}
$$

Analogamente à dedução anterior, assume-se um campo de deslocamentos ao longo do comprimento da barra aproximado por função linear do tipo: $\theta_{\mathrm{x}}=\mathrm{a}_{1}+\mathrm{a}_{2} \mathrm{x}$

Procedendo-se de maneira análoga ao caso anterior, obtém-se a parcela correspondente aos esforços de torção, tanto para a matriz de rigidez, como para o vetor de cargas nodais. Abaixo, mostra-se então, a matriz implementada no código computacional para solução de grelhas.

$$
\left[\begin{array}{cccccc}
\frac{\mathrm{G} . \mathrm{J}_{\mathrm{T}}}{\mathrm{L}} & 0 & 0 & -\frac{\mathrm{G} . \mathrm{J}_{\mathrm{T}}}{\mathrm{L}} & 0 & 0 \\
0 & \frac{\mathrm{EI}}{1+2 \mathrm{~g}} \frac{2}{\mathrm{~L}}(2+\mathrm{g}) & \frac{\mathrm{EI}}{1+2 \mathrm{~g}} \frac{6}{\mathrm{~L}^{2}} & 0 & \frac{\mathrm{EI}}{1+2 \mathrm{~g}} \frac{2}{\mathrm{~L}}(1-\mathrm{g}) & -\frac{\mathrm{EI}}{1+2 \mathrm{~g}} \frac{6}{\mathrm{~L}^{2}} \\
0 & \frac{\mathrm{EI}}{1+2 \mathrm{~g}} \frac{6}{\mathrm{~L}^{2}} & \frac{\mathrm{EI}}{1+2 \mathrm{~g}} \frac{12}{\mathrm{~L}^{3}} & 0 & \frac{\mathrm{EI}}{1+2 \mathrm{~g}} \frac{6}{\mathrm{~L}^{2}} & -\frac{\mathrm{EI}}{1+2 \mathrm{~g}} \frac{12}{\mathrm{~L}^{3}} \\
-\frac{\mathrm{G} . \mathrm{J}_{\mathrm{T}}}{\mathrm{L}} & 0 & 0 & \frac{\mathrm{G} . J_{\mathrm{T}}}{\mathrm{L}} & 0 & 0 \\
0 & \frac{\mathrm{EI}}{1+2 \mathrm{~g}} \frac{2}{\mathrm{~L}}(1-\mathrm{g}) & \frac{\mathrm{EI}}{1+2 \mathrm{~g}} \frac{6}{\mathrm{~L}^{2}} & 0 & \frac{\mathrm{EI}}{1+2 \mathrm{~g}} \frac{2}{\mathrm{~L}}(2+\mathrm{g}) & -\frac{\mathrm{EI}}{1+2 \mathrm{~g}} \frac{6}{\mathrm{~L}^{2}} \\
0 & -\frac{\mathrm{EI}}{1+2 \mathrm{~g}} \frac{6}{\mathrm{~L}^{2}} & -\frac{\mathrm{EI}}{1+2 \mathrm{~g}} \frac{12}{\mathrm{~L}^{3}} & 0 & -\frac{\mathrm{EI}}{1+2 \mathrm{~g}} \frac{6}{\mathrm{~L}^{2}} & \frac{\mathrm{EI}}{1+2 \mathrm{~g}} \frac{12}{\mathrm{~L}^{3}}
\end{array}\right]
$$

Onde a constante 'g' está indicada na equação (3.14). 


\section{Modelo CONSTitutivo DE DANO}

\section{1 - GENERALIDADES}

Neste capítulo, descreve-se o modelo de dano proposto por MAZARS(1984), considerando-se um estado biaxial de deformações para o concreto, que foi utilizado na elaboração do código computacional desenvolvido neste trabalho. Descrevem-se aqui toda a formulação e hipóteses básicas para a análise não-linear pretendida. $\mathrm{O}$ modelo foi escolhido devido sua adequação à modelagem de peças de concreto armado, já verificada em diversos outros trabalhos desenvolvidos na EESCUSP. Este trabalho representa portanto uma continuidade dos trabalhos anteriores tanto do ponto de vista do estudo da adequação do modelo de dano como também do estudo de estruturas de pavimentos de edifícios

Com o emprego de um modelo para concreto baseado na mecânica do dano, pretende-se simular as perdas progressivas de rigidez e de resistência do material devidas ao seu processo de degradação. Vários foram os modelos estudados nos últimos anos, isótropos ou anisótropos, segundo os quais a variável representativa do dano pode ser um escalar ou um tensor. Estas formulações justificam-se pela presença do ramo "softening" nas relações constitutivas dos materiais, ficando evidente a modificação de suas características mecânicas.

Os modelos definidos no contexto da mecânica do dano são adequados para levar-se em conta o efeito causado pela evolução dos microdefeitos no interior do volume do sólido nas propriedades físicas e mecânicas dos corpos que estão sujeitos a quaisquer ações.

A sua diferença em relação à mecânica da fratura é que esta última lida com distúrbios discretos no material, considerando intacto o material encontrado em volta do defeito e suas propriedades elásticas iniciais não encontram-se alteradas, 
enquanto que na mecânica do dano levam-se em conta apenas as perturbações infinitesimais distribuídas continuamente no interior do volume do sólido de forma aleatória. Fica evidente que as múltiplas fissuras são o mecanismo de degradação dominante no caso do concreto. Esta simplificação levou a teoria do dano a grandes progressos, segundo consta da literatura sobre o assunto.

Conclui-se então, que o tamanho e o modo de distribuição das fissuras são os fatores primordiais que definem os limites entre os campos de atuação das duas teorias, conforme está ilustrado na Figura 4.1. Pode ser feita uma analogia com a teoria da elasticidade, que teve grande êxito a partir do instante em que foram desconsiderados os fenômenos de natureza discreta que ocorrem no interior dos sólidos, com a mecânica do dano, que logrou avanços a partir da idealização da descrição do fenômeno através da variável escalar.
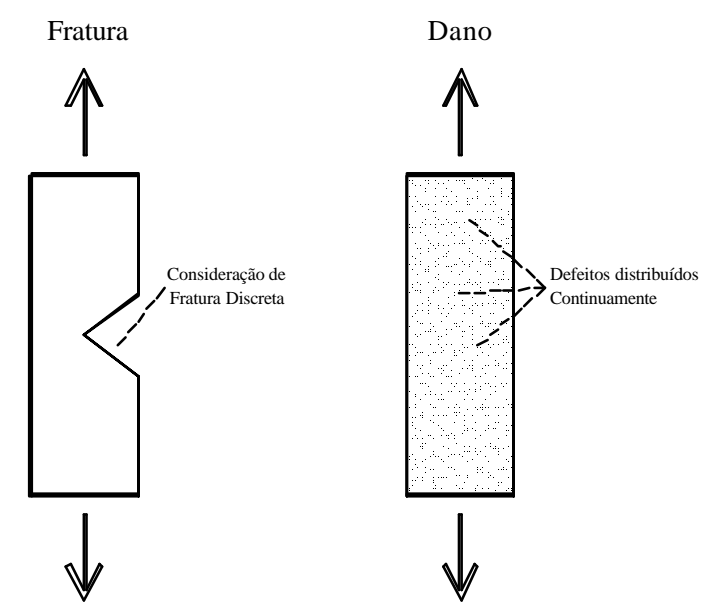

Figura 4.1 - Mecânica do Dano e Mecânica da Fratura.

\section{2 - REVISÃo BIBLIOGRÁFICA}

Vários são os modelos que procuram representar matematicamente o comportamento mecânico do concreto armado. É uma tarefa árdua, pois o material é extremamente heterogêneo, formado por diferentes sólidos e por vazios de naturezas diversas, possui a capacidade de modificação de sua microestrutura com o tempo, em função das reações químicas dos seus materiais constituintes, ou da sua interação com o meio ambiente. Isto tudo torna-o extremamente imprevisível, difícil de ser modelado, e com forte grau de não-linearidade física. 
KACHANOV(1958), tentou idealizar no seu modelo uma maneira de representar o comportamento dos metais em solicitações próximas à de ruptura, devidas às deformações lentas causadas por efeitos de temperatura. Este trabalho deu início à idéia na qual se fundamenta a teoria do dano contínuo. Ele foi, segundo consta da literatura, o primeiro a tentar descrever um comportamento de formação de fissuras causadas por deformações lentas, introduzindo uma variável interna de dano nas relações constitutivas do material. A partir da sua idéia, outros pesquisadores aprofundaram a teoria e desenvolveram vários trabalhos.

Por bastante tempo, em função das dificuldades matemáticas, outros pesquisadores contribuíram, mas de maneira lenta, surgindo assim poucos avanços. Foi apenas recentemente a Mecânica do Dano Contínuo teve a sua base teórica solidificada na termodinâmica dos processos irreversíveis. O trabalho de CHABOCHE (1988) foi um dos primeiros a descrever o dano com esta base. Este trabalho limita-se às hipóteses de pequenas deformações, dano isótropo e encruamento isótropo, muito embora a extensão para o encruamento cinemático já tenha sido efetuada por outros pesquisadores em anos anteriores, e também a teoria do dano anisótropo tenha sido formulada pelo próprio CHABOCHE, no ano de 1978. Além disso, a extensão para a consideração de deformações finitas também já tinha sido feita anteriormente. O mérito de CHABOCHE foi exclusivamente a idéia da analogia com a termodinâmica. São discutidos ainda nesse trabalho, as definições e medidas de dano. Algumas equações práticas de crescimento do dano são revistas para fluência, fadiga, interação fluência-fadiga, dano em materiais frágeis e dúcteis. Ferramentas para se estimar a iniciação e propagação de fissuras e os novos desenvolvimentos de aproximações locais para fratura são discutidos.

PROENÇA(1988), apresentou diversos modelos matemáticos para o concreto armado, apresentando modelos com e sem a presença do ramo "softening" na devida relação constitutiva. 
KRAJCINOVIC (1989), em seu trabalho, faz uma grande revisão apresentando um estado da arte completo da mecânica do dano. Ele expôs os principais modelos mecânicos utilizados, mostrando as relações tensão x deformação para sólidos degenerados por vários estados de fissuração diferentes, dependendo do seu tamanho e distribuição. Segundo ele, o fenômeno de evolução do dano compreende três fases: A formação de um núcleo da fissura, o alargamento na sua abertura, e depois a reunião dos defeitos em um macro defeito. Estuda ainda modelos de resposta frágil e semi-frágil de sólidos submetidos à tração e a compressão, com modelos de dano isótropos e anisótropos. Esse trabalho, com ainda muitos outras abordagens, teve, sem dúvida, muito a contribuir para o avanço da teoria da mecânica do dano.

MAZARS \& PIJAUDIER-CABOT (1989) apresentam uma revisão dos diferentes modelos baseados na Mecânica do Dano Contínuo formulados anteriormente. Segundo eles, as relações constitutivas podem ser deduzidas em função da danificação do material. Porém, afirmaram que deve ser feita uma escolha adequada para a variável de dano, conforme o modelo. Caso o modelo seja isótropo, a variável de dano é escalar. No caso anisótropo é um tensor. Introduzem aqui a base da teoria formulada no âmbito da termodinâmica dos processos irreversíveis, estendendo o trabalho do ano anterior de CHABOCHE. Fazem ainda estudos de anisotropia induzida e comportamento dúctil. Propõem alguns modelos de dano: escalar, unilateral, anisótropo com deformações plásticas, e um modelo para grandes deformações de compressão. Concluem que embora com as limitações e hipóteses de cada modelo, são obtidos bons resultados no confronto com os experimentais. Comentam ainda, que fenômenos como o fechamento de fissuras, que podem levar à redução da danificação com o tempo, podem ser modelados facilmente, com a introdução de duas variáveis representativas de dano à tração e dano à compressão. Implementada no método dos elementos finitos, a formulação de dano leva a uma boa descrição da evolução do processo de fissuração de elementos estruturais armados.

PEREGO(1989), analisa numericamente o modelo de MAZARS através de elementos finitos bidimensionais e tridimensionais, concluindo que o dano é uma alternativa válida para a análise não-linear, sendo interessante que estudos futuros levem em consideração a interação concreto-aço e uma possível plastificação do aço. 
ALVES e LUBLINER (1992), apresentaram um modelo para vigas em concreto armado. Chegaram a resultados que, segundo eles próprios, precisariam ser calibrados através da introdução de novos parâmetros para representar a forte influência da não-linearidade na zona de momentos máximos das vigas, sendo então necessários novos estudos.

ÁLVARES (1993), da EESC-USP, classifica os modelos constitutivos para o concreto armado através de critérios próprios. Nesse trabalho, é discutido especificamente, o modelo isótropo de MAZARS(1984), feita a sua identificação paramétrica, e uma abordagem de acordo com uma formulação através do método dos elementos finitos. Esse trabalho trouxe grande contribuição à pesquisa nesse ramo na EESC-USP, pois foram ainda realizados testes experimentais com vigas de concreto armado, a fim de confrontar os resultados do modelo, e calibrar os parâmetros, percebendo-se que o modelo leva a bons resultados, se efetuada uma boa análise paramétrica.

CHEN (1993), trata de um modelo de plasticidade aplicado ao concreto e ressalta aspectos do comportamento elasto-plástico presente no mesmo. Trata ainda de uma formulação geral para o ramo de comportamento "softening" utilizando-se a teoria da plasticidade combinada com a mecânica do dano. Sugere que o desenvolvimento de modelos específicos podem levar a uma modelagem mais correta do concreto, tendo-se entretanto a preocupação de torná-los absorvíveis e simples de serem tratados pelo meio científico. Conclui que as relações constitutivas são de fundamental importância para o cálculo das distribuições de tensão no trecho pós-elástico, e que a dificuldade de modelar o concreto nesse ramo, está na mudança contínua dessas relações. Conclui ainda, que os modelos já citados, combinando dano e plasticidade, são úteis para prover a teoria base para descrever a mudança de comportamento do concreto, quando da evolução do carregamento.

BUSSAMRA (1993), da EP-USP, estuda a teoria da Mecânica do Dano Contínuo, visando a sua interferência nas relações constitutivas do concreto.

PAAS et al. (1993) mostram um modelo de dano com variável escalar. Estudam o modelo aplicado à ruptura de materiais frágeis e citam que este processo requer relações tensão x deformação penalizadas de um fator referente à danificação, 
juntamente com um critério de evolução do dano. Chegaram ainda, com sucesso, a uma aproximação para previsão de formação e propagação de fissuras através da representação da zona fissurada por elementos completamente danificados. Como exemplo, apresentam resultados de uma placa com uma fissura induzida sujeita a carregamento periódico e leis de evolução do dano.

BURR (1995) cita que as propriedades elásticas dos materiais são em geral dependentes das direções de análise e portanto um modelo anisótropo, com variável de dano tensorial traria melhores resultados em materiais onde seja verificada forte anisotropia. Estudou mecanismos associados ao processo de crescimento do dano em materiais frágeis, como o concreto. Este trabalho atenta mais para a reunião de conhecimentos de trabalhos anteriores, do que propriamente para dar novas contribuições à teoria.

DIAO (1995) formula uma teoria de dano fundamentada em estudos estatísticos, e afirma que sua teoria é uma evolução da teoria de KACHANOV e que naquela a variável de dano não tem significado físico claro. Segundo ele, a sua teoria de evolução estatística do dano é mais consistente do que aquela fenomenológica proposta por KACHANOV.

DRIEMEIER (1995) estuda um modelo de dano para o concreto, evolução e propagação do dano, apresentando uma extensão do modelo de MAZARS (1984) considerando solicitações cíclicas em vigas de concreto armado, efetuando implementação numérica utilizando-se da técnica dos elementos finitos.

FERNANDES(1998), em seu trabalho, estuda modelo de dano para proceder a uma análise não-linear de placas, utilizando-se da sua acoplagem com o método dos elementos de contorno, no campo limitado pela teoria clássica de Kirchhoff, isto é, sem considerar as distorções presentes em uma seção transversal da placa. Chega a conclusão de que o modelo de MAZARS é estável, pois converge sempre, com aumento da malha ou número de pontos de Gauss.

BOTTA(1998), implementa os modelos de MAZARS (1984) e CERVERA et. al (1996), a um código computacional, com a finalidade de calcular os esforços e deslocamentos em grelhas de concreto armado. Conclui que a identificação paramétrica é fundamental para que um modelo de dano seja consistente e que estes, ao 
serem formulados, devem permitir que a sua identificação paramétrica seja feita através de simples ensaios em laboratório.

A seguir, descreve-se o modelo isótropo de MAZARS (1984), que será utilizado nas aplicações deste trabalho.

\section{3 - DESCRIÇÃO DO MODELO}

\subsection{1 - Elemento representativo de volume}

O fato óbvio de um material qualquer poder ser considerado homogêneo a olho nu e não sê-lo a nível microscópico, limita as aplicações de qualquer teoria baseada no princípio da continuidade do meio. Surge então a dúvida: em que âmbito definir o problema? Fica claro que se devem criar limites para o nível de observação microscópica de um sólido, tornando-se necessário recorrer ao conceito de elemento representativo de volume, que é aquele volume que vai definir a escala do meio contínuo onde será formulada a teoria.

$\mathrm{O}$ elemento representativo de volume ou RVE, do inglês representative volume element, deve possuir as seguintes características:

- $\quad$ É o mínimo volume em que as teorias de meio contínuo ainda podem ser consideradas válidas;

- $\quad$ Possui as mesmas características físicas do material;

- $\quad$ Ser grande o suficiente para que o material seja considerado homogêneo;

- Ser pequeno o suficiente para que os infinitésimos de ordem superior possam ser desprezados. 


\subsection{2 - Hipóteses}

Seja definido um elemento representativo de volume como na Figura 4.2, onde define-se uma superfície $S$, com versor normal $n$, que contém uma área $S_{0}$ de microdefeitos que são proporcionais ao dano.

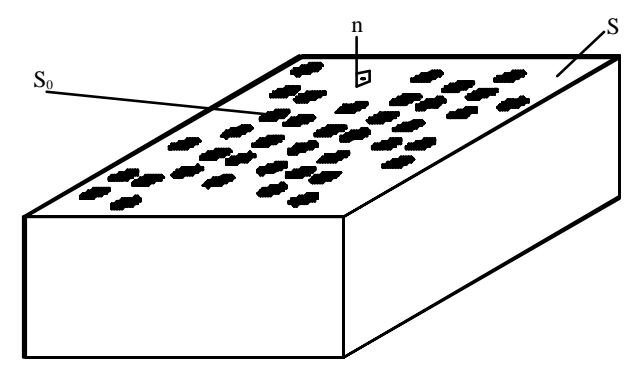

Figura 4.2 - Elemento representativo de volume danificado

A variável de dano é a razão entre a área danificada e a área total:

$\mathrm{D}=\frac{\mathrm{S}_{0}}{\mathrm{~S}}$

Da maneira que for formulado o modelo, se não houver dependência entre a variável "D" e a direção da normal "n", o modelo será dito isótropo, por razões óbvias. "D" é uma variável escalar definida em cada ponto do material e vai indicar o quanto o material está danificado. " $D$ ” está definida no intervalo [0,1], onde o valor zero indica material intacto, e o valor um, indica material rompido, com resistência zero. No trabalho de MAZARS também é admitido que o dano independe da direção da normal e portanto o dano é descrito através de uma variável escalar.

Admitindo-se tensão constante na área $S$ da Figura 4.2, na qual uma força "F" atua segundo a normal n, define-se a tensão efetivamente atuante no material intacto:

$\tilde{\sigma}=\frac{F}{\widetilde{S}}$

Na expressão (4.02), $\widetilde{\mathrm{S}}=\mathrm{S}-\mathrm{S}_{0}$ é a área de material intacto, que é denominada área efetiva. Trabalhando-se com as expressões (4.01) e (4.02), tem-se:

$$
\widetilde{\sigma}=\frac{\sigma}{(1-\mathrm{D})}
$$

Onde a tensão " $\sigma$ " é a razão entre a força atuante " $F$ " e a área total "S". 
No modelo de MAZARS, faz-se uso da hipótese da deformação equivalente, que consiste em afirmar que a deformação de um material com dano equivale à do material íntegro, com a tensão efetiva substituindo a tensão atuante:
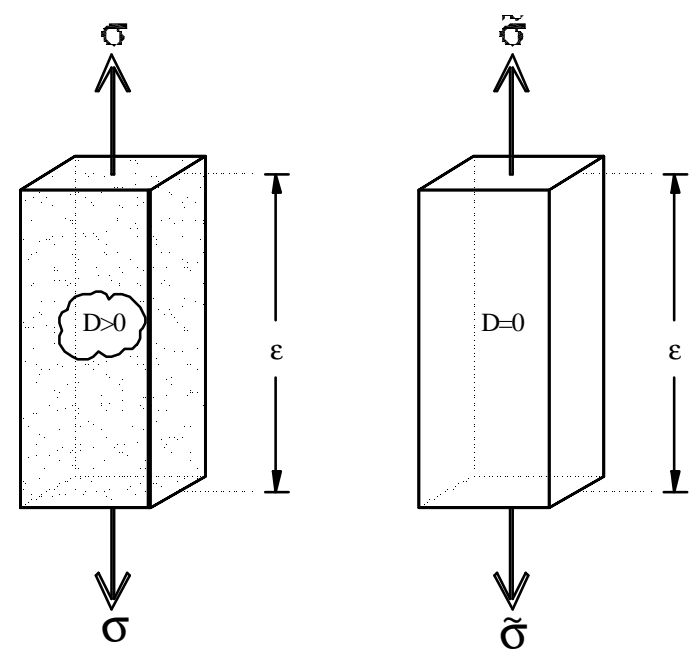

Figura 4.3 - Hipótese da deformação equivalente

Portanto, pode-se escrever a igualdade:

$\varepsilon=\frac{\tilde{\sigma}}{E}=\frac{\sigma}{(1-\mathrm{D}) \mathrm{E}}$

Neste trabalho, assim como em problemas comuns da engenharia, o estado de deformações em um ponto é conhecido; a partir dele, determinam-se as tensões, através da devida relação constitutiva. Para isto, basta associar a variável de dano a uma propriedade do concreto, como por exemplo, o módulo de elasticidade "E". Obtém-se então, a seguinte expressão:

$\widetilde{\mathrm{E}}=(1-\mathrm{D}) \mathrm{E}$

E portanto:

$\varepsilon=\frac{\sigma}{\widetilde{\mathrm{E}}}$

MAZARS utilizou a variável escalar $\mathrm{D} \subset[0,1]$, para representar a degradação do módulo de elasticidade do concreto com o tempo. No modelo, não se consideram as deformações plásticas, e portanto, no descarregamento a rigidez é secante à curva tensão $\mathrm{x}$ deformação, passando pela origem dos eixos e pelo ponto onde se iniciou o descarregamento. 
Porém, mesmo com esta hipótese, já se verificou que o modelo conduz a bons resultados, pois o modelo representa bem materiais com ruptura frágil. O modelo é formulado para carregamento crescente, mas nos casos onde os descarregamentos devem ser levados em conta, deve-se atentar para o fenômeno da recuperação da rigidez quando um elemento de concreto é tracionado e comprimido em seguida.

A hipótese principal do modelo consiste em afirmar que a deterioração do material está intrinsecamente ligada ao fato de existir deformação de tração, em pelo menos uma das direções principais. Para medir quanto cada fibra da estrutura está sendo influenciada por deformações de tração, define-se a grandeza deformação equivalente como:

$$
\widetilde{\varepsilon}=\sqrt{\left\langle\varepsilon_{1}\right\rangle_{+}^{2}+\left\langle\varepsilon_{2}\right\rangle_{+}^{2}+\left\langle\varepsilon_{3}\right\rangle_{+}^{2}}
$$

Onde os $\left\langle\varepsilon_{\mathrm{i}}\right\rangle_{+}$são as componentes positivas do vetor de deformações principais. Logo, pode-se obtê-las recorrendo-se à expressão:

$$
\left\langle\varepsilon_{\mathrm{i}}\right\rangle_{+}=\frac{1}{2}\left[\varepsilon_{\mathrm{i}}+\left|\varepsilon_{\mathrm{i}}\right|\right]
$$

De onde percebe-se que $\left\langle\varepsilon_{\mathrm{i}}\right\rangle_{+}$vale $\varepsilon_{\mathrm{i}}$ quando $\varepsilon_{\mathrm{i}}$ é positivo e zero quando $\varepsilon_{\mathrm{i}}$ é negativo. A seguir, na Tabela 4.1, têm-se algumas situações particulares de estados de tensões e os valores das respectivas deformações equivalentes, já calculados.

\begin{tabular}{|c|c|}
\hline Estado de Tensões & Deformação equivalente $\tilde{\varepsilon}$ \\
\hline Tração Uniaxial na Direção 1 & $\tilde{\varepsilon}=\varepsilon_{1}$ \\
\hline Compressão Uniaxial na Direção 1 & $\tilde{\varepsilon}=\sqrt{{\varepsilon_{2}{ }^{2}+\varepsilon_{3}{ }^{2}}^{2}=-v \varepsilon_{1} \sqrt{2}}$ \\
\hline Compressão Biaxial nas Direções 1 e 2 & $\widetilde{\varepsilon}=\sqrt{\varepsilon_{3}{ }^{2}}=-\frac{v}{1-v}\left(\varepsilon_{1}+\varepsilon_{2}\right)$ \\
\hline Compressão Hidrostática & $\tilde{\varepsilon}=0$ \\
\hline Multiaxiais & $\tilde{\varepsilon}=\sqrt{\left\langle\varepsilon_{1}\right\rangle_{+}^{2}+\left\langle\varepsilon_{2}\right\rangle_{+}{ }^{2}+\left\langle\varepsilon_{3}\right\rangle_{+}^{2}}$ \\
\hline
\end{tabular}

Tabela 4.1 - Casos de determinação da deformação equivalente 
MAZARS considera que o início do dano acontece, quando esta deformação equivalente atinge um valor correspondente à tensão de pico em um ensaio de tração uniaxial em um corpo prova de concreto. Esse valor limite é denominado $\varepsilon_{\mathrm{d} 0}$, sendo determinado na identificação paramétrica do modelo e é mostrado na Figura 4.4.
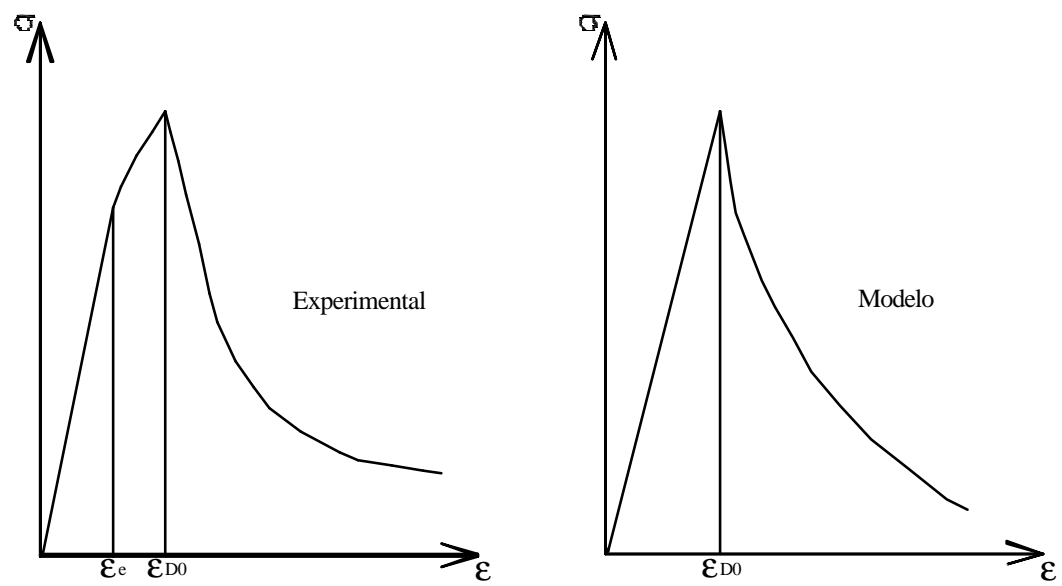

Figura 4.4 - Diagrama experimental do concreto à tração e diagrama adotado pelo modelo

\subsection{3 - Critério de danificação}

Já que não existe danificação enquanto a deformação equivalente for menor ou igual à deformação limite $\varepsilon_{\mathrm{d} 0}$, pode-se estabelecer, analogamente aos estabelecidos anteriormente, o seguinte critério de danificação:

$f(\widetilde{\varepsilon}, D)=\widetilde{\varepsilon}-\hat{S}(D) \leq 0$

$\mathrm{Na}$ equação acima, a função $\mathrm{S}(\mathrm{D})$ retorna uma deformação equivalente, em função do valor da variável de dano D .

O modelo é definido em taxas de variação no tempo da seguinte forma:

$\dot{\mathrm{D}}=0 \quad$ se $\mathrm{f}<0$ ou $\mathrm{f}=0$ e $\dot{\mathrm{f}}<0$

$\dot{\mathrm{D}}=\mathrm{F}(\tilde{\varepsilon})\langle\dot{\widetilde{\varepsilon}}\rangle_{+} \quad$ se $\mathrm{f}=0$ e $\dot{\mathrm{f}}=0$

A função $\mathrm{F}(\widetilde{\varepsilon})$ é contínua e positiva, definida em função de resultados experimentais, reproduzindo as curvas de ensaios de corpos de prova em concreto. Pode-se assim observar que uma variação da deformação equivalente positiva ou nula, indica também uma variação positiva ou nula do dano. 


\subsection{4 - Equacionamento}

Conforme citado na revisão bibliográfica, e no próprio trabalho de MAZARS \& PIJAUDIER-CABOT (1989), o fenômeno de fechamento de fissuras traduz-se em uma recuperação da rigidez da peça de concreto. Para isso, devem ser introduzidas duas variáveis representativas dos ramos não-lineares das curvas tensão $\mathrm{x}$ deformação do concreto à tração e à compressão.

MAZARS chamou estas variáveis de $D_{T}$ e $D_{C}$, respectivamente.

Decompôs também a função $\mathrm{F}(\widetilde{\varepsilon})$ em $\mathrm{F}_{\mathrm{T}}(\widetilde{\varepsilon})$ e $\mathrm{F}_{\mathrm{C}}(\widetilde{\varepsilon})$. Dessa maneira tem-se:

$$
\begin{aligned}
& \dot{\mathrm{D}}_{\mathrm{T}}=\mathrm{F}_{\mathrm{T}}(\tilde{\varepsilon})\langle\dot{\tilde{\varepsilon}}\rangle_{+} \\
& \dot{\mathrm{D}}_{\mathrm{C}}=\mathrm{F}_{\mathrm{C}}(\tilde{\tilde{\varepsilon}})\langle\dot{\tilde{\varepsilon}}\rangle_{+}
\end{aligned}
$$

As funções $\mathrm{D}_{\mathrm{T}}(\widetilde{\varepsilon})$ e $\mathrm{D}_{\mathrm{C}}(\widetilde{\varepsilon})$, são obtidas por integração em relação ao tempo, de onde resultam as expressões:

$$
\begin{aligned}
& \mathrm{D}_{\mathrm{T}}(\tilde{\varepsilon})=1-\frac{\varepsilon_{\mathrm{d} 0}\left(1-\mathrm{A}_{\mathrm{T}}\right)}{\tilde{\varepsilon}}-\frac{\mathrm{A}_{\mathrm{T}}}{\mathrm{e}^{\mathrm{B}_{\mathrm{T}}\left(\tilde{\varepsilon}-\varepsilon_{\mathrm{d} 0}\right)}} \\
& \mathrm{D}_{\mathrm{C}}(\tilde{\varepsilon})=1-\frac{\varepsilon_{\mathrm{d} 0}\left(1-\mathrm{A}_{\mathrm{C}}\right)}{\tilde{\varepsilon}}-\frac{\mathrm{A}_{\mathrm{C}}}{\mathrm{e}^{\mathrm{B}_{\mathrm{C}}\left(\tilde{\varepsilon}-\varepsilon_{\mathrm{d} 0}\right)}}
\end{aligned}
$$

Nas quais, os valores $\mathrm{A}_{\mathrm{T}}, \mathrm{B}_{\mathrm{T}}, \mathrm{A}_{\mathrm{C}}, \mathrm{B}_{\mathrm{C}}, \varepsilon_{\mathrm{D} 0}$, são os parâmetros de cada material, definidos pelo modelo. Estes parâmetros, devem ser identificados em laboratório. O seu ajuste deve ser feito de maneira que a curva tensão x deformação definida seja a mais próxima possível da curva experimental. 
Abaixo, temos a evolução dos parâmetros $\mathrm{D}_{\mathrm{T}}$ e $\mathrm{D}_{\mathrm{C}}$, com o crescimento da deformação equivalente. Essa curva é apenas ilustrativa, pois foi plotada para parâmetros de um exemplo qualquer retirado do programa desenvolvido e é mostrada aqui apenas para se ter idéia da sua forma.

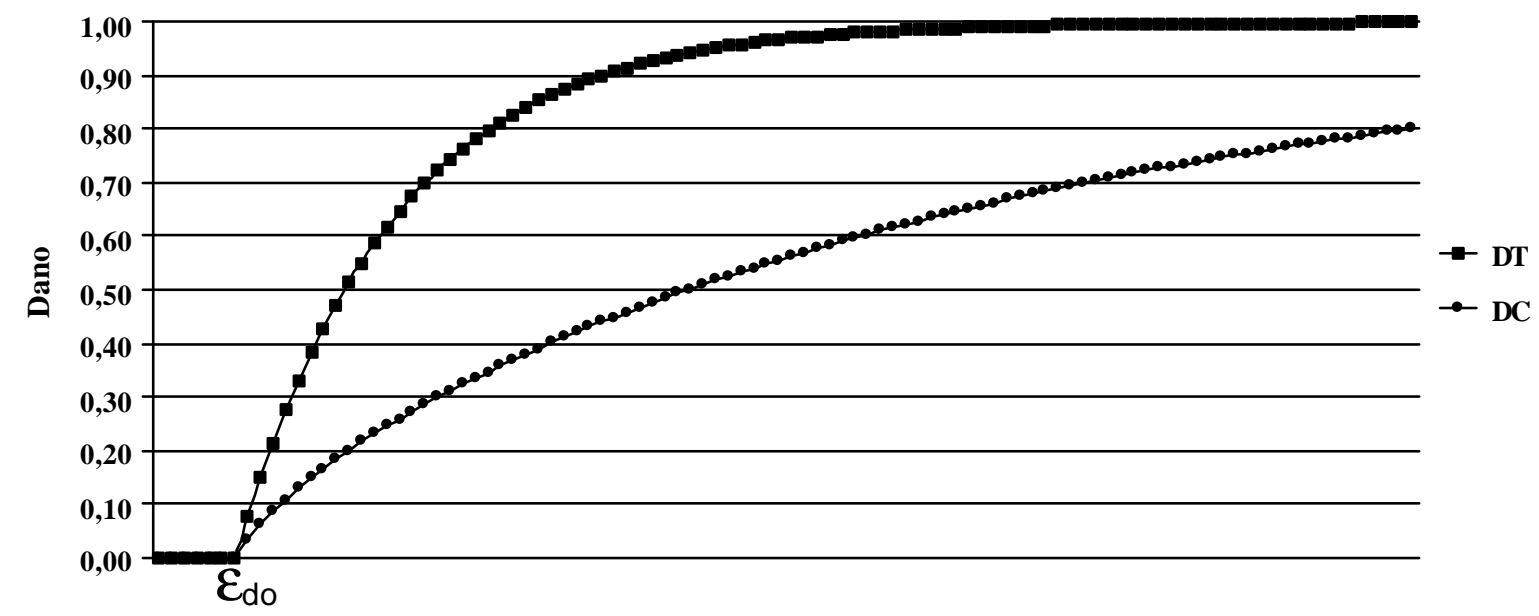

Figura 4.5 - Evolução dos parâmetros DT e DC com a deformação equivalente

Do modelo, sabemos que a variável escalar $\mathrm{D}$, nos casos de solicitações multiaxiais, é uma combinação linear de $\mathrm{D}_{\mathrm{T}}$ e $\mathrm{D}_{\mathrm{C}}$, isto é:

$\mathrm{D}=\alpha_{\mathrm{T}} \mathrm{D}_{\mathrm{T}}+\alpha_{\mathrm{C}} \mathrm{D}_{\mathrm{C}}$

Veja-se agora, a implementação feita neste trabalho para o modelo de dano de MAZARS, aplicando-o a um estado de tensão biaxial.

De acordo com a curvatura e a linha neutra de uma seção, calculadas em um certo ponto do algoritmo, obtêm-se as deformações nas fibras correspondentes aos pontos de Gauss em que se divide a seção transversal, observando-se a hipótese da manutenção das seções planas. Fazendo-se uso das equações da teoria da elasticidade, calcula-se o tensor das deformações principais em cada ponto.

Em seguida, o tensor de tensões principais é definido como sendo a aplicação do tensor elástico $\underline{\underline{D}}_{0}$ no tensor de deformações principais do material, no passo de carga e iteração analisados. Portanto:

$\underline{\tilde{\sigma}}=\underline{\mathrm{D}}_{0} \underline{\varepsilon}$ 
Para automatizar o processo, veja-se o roteiro descrito adiante:

a) Calcular o tensor de tensões principais, atentando-se para o fato de que as deformações da expressão descrita abaixo são principais, da seguinte maneira:

$$
\left\langle\sigma_{\mathrm{i}}\right\rangle=\left[\begin{array}{ccc}
\sigma_{\mathrm{x}}=\frac{\mathrm{E}}{1-v^{2}} \times\left(\varepsilon_{\mathrm{x}}+v \varepsilon_{\mathrm{y}}\right) & 0 & 0 \\
0 & \sigma_{\mathrm{y}}=\frac{\mathrm{E}}{1-v^{2}} \times\left(\varepsilon_{\mathrm{y}}+v \varepsilon_{\mathrm{x}}\right) & 0 \\
0 & 0 & \sigma_{\mathrm{z}}=0
\end{array}\right]
$$

b) Decompor o tensor de tensões em uma parte negativa e outra positiva, devido ao comportamento distinto do concreto à tração e à compressão:

$$
\begin{aligned}
& \left\langle\sigma_{\mathrm{i}}\right\rangle_{+}=\frac{\left\langle\sigma_{\mathrm{i}}\right\rangle+\left|\left\langle\sigma_{\mathrm{i}}\right\rangle\right|}{2} \Rightarrow\left\langle\sigma_{\mathrm{i}}\right\rangle_{+}=\left[\begin{array}{ccc}
\left\langle\sigma_{\mathrm{i}}\right\rangle_{+} 11 & 0 & 0 \\
0 & \left\langle\sigma_{\mathrm{i}}\right\rangle_{+22} & 0 \\
0 & 0 & 0
\end{array}\right] \\
& \left\langle\sigma_{\mathrm{i}}\right\rangle_{-}=\frac{\left\langle\sigma_{\mathrm{i}}\right\rangle-\left|\left\langle\sigma_{\mathrm{i}}\right\rangle\right|}{2} \Rightarrow\left\langle\sigma_{\mathrm{i}}\right\rangle_{-}=\left[\begin{array}{ccc}
\left\langle\sigma_{\mathrm{i}}\right\rangle_{-11} & 0 & 0 \\
0 & \left\langle\sigma_{\mathrm{i}}\right\rangle_{-22} & 0 \\
0 & 0 & 0
\end{array}\right]
\end{aligned}
$$

Onde os índices inferiores 11 e 22 referem-se às posições na matriz. Nota-se também, que $\left\langle\sigma_{i}\right\rangle_{+}$só apresenta valores positivos e $\left\langle\sigma_{i}\right\rangle_{-}$só valores negativos, valendo, portanto, a relação:

$$
\left\langle\sigma_{i}\right\rangle=\left\langle\sigma_{i}\right\rangle_{+}+\left\langle\sigma_{i}\right\rangle_{-}
$$

c) decompor o tensor de deformações nos tensores $\varepsilon_{\mathrm{t}}$ e $\varepsilon_{\mathrm{c}}$, onde:

$$
\begin{aligned}
& \varepsilon_{\mathrm{t} 11}=\frac{1+v}{\mathrm{E}} \times\left\langle\sigma_{\mathrm{i}}\right\rangle_{+11}-\frac{v}{\mathrm{E}} \times\left[\left\langle\sigma_{\mathrm{i}}\right\rangle_{+11}+\left\langle\sigma_{\mathrm{i}}\right\rangle_{+22}\right] \\
& \varepsilon_{\mathrm{t} 22}=\frac{1+v}{\mathrm{E}} \times\left\langle\sigma_{\mathrm{i}}\right\rangle_{+22}-\frac{v}{\mathrm{E}} \times\left[\left\langle\sigma_{\mathrm{i}}\right\rangle_{+11}+\left\langle\sigma_{\mathrm{i}}\right\rangle_{+22}\right] \\
& \varepsilon_{\mathrm{t} 33}=\frac{1+v}{\mathrm{E}} \times\left\langle\sigma_{\mathrm{i}}\right\rangle_{+33}-\frac{v}{\mathrm{E}} \times\left[\left\langle\sigma_{\mathrm{i}}\right\rangle_{+11}+\left\langle\sigma_{\mathrm{i}}\right\rangle_{+22}\right]
\end{aligned}
$$




$$
\begin{aligned}
& \varepsilon_{\mathrm{c} 11}=\frac{1+v}{\mathrm{E}} \times\left\langle\sigma_{\mathrm{i}}\right\rangle_{-11}-\frac{\mathrm{v}}{\mathrm{E}} \times\left[\left\langle\sigma_{\mathrm{i}}\right\rangle_{-11}+\left\langle\sigma_{\mathrm{i}}\right\rangle_{-22}\right] \\
& \varepsilon_{\mathrm{c} 22}=\frac{1+v}{\mathrm{E}} \times\left\langle\sigma_{\mathrm{i}}\right\rangle_{-22}-\frac{v}{\mathrm{E}} \times\left[\left\langle\sigma_{\mathrm{i}}\right\rangle_{-11}+\left\langle\sigma_{\mathrm{i}}\right\rangle_{-22}\right] \\
& \varepsilon_{\mathrm{c} 33}=\frac{1+v}{\mathrm{E}} \times\left\langle\sigma_{\mathrm{i}}\right\rangle_{-33}-\frac{\mathrm{v}}{\mathrm{E}} \times\left[\left\langle\sigma_{\mathrm{i}}\right\rangle_{-11}+\left\langle\sigma_{\mathrm{i}}\right\rangle_{-22}\right]
\end{aligned}
$$

Os tensores $\varepsilon_{\mathrm{t}}$ e $\varepsilon_{\mathrm{c}}$, podem apresentar valores positivos e negativos.

Representando-se por $\varepsilon_{\mathrm{t}}^{+}$e $\varepsilon_{\mathrm{c}}^{+}$as partes positivas destes tensores, definem-se:

$$
\begin{aligned}
& \varepsilon_{\mathrm{V}}{ }^{+}=\left(\varepsilon_{\mathrm{t}}{ }^{+} 11+\varepsilon_{\mathrm{t}}{ }^{+} 22+\varepsilon_{\mathrm{t} 33}{ }^{+}\right)+\left(\varepsilon_{\mathrm{c}}{ }^{+} 11+\varepsilon_{\mathrm{c}}{ }^{+} 22+\varepsilon_{\mathrm{c}}{ }^{+} 33\right)
\end{aligned}
$$

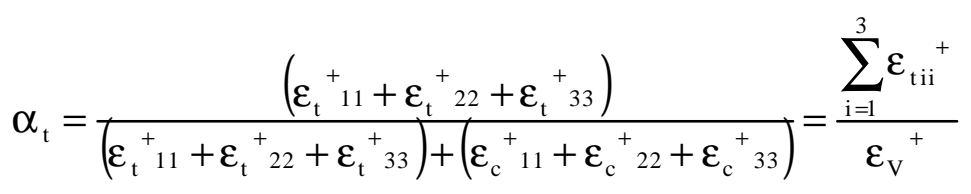

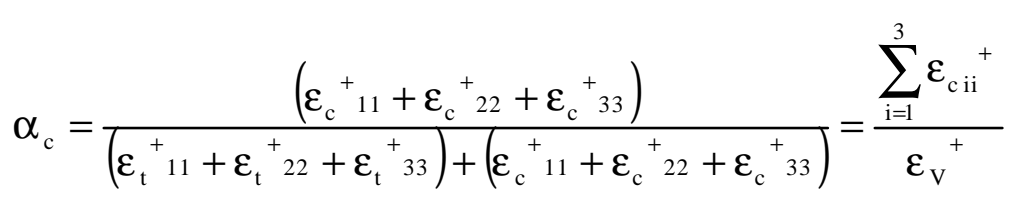

Abaixo, temos uma exemplificação numérica retirada do processamento de um exemplo no código computacional implementado, do cálculo desses coeficientes.

Foram adotados $\mathrm{E}=2.000,0$ e $v=0,2$.

- Tensor de deformações principais

$$
\varepsilon_{\mathrm{p}}=\left[\begin{array}{ccc}
10 & 0 & 0 \\
0 & -20 & 0 \\
0 & 0 & 2,5
\end{array}\right]
$$

- Tensor de tensões principais

$$
\sigma_{p}=\left[\begin{array}{ccc}
12.500 & 0 & 0 \\
0 & -37.500 & 0 \\
0 & 0 & 0
\end{array}\right]
$$

- Componentes positivas do Tensor de tensões principais

$$
\left\langle\sigma_{\mathrm{i}}\right\rangle_{+}=\left[\begin{array}{ccc}
12.500 & 0 & 0 \\
0 & 0 & 0 \\
0 & 0 & 0
\end{array}\right]
$$


- Componentes negativas do Tensor de tensões principais

$\left\langle\sigma_{\mathrm{i}}\right\rangle_{-}=\left[\begin{array}{ccc}0 & 0 & 0 \\ 0 & -37.500 & 0 \\ 0 & 0 & 0\end{array}\right]$

- Tensor $\varepsilon_{\mathrm{t}}$ de deformações

$\varepsilon_{t}=\left[\begin{array}{ccc}6,25 & 0 & 0 \\ 0 & -1,25 & 0 \\ 0 & 0 & -1,25\end{array}\right]$

- Tensor $\varepsilon_{\mathrm{c}}$ de deformações

$\varepsilon_{\mathrm{c}}=\left[\begin{array}{ccc}3,75 & 0 & 0 \\ 0 & -18,75 & 0 \\ 0 & 0 & 3,75\end{array}\right]$

- Somatória das componentes positivas de $\varepsilon_{\mathrm{t}}$ :

$\sum_{\mathrm{i}=1}^{3} \varepsilon_{\mathrm{t} \text { ii }}{ }^{+}=6,25$

- Somatória das componentes positivas de $\varepsilon_{\mathrm{c}}$ :

$\sum_{\mathrm{i}=1}^{3} \varepsilon_{\mathrm{c} \text { ii }}^{+}=7,5$

- Cálculo de $\varepsilon_{\mathrm{v}}^{+}$

$\varepsilon_{\mathrm{V}}^{+}=13,75$

- Cálculo de $\alpha_{\mathrm{t}}$ e $\alpha_{\mathrm{c}}$

$\alpha_{\mathrm{t}}=\frac{6,25}{13,75}=0,4545$ e $\alpha_{\mathrm{c}}=\frac{7,5}{13,75}=0,5455$ 
$\alpha_{\mathrm{T}}$ e $\alpha_{\mathrm{C}}$ estão definidos em $[0,1] \subset \mathrm{R}$ e devem satisfazer as condições descritas abaixo:

\begin{tabular}{|c|c|c|c|}
\hline Estado de Tensões & $\alpha_{\mathrm{T}}$ & $\alpha_{\mathrm{C}}$ & $\mathrm{D}$ \\
\hline Tração Uniaxial & 1 & 0 & $\mathrm{D}_{\mathrm{T}}$ \\
\hline Compressão Uniaxial & 0 & 1 & $\mathrm{D}_{\mathrm{C}}$ \\
\hline Multiaxiais & $0<\alpha_{\mathrm{T}}<1$ & $0<\alpha_{\mathrm{C}}<1$ & $\alpha_{\mathrm{C}} . \mathrm{Dc}+\alpha_{\mathrm{T}} . \mathrm{D}_{\mathrm{T}}$ \\
\hline
\end{tabular}

Tabela 4.2 - Casos de determinação dos parâmetros $\alpha_{T}$ e $\alpha_{C}$

Com os coeficientes $\alpha_{t}$ e $\alpha_{c}$ e os parâmetros Dc e Dt, determina-se a variável D, e em seguida, através das relações constitutivas intrínsecas do material, determina-se o tensor de tensões reais, recorrendo-se à expressão:

$\underline{\sigma}=(1-\mathrm{D}) \underline{\underline{D}}_{0} \underline{\varepsilon}$

MAZARS, em seu trabalho, propõe limites para a variação dos parâmetros de seu modelo. Como esses limites são largos, percebe-se que a identificação cuidadosa destes parâmetros é muito importante

$0.7 \leq \mathrm{A}_{\mathrm{T}} \leq 1$

$10^{4} \leq \mathrm{B}_{\mathrm{T}} \leq 10^{5}$

$1 \leq \mathrm{A}_{\mathrm{C}} \leq 1.5$

$10^{3} \leq \mathrm{B}_{\mathrm{C}} \leq 2.10^{3}$

$10^{-5} \leq \varepsilon_{\mathrm{d} 0} \leq 10^{-4}$ 


\section{ANÁLISE NÃO-LINEAR DE GRELHAS}

\section{1 - MÉTOdO DA ENERGIA}

Um sistema elástico possui energia potencial igual à soma de duas componentes distintas: a energia potencial dos esforços internos, também chamada de energia de deformação, e a energia produzida pelas cargas externas. Existem ainda as expressões de energia relacionadas aos vínculos elásticos discretos, ou molas, e vínculos elásticos contínuos, ou bases elásticas. A expressão geral para a energia potencial total é dada por:

$\pi=\mathrm{u}+\mathrm{W}$

Em que " $\pi$ " representa a energia potencial total da estrutura, "u" é a somatória das energias produzidas pelos esforços internos na estrutura e W significa a somatória das energia produzidas pelas cargas externas atuantes na estrutura.

A energia de deformação é a energia que a estrutura absorve quando deforma-se recebendo solicitações de um carregamento externo. Ela é fruto dos trabalhos realizados pelos esforços internos ao atuarem sobre os deslocamentos que cada um produz. A fórmula genérica para o seu cálculo é dada por:

$\mathrm{u}=\frac{1}{2} \int_{\mathrm{V}}\left(\sigma_{\mathrm{X}} \varepsilon_{\mathrm{X}}+\sigma_{\mathrm{Y}} \varepsilon_{\mathrm{Y}}+\sigma_{\mathrm{Z}} \varepsilon_{\mathrm{Z}}+\tau_{\mathrm{XY}} \gamma_{\mathrm{XY}}+\tau_{\mathrm{XZ}} \gamma_{\mathrm{XZ}}+\tau_{\mathrm{YZ}} \gamma_{\mathrm{YZ}}\right) \mathrm{dV}$

Para se obter a energia potencial das cargas externas, basta efetuar o produto entre cada esforço externo e o respectivo deslocamento no seu ponto de aplicação. 
No caso de carregamentos distribuídos ao longo do domínio do corpo, deve-se efetuar integração, do valor da carga pela função que representa a elástica do elemento.

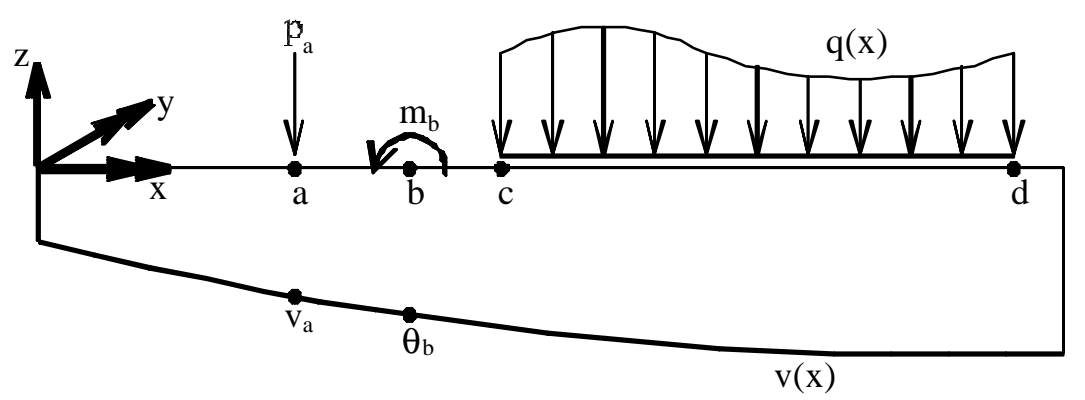

Figura 5.1 - Elemento de barra submetido a um carregamento genérico

Então, a energia potencial das cargas externas é:

$\mathrm{w}_{\mathrm{i}}=-\int \mathrm{q}(\mathrm{x}) \mathrm{v}(\mathrm{x}) \mathrm{dx}$

No caso da Figura 5.1 tem-se:

$\mathrm{w}_{\mathrm{i}}=-\mathrm{p}_{\mathrm{a}} \mathrm{v}_{\mathrm{a}}-\mathrm{m}_{\mathrm{b}} \theta_{\mathrm{b}}-\int_{\mathrm{c}}^{\mathrm{d}} \mathrm{q}(\mathrm{x}) \cdot \mathrm{v}(\mathrm{x}) \cdot \mathrm{dx}$

Pelo princípio da mínima energia potencial total tem-se que a variação desta é nula quando um corpo está em equilíbrio. Logo, da mesma maneira que foi deduzido no capítulo 3 deste trabalho, tem-se:

$\mathrm{d} \pi=0 \Rightarrow \frac{\mathrm{d} \pi}{\mathrm{dv}_{\mathrm{i}}}=0$

onde, os vi são os deslocamentos na direção 'i’ .

Considere-se agora, um material com relações constitutivas não-lineares escritas em qualquer modelo. Para que aconteça o equilíbrio em qualquer posição, ainda vale a relação (5.05). A diferença é que agora como são introduzidos valores de deformações residuais no sistema, aparecerão termos complementares na expressão (5.02), e a energia proveniente dos esforços internos, será dada por:

$\mathrm{u}=\mathrm{u}+\mathrm{u}_{\mathrm{r}}$ 
Expressão na qual o termo $\mathrm{u}_{\mathrm{r}}$ corresponde ao produto da parcela das deformações não-lineares $\varepsilon_{\mathrm{p}}$ pelas respectivas componentes de tensão, integradas no volume do corpo. Portanto, a expressão (5.01) deve ser re-escrita nestes termos: $\pi=(\mathrm{u}+\Delta \mathrm{u})+\mathrm{W}$

\section{2 -SOLUÇÃO DO SISTEMA DE EQUAÇÕES}

O vetor de resíduos consiste na parcela de energia de deformação que não é absorvida pelo sistema no atual nível de deslocamentos. Esta parcela deverá ser transformada em carregamento nodal e conseqüentemente reaplicada ao sistema. Percebe-se claramente que os novos deslocamentos serão função dos resíduos a serem aplicados. Assim, o sistema de equações será do tipo:

$[\mathrm{K}] \times\{\mathrm{U}+\Delta \mathrm{U}\}=\{\mathrm{F}\}$

Que é um sistema não-linear de equações, onde o símbolo "U” refere-se aos deslocamentos nodais. Várias técnicas foram desenvolvidas para solucionar este tipo de sistema, umas mais simples, outras mais complexas, que apresentam diferenças principalmente quanto à velocidade de convergência da solução.

Neste trabalho, para a solução do sistema de equações não-lineares foi utilizada a matriz de rigidez secante, que consiste em uma variante do procedimento de NEWTON-RAPHSON. O sistema de equações de equilíbrio é escrito em função da rigidez secante, da seguinte forma:

$[\mathrm{K}]_{\mathrm{S}} \times\{\mathrm{U}\}=\{\mathrm{F}\}$

$\mathrm{Ou}$, se escrito em função das parcelas da matriz de rigidez:

$\left([\mathrm{K}]_{\mathrm{L}}+[\mathrm{K}]_{\mathrm{N}}\right) \times\{\mathrm{U}\}=\{\mathrm{F}\}$

onde a parcela $[K]_{L}$ refere-se à parte linear e $[K]_{N}$ à parcela que é função dos deslocamentos residuais $\Delta \mathrm{U}$ descritos na expressão (5.08). A finalidade do procedimento é chegar à rigidez mais próxima do ponto onde a curva não-linear de carga x deslocamento intercepta o nível de carga aplicado. 
Para isto realizam-se atualizações da matriz de rigidez secante, que são decorrentes da determinação de novos níveis de deslocamentos, conforme ilustra a seguinte Tabela 5.1:

\begin{tabular}{|c|c|c|c|}
\hline It. & Matriz Secante & Deslocamentos & Esforço Resistente \\
\hline 1 & {$[\mathrm{~K}]_{\mathrm{S} 1}=[\mathrm{K}]_{\mathrm{L}}$} & $\{\mathrm{U}\}_{1}=[\mathrm{K}]_{\mathrm{L}}^{-1} \times\{\mathrm{F}\}_{\mathrm{T}}$ & $\{\mathrm{F}\}_{1}=\left[[\mathrm{K}]_{\mathrm{L}}+[\mathrm{K}]_{\mathrm{N}}\left(\{\mathrm{U}\}_{1}\right)\right) \times\{\mathrm{U}\}_{1}$ \\
2 & {$[\mathrm{~K}]_{\mathrm{S} 2}=[\mathrm{K}]_{\mathrm{L}}+[\mathrm{K}]_{\mathrm{N}}\left(\{\mathrm{U}\}_{1}\right)$} & $\{\mathrm{U}\}_{2}=\left([\mathrm{K}]_{\mathrm{L}}+[\mathrm{K}]_{\mathrm{N}}\left(\{\mathrm{U}\}_{1}\right)\right)^{-1} \times\{\mathrm{F}\}_{\mathrm{T}}$ & $\{\mathrm{F}\}_{2}=\left([\mathrm{K}]_{\mathrm{L}}+[\mathrm{K}]_{\mathrm{N}}\left(\{\mathrm{U}\}_{2}\right)\right) \times\{\mathrm{U}\}_{2}$ \\
3 & {$[\mathrm{~K}]_{\mathrm{S} 3}=[\mathrm{K}]_{\mathrm{L}}+[\mathrm{K}]_{\mathrm{N}}\left(\{\mathrm{U}\}_{2}\right)$} & $\{\mathrm{U}\}_{3}=\left([\mathrm{K}]_{\mathrm{L}}+[\mathrm{K}]_{\mathrm{N}}\left(\{\mathrm{U}\}_{2}\right)\right)^{-1} \times\{\mathrm{F}\}_{\mathrm{T}}$ & $\{\mathrm{F}\}_{3}=\left([\mathrm{K}]_{\mathrm{L}}+[\mathrm{K}]_{\mathrm{N}}\left(\{\mathrm{U}\}_{3}\right)\right) \times\{\mathrm{U}\}_{3}$ \\
4 & {$[\mathrm{~K}]_{\mathrm{S} 4}=[\mathrm{K}]_{\mathrm{L}}+[\mathrm{K}]_{\mathrm{N}}\left(\{\mathrm{U}\}_{3}\right)$} & $\{\mathrm{U}\}_{4}=\left([\mathrm{K}]_{\mathrm{L}}+[\mathrm{K}]_{\mathrm{N}}\left(\{\mathrm{U}\}_{3}\right)\right)^{-1} \times\{\mathrm{F}\}_{\mathrm{T}}$ & $\{\mathrm{F}\}_{4}=\left([\mathrm{K}]_{\mathrm{L}}+[\mathrm{K}]_{\mathrm{N}}\left(\{\mathrm{U}\}_{4}\right)\right) \times\{\mathrm{U}\}_{4}$ \\
$\vdots$ & $\vdots$ & \\
$\mathrm{i}$ & {$[\mathrm{K}]_{\mathrm{Si}}=[\mathrm{K}]_{\mathrm{L}}+[\mathrm{K}]_{\mathrm{N}}\left(\{\mathrm{U}\}_{\mathrm{i}-1}\right)$} & $\{\mathrm{UU}\}_{\mathrm{i}}=\left([\mathrm{K}]_{\mathrm{L}}+[\mathrm{K}]_{\mathrm{N}}\left(\{\mathrm{U}\}_{\mathrm{i}-1}\right)\right)^{-1} \times\{\mathrm{F}\}_{\mathrm{T}}$ & $\{\mathrm{F}\}_{\mathrm{i}}=\left([\mathrm{K}]_{\mathrm{L}}+[\mathrm{K}]_{\mathrm{N}}\left(\{\mathrm{U}\}_{\mathrm{i}}\right)\right) \times\{\mathrm{U}\}_{\mathrm{i}}$ \\
\hline
\end{tabular}

Tabela 5.1 Procedimento da rigidez secante - Adaptado de CORRÊA(1991)

Conforme a Tabela 5.1, escrevem-se as seguintes relações:

$$
\begin{aligned}
& \{\mathrm{F}\}_{\mathrm{i}}=\left([\mathrm{K}]_{\mathrm{L}}+[\mathrm{K}]_{\mathrm{N}}\left(\{\mathrm{U}\}_{\mathrm{i}}\right)\right) \times\{\mathrm{U}\}_{\mathrm{i}} \\
& \{\mathrm{U}\}_{\mathrm{i}+1}=\left([\mathrm{K}]_{\mathrm{L}}+[\mathrm{K}]_{\mathrm{N}}\left(\{\mathrm{U}\}_{\mathrm{i}}\right)\right)^{-1} \times\{\mathrm{F}\}_{\mathrm{T}}
\end{aligned}
$$

O procedimento da Tabela 5.1 pode ser descrito graficamente através da Figura 5.2. 


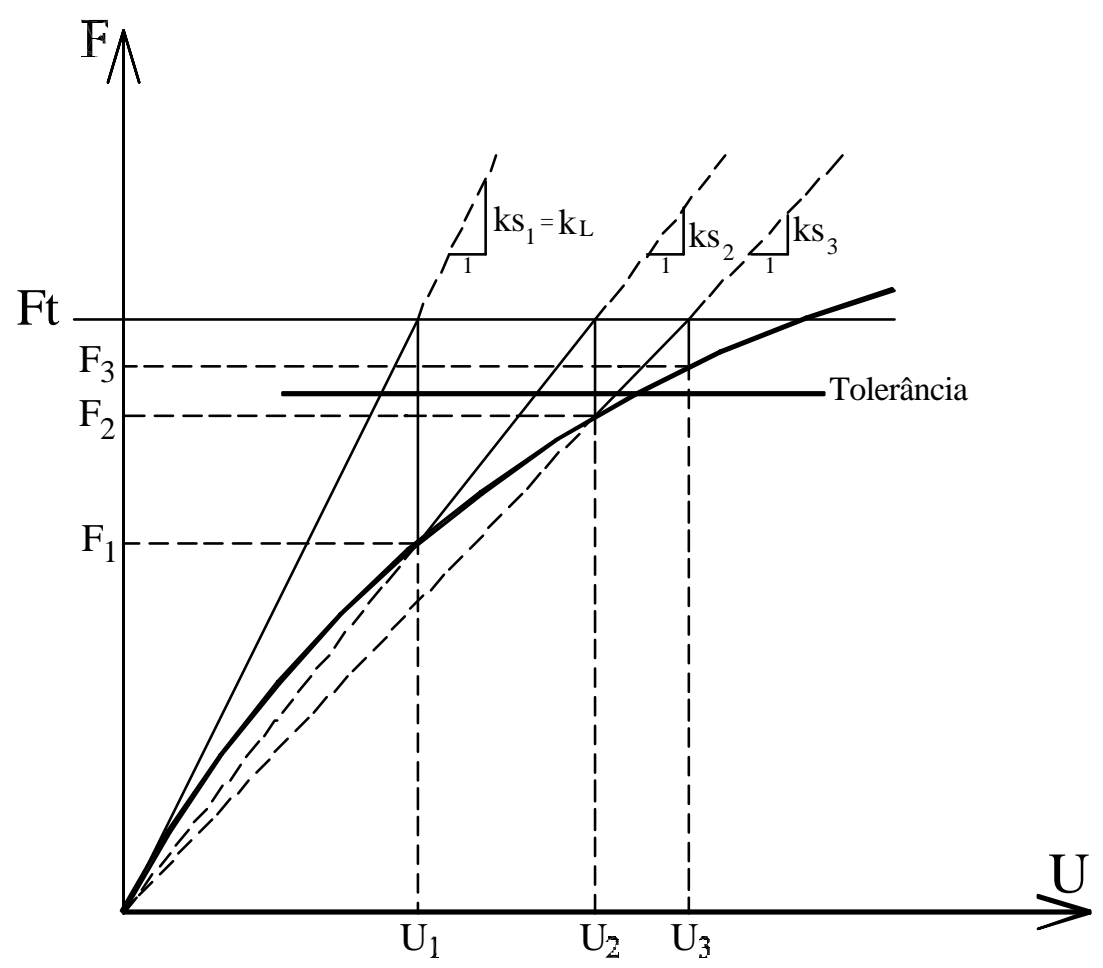

Figura 5.2 Procedimento de solução através da rigidez secante

De (5.11), conclui-se que :

$\{\mathrm{U}\}_{\mathrm{i}}=\left([\mathrm{K}]_{\mathrm{L}}+[\mathrm{K}]_{\mathrm{N}}\left(\{\mathrm{U}\}_{\mathrm{i}}\right)\right)^{-1} \times\{\mathrm{F}\}_{\mathrm{i}}$

Subtraindo-se (5.13) de (5.12), obtém-se:

$\{\mathrm{U}\}_{\mathrm{i}+1}-\{\mathrm{U}\}_{\mathrm{i}}=\left([\mathrm{K}]_{\mathrm{L}}+[\mathrm{K}]_{\mathrm{N}}\left(\{\mathrm{U}\}_{\mathrm{i}}\right)\right)^{-1} \times\left(\{\mathrm{F}\}_{\mathrm{T}}-\{\mathrm{F}\}_{\mathrm{i}}\right)$

Ou ainda:

$\Delta\{\mathrm{U}\}_{\mathrm{i}}=\left([\mathrm{K}]_{\mathrm{s}}\left(\{\mathrm{U}\}_{\mathrm{i}}\right)\right)^{-1} \times \Delta\{\mathrm{F}\}_{\mathrm{i}}$ 
Representando-se graficamente a eq. (5.15), obtém-se:

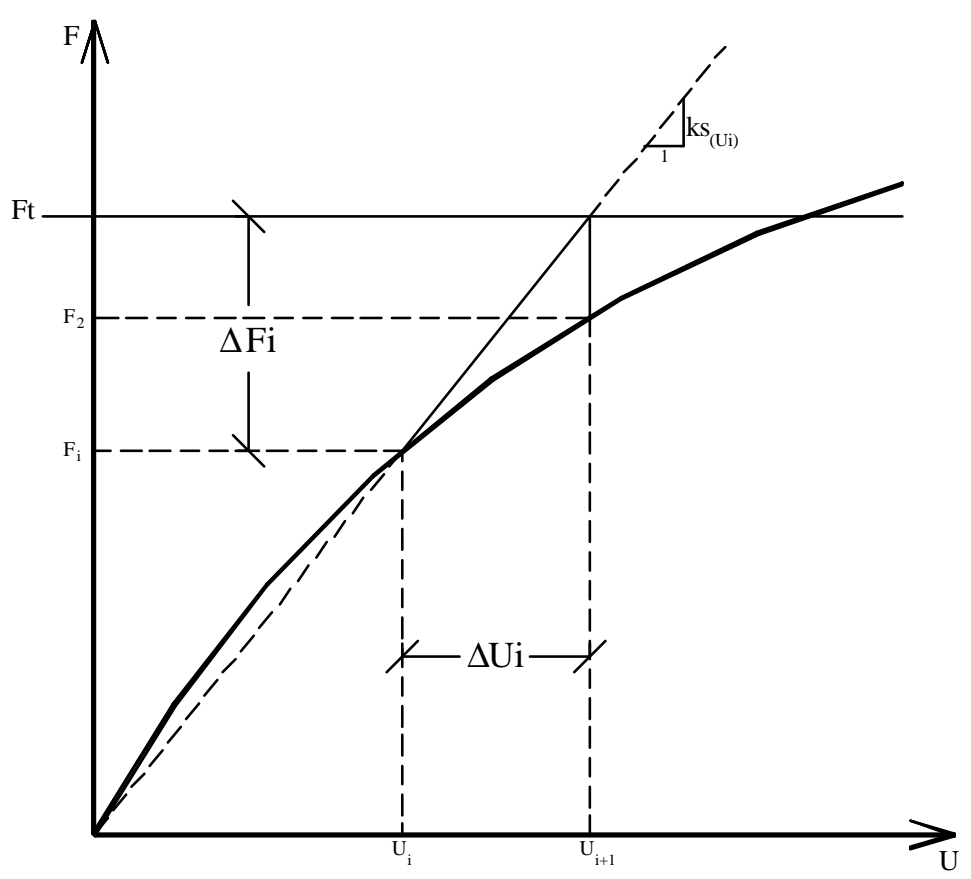

Figura 5.3 Iteração genérica

Da Figura 5.3 percebe-se que o vetor $\Delta\{F\}$ é a parcela de forças do sistema, na iteração “i”, que não está em equilíbrio. Logo, deve ser reaplicada em forma de carregamento. Isto quer dizer que deve-se equilibrar o sistema calculando-se o acréscimo de deslocamentos $\Delta\{U\}$ i produzido por $\Delta\{F\}$ no instante em que a rigidez secante vale $[K]_{S}\left(\{U\}_{\mathrm{i}}\right)$, isto é, no nível de deslocamentos “i”. O novo campo de deslocamentos é $\{\mathrm{U}\} \mathrm{i}+1=\{\mathrm{U}\} \mathrm{i}+\Delta\{\mathrm{U}\} \mathrm{i}$, recomeçando-se o processo. Este processo só irá terminar no momento em que o valor $\{\mathrm{F}\}_{\mathrm{T}}-\{\mathrm{F}\}_{\mathrm{i}}$, que simboliza o resíduo, for menor que uma tolerância pré-estipulada, caracterizando-se a convergência. 


\section{3 - CÁLCULO DOS ESFORÇOS INTERNOS}

\subsection{1 - Linha neutra da seção}

Para a obtenção dos esforços internos, foi utilizada a integração das tensões na área da seção transversal. Como o diagrama tensão x deformação é intrinsecamente não-linear, definido pelo modelo constitutivo de dano, a sua integração analítica torna-se trabalhosa. Parte-se então para um procedimento de integração numérica.

Para que se conheça a distribuição de tensões em uma seção transversal, obviamente é necessário conhecer quanto cada fibra está deformada. Sendo complexa a definição de uma distribuição analítica para as tensões, preferiu-se utilizar procedimentos numéricos para integração. Assim, alocaram-se ao longo da seção transversal doze pontos de Gauss, fixando-se as suas abcissas, conforme descrito em BREBBIA(1998) . Em um modelo de integração Gausseano, aproxima-se a distribuição de tensões por um polinômio de grau $2 \mathrm{~N}-1$, onde $\mathrm{N}$ é o número de pontos de Gauss. Portanto, nesse caso, a aproximação está sendo feita por polinômio do $23^{\circ}$ grau.

Para se determinarem-se as deformações em cada ponto de Gauss, é necessário conhecer-se a curvatura da seção e a posição da linha neutra. A curvatura é facilmente obtida através da equação (3.32). A linha neutra é obtida impondo-se a condição de que a força normal resultante na seção é nula. Portanto, procura-se através de um procedimento iterativo, que será descrito abaixo, o zero da função que relaciona força normal presente na seção e linha neutra, fixada a curvatura da seção.

O procedimento segue o roteiro abaixo:

- Determina-se a curvatura da seção, que é função do nível de deslocamentos e da rigidez;

- Assume-se inicialmente a linha neutra no centro da seção;

- Determina-se a força normal presente na seção, conforme o esquema abaixo. A resultante das tensões no concreto será obtida através da integração numérica, descrita no item seguinte. 


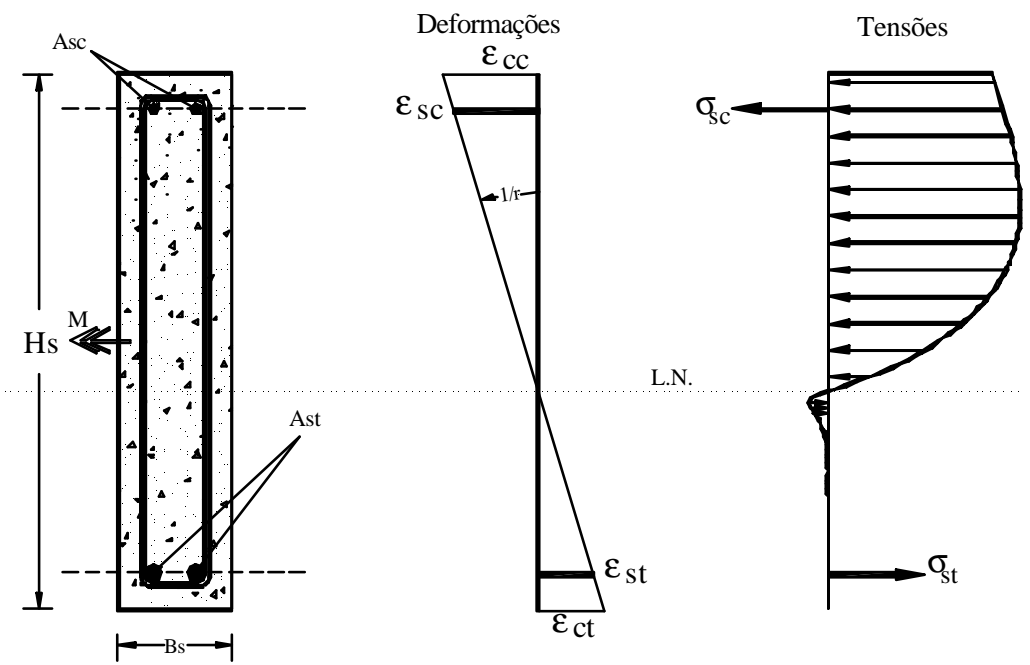

Figura 5.4 Distribuição das tensões na seção transversal

- Ajusta-se a posição da linha neutra, conforme o sinal do esforço necessário para atingir o equilíbrio, para a metade do novo intervalo restante, recalculando-se a força normal, que deve ser menor que a anterior, ou ter sinal contrário. A linha neutra, tem então a seguinte expressão :

$\mathrm{LN}_{(\mathrm{J})}=\mathrm{LN}_{(\mathrm{J}-1)} \pm \frac{\mathrm{H}_{\mathrm{S}}}{2^{(\mathrm{J}+1)}}$

Onde J é a iteração atual. O sinal da expressão (5.16) é definido pelos sinais da curvatura e do esforço normal resultante na seção.

O processo pára quando este esforço normal resultante for menor que uma tolerância pré-estipulada, ou quando $\mathrm{J}$ for tão grande que não represente mais nenhum acréscimo de esforço.

Ressalta-se aqui, que o modelo adotado para a obtenção das tensões no aço foi um modelo com encruamento isótropo, análogo ao da Figura 2.7, portanto, as tensões são obtidas da seguinte forma:

$$
\begin{array}{r}
\operatorname{Se} \varepsilon_{\mathrm{AÇO}} \leq \frac{\sigma_{\mathrm{Y}}}{\mathrm{E}_{\mathrm{AÇO}}}: \\
\sigma_{\mathrm{AÇO}}=\mathrm{E}_{\mathrm{AÇO}} \times \varepsilon_{\mathrm{AÇO}}
\end{array}
$$

$$
\text { Se } \varepsilon_{\mathrm{AÇO}}>\frac{\sigma_{\mathrm{Y}}}{\mathrm{E}_{\mathrm{AÇO}}}:
$$




$$
\sigma_{\mathrm{AÇO}}= \pm \sigma_{\mathrm{Y}}+\mathrm{H} \times\left( \pm \varepsilon_{\mathrm{AÇO}} \pm \frac{\sigma_{\mathrm{Y}}}{\mathrm{E}_{\mathrm{AÇO}}}\right)
$$

$\mathrm{Na}$ expressão (5.18), deve-se atentar para os casos de tração e compressão da armadura, refletindo no ajuste do sinal.

\subsection{2 - Integração numérica}

Para o cálculo dos esforços internos na seção, devidos à parcela do concreto, como já foi citado, recorre-se à expressão já conhecida da teoria da elasticidade:

$$
\mathrm{M}_{\mathrm{CON}}=\int_{\mathrm{A}} \sigma_{(\mathrm{y})} \mathrm{y} \mathrm{dA}
$$

A parcela devida à armadura é dada pela expressão clássica :

$$
\mathrm{M}_{\mathrm{AÇO}}=\left(\mathrm{A}_{\mathrm{s} 1} \sigma_{\mathrm{s} 1}-\mathrm{A}_{\mathrm{s} 2} \sigma_{\mathrm{s} 2}\right) \times\left(\mathrm{d}-\frac{\mathrm{hs}}{2}\right)
$$

Transformando-se a expressão (5.19) no domínio do elemento, a expressão total do momento interno pode ser escrita da seguinte maneira:

$$
\mathrm{M}_{\mathrm{INT}}=\left(\mathrm{b}_{\mathrm{s}} \int_{-\mathrm{hs} / 2}^{\mathrm{h} / 2} \sigma(\mathrm{y}) \mathrm{ydy}\right)+\left(\mathrm{A}_{\mathrm{s} 1} \sigma_{\mathrm{s} 1}-\mathrm{A}_{\mathrm{s} 2} \sigma_{\mathrm{s} 2}\right) \times\left(\mathrm{d}_{\mathrm{s}}-\frac{\mathrm{hs}}{2}\right)
$$

Em que $\sigma(y)$ é a tensão no concreto na ordenada y e $\sigma_{\mathrm{s} 1}$ e $\sigma_{\mathrm{s} 2}$ são, as tensões nas armaduras.

A integral presente no primeiro termo do segundo membro da expressão (5.21) refere-se à parcela do momento proveniente das tensões no concreto. Pode ser transformada numa somatória equivalente de termos, em um domínio normalizado, da seguinte maneira:

$\mathrm{b}_{\mathrm{s}} \int_{-\mathrm{hs} / 2}^{\mathrm{hs} / 2} \sigma(\mathrm{y}) \mathrm{ydy}=\mathrm{b}_{\mathrm{s}} \int_{-1}^{1} \sigma(\xi) \frac{\mathrm{h}_{\mathrm{s}}}{2} \frac{\mathrm{h}_{\mathrm{s}}}{2} \xi \mathrm{d} \xi=\frac{\mathrm{b}_{\mathrm{s}} \mathrm{h}_{\mathrm{s}}{ }^{2}}{4} \sum_{\mathrm{i}=1}^{\mathrm{n}} \sigma\left(\xi_{\mathrm{i}}\right) \xi_{\mathrm{i}} \mathrm{w}_{\mathrm{i}}$

Onde os valores $\sigma\left(\xi_{\mathrm{i}}\right)$ são as tensões calculadas de acordo com o modelo constitutivo de dano nos pontos adimensionais $\xi_{\mathrm{i}}$. 
Conhecendo-se esse artifício, escrevem-se as expressões utilizadas, neste trabalho, para o cálculo do momento fletor, esforço cortante e esforço normal:

$$
\begin{aligned}
& \mathrm{M}_{\mathrm{INT}}=\frac{\mathrm{b}_{\mathrm{s}} \mathrm{h}_{\mathrm{s}}^{2}}{4} \sum_{\mathrm{i}=1}^{\mathrm{n}} \sigma\left(\xi_{\mathrm{i}}\right) \xi_{\mathrm{i}} \mathrm{w}_{\mathrm{i}}+\left(\mathrm{A}_{\mathrm{s} 1} \sigma_{\mathrm{s} 1}-\mathrm{A}_{\mathrm{s} 2} \sigma_{\mathrm{s} 2}\right) \times\left(\mathrm{d}_{\mathrm{s}}-\frac{\mathrm{hs}}{2}\right) \\
& \mathrm{V}_{\mathrm{INT}}=\frac{\mathrm{b}_{\mathrm{s}} \mathrm{h}_{\mathrm{s}}}{2} \sum_{\mathrm{i}=1}^{\mathrm{n}} \tau\left(\xi_{\mathrm{i}}\right) \mathrm{w}_{\mathrm{i}} \\
& \mathrm{N}_{\mathrm{INT}}=\frac{\mathrm{b}_{\mathrm{s}} \mathrm{h}_{\mathrm{s}}}{2} \sum_{\mathrm{i}=1}^{\mathrm{n}} \sigma\left(\xi_{\mathrm{i}}\right) \mathrm{w}_{\mathrm{i}}+\left(\mathrm{A}_{\mathrm{s} 1} \sigma_{\mathrm{s} 1}+\mathrm{A}_{\mathrm{s} 2} \sigma_{\mathrm{s} 2}\right)
\end{aligned}
$$

\section{4 - RELAÇÕES CONSTITUTIVAS MOMENTO X CURVATURA}

O modelo de dano descrito anteriormente neste trabalho foi utilizado para determinar as tensões correspondentes a um determinado estado de tensões biaxial, presente em uma fibra genérica da seção de concreto. Porém, deve-se também considerar na análise a nova rigidez avaliada a partir do diagrama momento x curvatura.

Optou-se pela rigidez secante, por apresentar melhor velocidade de convergência que a rigidez inicial e por não ser tão trabalhosa quanto a tangente, mesmo sendo menos veloz que esta última.

Esta transformação já foi efetuada por BOTTA(1998), através do uso de um fator de dano genérico $d_{k}$, para representar o abatimento na inclinação da rigidez secante à curva. $\mathrm{O}$ fator $\mathrm{d}_{\mathrm{k}}$ nada tem a ver com a variável escalar de dano de MAZARS.

Optou-se, neste trabalho, por utilizar formulação semelhante, no sentido de penalizar a rigidez com este fator, como mostra a Figura 5.5: 


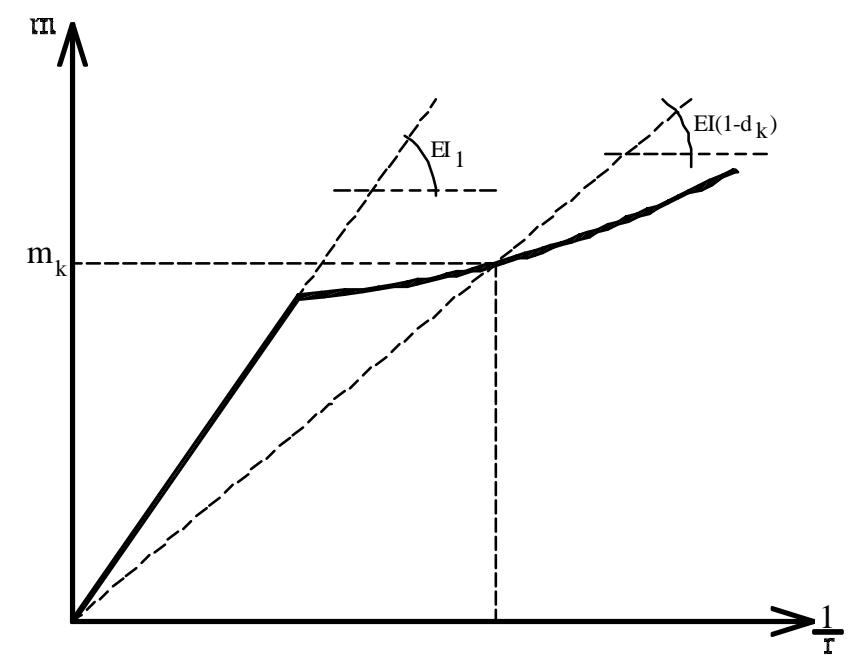

Figura 5.5 Modelo genérico de dano escrito em relação constitutiva momento x curvatura

Portanto, a consideração da perda de rigidez é dada atualizando-se a rigidez EI, simplesmente dividindo-se o momento interno encontrado na seção na iteração atual, pela respectiva curvatura. Como um mesmo elemento possui curvaturas diferentes no seu nó inicial e nó final, e o valor EI deve ser único na sua matriz de rigidez, toma-se a média dos seus valores e encontra-se uma rigidez característica do elemento para a iteração seguinte:

$\mathrm{EI}_{\mathrm{i}+1}=\frac{\left[\frac{\left(\mathrm{M}_{1}\right)_{\mathrm{i}}}{\left(1 / \mathrm{r}_{1}\right)_{\mathrm{i}}}+\frac{\left(\mathrm{M}_{2}\right)_{\mathrm{i}}}{\left(1 / \mathrm{r}_{2}\right)_{\mathrm{i}}}\right]}{2}$

Onde $M_{1}$ e $M_{2}$ são, respectivamente, os momentos atuantes no nó inicial e final do elemento, na iteração 'i' .

Sendo esse procedimento iterativo, deve adotar-se algum critério para a verificação da convergência. Estabeleceu-se o critério através da norma do vetor resíduo, conforme HINTON \& OWEN(1980):

$$
\|\varphi\|=\frac{\mid \sqrt{\left[\sum_{m=1}^{N}\left(q_{m}^{i}\right)^{2}\right]}-\sqrt{\left[\sum_{m=1}^{N}\left(q_{m}^{i-1}\right)^{2}\right]}}{\sqrt{\left[\sum_{m=1}^{N}\left(q_{m}^{1}\right)^{2}\right]}} \times 100<\delta
$$


onde o índice "i” representa a iteração atual, "i-1" representa a iteração anterior, e o número "1" significa a primeira iteração de cada incremento; $\delta$ é uma tolerância préestipulada para a verificação da convergência.

Quando a expressão acima estiver satisfeita, a convergência foi alcançada, podendo-se portanto aplicar um novo incremento de carga. $\mathrm{N}$ representa o número de graus de liberdade do problema. 


\section{5 - CÁLCULO DO VETOR DE ESFORÇOS RESIDUAIS}

Para a obtenção do vetor de esforços residuais, é necessário que seja efetuada uma transformação do vetor de resíduos em momentos fletores em carregamento atuante. Através de um simples equacionamento, descrito na tabela abaixo, é feita a determinação genérica do carregamento no nó "Q". O procedimento é análogo para todos os nós.

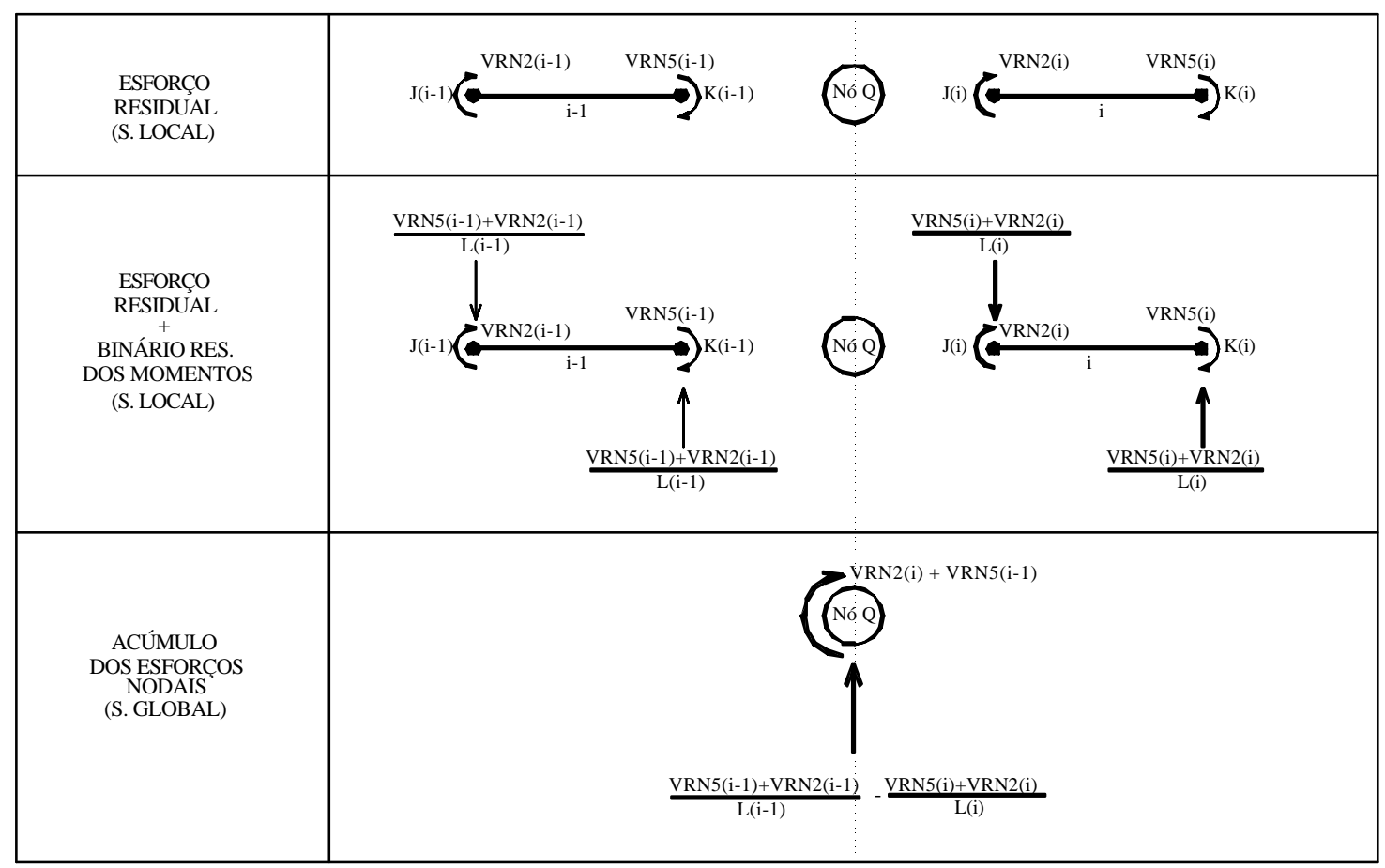

Figura 5.6 Caso genérico de determinação do vetor de esforços residuais

Com a expressão indicada na linha da tabela referente ao acúmulo dos esforços nos nós, basta reaplicar diretamente estes valores ao sistema e reiniciar o processo iterativo descrito no item 5.2, até que o critério de convergência esteja verificado. 


\section{6 - ESTRUTURA DO PROGRAMA}

O programa escrito em linguagem Fortran, foi dividido em três módulos, da seguinte maneira:

Declaração das Variáveis

Abertura dos arquivos de dados e de resultados

MÓDULO A - LEITURA DE DADOS

A.01 - Dados gerais da estrutura

A.02 - Alocação dinâmica dos vetores e matrizes

A.03 - Leitura das coordenadas dos nós da grelha

A.04 - Vinculação dos nós

A.05 - Características geométricas dos elementos

A.06 - Carregamento nodal

A.07 - Carregamento concentrado nas barras

A.08 - Carregamento distribuído nas barras

A.09 - Parâmetros de dano do modelo de MAZARS

A.10 - Características mecânicas do aço

A.11 - Características mecânicas do concreto, coeficiente ALFA

\section{MÓDULO B - DADOS ADICIONAIS}

B.01 - Características geométricas adicionais da barras e seções

B.02 - Determinação dos esforços de engastamento perfeito

\section{MÓDULO C - ANÁLISE NÃO-LINEAR}

C.01 - Cálculo dos esforços solicitantes

C.02 - Cálculo dos esforços verdadeiros

C.03 - Análise da convergência

C.04 - Reações de apoio

C.05 - Resultados finais de cada passo de carga

Obviamente, interessa explicitar o módulo "C", que contém o procedimento incremental-iterativo. À página seguinte, tem-se um algoritmo mais detalhado desse último módulo. 


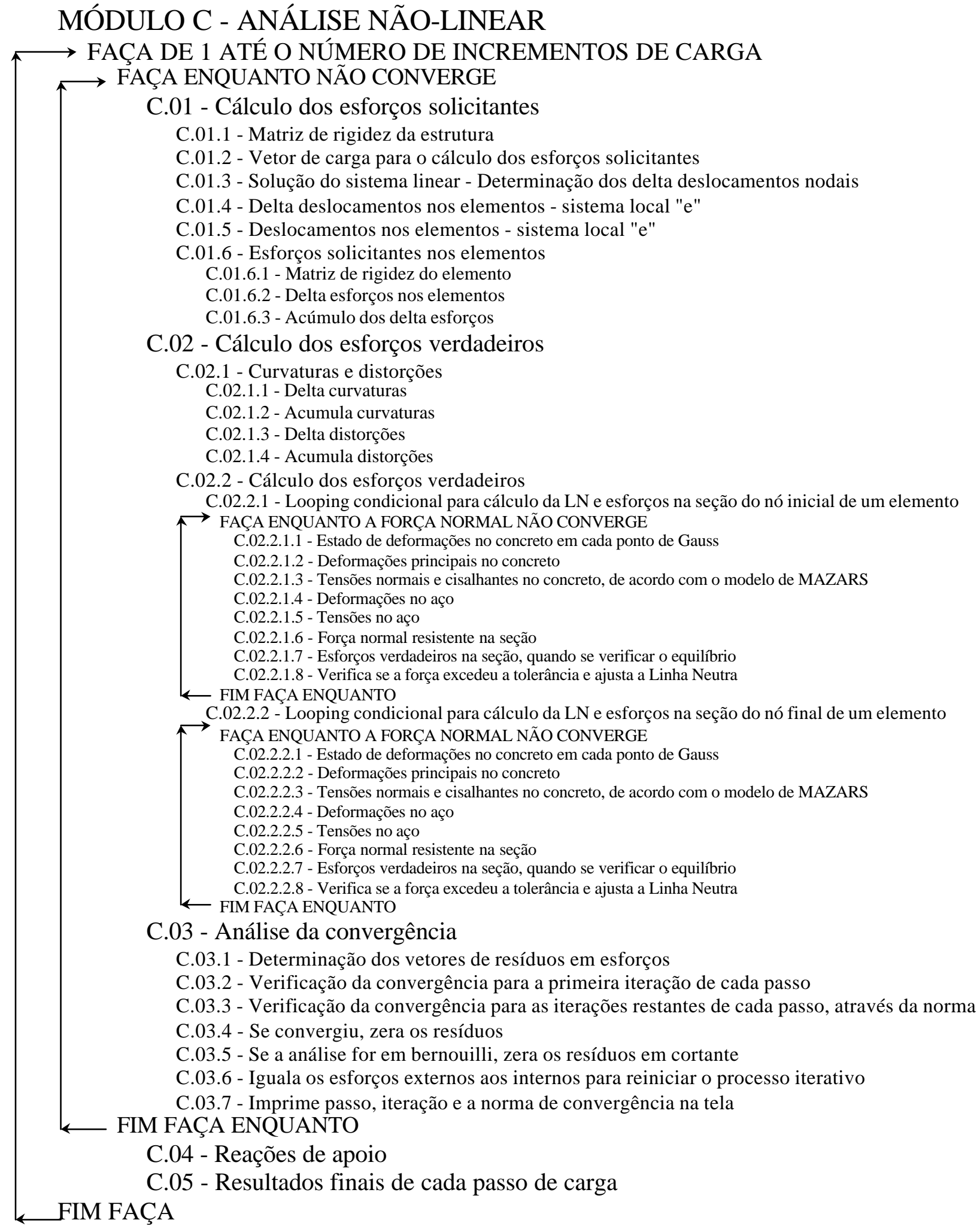

\section{MÓDULO C - ANÁLISE NÃO-LINEAR}




\section{MECANiSMOS RESISTENTES AO CISALHAMENTO}

\section{1 - COMENTÁRIOS GERAIS}

No dimensionamento de elementos lineares de concreto armado, sabe-se que se deve dimensionar a armadura de flexão de tal modo que a ruptura seja dúctil, portanto, devendo ocorrer por deformação excessiva da armadura longitudinal, já que é visível a grande fissuração que a prediz. A ruptura provocada por esforços de cisalhamento é complexa e o seu estudo não tem soluções totalmente fechadas, devendo-se portanto evitá-la em favor da segurança das estruturas correntes. Fica claro então, que o dimensionamento das armaduras transversais, com as devidas verificações contra os possíveis estados limites, deve ser feito após o cálculo das armaduras de flexão.

A diferença básica entre as tensões introduzidas em uma peça pela presença de momentos fletores e de esforços cortantes é a sua direção. Enquanto os momentos produzem tensão de tração e de compressão nas direções normais às seções transversais, os esforços cortantes produzem tensões tangenciais no plano da seção transversal. O momento fletor comprime a parte superior da peça e traciona a inferior ou vice-versa, dependendo de seu sentido. A força cortante, quando tratada isoladamente, se traduz em tensões de compressão e de tração diagonal em planos que formam ângulos de $45^{\circ}$ com o plano da seção transversal.

Procura-se aqui, discutir o problema da absorção das tensões de cisalhamento por uma seção transversal de uma peça de concreto armado, separando-se as parcelas absorvidas pelo concreto, que obedece a um critério previamente considerado e pela armadura transversal, colocada paralela à seção transversal.

Por fim, acoplou-se ao programa computacional um modelo aproximado para tentar representar de forma mais realista a tensões atuantes no aço e no concreto. 
Na elaboração do programa computacional, abandonou-se o princípio de que a parcela absorvida pelo concreto é fixa em função da sua resistência. Ao invés disso, calculou-se as tensões no concreto considerando-se o estado biaxial que obedeceu ao critério pré-estabelecido. Além disso parte da força cortante é resistida pela armadura vertical que terá tensões determinada a partir de deformações verticais fornecidas pelo modelo a ser proposto. A partir desse ponto, seria simples verificar se o estado de tensões no concreto está ou não compatível com os seus estados limites. A proposta é baseada no modelo de treliça que é a situação de ruptura da peça. Isto é, a parte da força cortante a ser levada aos estribos é estimada tomando-se como modelo mecânico a treliça clássica.

Faz-se, a seguir, uma breve revisão do modelo clássico de treliça, usualmente empregado nos cálculos e verificações de cisalhamento, para só então colocar a idéia do novo modelo proposto no trabalho.

\section{2 - ANALOGIA DE TRELIÇA}

\subsection{1 - Introdução}

Uma viga de concreto armado, quando submetida a esforços de flexão que a levem a estados próximos ao colapso, apresenta intensa fissuração, conforme a Figura 6.1

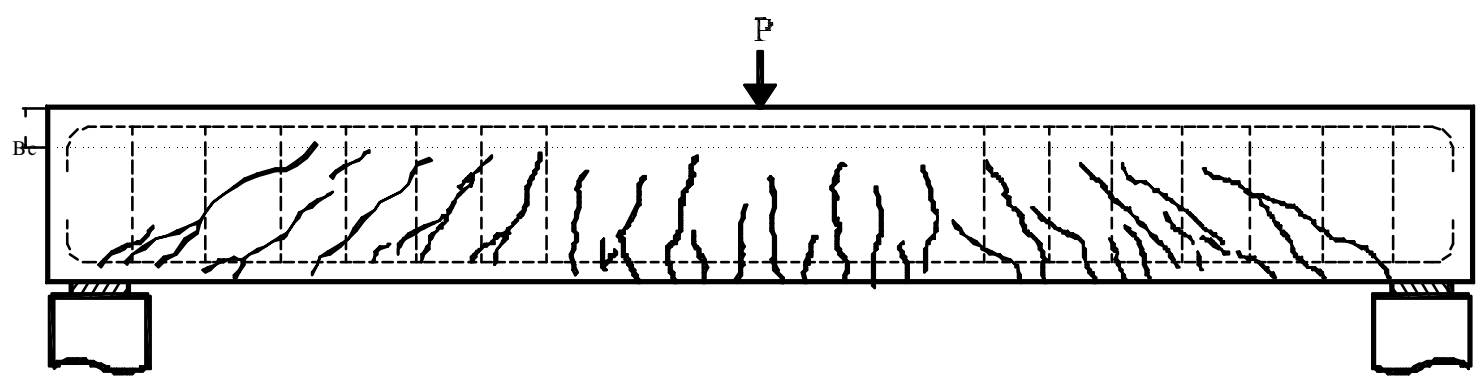

Figura 6.1 Viga fissurada de concreto armado

A viga acima, representando um estado genérico, foi retirada do trabalho de FUSCO(1981), que reproduz resultados de ensaios realizados por outros pesquisadores. A carga está em torno de $70 \%$ da de ruptura. Aumentando-se o 
carregamento, as fissuras começam a aparecer na parte comprimida da viga, indicada na figura pela sigla $\mathrm{Bc}$ - banzo comprimido.

Visualizando a viga fissurada, Mörsch formulou a hipótese de ser seu comportamento semelhante ao de uma treliça, onde o banzo superior e as diagonais seriam constituídos pelo concreto comprimido e o banzo inferior e os tirantes de ligação dos banzos pelo aço tracionado, da seguinte maneira:

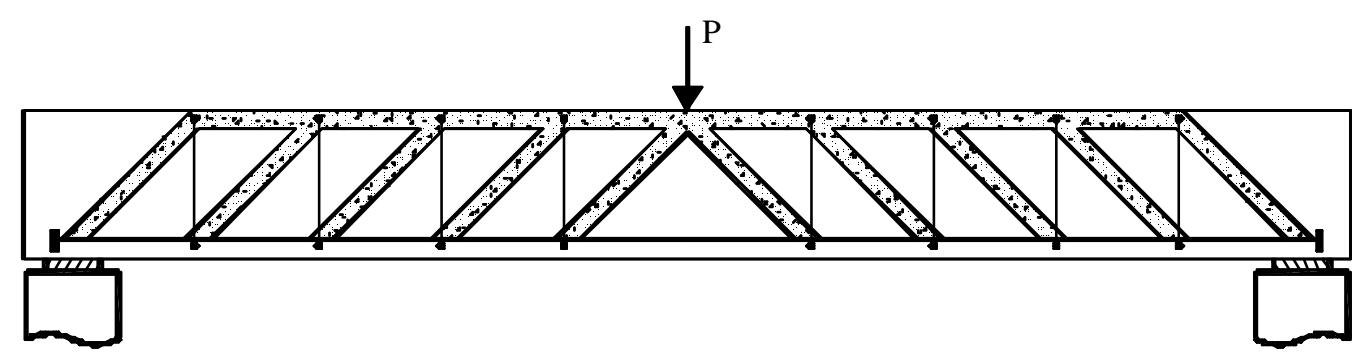

Figura 6.2 Treliça clássica de Mörsch

Para esta treliça, Mörsch idealizou o seguinte modelo:

- A treliça é isostática, e portanto os esforços internos são calculados apenas com as equações de equilíbrio nos nós, sem precisar de equações de compatibilidade de deformações. Considera-se que não existe engastamento nas ligação entre os banzos com as diagonais;

- Os banzos tracionado e comprimido são paralelos;

- As bielas de compressão estão inclinadas a $45^{\circ}$ em relação ao eixo da peça.

\subsection{2 - Determinação dos esforços na treliça}

Como já citado nas hipóteses, esta determinação segue apenas as equações de equilíbrio nos nós, pois a treliça é isostática. Um processo de determinação de esforços em treliças isostáticas é o método de Ritter, conforme citado em SÜSSEKIND(1991). Esse processo tem a particularização da solução quando se trata de treliça com altura constante, através do artifício da viga de substituição, conforme mostrado adiante. 
Mostra-se aqui uma treliça qualquer, onde todas as barras verticais e horizontais têm comprimento $\mathrm{L}=2 \mathrm{~m}$.

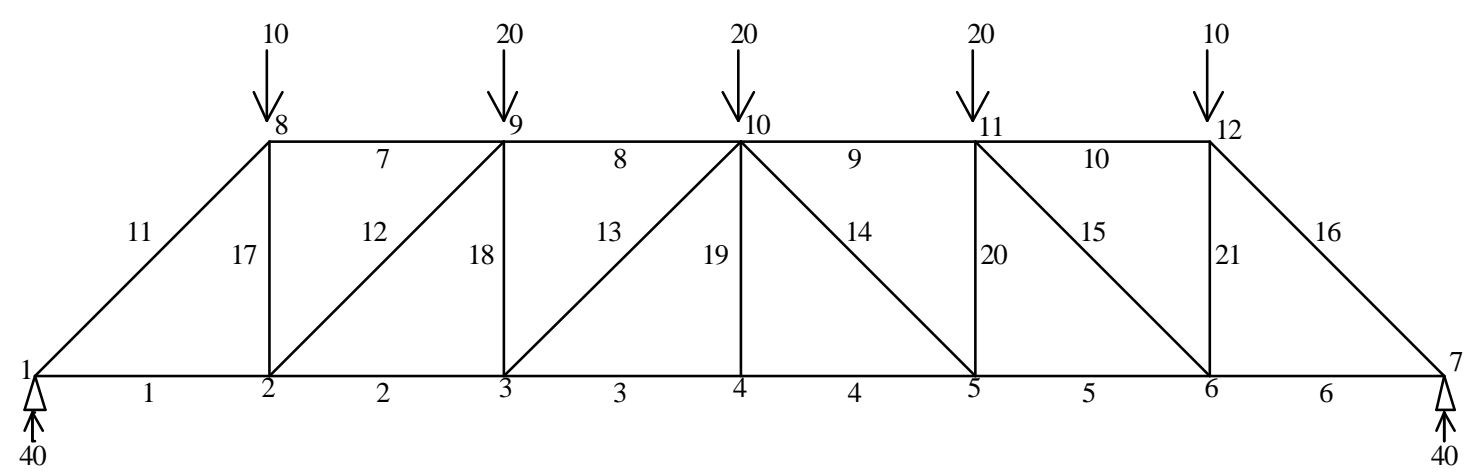

Figura 6.3 Treliça genérica carregada, de altura constante

Onde o diagrama de momentos da viga de substituição será:

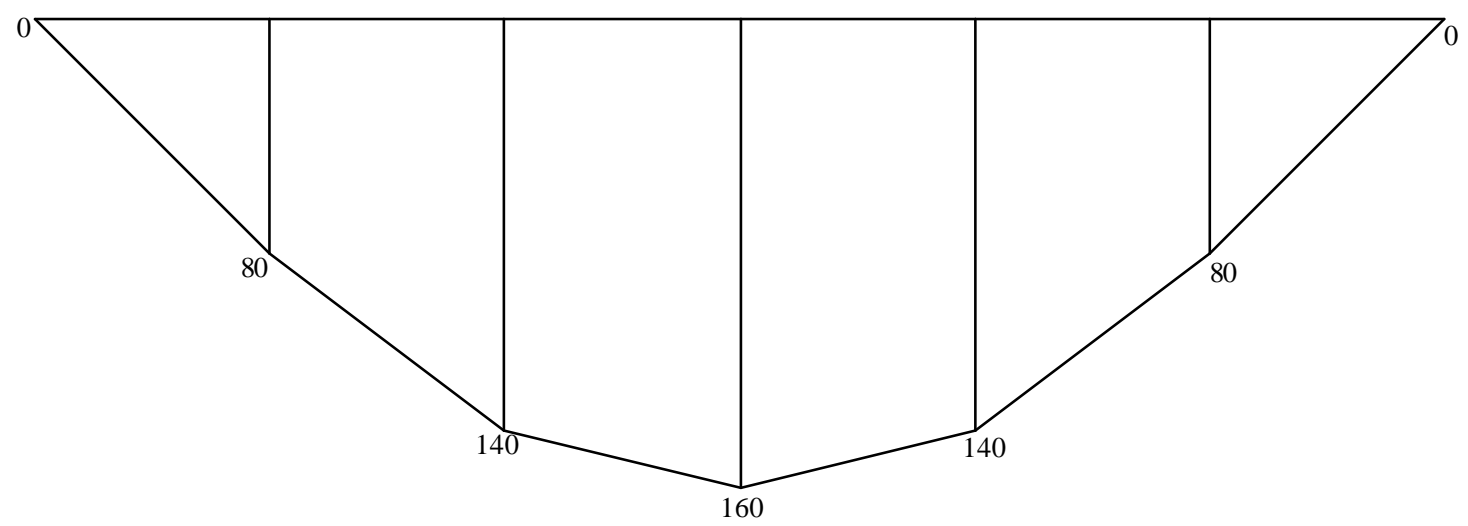

Figura 6.4 Diagrama de momentos da viga de substituição

Através deste processo, chega-se facilmente à conclusão de ser o esforço de tração nas barra do banzo inferior, em um seção genérica " $x$ ”, dado por:

$$
\mathrm{N}_{\mathrm{X}}=\frac{\mathrm{M}_{\mathrm{X}+\Delta \mathrm{X}}}{\mathrm{Z}}
$$

Extrapolando-se o resultado para a treliça clássica de Mörsch, vem:

$$
\mathrm{R}_{\mathrm{ST}, \mathrm{X}}=\frac{\mathrm{M}_{\mathrm{X}+\Delta \mathrm{X}}}{\mathrm{Z}}
$$

onde Rst,x é a resultante de tração na armadura do banzo inferior e $\mathrm{Z}$ é a altura da treliça. 
Analogamente, pode-se escrever para o banzo comprimido:

$\mathrm{R}_{\mathrm{CC}, \mathrm{X}+\Delta \mathrm{X}}=\frac{\mathrm{M}_{\mathrm{X}}}{\mathrm{Z}}$

Para efetuarem-se os cálculos dos esforços nos banzos, basta efetuar-se a translação a , no diagrama de momentos afetados do fator 1/Z. No banzo inferior, a translação deve se dar no sentido que aumenta Rst, procedendo-se de maneira contrária para o banzo inferior. A figura abaixo, indica os esforços no banzo tracionado (EBT), comprimido(EBC) e o diagrama de momentos divididos pela altura da treliça $(\mathrm{M} / \mathrm{z})$. É fácil verificar que o valor da translação a $\ell$ corresponde à altura da treliça, nesse caso.

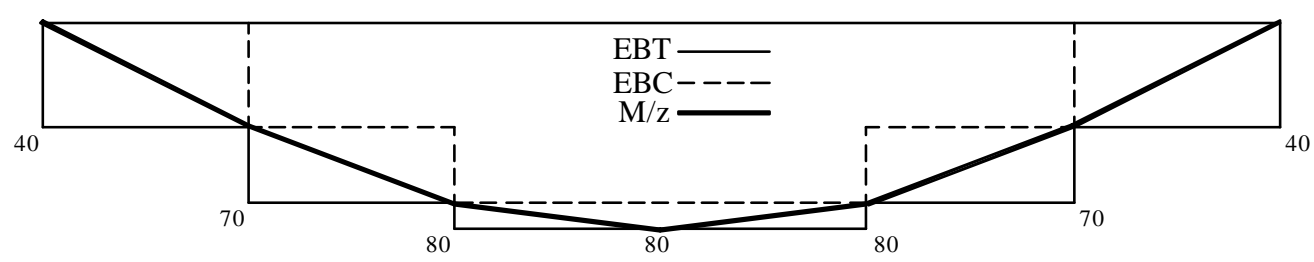

Figura 6.5 Esforços nos banzos da treliça

Os esforços nas diagonais vem do diagrama de esforços cortantes, e valem:

$\mathrm{R}_{\mathrm{C} 45}=-\mathrm{V}_{\mathrm{D}} \times \sqrt{2}$

E nos montantes tracionados, tem-se:

$\mathrm{R}_{\mathrm{TT}}=\mathrm{V}_{\mathrm{D}}$

\subsection{3 - Cálculo das tensões no aço e no concreto}

A área dos montantes tracionados vale:

$\mathrm{A}_{\mathrm{SM}}=\rho_{\mathrm{SW}} \times \mathrm{b}_{\mathrm{w}} \times \mathrm{Z}$

onde $\rho_{\mathrm{SW}}$ é a taxa de armadura transversal para a área $b_{\mathrm{W}} \mathrm{x} Z$.

E portanto, a tensão nos estribos vale:

$\sigma_{\mathrm{S}}=\frac{\mathrm{V}_{\mathrm{D}}}{\mathrm{A}_{\mathrm{SM}}}=\frac{\mathrm{V}_{\mathrm{D}}}{\rho_{\mathrm{SW}} \times \mathrm{b}_{\mathrm{W}} \times \mathrm{Z}}=\frac{\tau_{0}}{\rho_{\mathrm{SW}}}$

onde $\tau_{0}$ é chamada de tensão tangencial de referência, valendo: 
$\tau_{0}=\frac{\mathrm{V}_{\mathrm{D}}}{\mathrm{b}_{\mathrm{W}} \times \mathrm{d}}$

A área das bielas comprimidas vale:

$A_{B C}=\frac{b_{W}}{\operatorname{Cos} 45^{\circ}} \times \frac{Z}{2}=\frac{b_{w} \times Z}{\sqrt{2}}$

A tensão correspondente à biela comprimida vale:

$\sigma_{\mathrm{BC}}=\frac{\mathrm{R}_{\mathrm{C} 45}}{\mathrm{~A}_{\mathrm{BC}}}=-2 . \tau_{0}$

\section{3 - MODELO UTILIZADO}

Conforme os objetivos descritos durante o decorrer do trabalho, utilizouse a hipótese de Mörsch para a formulação de um modelo que representasse o mecanismo de absorção de esforços cortantes por uma seção transversal de concreto armado. Segundo as leis constitutivas estabelecidas para o concreto, conhece-se em um determinado ponto do algoritmo desenvolvido, o valor da parcela da força cortante devida à integral das tensões cisalhantes no concreto dada pela expressão abaixo:

$\mathrm{V}_{\mathrm{CON}}=\int_{\mathrm{A}} \tau \mathrm{dA}$

Em função do esforço cortante aplicado na seção, calcula-se a parcela que o concreto não absorve, e assume-se que esta será retida pela armadura, de maneira análoga àquela idealizada por Mörsch. A diferença aqui, é que a parcela absorvida pelo concreto não é mais uma função constante. Ela varia, nesta proposta, de acordo com a danificação do material. Admite-se então que as armaduras transversais só recebem esforços de tração a partir do momento em que ocorre a danificação de alguma das seções da peça. Estas armaduras foram tratadas de forma linear, por simplicidade, porém sem perder a generalidade da proposta:

$\mathrm{V}_{\mathrm{Apl}}=[\mathrm{K}]\{\mathrm{U}\}$

Determinando-se a parcela referente ao concreto pela eq.(6.12), define-se então a força que atua na área da armadura transversal:

$\mathrm{V}_{\mathrm{S}}=\mathrm{V}_{\mathrm{APL}}-\mathrm{V}_{\mathrm{CON}}$ 
A hipótese do modelo pode ser melhor ilustrada pela Figura 6.6, que representa o diagrama teórico de carga x deformação nos estribos. Fica claro então que o ponto onde estas armaduras passam a receber esforços é o ponto onde a seção está submetida à carga de danificação $\mathrm{P}_{\text {dano. }}$.

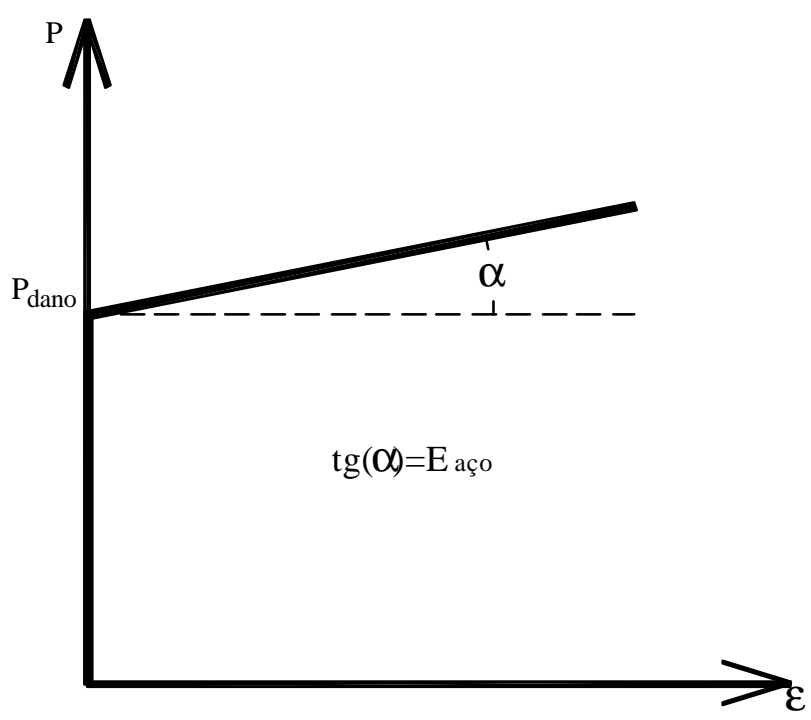

Figura 6.6 Diagrama teórico de carga x deformação nos estribos.

Já que os estribos foram tratados de forma linear, conclui-se que o modelo adotado não contempla resíduos em esforços cortantes. Também não foram computados no equilíbrio de esforços, os resíduos referentes à plastificação das barras das armaduras transversais. A absorção dos esforços será feita então, da seguinte maneira:

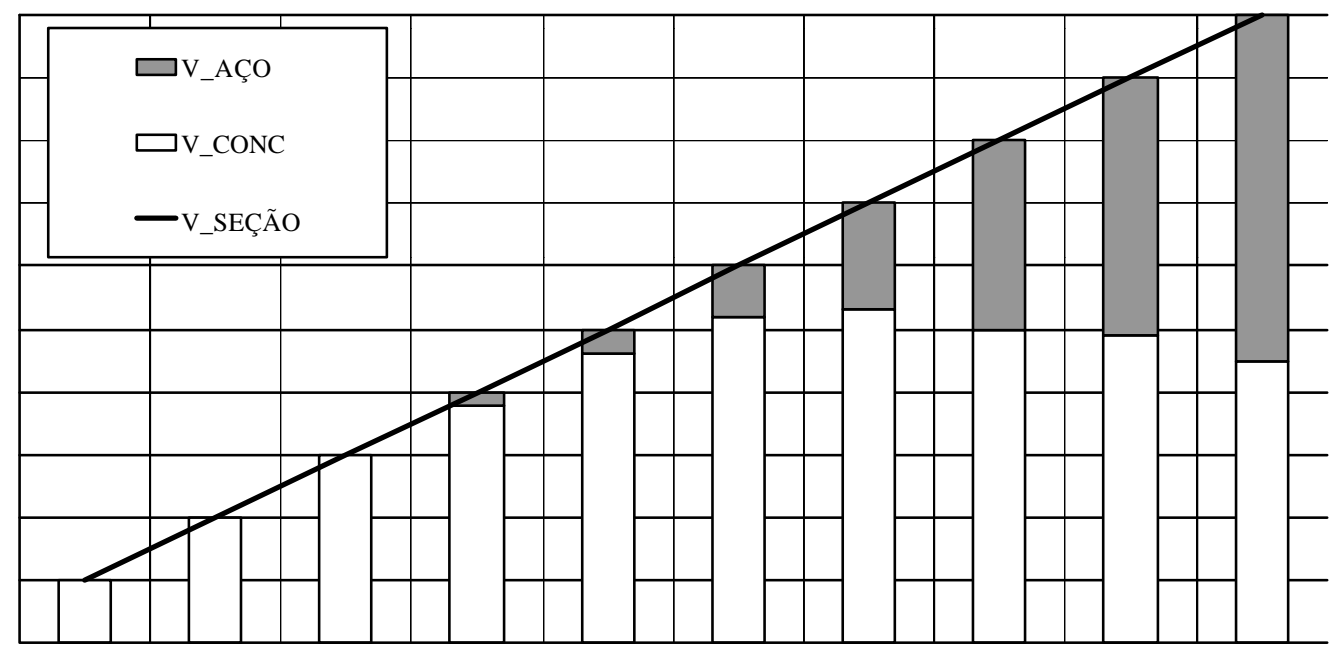

Figura 6.7 Esquema teórico de absorção dos esforços cortantes em uma seção. 
A integração dos esforços cortantes no concreto só é possível se forem consideradas no modelo os acréscimos de deslocamentos devidos às distorções das seções transversais. A figura 6.8 ilustra o estado deformado de um elemento. Os esforços cortantes internos serão provenientes dessa distorção $\gamma$.

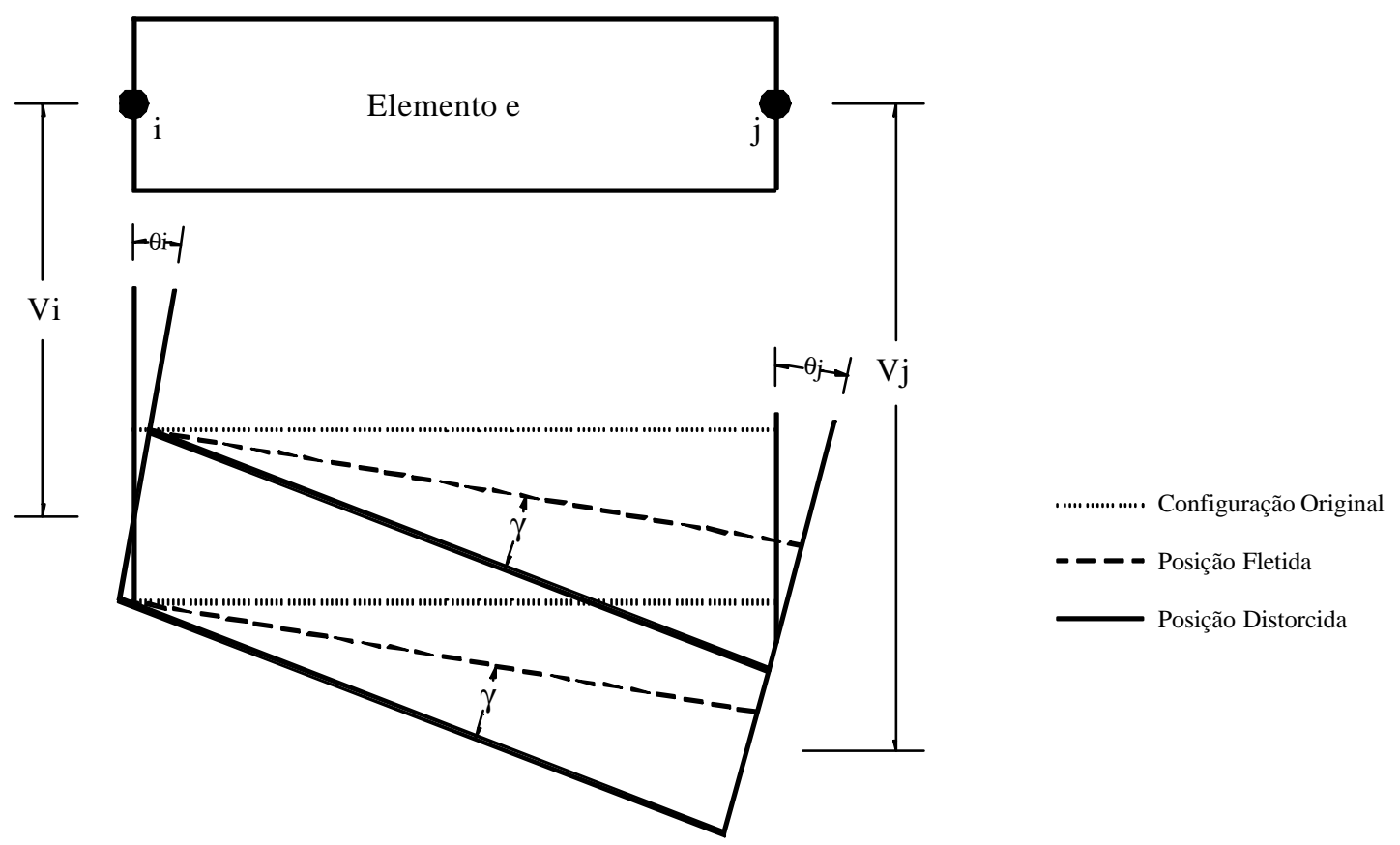

Figura 6.8 Configuração do elemento distorcido

As tensões cisalhantes em cada ponto ao longo da altura da seção serão função da variável escalar de dano "D", descrita anteriormente neste trabalho, da distorção " $\gamma$ " da seção transversal e do módulo de elasticidade transversal "G" do concreto. Daí é feita a sua integração, descrita na expressão (6.12), calculando-se a parcela absorvida pelo concreto. 


\section{EXEMPLOS}

\section{1 - COMENTÁRIOS GERAIS}

Apresentam-se, neste capítulo, alguns exemplos de análises numéricas de estruturas, com o uso de modelo de dano para a consideração da não-linearidade física do concreto, que teve a sua formulação descrita anteriormente, além do uso da teoria de vigas de Timoshenko.

Inicialmente, tomam-se os resultados obtidos por ÁLVARES(1993), juntamente com os parâmetros de dano por ele identificados, para um confronto com as respostas numéricas obtidas com o uso do programa computacional desenvolvido.

Faz-se em seguida, análise de uma viga curta isostática, onde a consideração do efeito das distorções se torna importante para uma boa precisão na determinação de deslocamentos e esforços.

Mais adiante, mostra-se o exemplo de uma viga curta hiperestática onde, a danificação leva à mudança de posição do diagrama de momentos fletores.

Em seguida, faz-se a análise de um consolo curto, com comprimento igual à altura. Embora em uma estrutura desse tipo não se possa mais considerar válido que as seções planas permaneçam planas após a deformação, o exemplo, torna-se interessante para se ter uma idéia do efeito da distorção sobre os deslocamentos obtidos.

Por último, faz-se uma comparação entre resultados obtidos experimentalmente e com o programa desenvolvido, para os valores de deformações da armadura transversal de uma viga de concreto armado, com o intuito de verificar o grau de aproximação do modelo. 


\section{2 - VIGA BIAPOIADA COM CARGAS CONCENTRADAS}

No exemplo a ser analisado toma-se uma viga simplesmente apoiada com duas cargas concentradas simetricamente dispostas em relação ao centro da peça. Os dados principais estão dados na Figura 7.1 e completados abaixo.

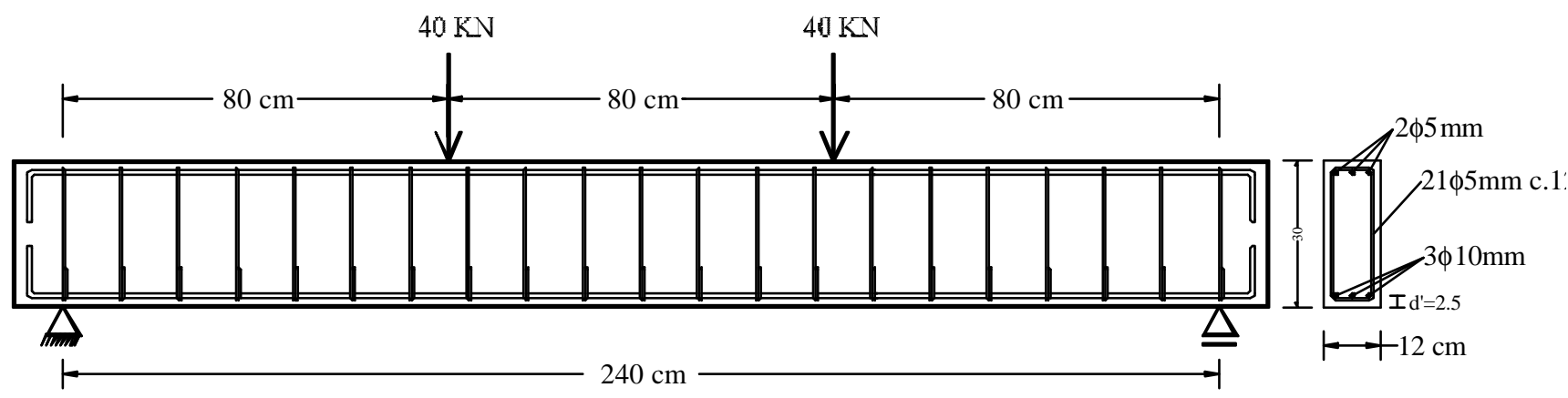

Figura 7.1Exemplo 1 - Viga biapoiada com cargas concentradas

Módulo de elasticidade longitudinal do concreto $-\mathrm{E}=2.920 \mathrm{KN} / \mathrm{cm}^{2}$

Coeficiente de Poisson $-v=0,20$

Erro percentual dos resíduos em esforços e norma dos deslocamentos $-0,01 \%$

Passos de carga - 20

Número máximo de iterações por passo - 200

Precisão da linha neutra $-0,001$

Tensão de escoamento do aço - $50 \mathrm{KN} / \mathrm{cm}^{2}$

Módulo de elasticidade do aço - $19.600 \mathrm{KN} / \mathrm{cm}^{2}$

Módulo plástico do aço $-1.960 \mathrm{KN} / \mathrm{cm}^{2}$

Parâmetros de dano:

$\varepsilon_{\mathrm{d} 0}=0,00007 \quad ; \mathrm{AT}=0,995 \quad ; \mathrm{BT}=8.000 \quad ; \mathrm{AC}=0,850 \quad ; \mathrm{BC}=1.620$ 
Na Tabela 7.1 são mostrados os resultados obtidos pelas análise na teoria de Bernouilli, com e sem o emprego do modelo de dano, teoria de Timoshenko, com e sem o emprego do modelo de dano, além dos resultados experimentais obtidos pelos ensaios de ÁLVARES(1993). Percebe-se que há uma boa aproximação para os deslocamentos nas duas análises não-lineares. O carregamento aplicado levou a viga à ruína.

\begin{tabular}{|c|c|c|c|c|c|c|}
\hline Resultados & & & oria Utilizada & & & \\
\hline Carga & Bernouilli Linear & \begin{tabular}{|l|} 
Timoshenko Linear \\
\end{tabular} & Bernouilli Não Linear & Timoshenko Não Linear & Carga Ensaio & Experimental \\
\hline 00 & 0,000000000 & 0,000000000 & 0,000000000 & 0,000000000 & 0 & 0 \\
\hline 02 & 0,011273278 & 0,011711635 & 0,011273278 & 0,011711635 & 2 & 0.011 \\
\hline 04 & 0,022546558 & 0,023423271 & 0,022546558 & 0,023423271 & 4 & 0,026 \\
\hline 06 & 0,033819838 & 0,035134906 & 0,033988289 & 0,035317540 & 6 & 0,036 \\
\hline 08 & 0,045093118 & 0.046846542 & 0.047545687 & 0.049504384 & 8 & 0.051 \\
\hline 10 & 0,056366397 & 0,058558178 & 0,066019434 & 0,069182321 & 10 & 0,08 \\
\hline 12 & 0,067639677 & 0,070269814 & 0,108343003 & 0,121837996 & 12 & 0,124 \\
\hline 14 & 0,078912957 & 0,081981450 & 0,209553778 & 0,227507562 & 14 & 0.172 \\
\hline 16 & 0,090186237 & 0.093693086 & 0.271192819 & 0.290926519 & 16 & 0.215 \\
\hline 18 & 0,101459517 & 0,105404722 & 0,327082379 & 0,346699174 & 18 & 0,272 \\
\hline 20 & 0,112732796 & 0,117116358 & 0,379975608 & 0,400063220 & 20 & 0,322 \\
\hline 22 & 0,124006076 & 0,128827994 & 0,431384710 & 0,451849856 & 22,5 & 0,375 \\
\hline 24 & 0,135279356 & 0,140539630 & 0,481382401 & 0,502802207 & 25 & 0,44 \\
\hline 26 & 0,146552636 & 0,152251266 & 0,531275501 & 0,552768607 & 27,5 & 0,505 \\
\hline 28 & 0,157825915 & 0,163962902 & 0.580419579 & 0,602060589 & 30 & 0.567 \\
\hline 30 & 0,169099195 & 0,175674538 & 0,629593706 & 0,651363788 & 32,5 & 0,634 \\
\hline 32 & 0,180372475 & 0,187386174 & 0,678293992 & 0,700880518 & 35 & 0,709 \\
\hline 34 & 0,191645755 & 0,199097809 & 0.727944320 & 0,749932790 & 40 & 1.058 \\
\hline 36 & 0,202919034 & 0,210809445 & 0,777493364 & 0,800065705 & - & - \\
\hline 38 & 0,214192314 & 0,222521081 & 0,991285192 & 1,016363791 & - & - \\
\hline 40 & 0,225465594 & 0.234232717 & 1.289001650 & 1.316491084 & - & - \\
\hline
\end{tabular}

Tabela 7.1 Exemplo 1 - Deslocamentos no centro da viga 
$\mathrm{Na}$ Figura 7.2 ilustra-se o diagrama carga $\mathrm{x}$ deslocamento do ponto central da viga, onde os resultados podem ser melhor acompanhados. Os esforços estão em $\mathrm{KN}$ no eixo das ordenadas, e os deslocamentos estão em centímetros no eixo das abcissas.

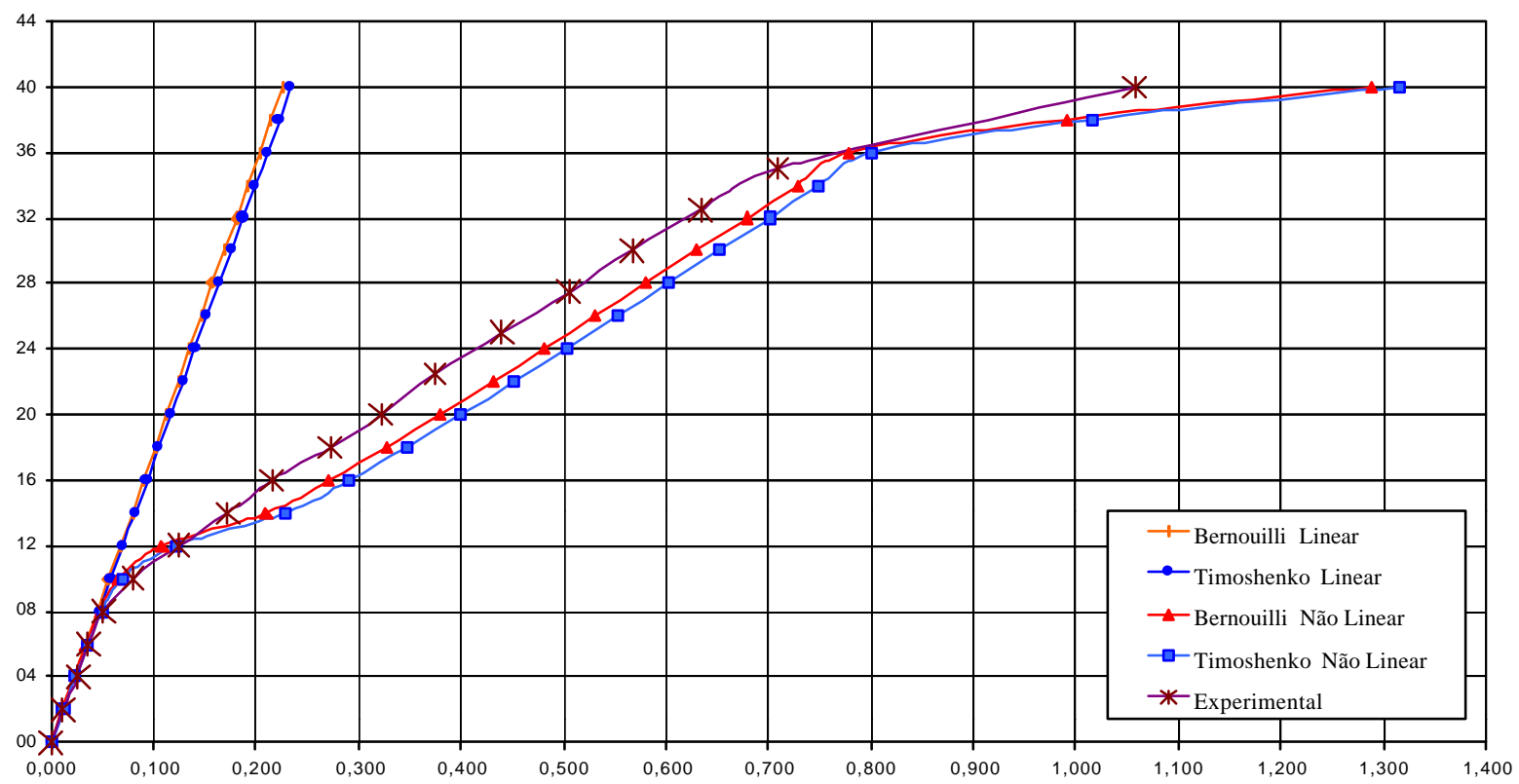

Figura 7.2 - Exemplo 1 - Diagrama carga-deslocamento do ponto central da viga

Verifica-se de fato, que os modelos não lineares tem boa aproximação. Se forem parametrizados corretamente, poderão conduzir a margens de erro muito pequenas. 
Na Figura 7.3, mostra-se a variação da rigidez de um elemento situado na zona de maior danificação da viga com a evolução do carregamento atuante. Nota-se a perda de rigidez a partir do passo de carga 03, devida à danificação do concreto, e em seguida, no passo 19 outro pico devido à plastificação da armadura longitudinal.

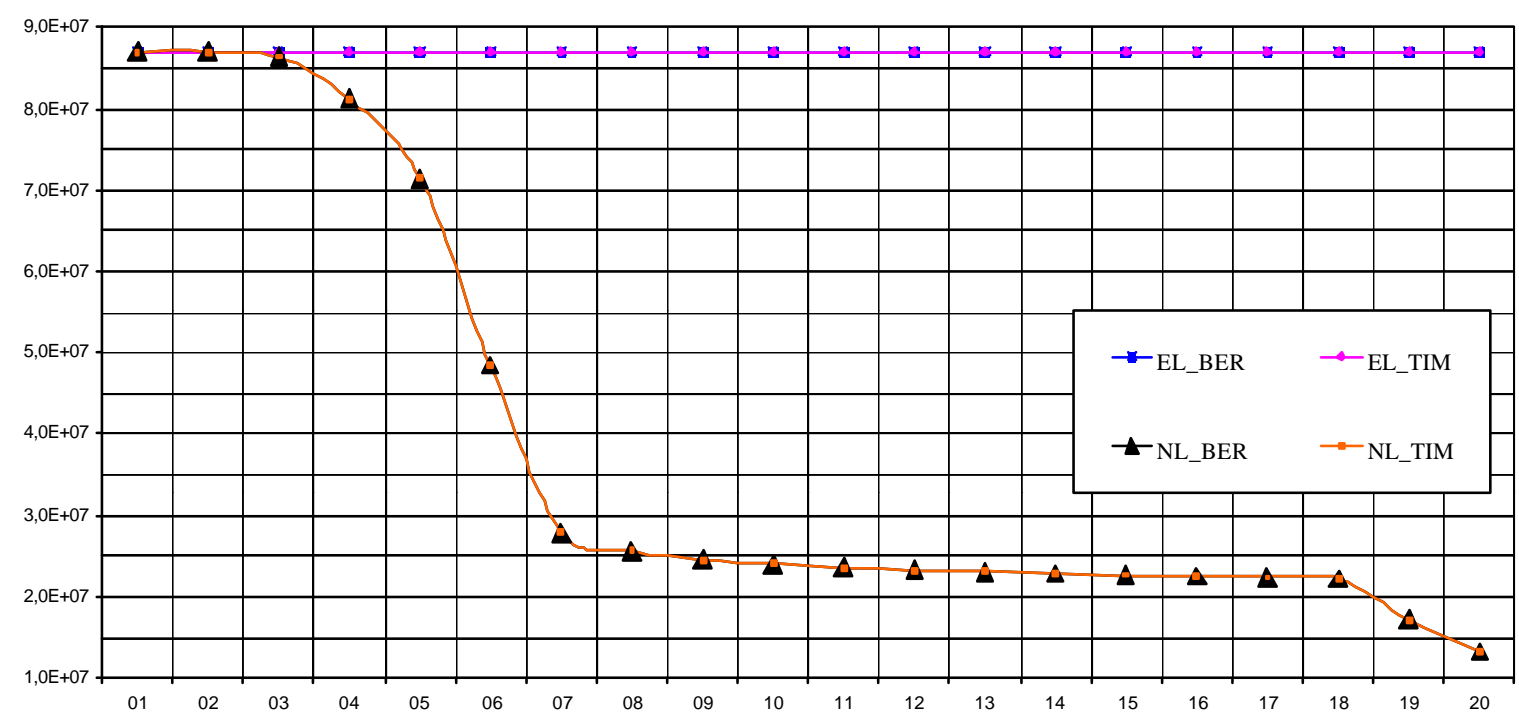

Figura 7.3 - Exemplo 1 - Rigidez de um elemento na região de momento máximo 
Na Figura 7.4, mostra-se o diagrama momento curvatura da seção transversal situada no centro do vão da viga. De maneira análoga ao exemplo anterior mostra-se a plastificação do concreto no passo 03 e a plastificação do aço no passo 19.

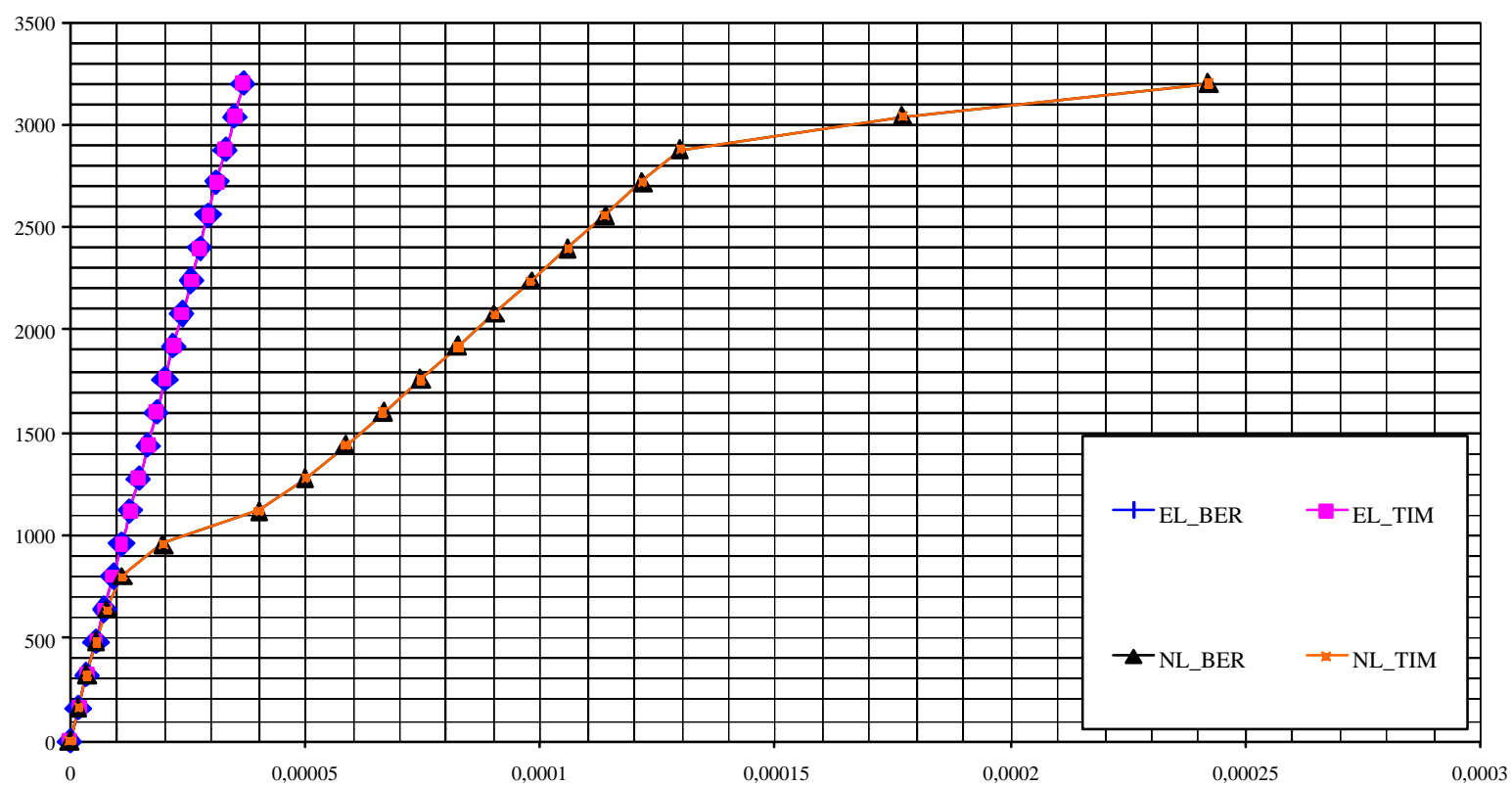

Figura 7.4 - Exemplo 1 - Diagrama momento x curvatura da seção central

Na Tabela 7.2, são mostrados os resultados referentes à variação da rigidez dos elementos ao longo do comprimento da viga. 


\begin{tabular}{|c|c|c|c|c|c|}
\hline BARRA & Estádio I & EL BER & EL TIM & NL BER & NL TIM \\
\hline 01 & $8,70 \mathrm{E}+07$ & $8,70 \mathrm{E}+07$ & $8,70 \mathrm{E}+07$ & $8,70 \mathrm{E}+07$ & $8,68 \mathrm{E}+07$ \\
\hline 02 & $8,70 \mathrm{E}+07$ & $8,70 \mathrm{E}+07$ & $8,70 \mathrm{E}+07$ & $8,70 \mathrm{E}+07$ & $8,24 \mathrm{E}+07$ \\
\hline 03 & $8,70 \mathrm{E}+07$ & $8,70 \mathrm{E}+07$ & $8,70 \mathrm{E}+07$ & $8,49 \mathrm{E}+07$ & $6,94 \mathrm{E}+07$ \\
\hline 04 & $8,70 \mathrm{E}+07$ & $8,70 \mathrm{E}+07$ & $8,70 \mathrm{E}+07$ & $7,71 \mathrm{E}+07$ & $3,26 \mathrm{E}+07$ \\
\hline 05 & $8,70 \mathrm{E}+07$ & $8,70 \mathrm{E}+07$ & $8,70 \mathrm{E}+07$ & $5,43 \mathrm{E}+07$ & $2,72 \mathrm{E}+07$ \\
\hline 06 & $8,70 \mathrm{E}+07$ & $8,70 \mathrm{E}+07$ & $8,70 \mathrm{E}+07$ & $3,18 \mathrm{E}+07$ & $2,52 \mathrm{E}+07$ \\
\hline 07 & $8,70 \mathrm{E}+07$ & $8,70 \mathrm{E}+07$ & $8,70 \mathrm{E}+07$ & $2,56 \mathrm{E}+07$ & $2,43 \mathrm{E}+07$ \\
\hline 08 & $8,70 \mathrm{E}+07$ & $8,70 \mathrm{E}+07$ & $8,70 \mathrm{E}+07$ & $2,44 \mathrm{E}+07$ & $2,38 \mathrm{E}+07$ \\
\hline 09 & $8,70 \mathrm{E}+07$ & $8,70 \mathrm{E}+07$ & $8,70 \mathrm{E}+07$ & $2,38 \mathrm{E}+07$ & $2,35 \mathrm{E}+07$ \\
\hline 10 & $8,70 \mathrm{E}+07$ & $8,70 \mathrm{E}+07$ & $8,70 \mathrm{E}+07$ & $2,33 \mathrm{E}+07$ & $2,33 \mathrm{E}+07$ \\
\hline 11 & $8,70 \mathrm{E}+07$ & $8,70 \mathrm{E}+07$ & $8,70 \mathrm{E}+07$ & $2,30 \mathrm{E}+07$ & $2,31 \mathrm{E}+07$ \\
\hline 12 & $8,70 \mathrm{E}+07$ & $8,70 \mathrm{E}+07$ & $8,70 \mathrm{E}+07$ & $2,28 \mathrm{E}+07$ & $2,29 \mathrm{E}+07$ \\
\hline 13 & $8,70 \mathrm{E}+07$ & $8,70 \mathrm{E}+07$ & $8,70 \mathrm{E}+07$ & $2,26 \mathrm{E}+07$ & $2,27 \mathrm{E}+07$ \\
\hline 14 & $8,70 \mathrm{E}+07$ & $8,70 \mathrm{E}+07$ & $8,70 \mathrm{E}+07$ & $2,24 \mathrm{E}+07$ & $2,26 \mathrm{E}+07$ \\
\hline 15 & $8,70 \mathrm{E}+07$ & $8,70 \mathrm{E}+07$ & $8,70 \mathrm{E}+07$ & $2,06 \mathrm{E}+07$ & $2,07 \mathrm{E}+07$ \\
\hline 16 & $8,70 \mathrm{E}+07$ & $8,70 \mathrm{E}+07$ & $8,70 \mathrm{E}+07$ & $1,61 \mathrm{E}+07$ & $1,61 \mathrm{E}+07$ \\
\hline 17 & $8,70 \mathrm{E}+07$ & $8,70 \mathrm{E}+07$ & $8,70 \mathrm{E}+07$ & $1,32 \mathrm{E}+07$ & $1,32 \mathrm{E}+07$ \\
\hline 18 & $8,70 \mathrm{E}+07$ & $8,70 \mathrm{E}+07$ & $8,70 \mathrm{E}+07$ & $1,32 \mathrm{E}+07$ & $1,32 \mathrm{E}+07$ \\
\hline 19 & $8,70 \mathrm{E}+07$ & $8,70 \mathrm{E}+07$ & $8,70 \mathrm{E}+07$ & $1,32 \mathrm{E}+07$ & $1,32 \mathrm{E}+07$ \\
\hline 20 & $8,70 \mathrm{E}+07$ & $8,70 \mathrm{E}+07$ & $8,70 \mathrm{E}+07$ & $1,32 \mathrm{E}+07$ & $1,32 \mathrm{E}+07$ \\
\hline 21 & $8,70 \mathrm{E}+07$ & $8,70 \mathrm{E}+07$ & $8,70 \mathrm{E}+07$ & $1,32 \mathrm{E}+07$ & $1,32 \mathrm{E}+07$ \\
\hline 22 & $8,70 \mathrm{E}+07$ & $8,70 \mathrm{E}+07$ & $8,70 \mathrm{E}+07$ & $1,32 \mathrm{E}+07$ & $1,32 \mathrm{E}+07$ \\
\hline 23 & $8,70 \mathrm{E}+07$ & $8,70 \mathrm{E}+07$ & $8,70 \mathrm{E}+07$ & $1,32 \mathrm{E}+07$ & $1,32 \mathrm{E}+07$ \\
\hline 24 & $8,70 \mathrm{E}+07$ & $8,70 \mathrm{E}+07$ & $8,70 \mathrm{E}+07$ & $1,32 \mathrm{E}+07$ & $1,32 \mathrm{E}+07$ \\
\hline 25 & $8,70 \mathrm{E}+07$ & $8,70 \mathrm{E}+07$ & $8,70 \mathrm{E}+07$ & $1,32 \mathrm{E}+07$ & $1,32 \mathrm{E}+07$ \\
\hline 26 & $8,70 \mathrm{E}+07$ & $8,70 \mathrm{E}+07$ & $8,70 \mathrm{E}+07$ & $1,32 \mathrm{E}+07$ & $1,32 \mathrm{E}+07$ \\
\hline 27 & $8,70 \mathrm{E}+07$ & $8,70 \mathrm{E}+07$ & $8,70 \mathrm{E}+07$ & $1,32 \mathrm{E}+07$ & $1,32 \mathrm{E}+07$ \\
\hline 28 & $8,70 \mathrm{E}+07$ & $8,70 \mathrm{E}+07$ & $8,70 \mathrm{E}+07$ & $1,32 \mathrm{E}+07$ & $1,32 \mathrm{E}+07$ \\
\hline 29 & $8,70 \mathrm{E}+07$ & $8,70 \mathrm{E}+07$ & $8,70 \mathrm{E}+07$ & $1,32 \mathrm{E}+07$ & $1,32 \mathrm{E}+07$ \\
\hline 30 & $8,70 \mathrm{E}+07$ & $8,70 \mathrm{E}+07$ & $8,70 \mathrm{E}+07$ & $1,32 \mathrm{E}+07$ & $1,32 \mathrm{E}+07$ \\
\hline 31 & $8,70 \mathrm{E}+07$ & $8,70 \mathrm{E}+07$ & $8,70 \mathrm{E}+07$ & $1,32 \mathrm{E}+07$ & $1,32 \mathrm{E}+07$ \\
\hline 32 & $8,70 \mathrm{E}+07$ & $8,70 \mathrm{E}+07$ & $8,70 \mathrm{E}+07$ & $1,32 \mathrm{E}+07$ & $1,32 \mathrm{E}+07$ \\
\hline 33 & $8,70 \mathrm{E}+07$ & $8,70 \mathrm{E}+07$ & $8,70 \mathrm{E}+07$ & $1,61 \mathrm{E}+07$ & $1,61 \mathrm{E}+07$ \\
\hline 34 & $8,70 \mathrm{E}+07$ & $8,70 \mathrm{E}+07$ & $8,70 \mathrm{E}+07$ & $2,06 \mathrm{E}+07$ & $2,07 \mathrm{E}+07$ \\
\hline 35 & $8,70 \mathrm{E}+07$ & $8,70 \mathrm{E}+07$ & $8,70 \mathrm{E}+07$ & $2,24 \mathrm{E}+07$ & $2,26 \mathrm{E}+07$ \\
\hline 36 & $8,70 \mathrm{E}+07$ & $8,70 \mathrm{E}+07$ & $8,70 \mathrm{E}+07$ & $2,26 \mathrm{E}+07$ & $2,27 \mathrm{E}+07$ \\
\hline 37 & $8,70 \mathrm{E}+07$ & $8,70 \mathrm{E}+07$ & $8,70 \mathrm{E}+07$ & $2,28 \mathrm{E}+07$ & $2,29 \mathrm{E}+07$ \\
\hline 38 & $8,70 \mathrm{E}+07$ & $8,70 \mathrm{E}+07$ & $8,70 \mathrm{E}+07$ & $2,30 \mathrm{E}+07$ & $2,31 \mathrm{E}+07$ \\
\hline 39 & $8,70 \mathrm{E}+07$ & $8,70 \mathrm{E}+07$ & $8,70 \mathrm{E}+07$ & $2,33 \mathrm{E}+07$ & $2,33 \mathrm{E}+07$ \\
\hline 40 & $8,70 \mathrm{E}+07$ & $8,70 \mathrm{E}+07$ & $8,70 \mathrm{E}+07$ & $2,38 \mathrm{E}+07$ & $2,35 E+07$ \\
\hline 41 & $8,70 \mathrm{E}+07$ & $8,70 \mathrm{E}+07$ & $8,70 \mathrm{E}+07$ & $2,44 \mathrm{E}+07$ & $2,38 \mathrm{E}+07$ \\
\hline 42 & $8,70 \mathrm{E}+07$ & $8,70 \mathrm{E}+07$ & $8,70 \mathrm{E}+07$ & $2,56 \mathrm{E}+07$ & $2,43 E+07$ \\
\hline 43 & $8,70 \mathrm{E}+07$ & $8,70 \mathrm{E}+07$ & $8,70 \mathrm{E}+07$ & $3,18 \mathrm{E}+07$ & $2,52 \mathrm{E}+07$ \\
\hline 44 & $8,70 \mathrm{E}+07$ & $8,70 \mathrm{E}+07$ & $8,70 \mathrm{E}+07$ & $5,43 \mathrm{E}+07$ & $2,72 \mathrm{E}+07$ \\
\hline 45 & $8,70 \mathrm{E}+07$ & $8,70 \mathrm{E}+07$ & $8,70 \mathrm{E}+07$ & $7,71 \mathrm{E}+07$ & $3,26 \mathrm{E}+07$ \\
\hline 46 & $8,70 \mathrm{E}+07$ & $8,70 \mathrm{E}+07$ & $8,70 \mathrm{E}+07$ & $8,49 \mathrm{E}+07$ & $6,94 \mathrm{E}+07$ \\
\hline 47 & $8,70 \mathrm{E}+07$ & $8,70 \mathrm{E}+07$ & $8,70 \mathrm{E}+07$ & $8,70 \mathrm{E}+07$ & $8,24 \mathrm{E}+07$ \\
\hline 48 & $8,70 \mathrm{E}+07$ & $8,70 \mathrm{E}+07$ & $8,70 \mathrm{E}+07$ & $8,70 \mathrm{E}+07$ & $8,68 \mathrm{E}+07$ \\
\hline
\end{tabular}

Tabela 7.2 Exemplo 1 - Variação da rigidez nas barras 
Na Figura 7.5 são plotados os resultados da Tabela 7.2. É interessante perceber que a curva em vermelho representa os estados de deformação que incluem a distorção. Nota-se claramente que a perda de rigidez é maior nas regiões aonde existe força cortante. No terço central da viga, a força cortante vale zero devido à disposição do carregamento aplicado, e as rigidezes são iguais.

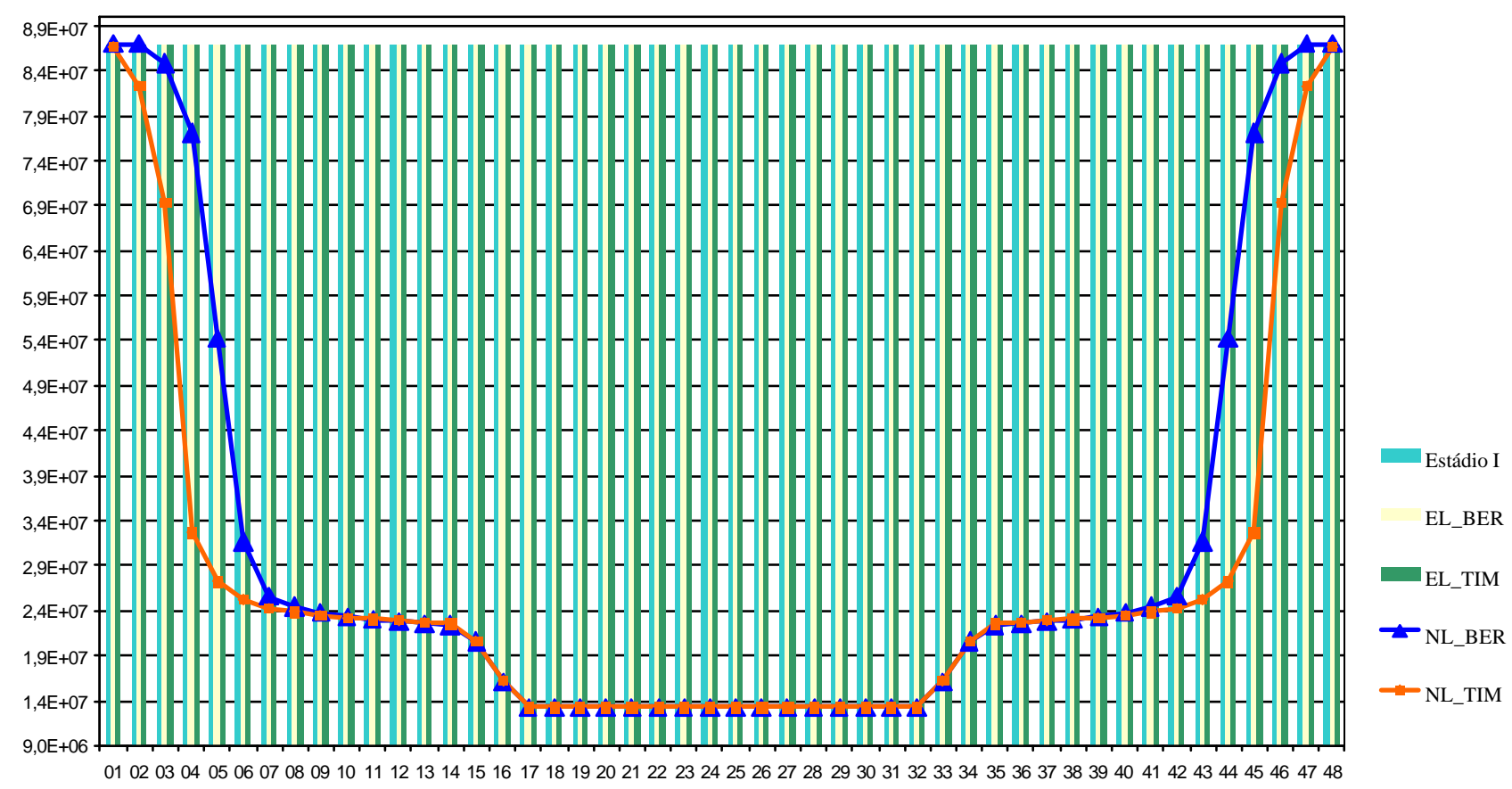

Figura 7.5 - Exemplo 1 -Variação da rigidez nas barras

De modo geral, o que se pode concluir deste exemplo é que devido ser esta uma viga longa, com relação h/l igual a 0,125, não há influência significativa que justifique a análise considerando-se a deformabilidade da seção ao esforço cortante. Isto pôde ser observado nos resultados de deslocamentos e esforços.

Entretanto, mesmo neste caso o procedimento é justificável, pois não acarreta nenhum prejuízo computacional e garante a consideração de estados múltiplos de tensão que poderiam ter alguma influência. 


\section{3 - VIGA CURTA ISOSTÁTICA}

Este é um exemplo onde se espera uma influência significativa da força cortante. Poderá ser claramente vista a influência da perda de rigidez devido as tensões cisalhantes. Os dados para este exemplo estão na Figura 7.6 e complementados abaixo.
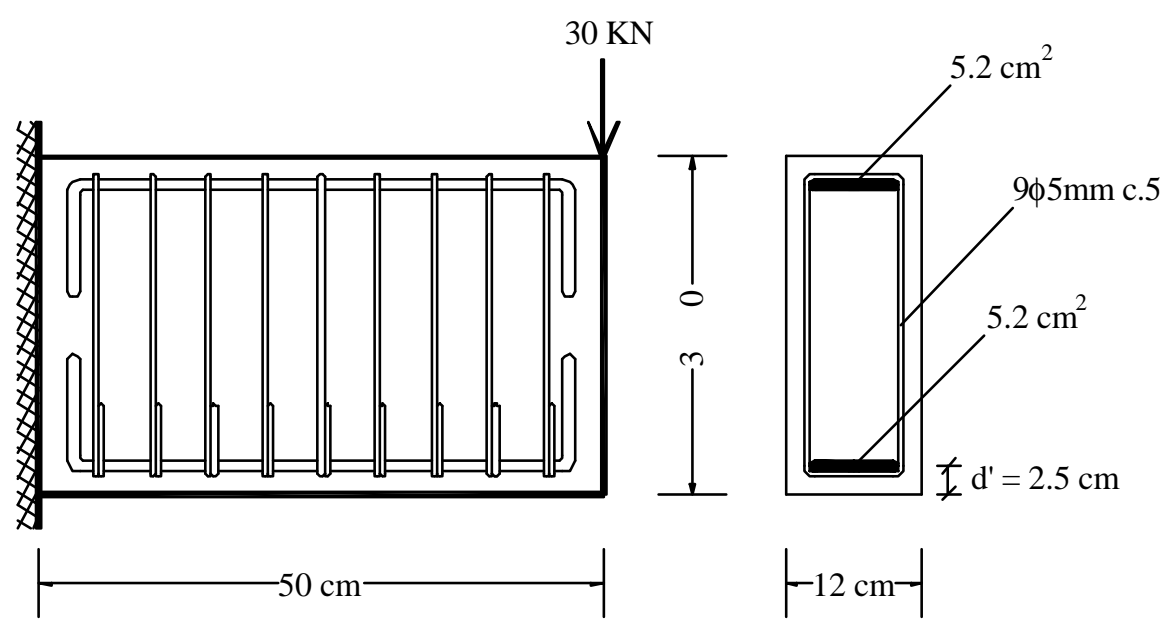

Figura 7.6 - Exemplo 2 -Viga curta isostática

Módulo de elasticidade longitudinal do concreto $-\mathrm{E}=2.500 \mathrm{KN} / \mathrm{cm}^{2}$

Coeficiente de Poisson $-v=0,25$

Erro percentual dos resíduos em esforços e norma dos deslocamentos $-0,001 \%$

Passos de carga - 5

Número máximo de iterações por passo - 200

Precisão da linha neutra $-0,0001$

Tensão de escoamento do aço - $50 \mathrm{KN} / \mathrm{cm}^{2}$

Módulo de elasticidade do aço $-20.000 \mathrm{KN} / \mathrm{cm}^{2}$

Módulo plástico do aço $-2.000 \mathrm{KN} / \mathrm{cm}^{2}$

Parâmetros de dano:

$\varepsilon_{\mathrm{d} 0}=0,00007 \quad ; \mathrm{AT}=0,995 \quad ; \mathrm{BT}=8.000 \quad ; \mathrm{AC}=0,850 \quad ; \mathrm{BC}=1.620$ 
Os resultados obtidos para os deslocamentos no ponto extremo do balanço estão dados na Tabela 7.3. A análise é feita a partir das hipóteses de Bernouilli e de Timoshenko, considerando-se os casos linear e não-linear(dano).

\begin{tabular}{|c|c|c|c|c|}
\hline Resultados & \multicolumn{4}{|c|}{ Teoria Utilizada } \\
\hline Passo & Bernouilli Linear & Timoshenko Linear & Bernouilli Não Linear & Timoshenko Não Linear \\
\hline 01 & 0,002500000 & 0,003500000 & 0,002500000 & 0,003500000 \\
\hline 02 & 0,005000000 & 0,007000000 & 0,005024845 & 0,007109631 \\
\hline 03 & 0,007500000 & 0,010500000 & 0,007967797 & 0,011886659 \\
\hline 04 & 0,010000000 & 0,014000000 & 0,011902689 & 0,019088425 \\
\hline 05 & 0,012500000 & 0,017500000 & 0,017315500 & 0,027853448 \\
\hline
\end{tabular}

Tabela 7.3 Exemplo 2 - Deslocamento da extremidade do balanço (cm)

Na Figura 7.7 mostram-se os deslocamentos obtidos, cujos valores estão indicados na Tabela 7.3. Fica fácil perceber, a grande influência do efeito da distorção, considerando-se a hipótese de Timoshenko, já na fase elástica linear, ficando clara a diferença entre as curvas azul e vermelha.

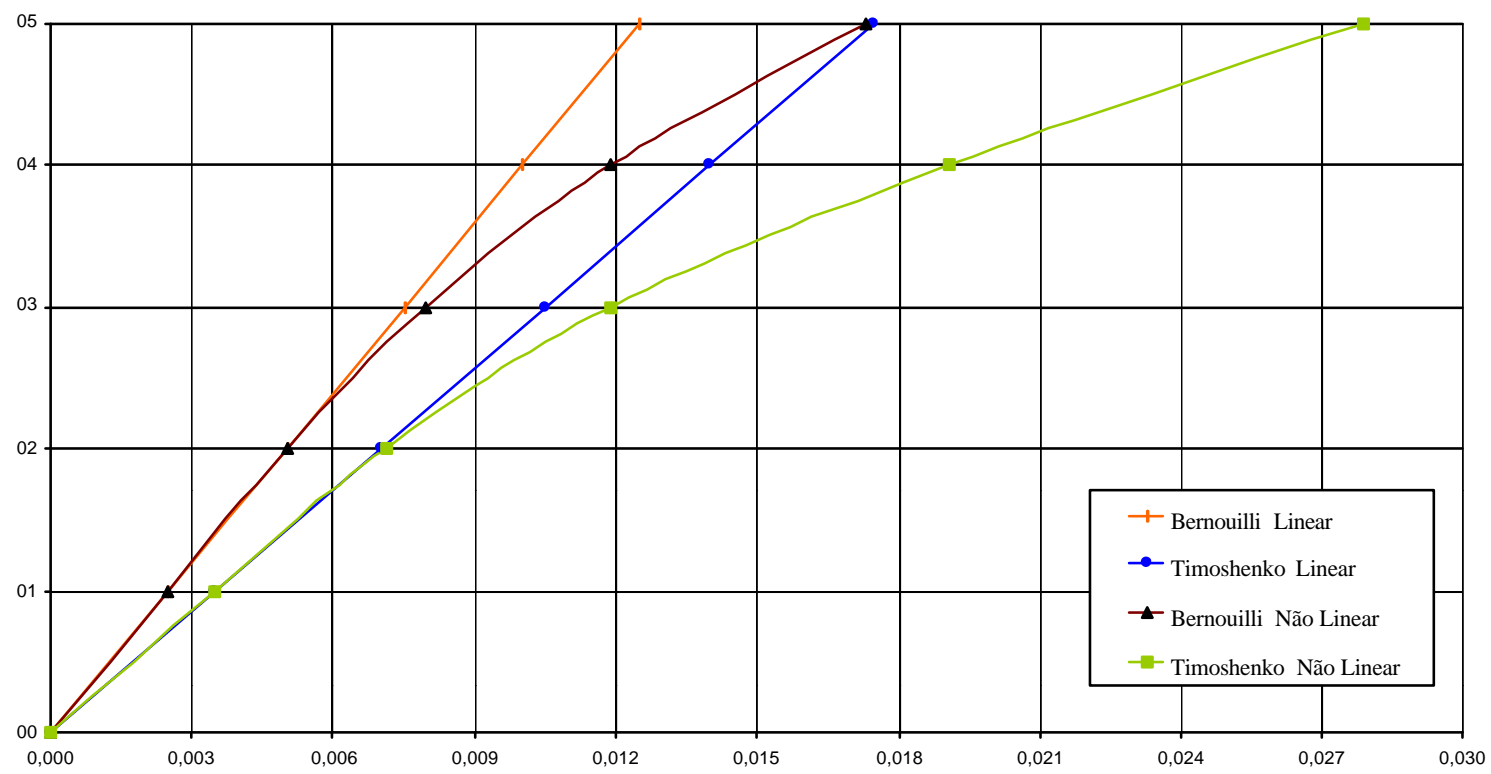

Figura 7.7 - Exemplo 2 -Deslocamento da extremidade do balanço 
$\mathrm{Na}$ Tabela 7.4 mostram-se os valores das rotações no ponto da extremidade do balanço, utilizando-se também as hipóteses de Bernouilli e Timoshenko, com e sem danificação.

\begin{tabular}{|c|c|c|c|c|}
\hline Resultados & \multicolumn{4}{|c|}{ Teoria Utilizada } \\
\hline Passo & Bernouilli Linear & Timoshenko Linear & Bernouilli Não Linear & Timoshenko Não Linear \\
\hline 01 & 0,000075000 & 0,000075000 & 0,000075000 & 0,000075000 \\
\hline 02 & 0,000150000 & 0,000150000 & 0,000150534 & 0,000151115 \\
\hline 03 & 0,000225000 & 0,000225000 & 0,000235708 & 0,000244788 \\
\hline 04 & 0,000300000 & 0,000300000 & 0,000344666 & 0,000383417 \\
\hline 05 & 0,000375000 & 0,000375000 & 0,000490051 & 0,000562617 \\
\hline
\end{tabular}

Tabela 7.4 Exemplo 2 - Rotação da extremidade do balanço (cm)

Na Figura 7.8 plotam-se os valores da Tabela 7.4. Percebe-se que não há diferença entre os resultados obtidos para as rotações na fase elástica. Isto ocorre em função da escolha dos graus de liberdade do problema, conforme explicado anteriormente neste trabalho. Já no caso não-linear, há acréscimo de rotação de uma em relação a outra em decorrência da redistribuição dos esforços internos absorvidos por cada elemento.

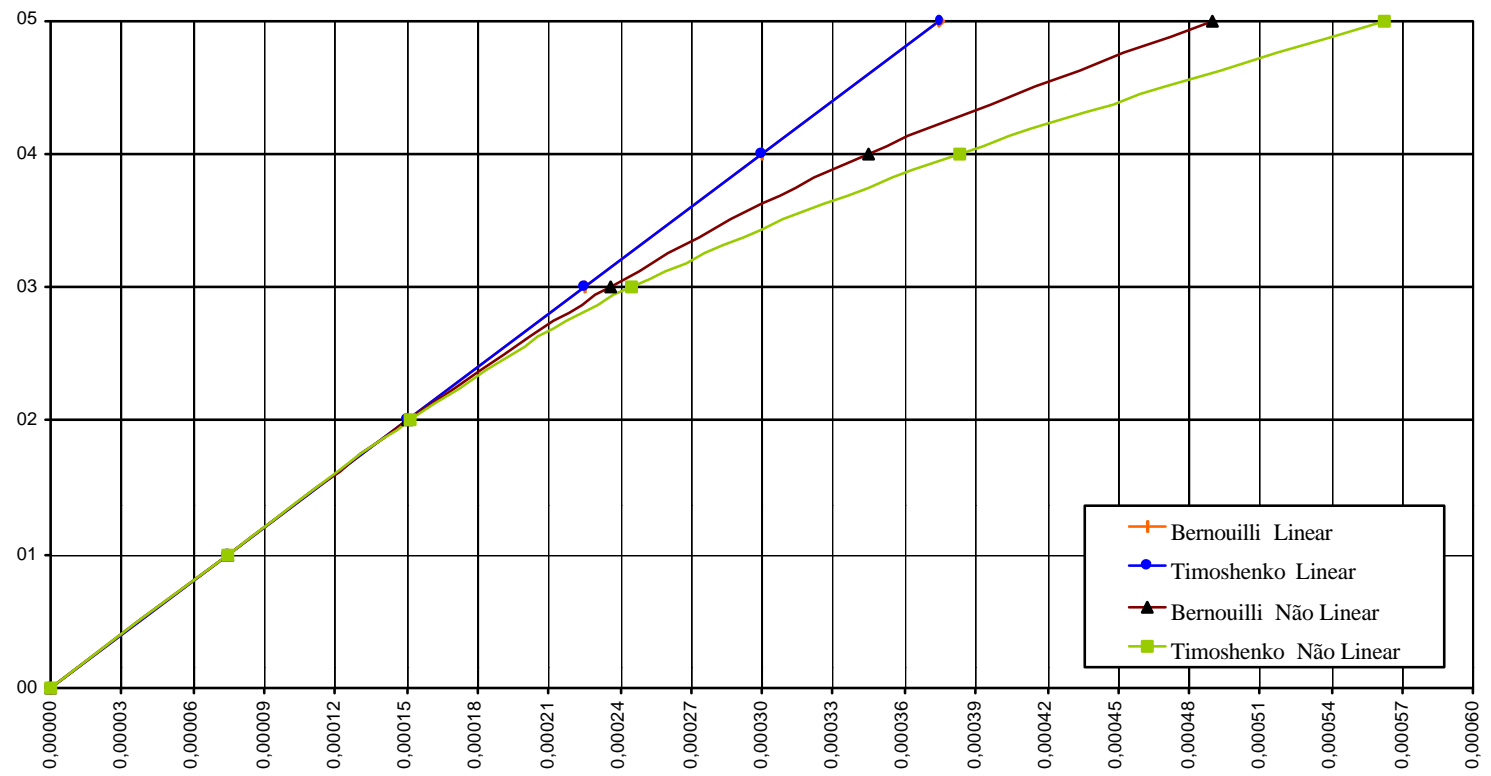

Figura 7.8 - Exemplo 2 - Rotação da extremidade do balanço 
Na Figura 7.9 mostra-se o diagrama momento x curvatura da seção transversal submetida ao momento máximo da viga, que é a seção do engaste. Nota-se na análise elástica, que a distorção não influencia no cálculo da curvatura, já que, conforme foi dito, é considerada independente dos graus de liberdade, e calculada em função deles.

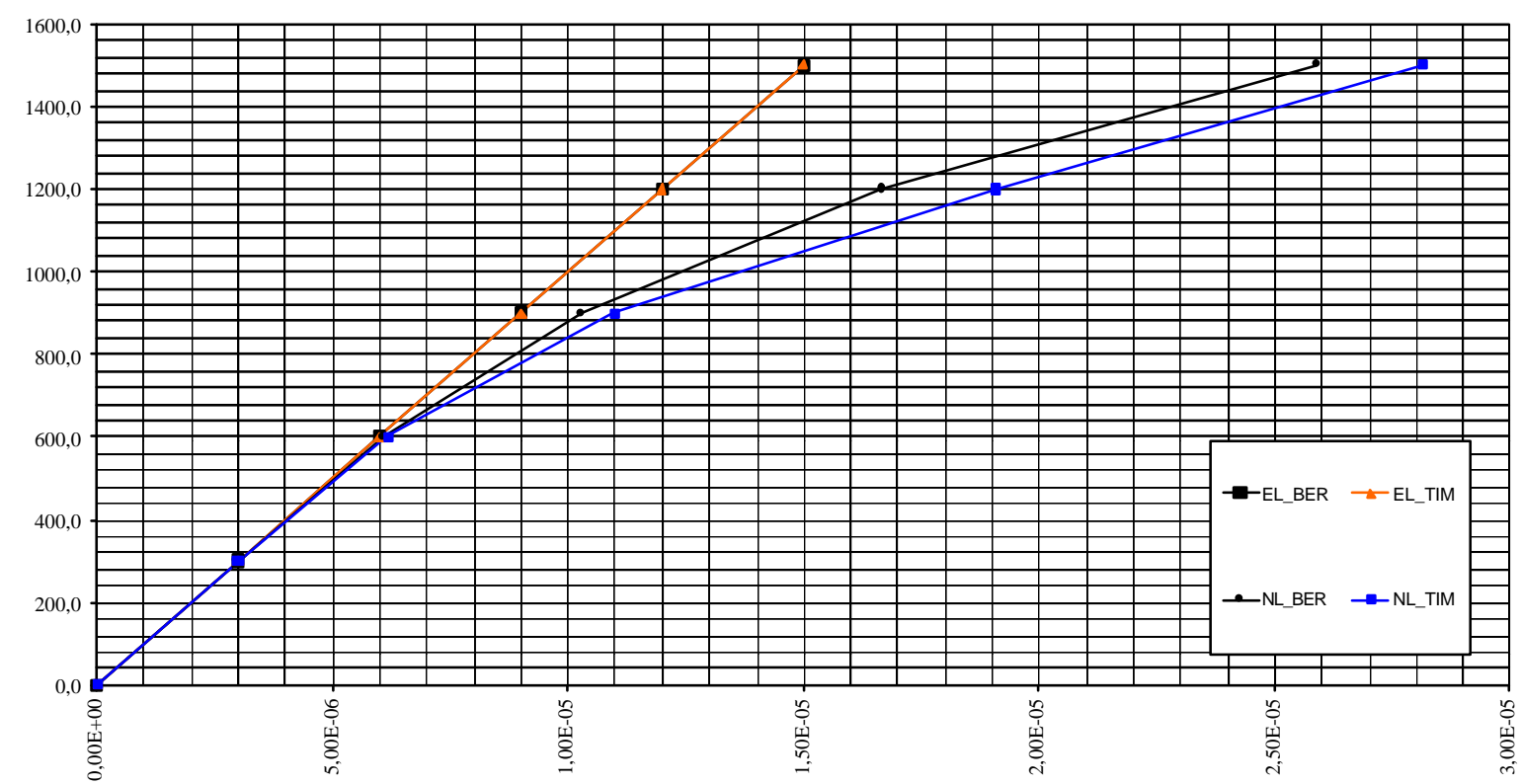

Figura 7.9 - Exemplo 2 - Diagrama momento curvatura da seção do engaste

Na Figura 7.10 mostra-se a variação da rigidez do elemento solicitado pelo máximo momento fletor.

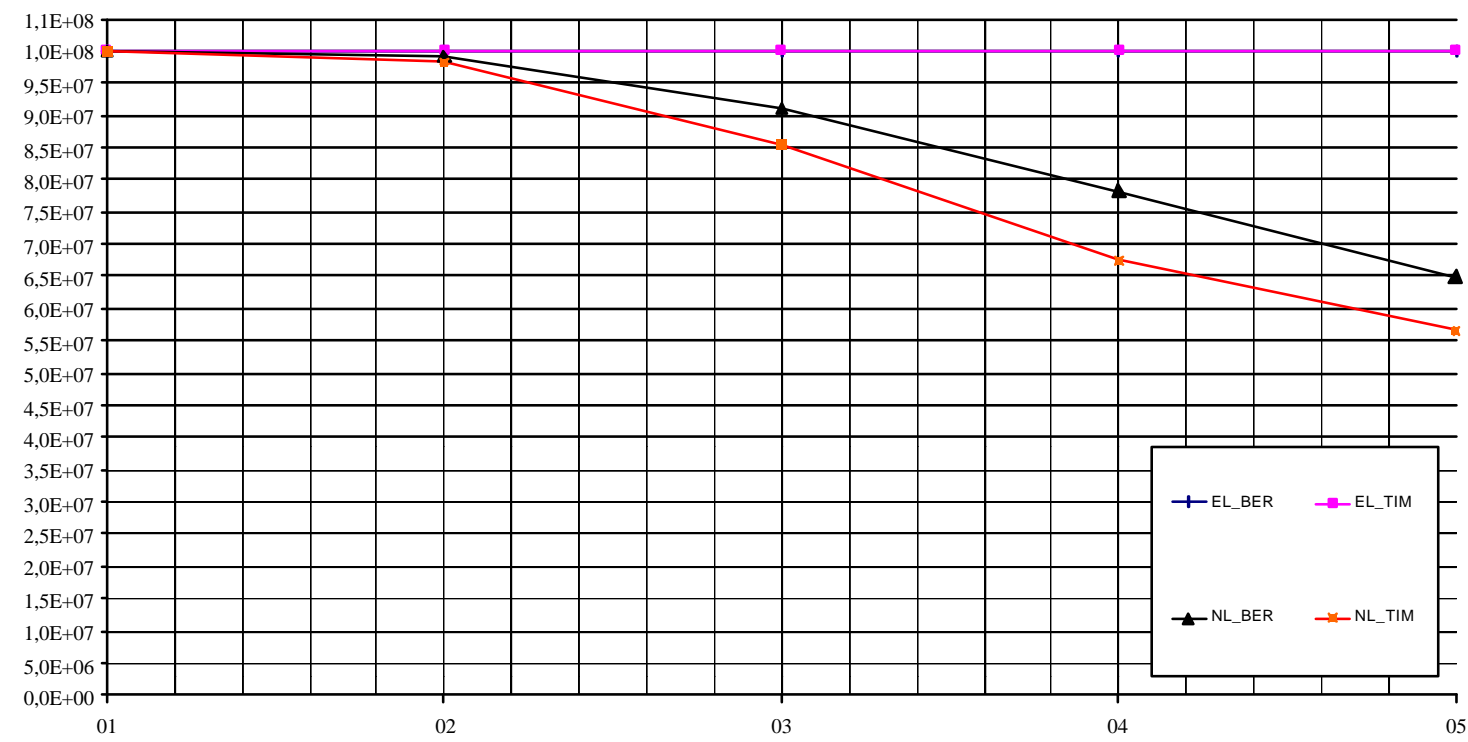

Figura 7.10 - Exemplo 2 - Avaliação da rigidez do elemento solicitado pelo momento máximo 
Na Tabela 7.5 mostra-se a variação das rigidezes dos elementos em cada passo de carga aplicado à viga.

\begin{tabular}{|c|c|c|c|c|c|}
\hline BARRA & EI Estádio I & EI_EL_BER & EI_EL_TIM & EI_NL_BER & EI_NL_TIM \\
\hline 01 & $1,00 \mathrm{E}+08$ & $1,00 \mathrm{E}+08$ & $1,00 \mathrm{E}+08$ & $6,50 \mathrm{E}+07$ & $5,65 \mathrm{E}+07$ \\
\hline 02 & $1,00 \mathrm{E}+08$ & $1,00 \mathrm{E}+08$ & $1,00 \mathrm{E}+08$ & $7,97 \mathrm{E}+07$ & $6,56 \mathrm{E}+07$ \\
\hline 03 & $1,00 \mathrm{E}+08$ & $1,00 \mathrm{E}+08$ & $1,00 \mathrm{E}+08$ & $9,29 \mathrm{E}+07$ & $8,05 \mathrm{E}+07$ \\
\hline 04 & $1,00 \mathrm{E}+08$ & $1,00 \mathrm{E}+08$ & $1,00 \mathrm{E}+08$ & $9,91 \mathrm{E}+07$ & $9,37 \mathrm{E}+07$ \\
\hline 05 & $1,00 \mathrm{E}+08$ & $1,00 \mathrm{E}+08$ & $1,00 \mathrm{E}+08$ & $1,00 \mathrm{E}+08$ & $9,94 \mathrm{E}+07$ \\
\hline
\end{tabular}

Tabela 7.5 Exemplo 2 - Variação da rigidez ao longo do comprimento

Na Figura 7.11 mostram-se a os dados da Tabela 7.5, onde nota-se que na análise não-linear com a hipótese em Bernouilli, a rigidez do elemento mais danificado diminui para $65 \%$ de seu valor inicial, enquanto que na hipótese de Timoshenko esse valor cai para aproximadamente $56 \%$ do valor obtido com a inércia homogeneizada no estádio I.

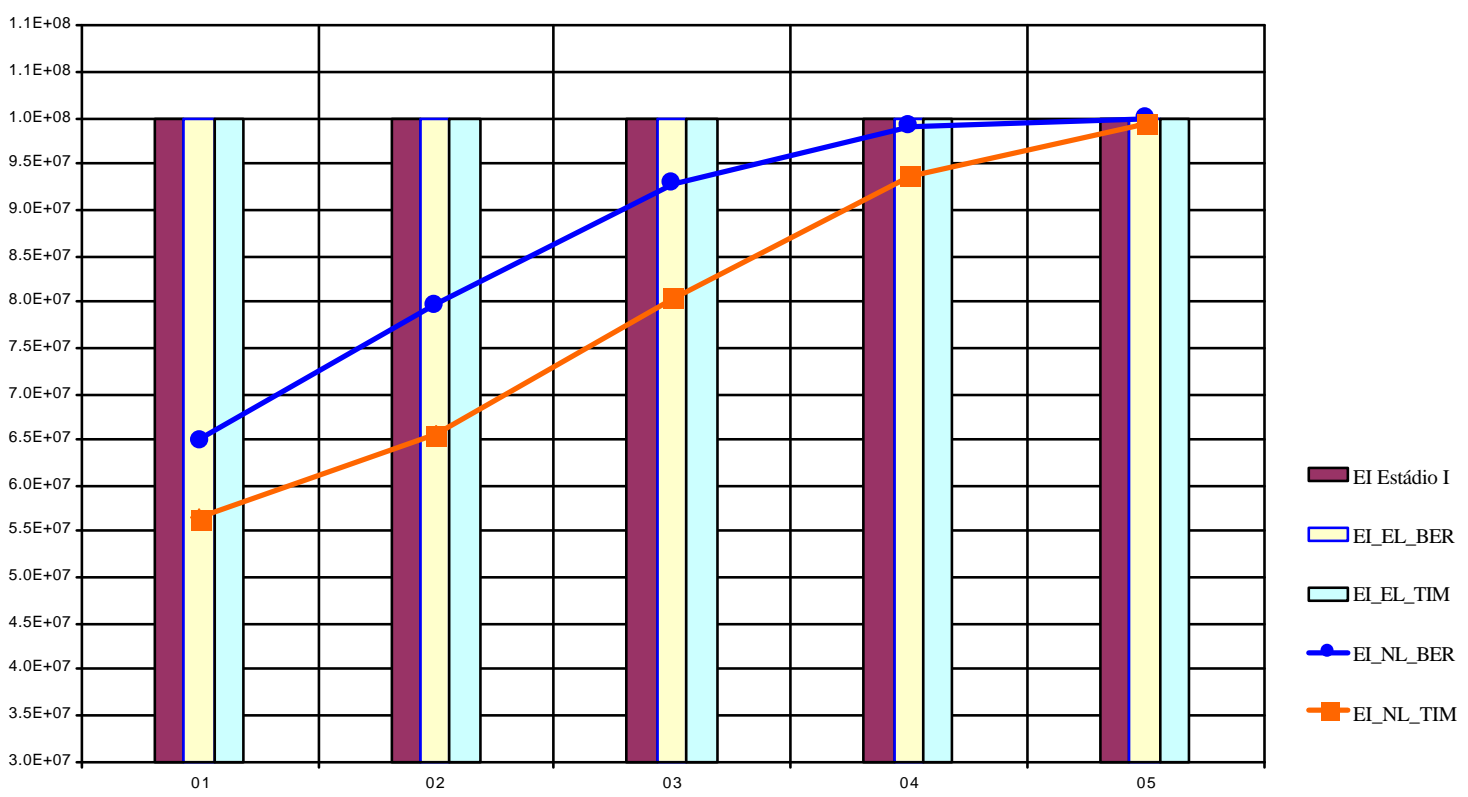

Figura 7.11 - Exemplo 2 - Variação da rigidez ao longo do comprimento

Já nesse caso, onde a relação h/l é de 0,6 faz-se necessário incluir o efeito da força cortante, já que este efeito faz aumentar o estado de danificação da estrutura em cerca de $9 \%$. 


\section{4 - VIGA CURTA HIPERESTÁTICA}

Esperou-se com essa viga obter-se redistribuição de esforços, já que se trata de uma estrutura hiperestática, além de um significativo efeito nas perdas de rigidez em decorrência da força cortante. A geometria da viga é dada na Figura $7.12 \mathrm{e}$ completada abaixo.

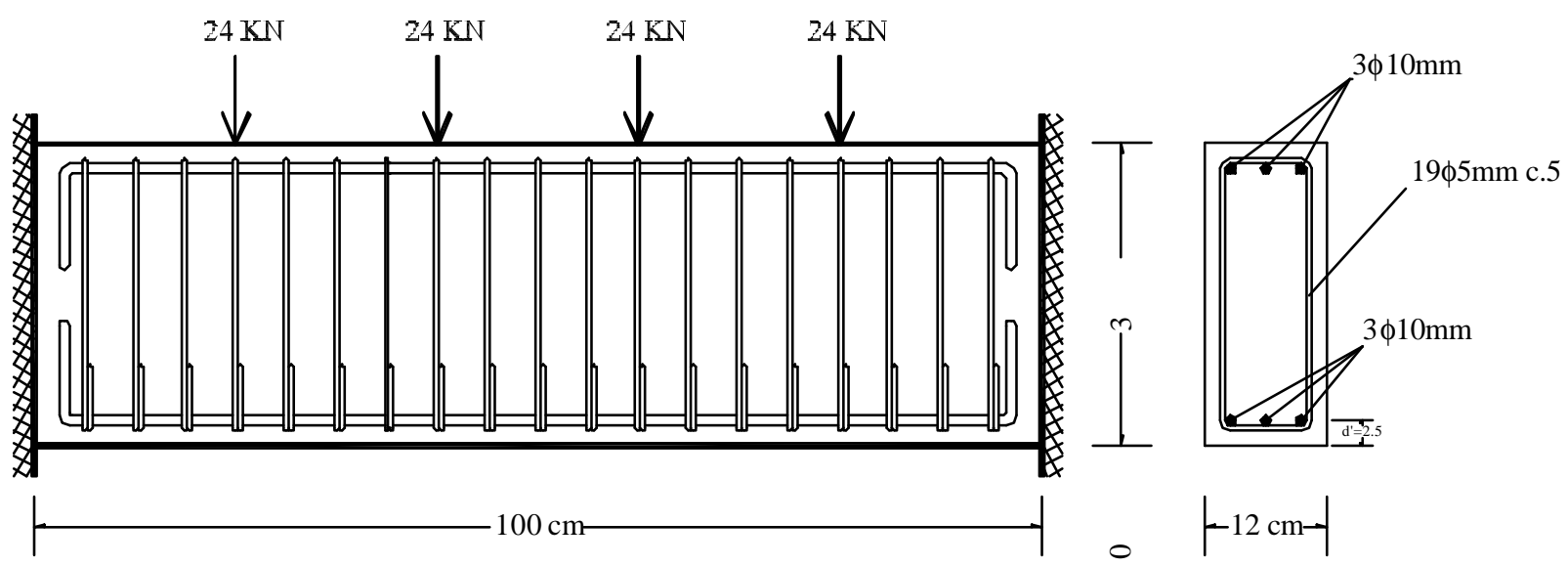

Figura 7.12 - Exemplo 3 - Viga curta hiperestática

Módulo de elasticidade longitudinal do concreto $-\mathrm{E}=2.920 \mathrm{KN} / \mathrm{cm}^{2}$

Coeficiente de Poisson $-v=0,2$

Erro percentual dos resíduos em esforços e norma dos deslocamentos - 0,001\%

Passos de carga - 12

Número máximo de iterações por passo - 200

Precisão da linha neutra $-0,0001$

Tensão de escoamento do aço - $50 \mathrm{KN} / \mathrm{cm}^{2}$

Módulo de elasticidade do aço $-19.600 \mathrm{KN} / \mathrm{cm}^{2}$

Módulo plástico do aço - $1.960 \mathrm{KN} / \mathrm{cm}^{2}$

Parâmetros de dano:

$\varepsilon_{\mathrm{d} 0}=0,00007 \quad ; \mathrm{AT}=0,995 \quad ; \mathrm{BT}=8.000 \quad ; \mathrm{AC}=0,850 \quad ; \mathrm{BC}=1.620$ 
Na Tabela 7.6 estão os valores dos deslocamentos no ponto central da viga. A análise novamente foi efetuada para quatro os casos (hipóteses de Bernouilli e de Timoshenko, linear e não-linear).

\begin{tabular}{|c|c|c|c|c|}
\hline Resultados & \multicolumn{4}{|c|}{ Teoria Utilizada } \\
\hline Passo & Bernouilli Linear & Timoshenko Linear & Bernouilli Não Linear & Timoshenko Não Linear \\
\hline 00 & 0,000000 & 0,000000 & 0,000000 & 0,000000 \\
\hline 01 & 0,000279 & 0,000608 & 0,000279 & 0,000608 \\
\hline 02 & 0,000558 & 0,001220 & 0,000558 & 0,001215 \\
\hline 03 & 0,000836 & 0,001820 & 0,000836 & 0,001823 \\
\hline 04 & 0,001115 & 0,002430 & 0,001115 & 0,002430 \\
\hline 05 & 0,001394 & 0,003040 & 0,001394 & 0,003040 \\
\hline 06 & 0,001673 & 0,003650 & 0,001674 & 0,003705 \\
\hline 07 & 0,001951 & 0,004250 & 0,001963 & 0,004458 \\
\hline 08 & 0,002230 & 0,004860 & 0,002270 & 0,005320 \\
\hline 09 & 0,002509 & 0,005470 & 0,002597 & 0,006357 \\
\hline 10 & 0,002788 & 0,006080 & 0,002946 & 0,007739 \\
\hline 11 & 0,003066 & 0,006680 & 0,003339 & 0,009963 \\
\hline 12 & 0,003345 & 0,007290 & 0,003817 & 0,012050 \\
\hline
\end{tabular}

Tabela 7.6 Exemplo 3 - Deslocamento do ponto central da viga $(\mathrm{cm})$

Na Figura 7.13 plota-se a curva carga $\mathrm{x}$ deslocamento por incremento de carga para o ponto central da viga. Note-se a grande diferença do caso hiperestático.

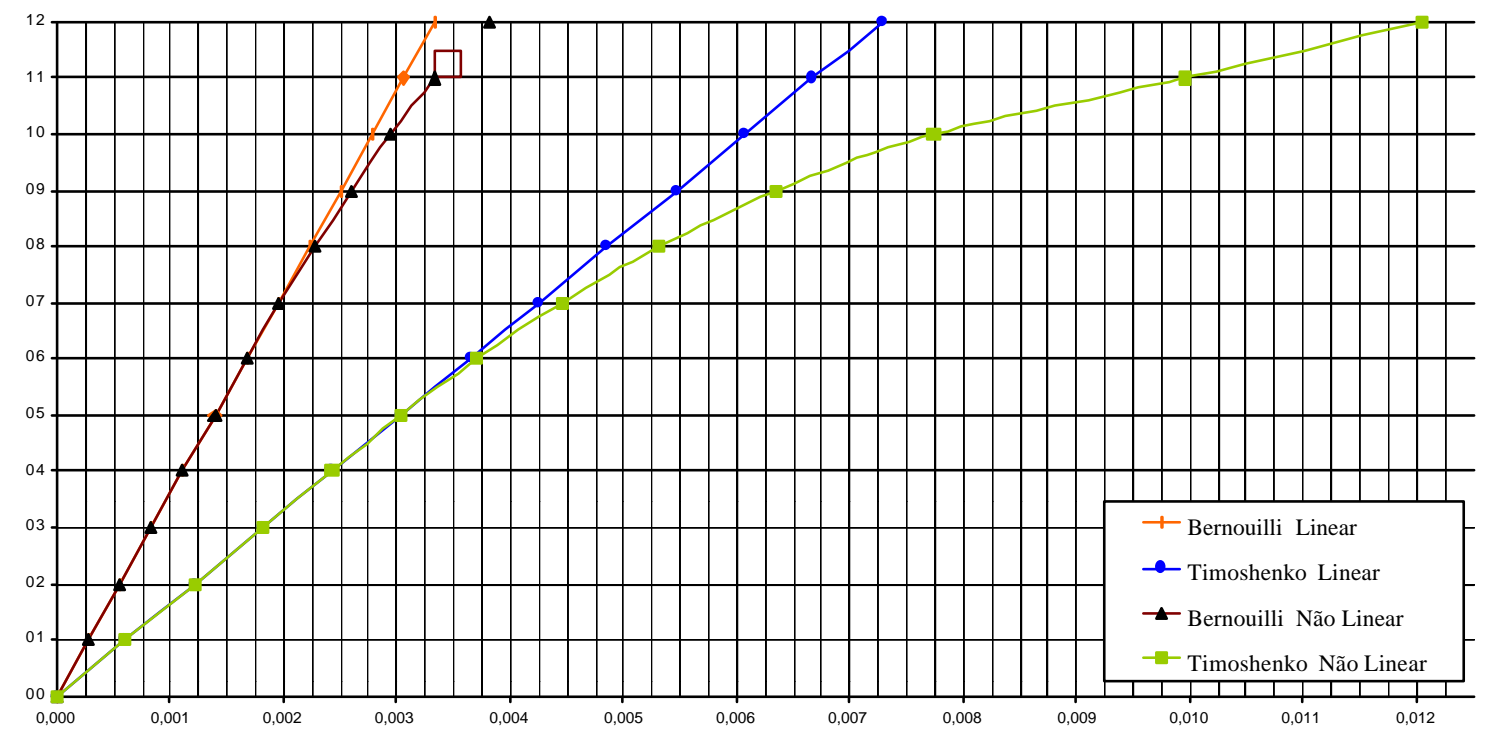

Figura 7.13 - Exemplo 3 - Deslocamento do ponto central da viga $(\mathrm{cm})$ 
Na Figura 7.14 tem-se o diagrama momento x curvatura de um dos engastes da viga. Verifica-se a grande perda de rigidez na análise com viga de Timoshenko.

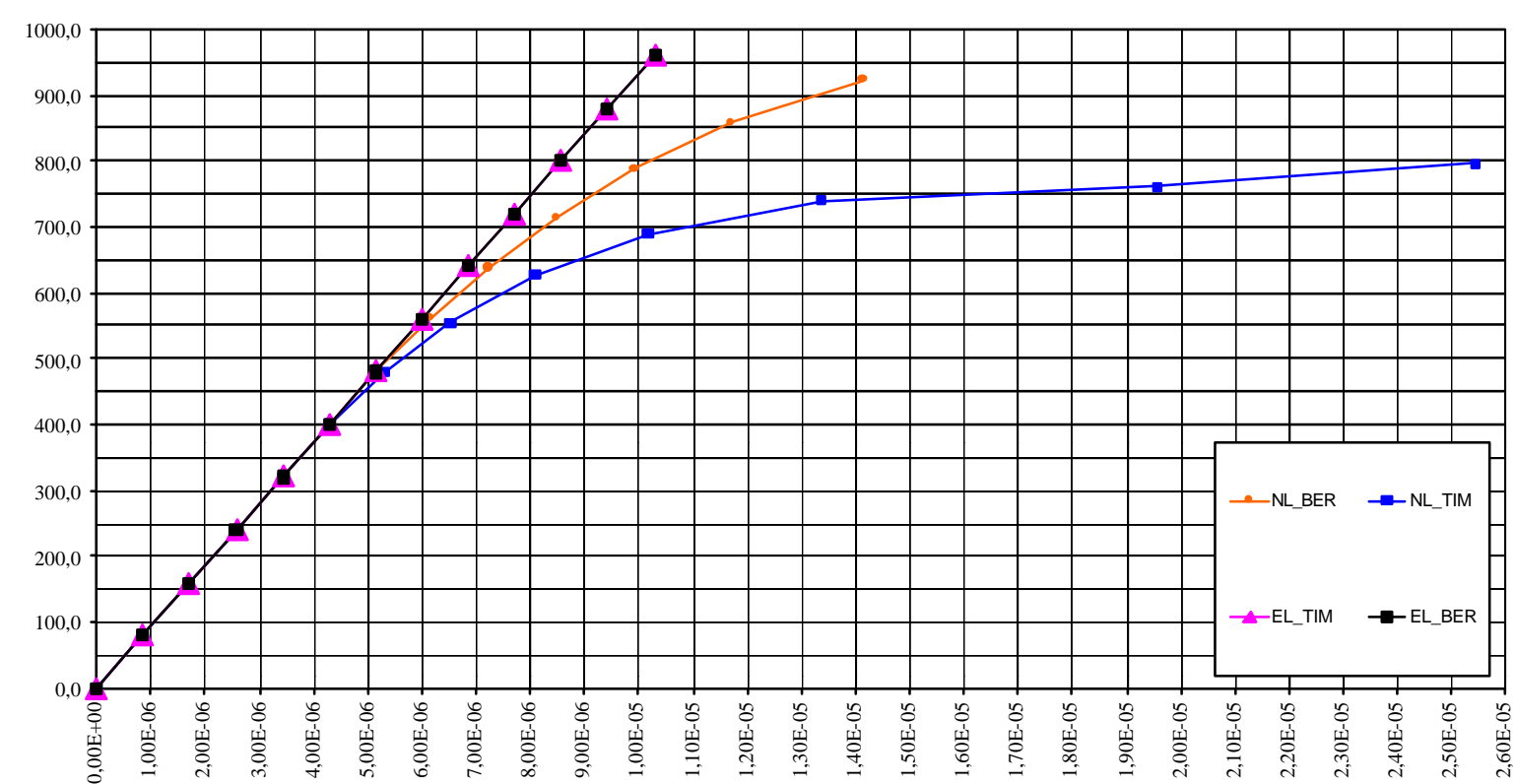

Figura 7.14 - Exemplo 3 - Diagrama momento curvatura de um dos engastes

Na Figura 7.15 vê-se a evolução da rigidez de um elemento que tem o engaste como seu nó inicial. Note-se que a rigidez chega a $45 \%$ da rigidez original.

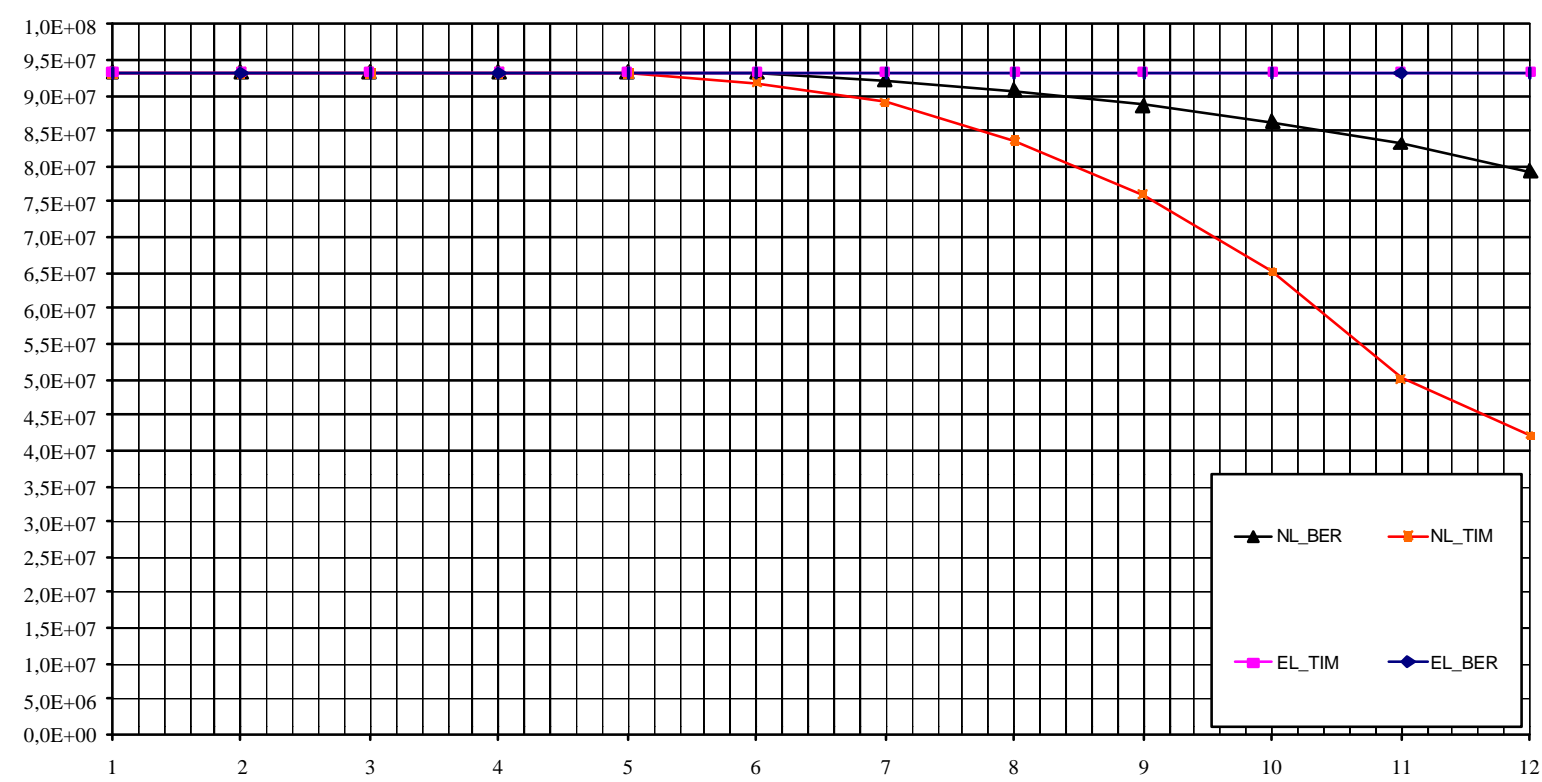

Figura 7.15 - Exemplo 3 - Avaliação da rigidez do elemento solicitado pelo momento máximo 
Na Tabela 7.7 tem-se a variação das rigidezes dos elementos ao longo do comprimento em cada passo de carga aplicado à viga.

\begin{tabular}{|c|c|c|c|c|c|}
\hline BARRA & EI Estádio I & EI_EL_BER & EI_EL_TIM & EI_NL_BER & EI_NL_TIM \\
\hline 01 & $9,33 \mathrm{E}+07$ & $9,33 \mathrm{E}+07$ & $9,33 \mathrm{E}+07$ & $7,93 \mathrm{E}+07$ & $4,22 \mathrm{E}+07$ \\
\hline 02 & $9,33 \mathrm{E}+07$ & $9,33 \mathrm{E}+07$ & $9,33 \mathrm{E}+07$ & $9,33 \mathrm{E}+07$ & $8,85 \mathrm{E}+07$ \\
\hline 03 & $9,33 \mathrm{E}+07$ & $9,33 \mathrm{E}+07$ & $9,33 \mathrm{E}+07$ & $9,33 \mathrm{E}+07$ & $9,29 \mathrm{E}+07$ \\
\hline 04 & $9,33 \mathrm{E}+07$ & $9,33 \mathrm{E}+07$ & $9,33 \mathrm{E}+07$ & $9,28 \mathrm{E}+07$ & $8,58 \mathrm{E}+07$ \\
\hline 05 & $9,33 \mathrm{E}+07$ & $9,33 \mathrm{E}+07$ & $9,33 \mathrm{E}+07$ & $9,22 \mathrm{E}+07$ & $8,78 \mathrm{E}+07$ \\
\hline 06 & $9,33 \mathrm{E}+07$ & $9,33 \mathrm{E}+07$ & $9,33 \mathrm{E}+07$ & $9,22 \mathrm{E}+07$ & $8,78 \mathrm{E}+07$ \\
\hline 07 & $9,33 \mathrm{E}+07$ & $9,33 \mathrm{E}+07$ & $9,33 \mathrm{E}+07$ & $9,28 \mathrm{E}+07$ & $8,58 \mathrm{E}+07$ \\
\hline 08 & $9,33 \mathrm{E}+07$ & $9,33 \mathrm{E}+07$ & $9,33 \mathrm{E}+07$ & $9,33 \mathrm{E}+07$ & $9,29 \mathrm{E}+07$ \\
\hline 09 & $9,33 \mathrm{E}+07$ & $9,33 \mathrm{E}+07$ & $9,33 \mathrm{E}+07$ & $9,33 \mathrm{E}+07$ & $8,85 \mathrm{E}+07$ \\
\hline 10 & $9,33 \mathrm{E}+07$ & $9,33 \mathrm{E}+07$ & $9,33 \mathrm{E}+07$ & $7,93 \mathrm{E}+07$ & $4,22 \mathrm{E}+07$ \\
\hline
\end{tabular}

Tabela 7.7 Exemplo 3 - Variação da rigidez ao longo do comprimento da barra

Os resultados da Tabela 7.7 podem ser melhor visualizados na Figura 7.16, onde percebe-se a grande perda de rigidez da região dos apoios em relação às outras seções. Percebe-se que a influência do estado biaxial de deformações aumenta consideravelmente o dano.

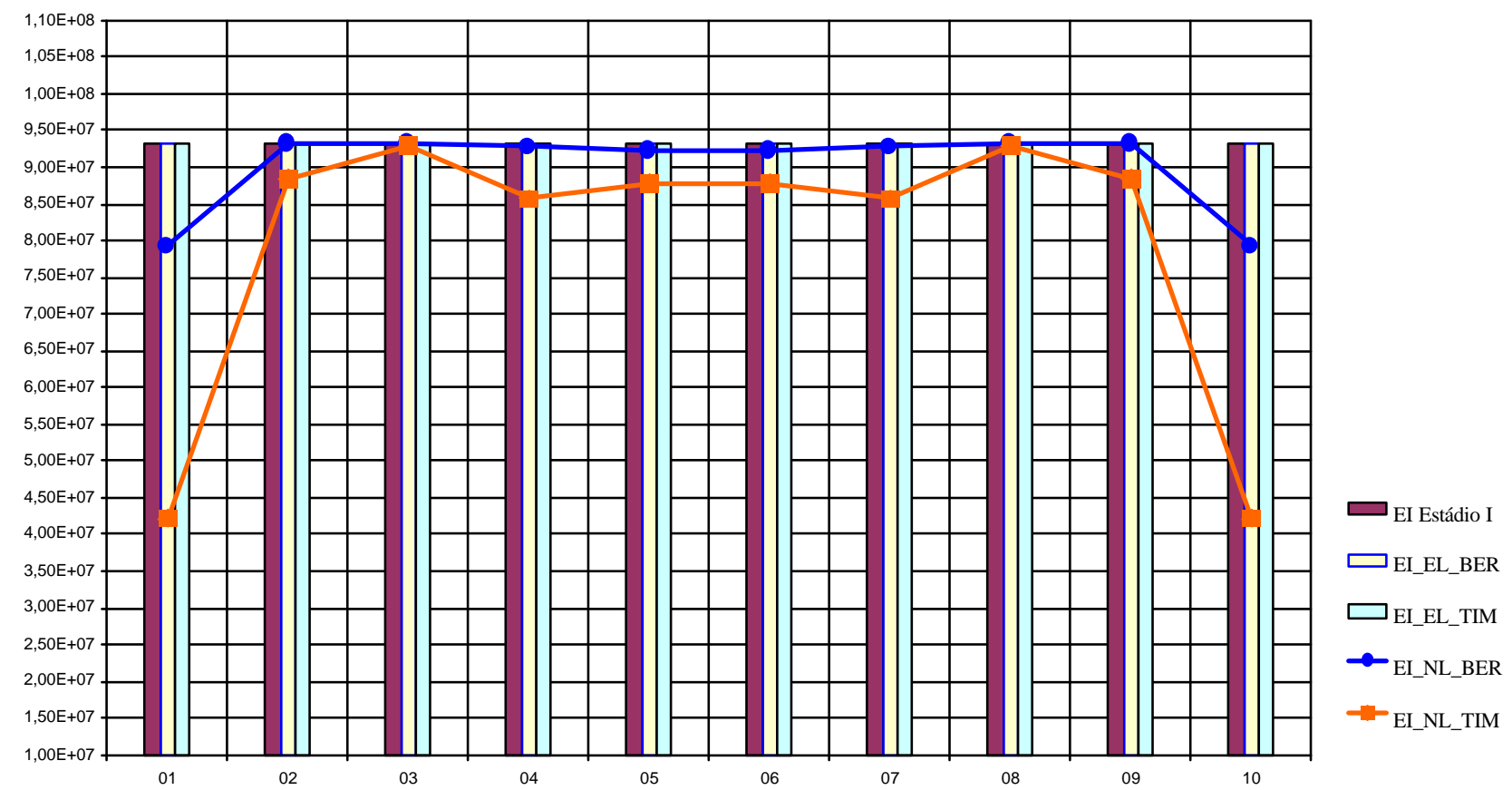

Figura 7.16 - Exemplo 3 - Variação da rigidez ao longo do comprimento da barra 
E na Figura 7.17, tem-se a esperada redistribuição de esforços. Ocorre com a danificação o abaixamento do diagrama de momentos fletores. A viga tende assim a se tornar uma viga biapoiada, perdendo rigidez nos seus engastes. Nota-se também a clara diferença entre as curvas representativas das análises em Bernouilli e em Timoshenko.

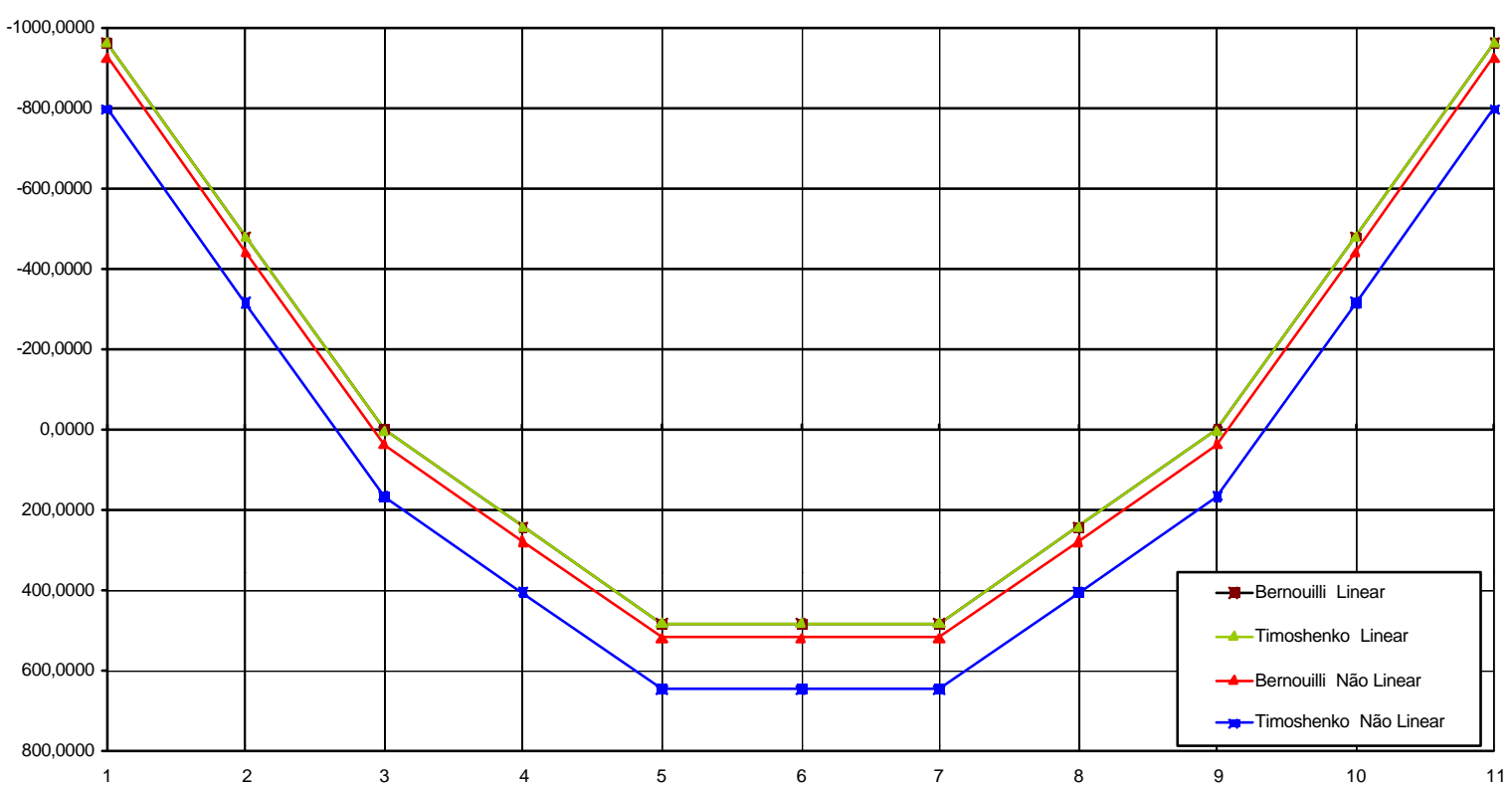

Figura 7.17 - Exemplo 3 - Diagramas de momentos fletores 


\section{5 - CONSOLO}

Neste exemplo, convém reafirmar o que já foi dito anteriormente. A hipótese da manutenção das seções planas não vale mais para esse caso. Mesmo assim, achou-se interessante descrever este exemplo para ser ter idéia do acréscimo de deslocamentos que acontece quando se considera o efeito da distorção em uma peça muito curta. O consolo possui comprimento igual à altura, submetido à uma carga concentrada na sua extremidade. Abaixo são gerados os dados complementares.

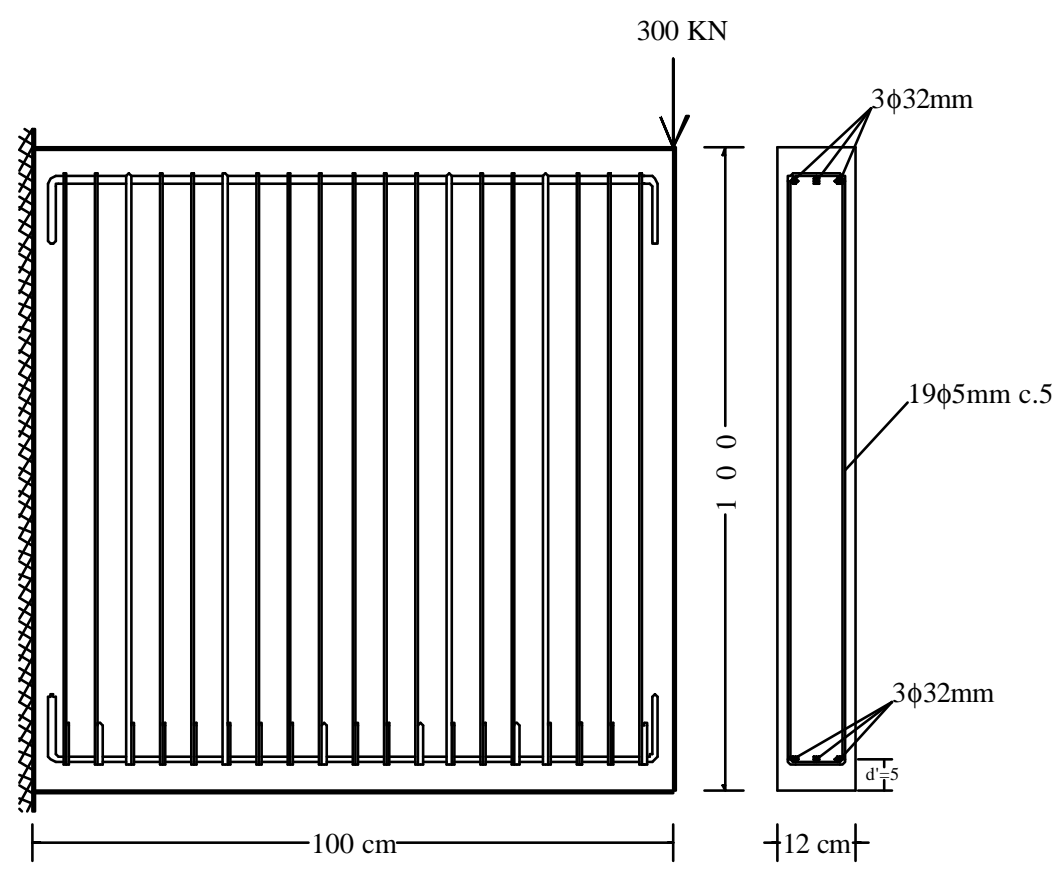

Figura 7.18 - Exemplo 4 - Consolo

Módulo de elasticidade longitudinal do concreto $-\mathrm{E}=2.500 \mathrm{KN} / \mathrm{cm}^{2}$

Coeficiente de Poisson $-v=0,25$

Erro percentual dos resíduos em esforços e norma dos deslocamentos $-0,001 \%$

Passos de carga - 10

Número máximo de iterações por passo - 200

Precisão da linha neutra $-0,0001$

Tensão de escoamento do aço - $50 \mathrm{KN} / \mathrm{cm}^{2}$

Módulo de elasticidade do aço $-20.000 \mathrm{KN} / \mathrm{cm}^{2}$

Módulo plástico do aço $-2.000 \mathrm{KN} / \mathrm{cm}^{2}$ 
Parâmetros de dano:

$\varepsilon_{\mathrm{d} 0}=0,00007 \quad ; \mathrm{AT}=0,995 \quad ; \mathrm{BT}=8.000 \quad ; \mathrm{AC}=0,850 \quad ; \mathrm{BC}=1.620$

Na tabela 7.8 podem ser vistos os deslocamentos da extremidade da viga.

\begin{tabular}{|c|c|c|c|c|}
\hline Resultados & \multicolumn{4}{|c|}{ Teoria Utilizada } \\
\hline Passo & Bernouilli Linear & Timoshenko Linear & Bernouilli Não Linear & Timoshenko Não Linear \\
\hline 00 & 0,000000000 & 0,000000000 & 0,000000000 & 0,000000000 \\
\hline 01 & $2,25 \mathrm{E}-03$ & $5,25 \mathrm{E}-03$ & $2,25 \mathrm{E}-03$ & $5,25 \mathrm{E}-03$ \\
\hline 02 & $4,49 \mathrm{E}-03$ & $1,05 \mathrm{E}-02$ & $4,49 \mathrm{E}-03$ & $1,05 \mathrm{E}-02$ \\
\hline 03 & $6,74 \mathrm{E}-03$ & $1,57 \mathrm{E}-02$ & $6,81 \mathrm{E}-03$ & $1,69 \mathrm{E}-02$ \\
\hline 04 & $8,98 \mathrm{E}-03$ & $2,10 \mathrm{E}-02$ & $9,40 \mathrm{E}-03$ & $2,47 \mathrm{E}-02$ \\
\hline 05 & $1,12 \mathrm{E}-02$ & $2,62 \mathrm{E}-02$ & $1,24 \mathrm{E}-02$ & $3,38 \mathrm{E}-02$ \\
\hline 06 & $1,35 \mathrm{E}-02$ & $3,15 \mathrm{E}-02$ & $1,58 \mathrm{E}-02$ & $4,36 \mathrm{E}-02$ \\
\hline 07 & $1,57 \mathrm{E}-02$ & $3,67 \mathrm{E}-02$ & $1,98 \mathrm{E}-02$ & $5,33 \mathrm{E}-02$ \\
\hline 08 & $1,80 \mathrm{E}-02$ & $4,20 \mathrm{E}-02$ & $2,40 \mathrm{E}-02$ & $6,25 \mathrm{E}-02$ \\
\hline 09 & $2,02 \mathrm{E}-02$ & $4,72 \mathrm{E}-02$ & $2,84 \mathrm{E}-02$ & $7,13 \mathrm{E}-02$ \\
\hline 10 & $2,25 \mathrm{E}-02$ & $5,25 \mathrm{E}-02$ & $3,29 \mathrm{E}-02$ & $7,98 \mathrm{E}-02$ \\
\hline
\end{tabular}

Tabela 7.8 Exemplo 4 - Deslocamento da extremidade do balanço (cm)

Na Figura 7.19 plotam-se os deslocamentos mostrados na Tabela 7.8 e percebe-se que nesse caso, já na análise linear ocorre grande diferença entre as hipóteses da duas teorias. No caso não linear, com a danificação, acentuam-se as diferenças.

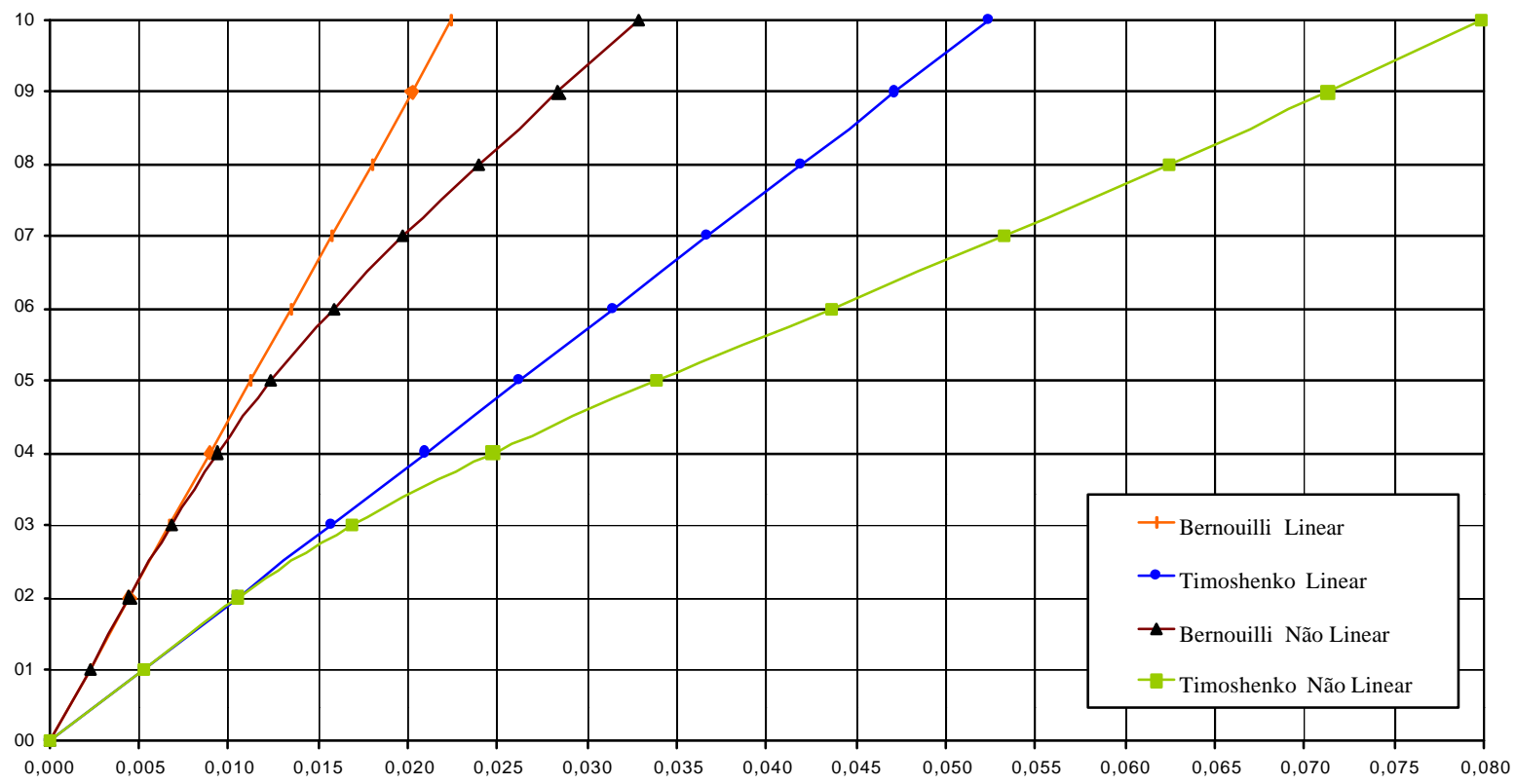

Figura 7.19 - Exemplo 4 - Deslocamento da extremidade do balanço (cm) 
De modo análogo às flechas, as rotações da extremidade da viga também sofrem aumento no caso não-linear quando se confrontam as duas teorias, conforme pode ser visto na Tabela 7.9 e na Figura 7.20. As rotações na fase elástica também não sofrem alterações também por conta dos graus de liberdade do problema.

\begin{tabular}{|c|c|c|c|c|}
\hline Resultados & \multicolumn{5}{|c|}{ Teoria Utilizada } \\
\hline Passo & Bernouilli Linear & Timoshenko Linear & Bernouilli Não Linear & Timoshenko Não Linear \\
\hline 00 & 0,000000000 & 0,000000000 & 0,000000000 & 0,000000000 \\
\hline 01 & $3,37 \mathrm{E}-05$ & $3,37 \mathrm{E}-05$ & $3,37 \mathrm{E}-05$ & $3,37 \mathrm{E}-05$ \\
\hline 02 & $6,74 \mathrm{E}-05$ & $6,74 \mathrm{E}-05$ & $6,74 \mathrm{E}-05$ & $6,74 \mathrm{E}-05$ \\
\hline 03 & $1,01 \mathrm{E}-04$ & $1,01 \mathrm{E}-04$ & $1,02 \mathrm{E}-04$ & $1,05 \mathrm{E}-04$ \\
\hline 04 & $1,35 \mathrm{E}-04$ & $1,35 \mathrm{E}-04$ & $1,40 \mathrm{E}-04$ & $1,53 \mathrm{E}-04$ \\
\hline 05 & $1,68 \mathrm{E}-04$ & $1,68 \mathrm{E}-04$ & $1,82 \mathrm{E}-04$ & $2,11 \mathrm{E}-04$ \\
\hline 06 & $2,02 \mathrm{E}-04$ & $2,02 \mathrm{E}-04$ & $2,31 \mathrm{E}-04$ & $2,78 \mathrm{E}-04$ \\
\hline 07 & $2,36 \mathrm{E}-04$ & $2,36 \mathrm{E}-04$ & $2,85 \mathrm{E}-04$ & $3,48 \mathrm{E}-04$ \\
\hline 08 & $2,69 \mathrm{E}-04$ & $2,69 \mathrm{E}-04$ & $3,44 \mathrm{E}-04$ & $4,19 \mathrm{E}-04$ \\
\hline 09 & $3,03 \mathrm{E}-04$ & $3,03 \mathrm{E}-04$ & $4,06 \mathrm{E}-04$ & $4,88 \mathrm{E}-04$ \\
\hline 10 & $3,37 \mathrm{E}-04$ & $3,37 \mathrm{E}-04$ & $4,69 \mathrm{E}-04$ & $5,57 \mathrm{E}-04$ \\
\hline
\end{tabular}

Tabela 7.9 Exemplo 4 - Rotação da extremidade do balanço $(\mathrm{cm})$

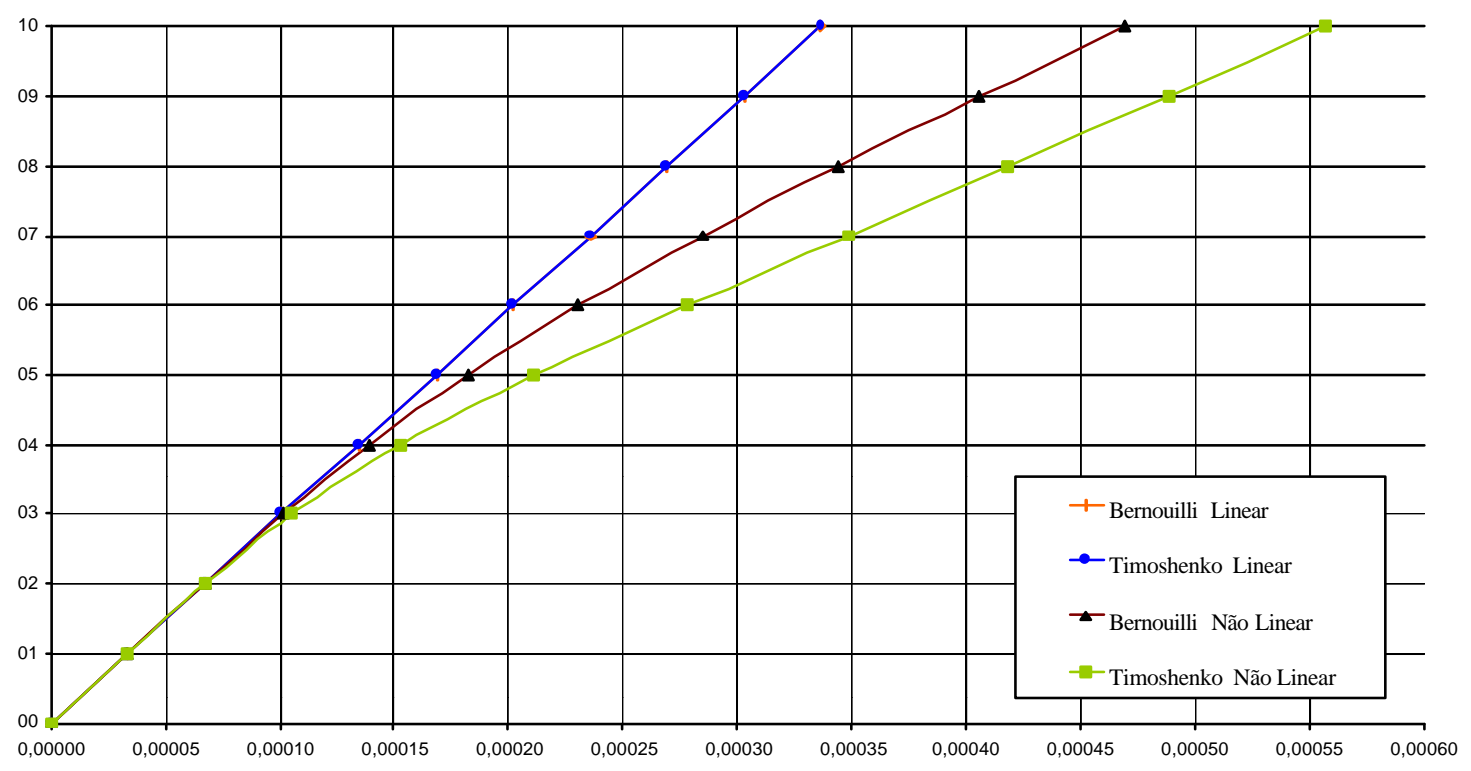

Figura 7.20 - Exemplo 4 - Rotação da extremidade do balanço (cm) 
Na Figura 7.21, apresenta-se o diagrama momento x curvatura da seção do engaste. Novamente percebe-se que não há diferenças nas curvaturas na fase elástica entre as hipóteses de Timoshenko e Bernouilli. Mesmo na fase não-linear, não existe grande diferença entre as duas teorias, já que a distorção é mais significativa do que as deformações longitudinais neste caso.

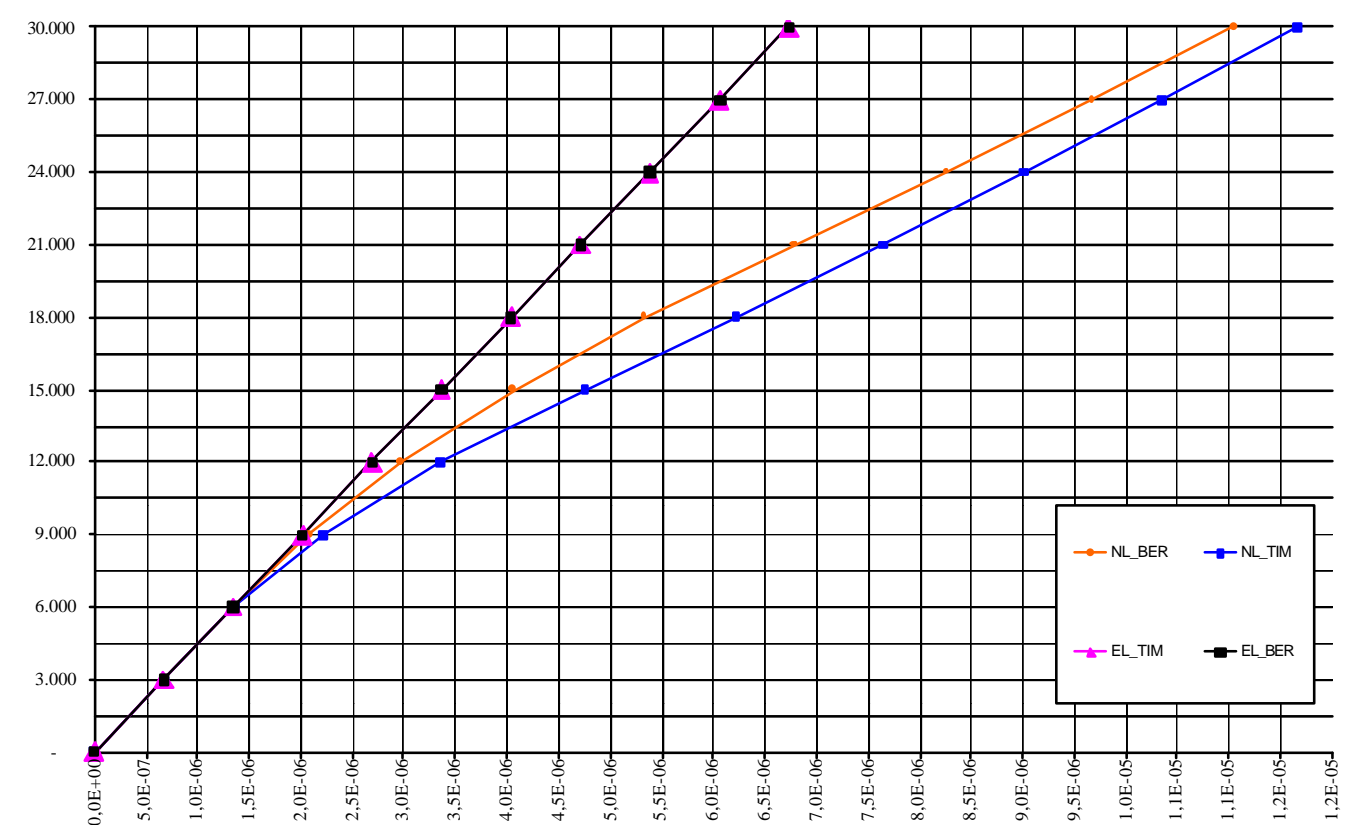

Figura 7.21 - Exemplo 4 - Diagrama momento curvatura da seção do engaste

Na Figura 7.22 apresenta-se o diagrama momento x curvatura da seção do engaste. Nota-se diminuição de $4,8 \%$ da rigidez considerando-se as duas teorias.

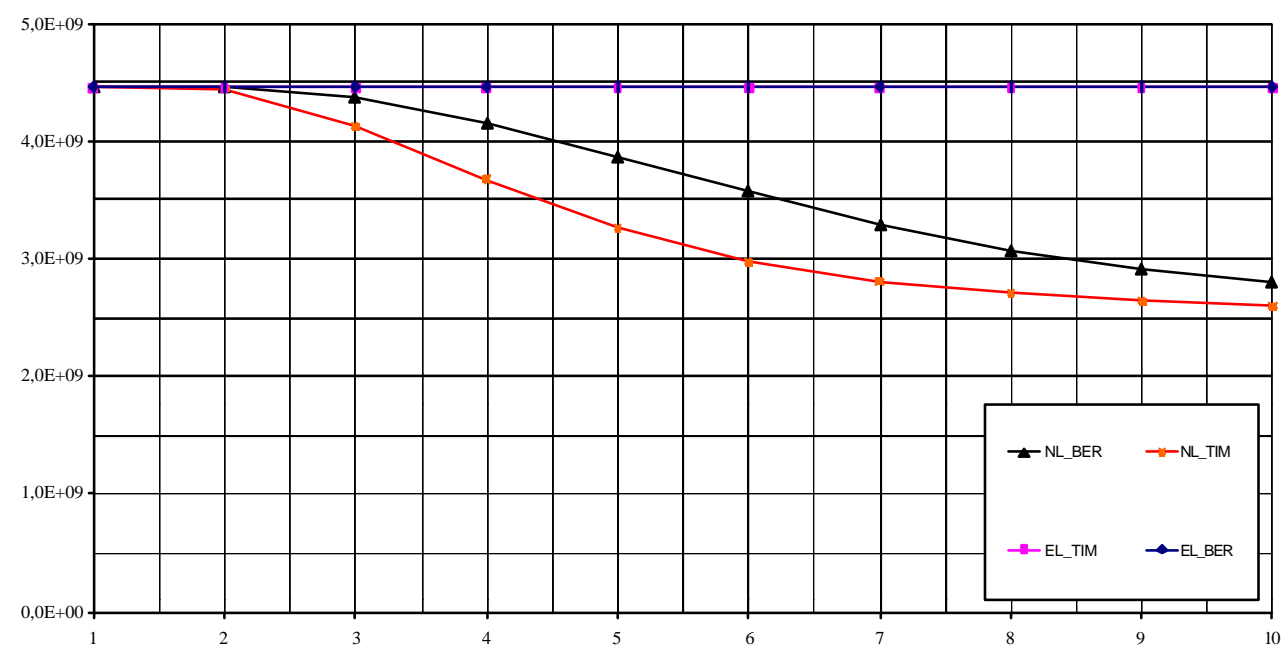

Figura 7.22 - Exemplo 4 - Rigidez do elemento solicitado pelo momento máximo 
$\mathrm{Na}$ Tabela 7.10, podem ser vistos os valores da rigidezes dos elementos ao longo do comprimento da barra em cada hipótese de análise, com o carregamento totalmente aplicado na estrutura.

\begin{tabular}{|c|c|c|c|c|c|}
\hline BARRA & Estádio I & EL_BER & EL_TIM & NL_BER & NL_TIM \\
\hline 01 & $4,45 \mathrm{E}+09$ & $4,45 \mathrm{E}+09$ & $4,45 \mathrm{E}+09$ & $2,81 \mathrm{E}+09$ & $2,59 \mathrm{E}+09$ \\
\hline 02 & $4,45 \mathrm{E}+09$ & $4,45 \mathrm{E}+09$ & $4,45 \mathrm{E}+09$ & $3,14 \mathrm{E}+09$ & $2,65 \mathrm{E}+09$ \\
\hline 03 & $4,45 \mathrm{E}+09$ & $4,45 \mathrm{E}+09$ & $4,45 \mathrm{E}+09$ & $3,70 \mathrm{E}+09$ & $2,75 \mathrm{E}+09$ \\
\hline 04 & $4,45 \mathrm{E}+09$ & $4,45 \mathrm{E}+09$ & $4,45 \mathrm{E}+09$ & $4,24 \mathrm{E}+09$ & $2,97 \mathrm{E}+09$ \\
\hline 05 & $4,45 \mathrm{E}+09$ & $4,45 \mathrm{E}+09$ & $4,45 \mathrm{E}+09$ & $4,45 \mathrm{E}+09$ & $3,16 \mathrm{E}+09$ \\
\hline
\end{tabular}

Tabela 7.10 Exemplo 4 - Variação da rigidez ao longo do comprimento

Na Figura 7.23, tem-se os valores da Tabela 7.10. Nota-se que não haveria dano na seção do extremo se não fosse considerado o efeito da distorção, já que não existe momento nessa seção.

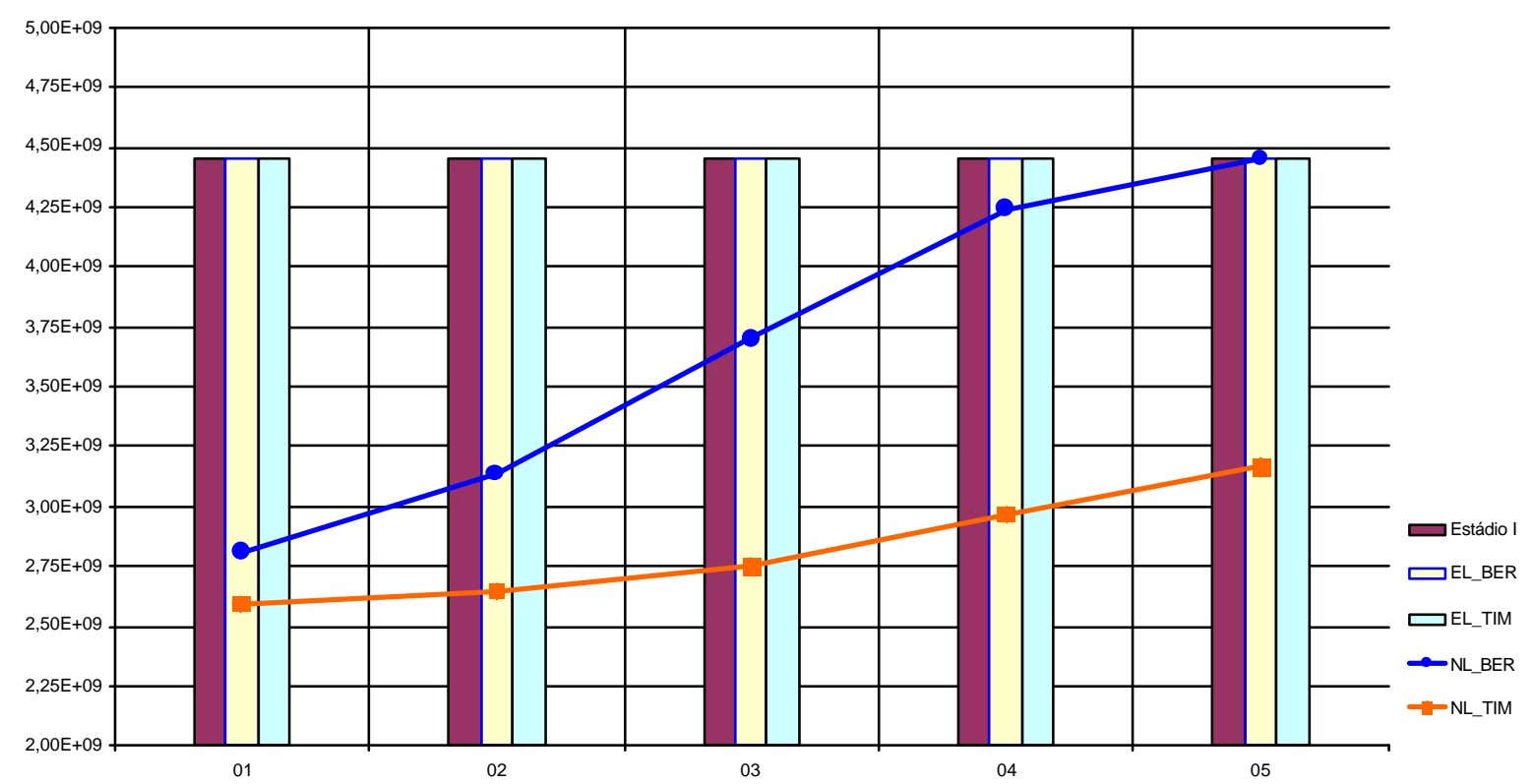

Figura 7.23 - Exemplo 4 - Variação da rigidez ao longo do comprimento 


\section{6 - GRELHA SEM INFLUÊNCIA DA TORÇÃO}

Já que os esforços de torção não foram considerados no equilíbrio das seções transversais, optou-se por analisar uma estrutura desse tipo, que não sofresse influência da inércia à torção de suas barras, nos deslocamentos e esforços finais calculados. Os dados estão na Figura 7.24 e complementados logo abaixo.
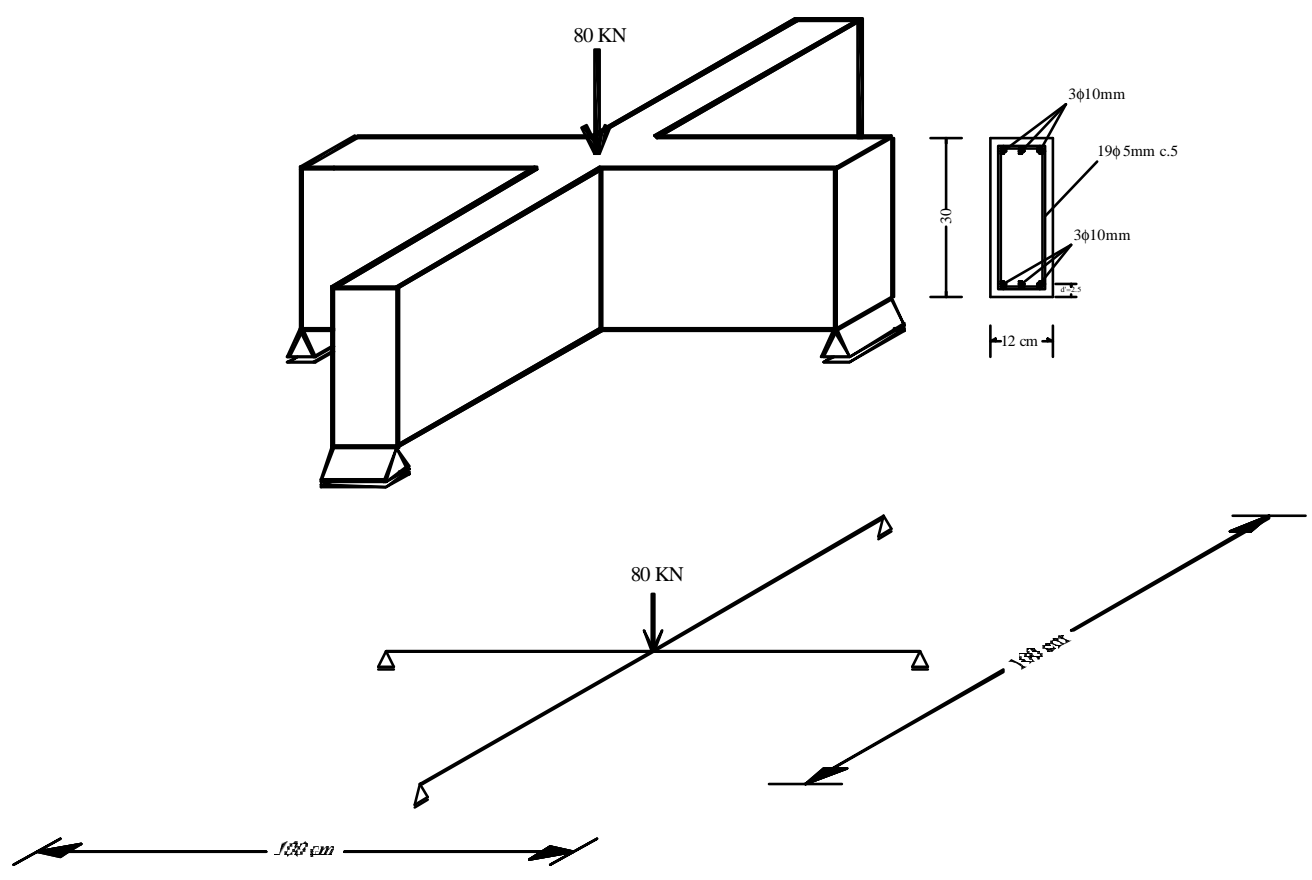

Figura 7.24 - Exemplo 5 - Grelha sem influência da torção

Módulo de elasticidade longitudinal do concreto $-\mathrm{E}=2.500 \mathrm{KN} / \mathrm{cm}^{2}$

Coeficiente de Poisson $-v=0,25$

Erro percentual dos resíduos em esforços e norma dos deslocamentos - 0,001\%

Passos de carga - 10

Número máximo de iterações por passo - 200

Precisão da linha neutra $-0,0001$

Tensão de escoamento do aço $-50 \mathrm{KN} / \mathrm{cm}^{2}$

Módulo de elasticidade do aço $-20.000 \mathrm{KN} / \mathrm{cm}^{2}$

Módulo plástico do aço $-2.000 \mathrm{KN} / \mathrm{cm}^{2}$

Parâmetros de dano:

$\varepsilon_{\mathrm{d} 0}=0,00007 \quad ; \mathrm{AT}=0,995 \quad ; \mathrm{BT}=8.000 \quad ; \mathrm{AC}=0,850 \quad ; \mathrm{BC}=1.620$ 
$\mathrm{Na}$ Tabela 7.11, analogamente aos exemplos anteriores, tem-se os deslocamentos do ponto de cruzamento das vigas, de acordo com as quatro hipóteses.

\begin{tabular}{|c|c|c|c|c|}
\hline Resultados & \multicolumn{4}{|c|}{ Teoria Utilizada } \\
\hline Passo & Bernouilli Linear & Timoshenko Linear & Bernouilli Não Linear & Timoshenko Não Linear \\
\hline 00 & 0,00000000 & 0,00000000 & 0,00000000 & 0,00000000 \\
\hline 01 & 0,00101348 & 0,00134681 & 0,00101348 & 0,00134681 \\
\hline 02 & 0,00202696 & 0,00269363 & 0,00202696 & 0,00269363 \\
\hline 03 & 0,00304044 & 0,00404044 & 0,00304044 & 0,00404044 \\
\hline 04 & 0,00405392 & 0,00538725 & 0,00405392 & 0,00539090 \\
\hline 05 & 0,00506740 & 0,00673406 & 0,00509828 & 0,00684574 \\
\hline 06 & 0,00608088 & 0,00808088 & 0,00624436 & 0,00855496 \\
\hline 07 & 0,00709436 & 0,00942769 & 0,00757490 & 0,01072367 \\
\hline 08 & 0,00810783 & 0,01077450 & 0,00923154 & 0,01444664 \\
\hline 09 & 0,00912131 & 0,01212131 & 0,01191038 & 0,02044270 \\
\hline 10 & 0,01013479 & 0,01346813 & 0,01654838 & 0,02730976 \\
\hline
\end{tabular}

Tabela 7.11 Exemplo 5 - Deslocamentos no ponto de cruzamento das vigas

Os resultados da Tabela 7.11 podem ser vistos também na Figura 7.25.

Percebe-se que há também forte influência da distorção no deslocamento.

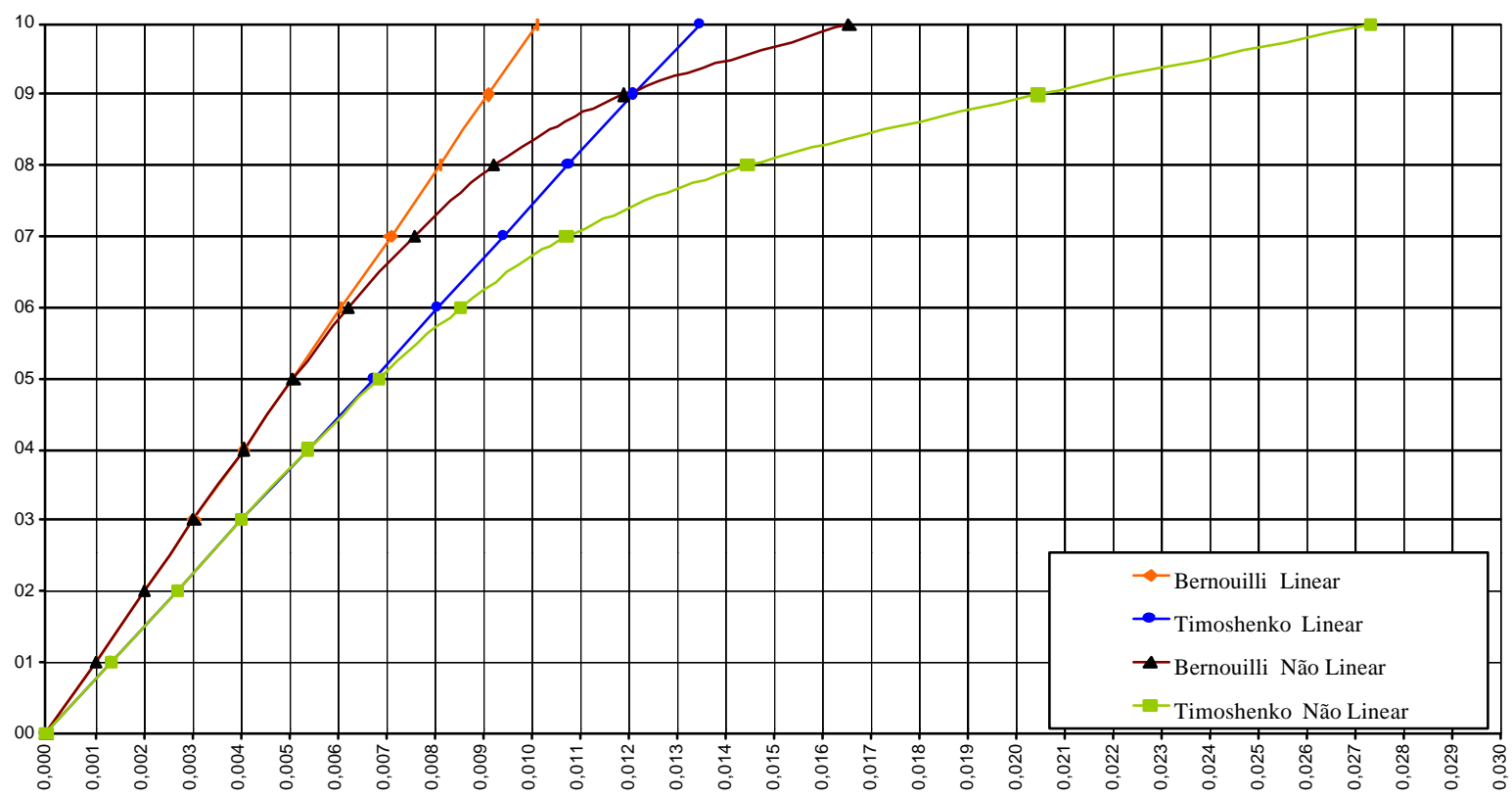

Figura 7.25 - Exemplo 5 - Deslocamentos no ponto de cruzamento das vigas 
Na Tabela 7.12 e na Figura 7.26 são mostradas as rotações nos apoios. Estas são iguais, já que a estrutura é simétrica. Convém reafirmar que não há diferença entre as duas teorias na fase elástica em função dos parâmetros nodais da formulação.

\begin{tabular}{|c|c|c|c|c|}
\hline Resultados & \multicolumn{5}{|c|}{ Teoria Utilizada } \\
\hline Passo & Bernouilli Linear & Timoshenko Linear & Bernouilli Não Linear & Timoshenko Não Linear \\
\hline 00 & 0,00000000 & 0,00000000 & 0,00000000 & 0,00000000 \\
\hline 01 & 0,00003040 & 0,00003040 & 0,00003040 & 0,00003040 \\
\hline 02 & 0,00006081 & 0,00006081 & 0,00006081 & 0,00006081 \\
\hline 03 & 0,00009121 & 0,00009121 & 0,00009121 & 0,00009121 \\
\hline 04 & 0,00012162 & 0,00012162 & 0,00012162 & 0,00012164 \\
\hline 05 & 0,00015202 & 0,00015202 & 0,00015268 & 0,00015312 \\
\hline 06 & 0,00018243 & 0,00018243 & 0,00018605 & 0,00018831 \\
\hline 07 & 0,00021283 & 0,00021283 & 0,00022375 & 0,00023075 \\
\hline 08 & 0,00024324 & 0,00024324 & 0,00026910 & 0,00029668 \\
\hline 09 & 0,00027364 & 0,00027364 & 0,00033737 & 0,00040924 \\
\hline 10 & 0,00030404 & 0,00030404 & 0,00044971 & 0,00055114 \\
\hline
\end{tabular}

Tabela 7.12 Exemplo 5 - Rotações nos apoios

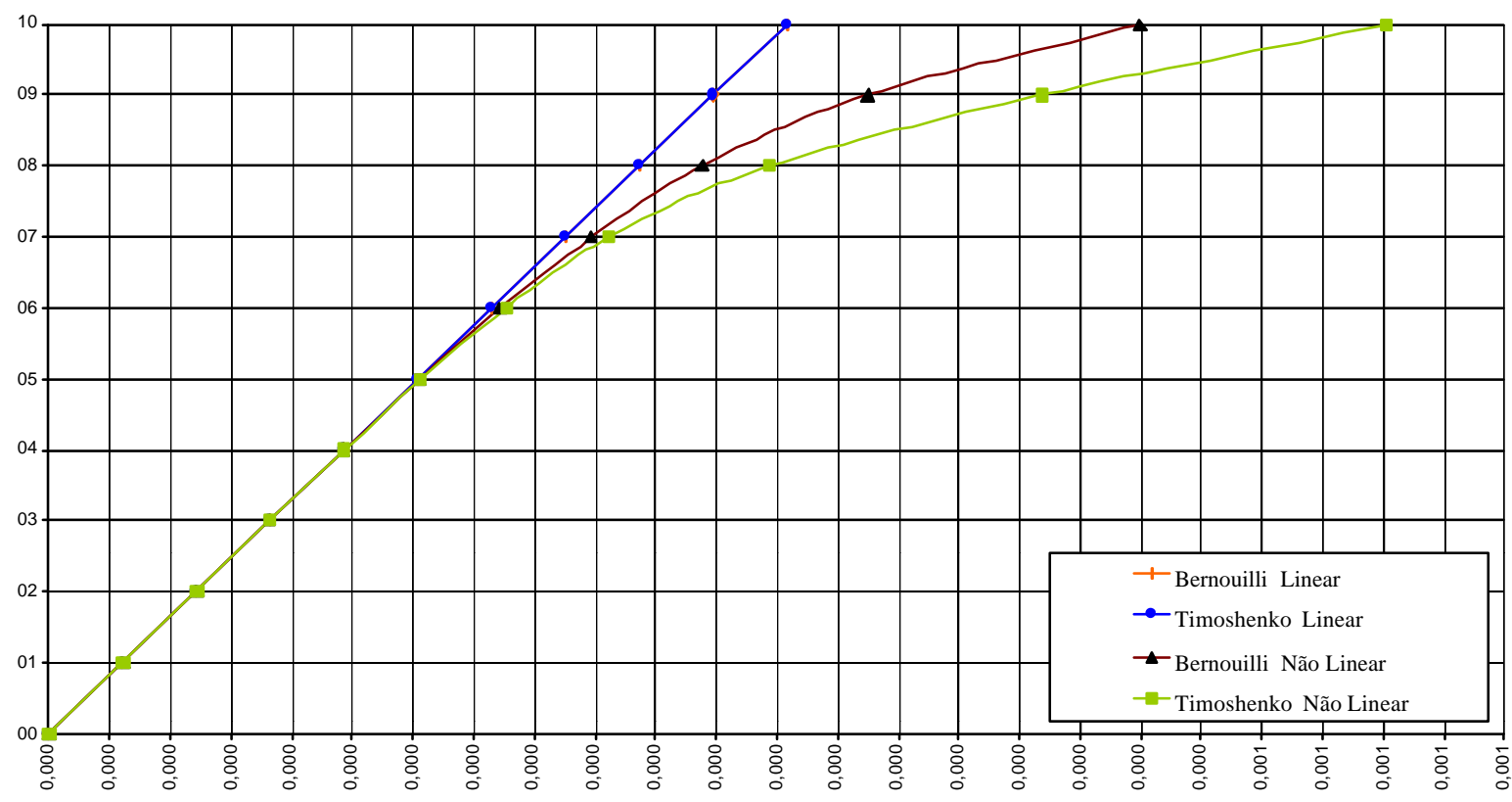

Figura 7.26 - Exemplo 5 - Rotações nos apoios 
Na Figura 7.27 mostra-se a rigidez do elemento presente na região de momentos máximos ao longo da evolução do carregamento. Percebe-se que embora a perda de rigidez seja grande em relação à fase elástica, entre as duas teorias há apenas $8,3 \%$ de diferença na queda da rigidez.

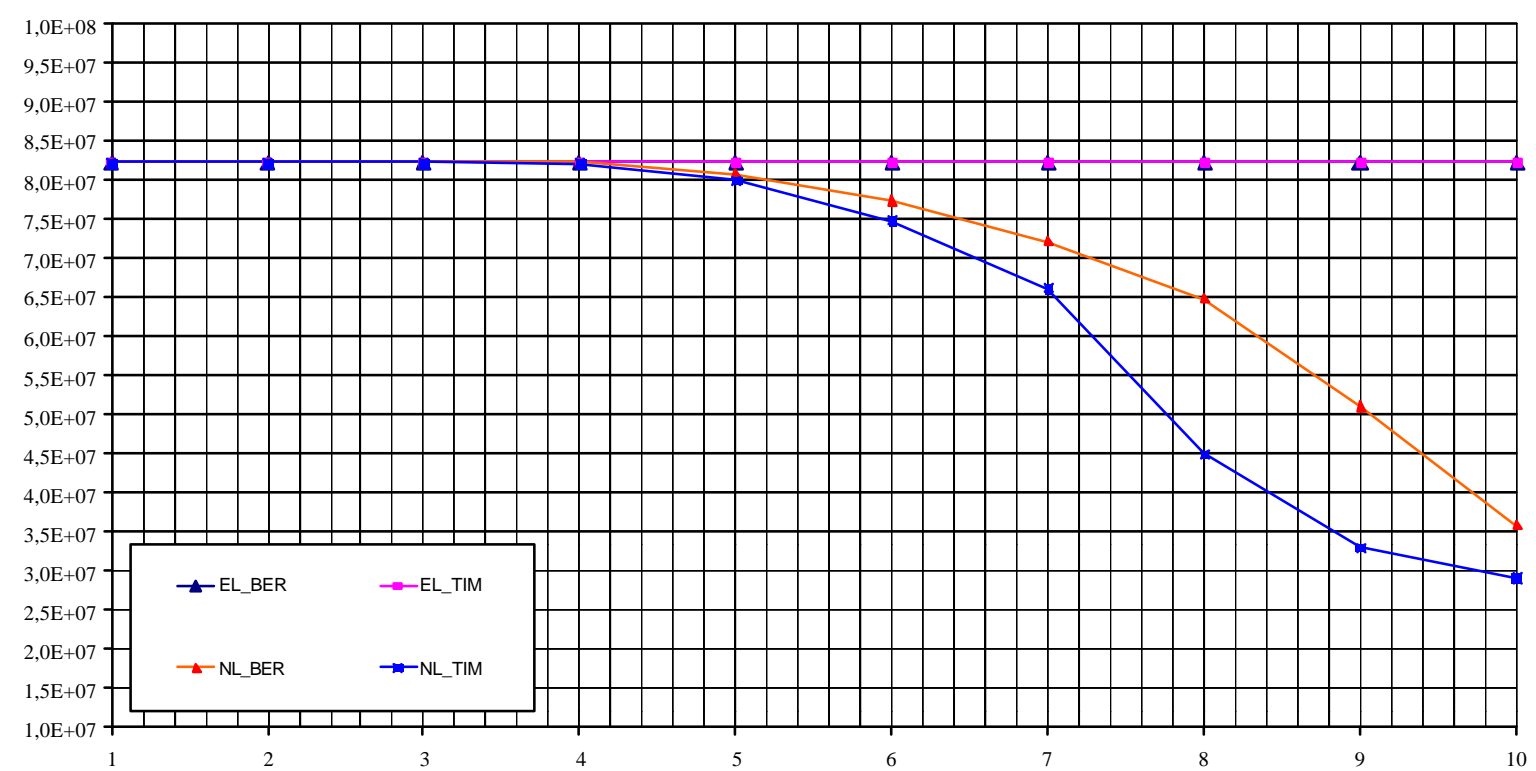

Figura 7.27 - Exemplo 5 - Rigidez de um elemento na região de momento máximo

Na Figura 7.28 mostra-se o diagrama momento curvatura da seção do meio do vão. Isto confirma a pequena diferença entre os dois casos não-lineares.

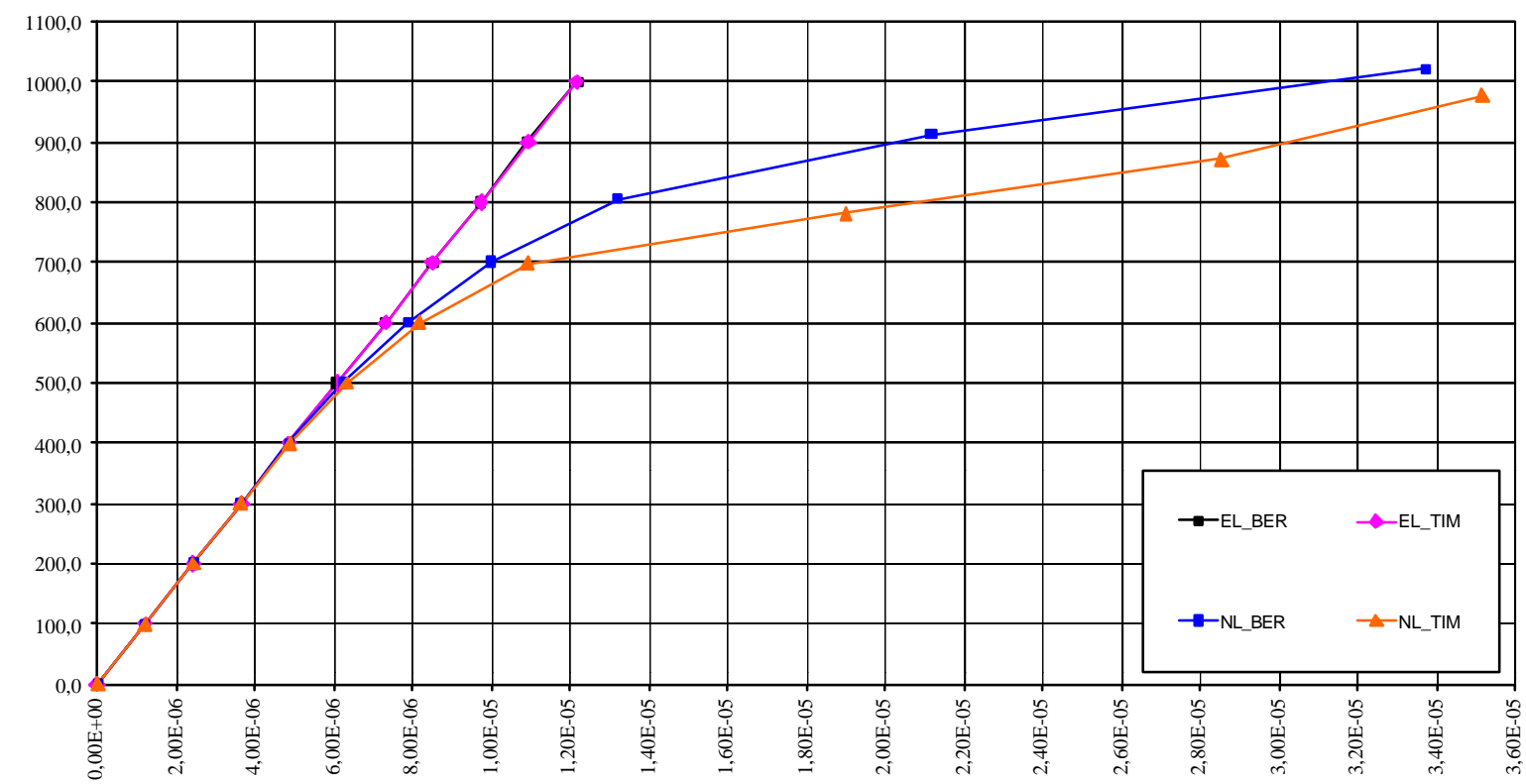

Figura 7.28 - Exemplo 5 - Diagrama momento curvatura da seção no cruzamento das vigas 
Ao longo do comprimento de uma das vigas, percebe-se a variação da rigidez com o carregamento totalmente aplicado. Note-se que algumas seções não apresentaram danificação.

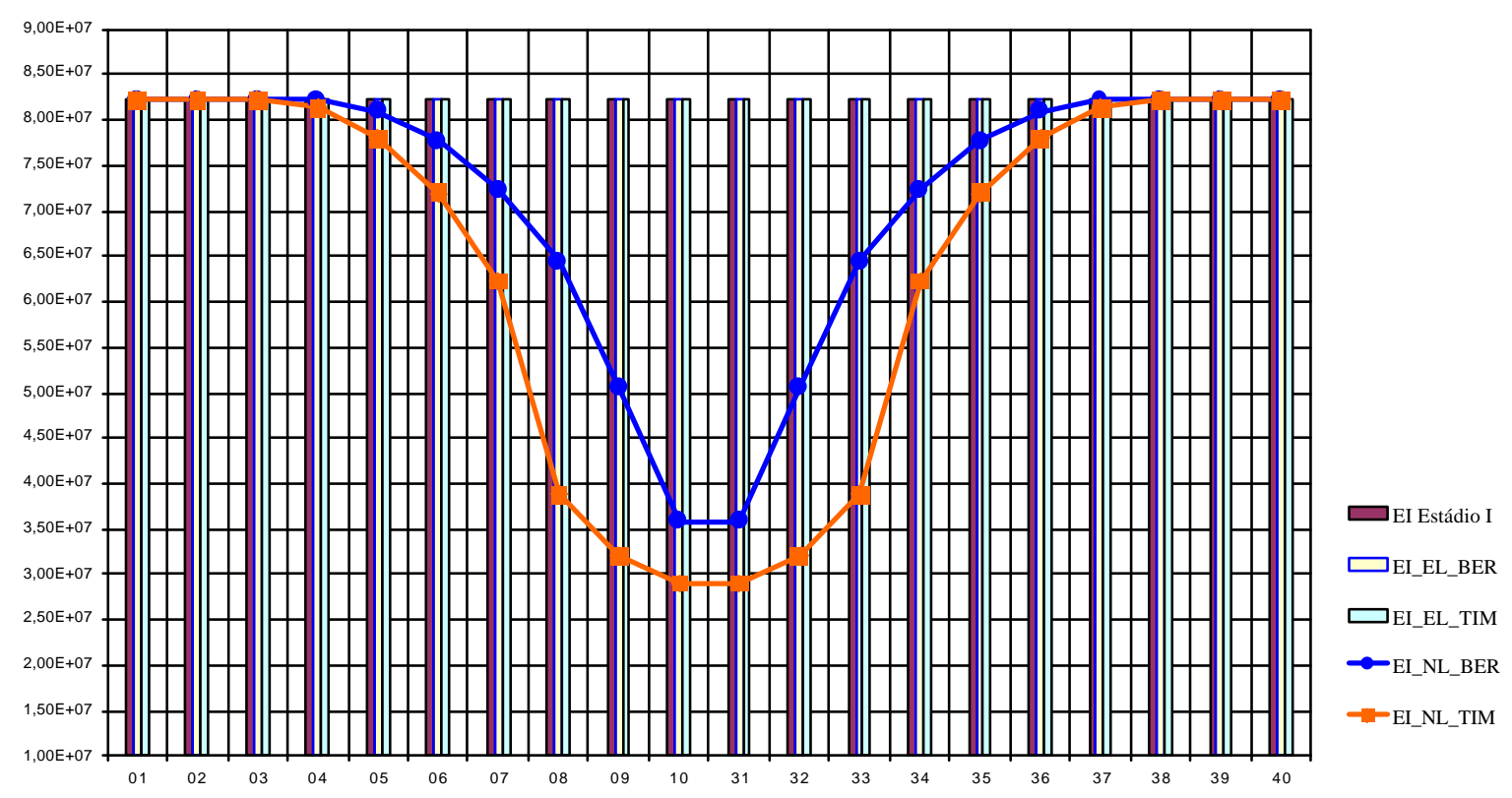

Figura 7.29 - Exemplo 5 - Variação da rigidez ao longo do comprimento da viga

Este exemplo veio apenas confirmar o que os anteriores já tinham apresentado. Serviu, no entanto para analisar-se a consideração de duas peças na rigidez global da estrutura. 


\section{7 - VERIFICAÇÃ̃ DA PRECISÃO DO MODELO}

Como um último exemplo, tomou-se uma viga de concreto armado ensaiada no laboratório de estruturas da EESC-USP, durante as atividades da disciplina de Análise Experimental de Estruturas, que teve as suas armaduras transversais instrumentadas. Em decorrência da ausência de resultados experimentais de vigas retangulares de concreto armado com instrumentação nos estribos, tomou-se a viga descrita abaixo, de seção transversal em 'I'. Para o cálculo dos seus resultados utilizando-se o programa desenvolvido, utilizaram-se alguns artifícios para a entrada de dados, já que o programa não contempla a seção 'I'. Em seguida, compararam-se os resultados obtidos com os verificados nos experimentos. Os dados da viga ensaiada e analisada numericamente estão dados na Figura 7.30 e complementados abaixo.

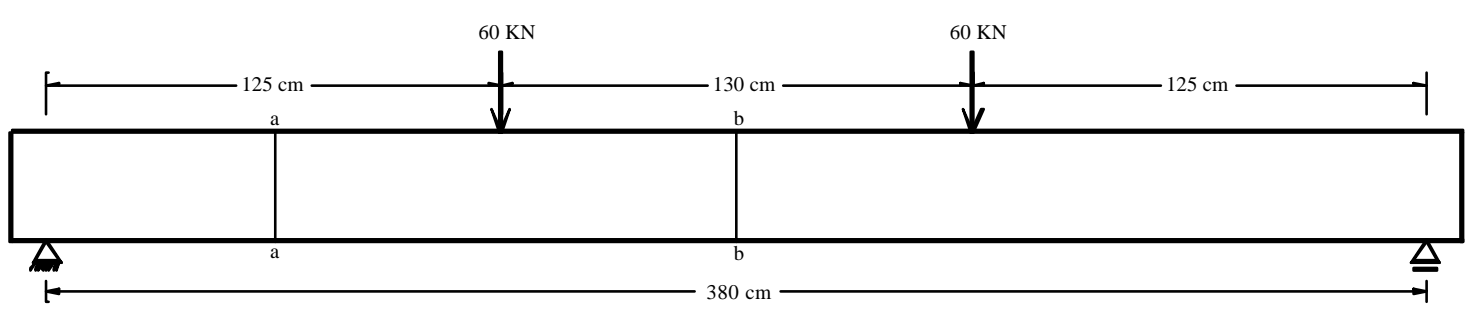

Figura 7.30 - Exemplo 6 - Viga ensaiada

Dados:

Armaduras de tração - $5 \phi 12.5$ mm

Porta estribos $-3 \phi 6.3 \mathrm{~mm}$

Estribos - 2 x $26 \phi 6.3 \mathrm{~mm} \mathrm{c.} 15 \mathrm{~cm}$

$\mathrm{E}$ aço $-17.789 \mathrm{KN} / \mathrm{cm}^{2}$

E concreto $-2.963,2 \mathrm{KN} / \mathrm{cm}^{2}$

Área da seção $-264 \mathrm{~cm}^{2}$

Foram instrumentados os estribos da seção 'aa' no seu ponto médio e foi medido o deslocamento do ponto central da viga, na seção 'bb'. O esquema da seção transversal está descrito na figura 7.31. 


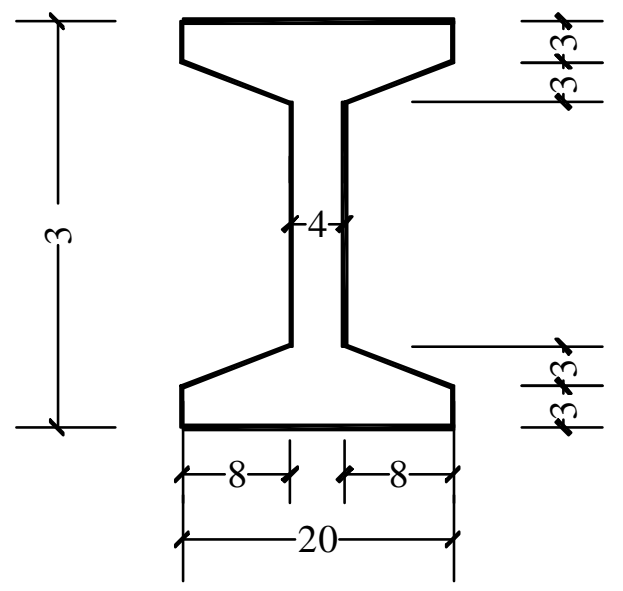

Figura 7.31 - Exemplo 6 - Seção transversal da viga ensaiada.

Para o cálculo do deslocamentos, utilizou-se seção retangular, com a mesma altura da seção 'I' e calculou-se a base para que se obtivesse a mesma inércia. A área obtida, foi de $432 \mathrm{~cm}^{2}$, maior que a área original da seção. Na tabela 7.14, tem-se os resultados dos deslocamentos para este caso.

\begin{tabular}{|c|c|c|}
\hline Força $(\mathrm{KN})$ & Presente Trabalho & Experimental \\
\hline 0 & 0 & 0 \\
\hline 5 & 0,084 & 0,083 \\
\hline 10 & 0,199 & 0,244 \\
\hline 15 & 0,440 & 0,461 \\
\hline 20 & 0,693 & 0,657 \\
\hline 25 & 0,926 & 0,863 \\
\hline 30 & 1,154 & 1,089 \\
\hline 35 & 1,383 & 1,31 \\
\hline 40 & 1,615 & 1,54 \\
\hline 45 & 1,854 & 1,81 \\
\hline 50 & 2,100 & 2,099 \\
\hline 55 & 2,359 & 2,378 \\
\hline 60 & 2,636 & 2,678 \\
\hline
\end{tabular}

Tabela 7.13 Exemplo 6 - Deslocamentos no meio do vão 
Na Figura 7.32 são plotados os valores da tabela 7.13, onde percebe-se que o modelo não-linear representou com boa aproximação os deslocamentos.

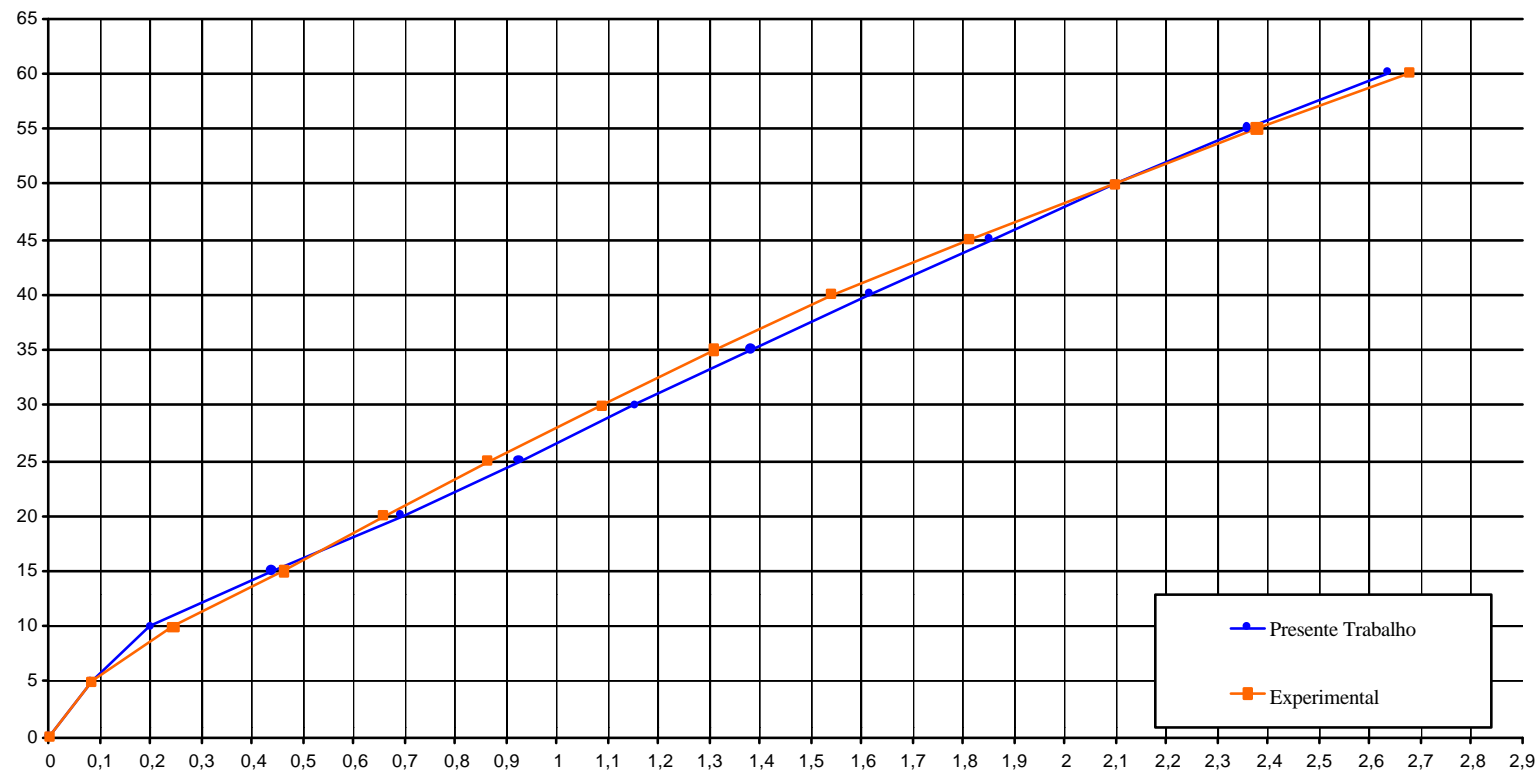

Figura 7.32 - Exemplo 6 - Deslocamentos no meio do vão

$\mathrm{Na}$ Tabela 7.14, são mostrados na coluna 'Base pela Inércia' o cálculo das deformações na armadura transversal, tomando-se uma seção retangular equivalente fixando-se a altura e inércia da seção 'I', porém com base maior e área maior. Na coluna base pela área, fixou-se a inércia, a altura, a área e variou-se a base. A seção retangular equivalente, porém, não suportou o carregamento aplicado, devido à sua pequena base. A conclusão a que se quer chegar é que o valor da base influencia bastante a resposta dessas deformações, e que o ideal seria que em pesquisas futuras se fizessem ensaios com vigas retangulares, para que se melhores aproximações nos valores calculados para estas deformações.

O modelo adotado, de aproximação constante, apresenta maior erro quando confrontado com seção 'I', já que o fator de forma de cisalhamento, como definido anteriormente, modifica-se bastante neste tipo de seção. Já que a integração das tensões ao longo da seção 'I' demandaria mais tempo, optou-se por fazer então dois tipos de análise, alterando-se a geometria da seção, transformando-a em uma seção retangular de área ou de inércia equivalente, com as suas características originais um 
pouco modificadas. Estes resultados podem ser vistos na Tabela 7.15 e mais adiante na Figura 7.33

\begin{tabular}{|c|c|c|c|c|}
\hline Esforço Seção & Base pela Inércia & Base pela área & NBR 6118 & Experimental \\
\hline 0 & 0 & 0 & 0 & 0 \\
\hline 5,00000000 & 0,0000000 & 0,0000000 & 0,0000000 & 0,95 \\
\hline 10,00040000 & 0,0000000 & 0,0000000 & 102,8300000 & 2,14 \\
\hline 15,00040000 & 0,0000000 & 0,0000000 & 382,0600000 & 9,03 \\
\hline 20,00039000 & 0,0000000 & 0,0000000 & 624,8300000 & 266,84 \\
\hline 24,99334000 & 0,0000000 & 0,0000000 & 867,6500000 & 523,38 \\
\hline 29,99704000 & 0,0000000 & 238,4021791 & 1122,6400000 & 805,5 \\
\hline 34,99705000 & 69,9318782 & 454,2792022 & 1373,5300000 & 1008,02 \\
\hline 39,99705000 & 349,6021545 & 656,1189499 & 1635,2100000 & 1265,65 \\
\hline 44,99705000 & 588,1029645 & 856,6299910 & 1892,9000000 & 1569,45 \\
\hline 49,99705000 & 803,9370602 & 1041,7592077 & 2149,2100000 & 1856,5 \\
\hline 54,99705000 & 1031,1653269 & 1224,9101845 & 2397,3900000 & 2067,65 \\
\hline 59,99705000 & 1233,1793396 & - & 2649,6700000 & 2259,95 \\
\hline
\end{tabular}

Tabela 7.14 Exemplo 6 - Deformações nos estribos

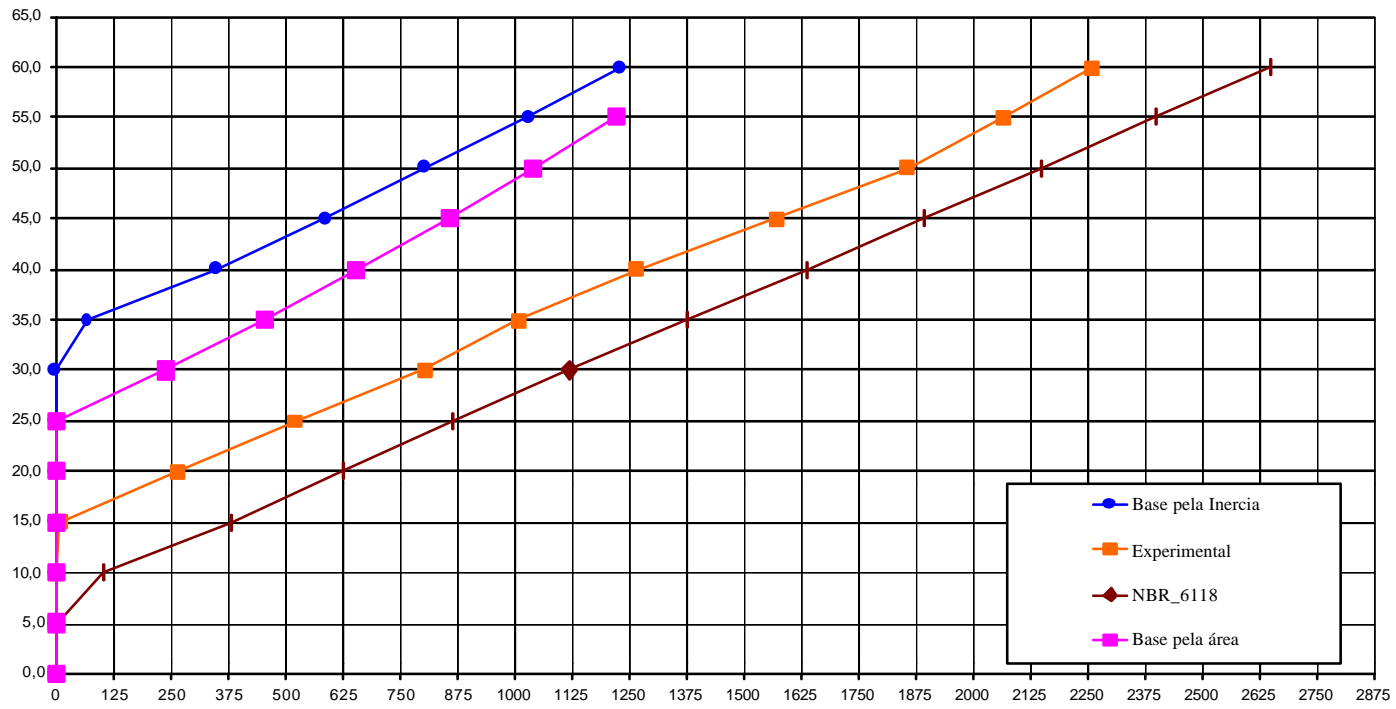

Figura 7.33 - Exemplo 6 - Deformações nos estribos

Isto mostra que os resultados do modelo proposto para as deformações nas armaduras de cisalhamento ainda estão bem acima dos lidos. Portanto o modelo é apenas aproximado, para este tipo de seção. Acredita-se que haja uma aproximação melhor se o modelo for confrontado com resultados de vigas de seção retangular. 


\section{CONCLUSÃo}

Este trabalho teve o objetivo de analisar grelhas de concreto armado, adaptando-se modelos não-lineares baseados na teoria da mecânica do dano e incorporando-se a distorção da seção transversal ao estado de deformações que entra no critério de danificação do modelo.

Inicialmente, procurou-se pesquisar a teoria de Vigas de Timoshenko, estudando-se as equações diferenciais que regem o problema. Em seguida abandonou-se tal aprofundamento e partiu-se para a obtenção de sua matriz de rigidez através do princípio clássico da mínima energia potencial total. Concluiu-se, como pôde ser visto nos exemplos mostrados, que a influência da inclusão da distorção é significativa no trecho pós-elástico em vigas curtas.

Terminada a etapa anterior, procurou-se estudar as teorias gerais sobre a mecânica do dano contínuo, fixando-se os seus conceitos, a fim de aplicá-los ao problema proposto. Optou-se pelo modelo de Mazars, pelas razões já expostas no trabalho. A implementação do modelo resultou em uma curva tensão x deformação do concreto de aproximação confiável, para os parâmetros utilizados. Nota-se, com a evolução destes modelos que este ramo e suas aplicações são ainda um extenso campo de pesquisa na engenharia de estruturas.

Em seguida criou-se um algoritmo para a solução do problema nãolinear, onde foi adotada a grelha como subsistema estrutural. No algoritmo foi realizada, a transformação do modelo em momento x curvatura, o que trouxe eficiência à análise. Computacionalmente, o uso de elementos finitos de barra reduziu a ordem do sistema linear, e ganhou-se tempo de processamento em relação a outras discretizações, como por exemplo, em elementos de chapa, a qual seria utilizada para um modelo em tensões. No entanto, em todas as iterações do procedimento do presente trabalho, houve a necessidade de ser efetuada a integração das tensões nas seções inicial e final de cada 
elemento, dentro do processo iterativo para busca da linha neutra dessas seções. Este processo também foi descrito neste trabalho.

Propôs-se por fim, a estudar o equilíbrio das tensões cisalhantes em uma seção de concreto armado, pois, até certo momento do trabalho não se tinha resultados que incorporassem as suas armaduras transversais. Adaptou-se então um modelo simplificado, onde a hipótese principal assumida foi que as tensões cisalhantes residuais, da fase não-linear da análise, são totalmente absorvidas pela armadura transversal. Acredita-se que esta hipótese traga boa precisão, pois crê-se que na prática, de fato, o concreto fissurado absorverá pequena parcela das tensões residuais. É extremamente oportuno ressaltar que este modelo é apenas aproximado. Ele é fruto de pesquisas iniciais, onde se encontrou pouca bibliografia especializada. Portanto, concluiu-se que os seus resultados foram bastante satisfatórios. Pôde-se observar, pelos exemplos aqui apresentados, que a continuação deste estudo certamente fornecerá ferramentas ainda melhores para a análise estrutural.

Os temas para futuras pesquisas nesta linha podem ser diversos. Como por exemplo pode-se efetuar a incorporação das tensões tangenciais provenientes das solicitações de torção no equilíbrio das seções transversais da grelha. Pode-se considerar um modelo não-linear para as armaduras transversais, através de um processo iterativo na seção, para verificar quem absorve as tensões cisalhantes mesmo em baixas solicitações. Pode-se ainda implementar um modelo de dano anisotrópico, já que o concreto armado é um material com essa característica. 


\section{REFERÊNCIAS BIBLIOGRÁFICAS}

ÁLVARES, M. S. Estudo de um modelo de dano para o concreto: formulação, identificação paramétrica e aplicação com o emprego do método dos elementos finitos. Dissertação (Mestrado) EESC/USP, 1993.

ALVES,B.K. \& LUBLINER, J. A damage mechanics model for beams. Application to reinforced concrete beams. Num. Met. Eng. Appl. Scs. 1992. Congresso Int. Metodos Numericos en Ingenieria y ciencias aplicadas. p 277-286.

ASSOCIAÇÃO BRASILEIRA DE NORMAS TÉCNICAS, NBR-6118, Projeto e execução de obras de concreto armado, 1980.

BATHE, K. J. Finite element procedures in engineering analysis. Prentice Hall, 1996.

BOTTA, A. S. Cálculo de esforços e deslocamentos em estruturas reticuladas considerando-se a mecânica do dano para a modelagem do concreto armado. Dissertação de mestrado. EESC-USP, 1998

BREBBIA,C.A. \& DOMINGUEZ,J. Boundary elements: an introductory course. 2.ed. Southampton, CMP / New York, MC-Graw-Hill, 1992.

BURR A. \& HILD, F. \& LECKIE, A. Micro-mechanics and continuum damage mechanics. Archive of applied mechanics. 65(1995), p 437-456.

BUSSAMRA, F. L. S. Equações constitutivas do concreto baseadas na mecânica do dano contínuo. Dissertação (Mestrado) - EPUSP, 1993

CARVALHO, R. C. Análise não-linear de pavimentos de edifícios de concreto armado através da analogia de grelha. Tese de Doutorado. EESC-USP, 1994

CERVERA, M.; OLIVER, J.; MANZOLI, O. A rate-dependent isotropic damage model for the seismic analysis of concrete dams. Earthquake Engineering and Structural Dynamics, vol. 25, pgs. 9871010, 1996.

CHABOCHE, Continuum damage mechanics: Part I - General concepts. Journal of applied mechanics. Vol 55, Mar 1988. Pg 59-64.

CILONI, A. D. Sobre o comportamento em serviço de estruturas planas de concreto armado. Tese de doutorado. EESC-USP. 1993.

COMITÉ EURO-INTERNATIONAL DU BÉTON, Manual on cracking and deformation. Bulletin D'Information, Lausanne, n.158-E, 1985.

CORRÊA, M.R.S., Aperfeiçoamento de modelos usualmente empregados no projeto de sistemas estruturais de edifícios. Tese de doutoramento. EESC-USP. 1991. 
DEBERNARDI, P. G. Behaviour of concrete structures in service. ASCE journal, p.32-50, 1989.

DIAO, A statistical equation of damage evolution. Enineering fracture mechanics. Vol 52, no 1, p 33-42, 1995.

DRIEMEIER, L. Considerações sobre a fadiga em metais e o comportamento do concreto sob solicitação cíclica. Dissertação (Mestrado) - EESC/USP, 1995.

FERNANDES, G.R. O método dos elementos de contorno aplicado à análise não-linear de placas. São Carlos, 1998. Dissertação de mestrado. EESC-USP.

FUSCO, P.B. Estruturas de concreto - solicitações tangenciais.Grêmio politécnico, São Paulo, SP, 1981.

GERE, J.M. \& WEAVER Jr, W. Análise de estruturas reticuladas. Guanabara. 1987. Rio de Janeior, RJ.

GHALI, A. \& FAVRE, R. Concrete structures: structures and deformation. London, Chapman \& Hall, 1986.

HEYLIGER, P.R. \& REDDY, J.N. A higher order beam finite element for bending and vibration problems. Journal of sound and vibration.126(2), p 309-326. 1988.

HINTON, H. \& OWEN, D. R. J Finite elements in plasticity. Swansea, U.K, Pineridge Press,1980.

KACHANOV, L.M. On the time to failure under creep conditions. Izv. Akad. Nauk. SSR, otd. Tekhn. N.8, 26-31, 1958.

KRAJCINOVIC, D. Damage mechanics. Mechanics of materials. 8(1989) p 117-197.

LEMAITRE J. \& CHABOCHE, J -L. Mechanics of solid materials. Cambridge University Press, 1994

MACHADO, C. P. Tensões, Deformações e deslocamentos em estruturas de concreto armado $e$ protendido, Dissertação de mestrado. EPUSP. 1989.

MAZARS, J. Application de la mécanique de l'endommagement au comportement nonlinéare et à la rupture du béton de structure. Dr of Science thesis. University of Paris 6, 1984.

MAZARS \& PIJAUDIER-CABOT, Continuum damage theory - application to concrete. Journal of Eng. Mechs. Vol 115, 2, Feb 1989, pg 345-365.

NARAYANASWAMI, R. \& ADELMAN, H.M. Inclusion of transverse shear deformation in finite element displacement formulation. AIAA Journal Vol 12 nº 11. P 1613-1614. Nov 1974.

NAVARRA, E.O.I, Calculo de estructuras por el metodo de elementos finitos. Centro Internacional de Métodos numéricos en Ingeniería. Barcelona, Espanha. 1995.

NEVILLE, A. M. Propriedades do concreto. Pini, São Paulo, SP, 1996.

NICKEL, R.E. \& SECOR, G.A., Convergence of consistently derived Timoshenko beam finite elements. Int. J. Num. Meth. Eng., 5, 243-253, 1972.

NÓBREGA, S.H.S. Sobre o desenvolvimento de elementos finitos de casca. Uma classe de formulações mistas. Tese (Doutorado) - EPUSP, 1997 
OLIVEIRA, R. S. Análise de pavimentos de edifícios de concreto armado com a consideração da nãolinearidade física. Dissertação de Mestrado, EESC-USP, 1997.

PAAS et al, A continuum approach to brittle and fatigue damage: Theory and numerical procedures. Int. J. Solids Structures. Vol 30, 4, pg 579-599, 1993.

PRATHAP, G. \& BHASHYAM, G.R., Reduced integration and the shear-flexible beam element. Int. J. Num. Meth. Eng., 18, 195-210, 1982.

PROENÇA, S.P.B. , Sobre modelos matemáticos do comportamento não-linear do concreto. Tese de Doutorado, EESC-USP, 1988.

PEREGO, M.A. Dannegiamento dei materiali lapidei: leggi costitutive, analisi per elementi finiti ed applicazioni. Politecnico di Milano, 1989.

REDDY, J.N., On locking-free shear deformable beam finite elements. Comp. Meth. App. Mech. Eng., 149, 113-132, 1997.

RIGITANO, A.C. Contribuição para a determinação de matrizes de rigidez e vetores de ações nodais equivalentes com o emprego da formulação hermitiana livre. Tese de doutorado, EESC-USP, 1999.

SANCHES Jr., F. Cálculo de esforços e deslocamentos em pavimentos de edifícios considerando-se modelos próprios para o concreto armado. Dissertação de mestrado, EESC-USP, 1998.

SEVERN, T.T., Inclusion of shear deformation in the stiffness matrix for a beam element, Journal of Strain Analysis, 5, 239-241, 1970.

SUSSEKIND, J.C. Curso de análise estrutural. V.1. 2.ed. Globo, 1979. Porto Alegre, RS.

TESSLER, A. \& DONG, S.B., On a hierarchy of conforming Timoshenko beam elements. Computers \& structures, Vol 14, nº 3-4, p 335-344. 1981.

TIMOSHENKO, S. P. , Vibration problems in engineering. New York, Van Nostrand, 1955. 


\section{BIBLIOGRAFIA COMPLEMENTAR}

AMERICAN CONCRETE INSTITUTE - ACI, Building code requeriments for reinforced concrete. 318R-89-Revised. 1992.

AMERICAN CONCRETE INSTITUTE. Committee 318. Building code requirements for concrete. Detroit, 1995.

AMERICAN SOCIETY OF CIVIL ENGINEERING -ASCE. Committee on Finite Element Analysis of Reinforced Concrete Structures State of the Art. Report on Finite Elements Analysis of Reinforced Concrete. ASCE, Structural Engineering Division, 1992.

ASCE/ACI. Committee 447. Finite Elements Analysis of Reinforced Concrete Structures. (ed. J. Isenberg). American Society of Civil Engineers. New York. 1991.

ASSAN, A. E. Vigas de concreto armado com não-linearidade física. In: "Congresso Ibero Latino Americano sobre Métodos Computacionais para Engenharia", 11., COPPE-UFRJ/AMC, Rio de Janeiro. 1990.

BARBOSA, A. F. Estudo de modelos para análise não-linear de estruturas de concreto pelo método dos elementos finitos. Dissertação de mestrado. UFMG, 1997.

BATOZ, J. L., BATHE, K. J. \& WONG, L. H. A study of three-node triangular plate bending elements. Int. J. Num. Meth. Eng., 15, p.1771-1812, 1980.

BERNARDO, T.R.R., Análise do comportamento de estruturas de pisos de concreto armado considerando-se carregamentos e propriedades dos materiais aleatórios. Dissertação de Mestrado. EESC-USP, 1998.

BORTOLIN, A.A. A racionalização e a automação do cálculo de edifícios de concreto armado. Dissertação de mestrado,. EESC-USP. 1991.

BORTOLIN, A.A. Flexão reta ou oblíqua em peças de concreto armado. Relatório FAPESP. 1989.

BRANSON, D. E. Design procedures for computing deflections. "ACI journal", 65(9): 730-742. 1968.

CHEN, W. F. Constitutive equations for engineering materials - volume 2: Plasticity and modelling. Elsevier, 1994

CHEN, W. F. Plasticity in reinforced concrete. McGraw-Hill, New York, 1982.

CHEN, W. F. \& LUI, E. M. Plasticity for structural engineers. New York, McGraw-Hill, 1988.

CHEN, W. F. \& SALEEB, A. F. Constitutive equations for engineering materials volume 1: Elasticity and modelling. Elsevier, 1994

CHEN, W. F., et alli. Constitutive models. In: Finite element Analysis of reinforced concrete structures II - ASCE, New York, ASCE, p.36-117, 1993 
COMITÉ EUROPEÉN DU BÉTON. "CEB-FIP - Model code1990, MC-90". Bulletin d'information $n$. 195,196 e 198. 1990.

COMITÉ EUROPEÉN DU BÉTON. Non-linear analysis. Safety Evaluation and monitoring. CEB-FIP Bulletin d'information, n. 239, 1997.

COMITÉ EUROPEÉN DU BÉTON. Serviceability Models. CEB-FIP Bulletin d'information, n. 235, 1997.

CORRÊA, M.R.S. E RAMALHO, M.A. Sistema LASER de análise estrutural. V Simpósio nacional de tecnologia de construção: software para o projeto do edifício. EPUSP. 1987.

COSTA, J.B. Automação de projetos de pavimentos tipo de edifícios de concreto armado. Dissertação de mestrado. EESC-USP. 1990.

COX, J. \& HERRMANN L. R. Model for bond between steel bars and concrete. Proceedings of Engineering Mechanics - ASCE, New York, p.647-650, 1995.

DARWIN, D. \& PECKNOLD, D. A. Non-linear bi-axial stress-strain law for concrete. J. Eng. Mech., ASCE, v.103, n.EM2, 1977.

DAWE, D.J., A finite element for the vibration of Timoshenko beams. J. Sound and Vibration, 60, 11-20, 1978.

DEBERNARDI , P. G. La deformazione differita delle strutture in c.a. soggete a fessurazione: considerazioni sui metodi approssimati di calcolo. L'industria Italiana del Cemento, Roma, (7/8): 499-510, 1983.

FIGUEIREDO FILHO, J. R. Sistemas estruturais de lajes sem vigas: subsídios para o projeto e execução. Tese de doutorado. EESC-USP. 1989.

FRIEDMAN, Z. \& KOSMATKA, J.B., An accurate two-node finite element for shear deformable curved beams. Int. J. Num. Meth. Eng., 41, 473-498, 1988.

FUSCO, P. B. Técnica de armar as estruturas de concreto. São Paulo, PINI, 1996.

HEYLIGER, P.R., A higher order beam finite element for bending and vibration problems. J. Sound and Vibration, 126, 309-326, 1988.

HOU, Y.C. \& TSENG, C.H., A new high-order non-uniform Timoshenko beam finite element on variable two-parameter foundations for vibration analysis. J. Sound and Vibration, 191, 91-106, 1996.

HUGHES, T. J. R. Finite element method: linear static and dynamic finite element analysis. Prentice Hall, 1987.

JIMENES MONTOYA, P., GARCIA MESEGUER, A. \& MORAN CABRÉ, F. Hormigón armado. 13a. Edicion, Gustavo Gili. Barcelona, 1998.

KIM, J. K. \& LEE, T. G. Non-linear analysis of reinforced concrete beams with softening. Computers \& structures, 30, p.1269-1288, 1993.

KUPFER, H. B. \& GERSTLE,K. H. Behaviour of concrete under biaxial stresses. Eng. Mech. Div., ASCE, v.99, 1973. 
LIMA, J. D. and MONTEIRO, V. Practical rules for the computation of deflections. In: Comité europeén du Béton (CEB). Manuel de Calcul 'fleches': limitation des flèches, London, Bul. d'Inf. n. 90, 1973.

MACGREGOR, J. G. Stability of reinforced concrete building frames. Concrete framed structures stability and strength. Elsevier, 1987.

MARTINS, P. C. R. A não-linearidade de estruturas de concreto armado e protendido numa análise até a ruptura. In: Seminário sobre não-linearidade física e geométrica das estruturas de concreto. IBRACON, 1995.

MESQUITA, A. D. Análise não-linear de Cascas pelo Método dos elementos finitos. EESC-USP. Dissertação de Mestrado 1998.

MORAN CABRÉ, F. Cálculo de secciones de hormigón armado, submetidas a solicitaciones normales, en el estado limite último. Instituto eduardo torroja. Madrid, 1972.

NGO, D. \& SCORDELIS, A. C. Finite element analysis of reinforced concrete beams. ACI Journal, 64, n.3, pp.152-163, 1967.

NOGUEIRA, L. A. Análise de vigas de pisos de edifícios considerando comportamento não-linear dos materiais, Iniciação Científica, rels. I e II. EESC-USP. 1993.

OLIVEIRA, M.E.A. Algoritmos computacionais para projetos de vigas de edifícios de concreto armado. Dissertação de mestrado. EESC-USP,1990.

PIMENTA, P.M. \& SOLER, J. G. M. Estabilidade de pórticos de concreto armado. In: Simpósio EPUSP sobre estruturas de concreto, 1São Paulo, Anais, v.2, p.501-527, 1989.

RAMALHO, M.A. Sistema para análise de estruturas considerando interação com o meio elástico. Tese de doutorado. EESC-USP. 1990.

RASHEED, H. A. S. \& DINO,K. S. An efficient non-linear analysis of RC sections. Computers \& Structures, 53, n.3, pp.613-623, 1994.

RODRIGUES, R.O. et al., Equações adimensionais para verificação e dimensionamento de peças de seção retangular de concreto armado no estado limite último. "IV Congresso de iniciação científica e tecnológica em engenharia". EESC-USP. São Carlos.1985.

RODRIGUES, R. O. et al. ,Ábacos para o dimensionamento de seções retangulares de concreto armado no estado limite último. IV Congresso de iniciação científica e tecnológica em engenharia. EESCUSP. São Carlos. 1985.

RODRIGUES, R.O. Automatização do projeto estrutural de pilares das estruturas correntes de concreto armado. Dissertação de mestrado. EESC-USP. 1992.

SANTOS, L. M. Cálculo de concreto armado. vol.1, Edgard Blucher Ltda., São Paulo, SP, 1977.

SANTOS, L. M. Cálculo de concreto armado. vol.2, LMS, São Paulo, 1981.

SCORDELIS, A. C. Computer models for non-linear analysis of reinforced and prestressed structures. ACI Journal, 29, .6, pp.116-135, 1984. 
SILVA, M. R. Análise não-linear de pórticos planos de concreto armado: modelagem Numérica e avaliação dos métodos aproximados. Tese de doutorado, EESC-USP, 1996.

SIMO, J. C. \& HUGHES T. J. R. Elastoplastic and viscoplastic: computational aspects. 1988.

SIMO, J. C. \& TAYLOR R. L. Consistent tangent operators for rate-independent elastoplasticity. Comp. Meth. And App. Mech. And Eng. ,48, 1985.

SOARES, R. C. Otimização de seções transversais de concreto armado sujeitas à flexão - aplicação a pavimentos. Dissertação de mestrado. EESC-USP, 1996.

SOLER, J. G. M. Análise de pórticos espaciais de concreto armado. Tese de doutorado, EPUSP, 1995.

THOMAS, D.L., WILSON, J.M. \& WILSON, R.R., Timoshenko Beam finite elements. Journal of sound and Vibration, 31, 315-330, 1973.

TOMAZELA, C.A. e VENTURINI, W.S. , Elaboração de ábacos para cálculo da armadura em peças de concreto armado submetidas à flexão composta. V Congresso de iniciação científica e tecnológica em engenharia. São Carlos. 1986.

TUMA S., Deslocamentos de barras de concreto armado considerando a contribuição do concreto entre fissuras. Iniciação científica, Rels. I e II. EESC-USP. 1993.

VENTURINI, W.S. , Dimensionamento de peças retangulares de concreto armado solicitadas à flexão oblíqua. EESC-USP. São Carlos. 1990.

ZIENKIEWICZ, O. C. \& TAYLOR, R. L. The finite element method: basic formulation and linear problems. 4.ed. New York, McGraw-Hill, 1991.

ZIENKIEWICZ, O. C. \& TAYLOR, R. L. The finite element method: solid and fluid mechanics dynamics and non-linearity. 4.ed. New York, McGraw-Hill, 1991. 